\title{
The autoreactive $B$ cell response in myasthenia gravis
}

Citation for published version (APA):

Vrolix, K. (2011). The autoreactive B cell response in myasthenia gravis. [Doctoral Thesis, Maastricht University]. Maastricht University. https://doi.org/10.26481/dis.20111007kv

Document status and date:

Published: 01/01/2011

DOI:

$10.26481 /$ dis.20111007kv

Document Version:

Publisher's PDF, also known as Version of record

\section{Please check the document version of this publication:}

- A submitted manuscript is the version of the article upon submission and before peer-review. There can be important differences between the submitted version and the official published version of record.

People interested in the research are advised to contact the author for the final version of the publication, or visit the DOI to the publisher's website.

- The final author version and the galley proof are versions of the publication after peer review.

- The final published version features the final layout of the paper including the volume, issue and page numbers.

Link to publication

\footnotetext{
General rights rights.

- You may freely distribute the URL identifying the publication in the public portal. please follow below link for the End User Agreement:

www.umlib.nl/taverne-license

Take down policy

If you believe that this document breaches copyright please contact us at:

repository@maastrichtuniversity.nl

providing details and we will investigate your claim.
}

Copyright and moral rights for the publications made accessible in the public portal are retained by the authors and/or other copyright owners and it is a condition of accessing publications that users recognise and abide by the legal requirements associated with these

- Users may download and print one copy of any publication from the public portal for the purpose of private study or research.

- You may not further distribute the material or use it for any profit-making activity or commercial gain

If the publication is distributed under the terms of Article $25 \mathrm{fa}$ of the Dutch Copyright Act, indicated by the "Taverne" license above, 
The autoreactive $B$ cell response in myasthenia gravis 
Copyright (C Kathleen Vrolix, Maastricht 2011

ISBN: 978-90-9026337-3

The autoreactive $B$ cell response in myasthenia gravis

Thesis with summary in English and Dutch

All rights reserved. No part may be reproduced or transmitted in any form or by any means, electronic or mechanical including photocopying, recording or by any information storage and retrieval system, without permission, in writing, from the copyright holder.

Coverdesign: Mariet Daemen

Typesetting and layout: Kathleen Vrolix

Production: Printservice Ede 


\title{
The autoreactive $B$ cell response in myasthenia gravis
}

\author{
PROEFSCHRIFT \\ ter verkrijging van de graad van doctor \\ aan de Universiteit Maastricht \\ op gezag van de Rector Magnificus \\ Prof. Mr. G.P.M.F. Mols \\ volgens het besluit van het college van Decanen, \\ in het openbaar te verdedigen op \\ vrijdag 7 oktober 2011 om 10.00 uur \\ door \\ Kathleen Vrolix \\ geboren te Bree op 14 februari 1986
}




\section{Promotores}

Prof. Dr. M.H. De Baets

Prof. Dr. V. Somers

\section{Co-promotores}

Dr. P. Martínez-Martínez

Dr. M. Losen

\section{Beoordelingscommissie}

Prof. Dr. H. Steinbusch (voorzitter)

Prof. Dr. W.A. Buurman

Prof. Dr. J.J.G.M. Verschuuren (Leiden University Medical Center)

Prof. Dr. P. Stinissen (Hasselt University)

The studies described in this thesis were funded by grants from the Translationale Universiteit Limburg and MYASTAID LSHM-CT-2006-037833. 


\section{Contents}

General introduction $\quad 9$

$\begin{array}{ll}\text { Chapter } 1 & 13\end{array}$

The auto-antigen repertoire in myasthenia gravis

Chapter 2

Antibody effector mechanisms in myasthenia gravis - pathogenesis at the neuromuscular junction

Chapter 3

A novel method for making human monoclonal antibodies

\section{Chapter 4}

Immortalization of thymic autoreactive B cells and monoclonal antibody production from AChR-antibody positive myasthenia gravis patients

\section{Chapter 5}

Different B cell and antibody repertoire in thymus of myasthenia gravis patients compared to controls

\section{Chapter 6}

Reduced thymic expression of ErbB receptors without auto-antibodies against synaptic ErbB in myasthenia gravis

\section{Chapter 7}

Proteasome inhibition with bortezomib depletes plasma cells and autoantibodies in experimental autoimmune myasthenia gravis

Summary and general discussion 



\section{Abbreviations}

$\alpha-B T$

AAG

$A b$

mAb

ACh

AChE

AChR

mAChR

nAChR

AChR-MG

AP

$C D$

CDR

CFA

CMAP

CMS

CMV

CSF

D

DAB

DHPR

EAMG

EBV

EM

EMG

EPP

Fab

FACS

FR

GC

GM-CSF

HEK

HSP

IF

IFN

$\lg$

Alpha-bungarotoxin

Autoimmune autonomic ganglionopathy

Antibody

Monoclonal antibody

Acetylcholine

Acetylcholinesterase

Acetylcholine receptor

Muscarinic acetylcholine receptor

Nicotinic acetylcholine receptor

Anti-acetylcholine receptor antibody positive myasthenia gravis

Alkaline phosphatase

Cluster of differentiation

Complementarity determining region

Complete Freund's adjuvant

Compound muscle action potential

Congenital myasthenic syndromes

Cytomegalovirus

Cerebrospinal fluid

Diversity region

3,3' diaminobenzidine

Dihydropyridine receptor

Experimental autoimmune myasthenia gravis

Epstein-Barr virus

Electron microscopy

Electromyography

Endplate potential

Antibody fragment

Fluorescence-activated cell sorting

Framework region

Germinal center

Granulocyte-macrophage colony stimulating factor

Human embryonic kidney

Heat shock protein

Immunofluorescence

Interferon

Immunoglobulin 
IL

J

MAC

MG

iMG

MGFA

LEMS

MEPP

MFI

MIR

MS

MUSK

MuSK-MG

NMJ

PBMC

PCR

PI

PsmR

$R$

RA

RBC

RIA

RyR

$S$

SEM

SLE

$S R$

TGF

TID1

TLR

TRPC3

TSH

$\mathrm{V}$

$V_{H}$

$V_{L}$

VAChT

VGCC

VGKC

VGSC
Interleukin

Joining region

Membrane attack complex

Myasthenia gravis

Idiopathic myasthenia gravis

Myasthenia gravis foundation of America

Lambert-Eaton Myasthenic syndrome

Miniature endplate potential

Mean fluorescence intensity

Main immunogenic region

Multiple sclerosis

Muscle-specific tyrosine kinase

Anti-muscle specific kinase antibody positive myasthenia gravis

Neuromuscular junction

Peripheral blood mononuclear cells

Polymerase chain reaction

Propidium iodide

Pre-synaptic membrane receptor

Replacement mutation

Rheumatoid arthritis

Red blood cells

Radio-immunoassay

Ryanodine receptor

Silent mutation

Standard error of the mean

Systemic lupus erythematosus

Sarcoplasmatic reticulum

Transforming growth factor

Tumorous imaginal disk 1

Toll-like receptor

Transient receptor potential canonical type 3

Thyroid stimulating hormone

Variable region

Variable region heavy chain locus

Variable region light chain locus

Vesicular acetylcholine transporter

Voltage-gated calcium channel

Voltage-gated potassium channel

Voltage-gated sodium channel 
General introduction 
The immune system consists of many different proteins, cells, tissues and organs which all collaborate to protect the body against invading pathogens. One of the main challenges of the immune system is to distinguish between non-self antigens and self-antigens. When the immune system fails to make this discrimination, it will erroneously attack selfantigens and induce autoimmunity. While low levels of autoimmune reactions are required to maintain the immune homeostasis in healthy individuals, autoimmunity above certain tresholds leads to autoimmune diseases.

Worldwide, $5-8 \%$ of the population is affected by autoimmune diseases and a multitude of different autoimmune diseases exist, involving almost every organ system. Autoimmune diseases can be subdivided into two categories: those that are non-organ specific, in which multiple organs can be affected, e.g. systemic lupus erythematosus and rheumatoid arthritis, and those that are organ specific, in which the damage is restricted to a single organ. Myasthenia gravis (MG) is a well studied example of an organ-specific autoimmune disease, and considered as a prototype antibody-mediated auto-immune disease. Indeed, MG fulfils all criteria of an antibody-mediated disease: B cells produce antibodies which bind the extracellular domain of a functionally important protein, plasma exchange induces clinical improvement in patients, MG can be transferred by injecting MG plasma into animals and by neonatal transfer from mother to child via the placenta, and the antibodies also exert pathological effects in vitro. Because of the prototypic position of MG, characterizing the autoreactive $B$ cell response in MG patients will also benefit many other autoimmune diseases.

The autoimmune attack in MG is restricted to the postsynaptic membrane of the neuromuscular junction (NMJ) in skeletal muscles. The acetylcholine receptor (AChR) is located at the top of the folds at the NMJ and is activated by the neurotransmitter acetylcholine (ACh) to initiate muscle contraction, necessary for all striated muscles of the body, including the respiratory muscles. Therefore, the number and organization of AChRs at the NMJ is tightly regulated by many other proteins in order to maintain an efficient neuromuscular transmission. In MG patients, antibodies produced by selfreactive $B$ cells which were not properly eliminated by the immune system, bind to proteins involved in the neuromuscular transmission at the NMJ and severely disturb the communication between nerves and skeletal muscle cells. This disturbed synaptic transmission leads to failure of muscle contraction, and consequently, to skeletal muscle weakness, which is the main symptom seen in MG patients. In more than $85 \%$ of the patients with generalized MG, pathogenic autoantibodies are specifically directed against the AChR at the NMJ and cause the destruction of this protein (AChR-MG). In about $10 \%$ of the MG patients, the autoantibodies target muscle-specific kinase (MuSK), which is a 
protein that contributes to the AChR clustering at the NMJ (MuSK-MG). The clear function and the accessible location of the NMJ ensured that the autoantigen characteristics and the effector function of the autoantibodies are well understood.

The relative contribution of $B$ cells to the pathogenesis of autoimmune diseases differs significantly among diseases. In MG, autoreactive B cells are key players in the pathophysiology after differentiation into plasma cells which contain a special cellular machinery to produce large quantities of autoreactive antibodies. Nevertheless, the etiology of MG remains uncertain, and therefore, in many cases the treatment is only symptom fighting and not curative. The aim of this thesis is to investigate $B$ cells and their antibodies in AChR-MG patients to obtain better insights into the development of the disease and to achieve better outcomes after treatment. First, we aimed at using B cell immortalization to characterize the B cell and antibody repertoire in the thymus of MG patients, since it will improve our understanding on the contribution of thymic $B$ cells to the MG pathology (Chapter 3-5). B cell immortalization allows the production of full-size human antibodies of which the target antigens can be identified. In addition, these human antibodies can be modified to be used as therapeutic antibodies. Second, we aimed at identifying the unknown auto-antigen in idiopathic MG patients (Chapter 6). Third, our aim was to develop a more effective treatment for MG by targeting plasma cells (Chapter 7).

Chapter 1 reviews all autoantibodies that have been reported in MG patients thus far. In AChR-MG, anti-AChR antibodies are considered the pathogenic antibodies, but also many other autoantibodies occur because the immune system of MG patients is generally dysregulated. The role of these autoantibodies in the pathophysiology of MG is discussed. In Chapter 2, we focus on the effector functions of pathogenic anti-AChR and anti-MuSK antibodies. Different immunoglobulin (Ig) subtypes of these autoantibodies exert different effects on the structure and function of the neuromuscular synapse and they will be broadly discussed in this review. In Chapter 3, we established a useful method to produce human monoclonal antibodies and to study antibodies which fully originate from the human immune system since it can significantly contribute to a better understanding of the autoimmune response. By using our improved B cell immortalization technique, we successfully produced human monoclonal antibodies. Chapter 4 focuses on B cells which originate from the thymus of MG patients. In AChR-MG patients, the thymus plays an important role in the pathophysiology of the disease because it contains all components to maintain the anti-AChR antibody production. However, the full antibody repertoire which is produced by thymic $B$ cells remains to be investigated. We applied our improved 
B cell immortalization method on thymic B cells of MG patients and isolated striational antibodies and a human monoclonal antibody against the gamma subunit of the AChR, thereby demonstrating that our method can be used to characterize the antibody repertoire produced by thymic B cells. In Chapter 5, we apply our method to extensively characterize the thymic $B$ cell repertoire in order to clarify the contribution of thymic $B$ cells to autoimmune diseases. Therefore, we compared the B cell and antibody repertoire from the thymus of healthy individuals and AChR-MG patients. Chapter 6 describes the search for anti-ErbB antibodies in idiopathic MG patients (iMG), where the autoantigen remains to be discovered. ErbB proteins are located at the postsynaptic membrane of the $\mathrm{NMJ}$ and influence the AChR density. When antibodies target ErbB proteins, the AChR density might be disturbed, which could potentially lead to myasthenic symptoms. Therefore, we focused on ErbB proteins to determine the autoantigen in iMG patients. In Chapter 7, we analyze a new therapeutic approach to treat MG patients. Many treatments suppress the immune system in general or kill B cells, but long-lived plasma cells which are responsible for the maintenance of autoantibody production often resist these treatments. Since Bortezomib has been shown to reduce plasma cells and antibody levels in mice suffering from a lupus-like autoimmune disease, we investigated the effect of Bortezomib treatment on plasma cell viability and anti-AChR antibody production in the experimental rat model for autoimmune myasthenia gravis (EAMG). 


\section{Chapter 1}

\section{The auto-antigen repertoire in myasthenia gravis}

Vrolix K, Fraussen J, Molenaar P, Losen M, Somers V, Stinissen P, De Baets MH and Martínez- Martínez P.

Published in: Autoimmunity 2010; 43 (5-6): 380-400. 


\section{Abstract}

Myasthenia gravis (MG) is an antibody-mediated autoimmune disorder affecting the postsynaptic membrane of the neuromuscular junction (NMJ). MG is characterized by an impaired signal transmission between the motor neuron and the skeletal muscle cell, caused by auto-antibodies directed against NMJ proteins. The auto-antibodies target the nicotinic acetylcholine receptor ( $\mathrm{nAChR}$ ) in about $90 \%$ of MG patients. In approximately $5 \%$ of MG patients, the muscle specific kinase (MuSK) is the auto-antigen. In the remaining $5 \%$ of MG patients, however, antibodies against the nAChR or MuSK are not detectable (idiopathic MG, iMG). Although only the anti-nAChR and anti-MuSK autoantibodies have been demonstrated to be pathogenic, several other antibodies recognizing self-antigens can also be found in MG patients. Various auto-antibodies associated with thymic abnormalities have been reported, as well as many non-MG specific auto-antibodies. However, their contribution to the cause, pathology, and severity of the disease is still poorly understood. Here we comprehensively review the reported auto-antibodies in MG patients, and discuss their role in the pathology of this autoimmune disease. 


\section{Introduction}

Myasthenia gravis (MG) is a relatively rare, organ-specific autoimmune disease with a prevalence of 100-200 per million (Gilhus, 2009; Verschuuren et al., 2010). In MG patients, auto-antibodies are mainly directed against proteins of the neuromuscular junction (NMJ), notably the acetylcholine receptor (AChR), where they cause weakness and fatigability of skeletal muscles by disturbing the synaptic transmission between the motor neuron and the muscle fiber. Myasthenic auto-antibodies of the blood plasma bind at the NMJ (Engel et al., 1977) and they cause symptoms when injected in rodents (Toyka et al., 1977). In addition, the immunization of animals with the AChR reproduces the disease (Patrick and Lindstrom, 1973). Removal of the antibodies by plasma exchange decreases the severity of MG symptoms (Newsom-Davis et al., 1978). Because of these characteristics, MG is considered a prototypical antibody-mediated autoimmune disease, where well-defined synaptic proteins are characterized as antigens.

MG is strongly associated with an increased incidence of auto-antibodies other than anti-AChRs. Here we review both disease-specific and non-disease specific autoantibodies that have been reported in MG patients, and clarify their role in the pathology of this autoimmune disease.

\section{Myasthenia gravis and myasthenic syndromes}

To date, two well-characterized auto-antibodies are known that are specific to and responsible for MG; namely, the anti-AChR and the anti-MuSK auto-antibodies.

AChR-MG and MuSK-MG together cover more than $90 \%$ of the MG cases (Chan et al., 2007). The remaining patients also mostly have an autoimmune disorder, since many of them appear to benefit from immunosuppression or plasma exchange. Historically, the term "seronegative MG" has been used for MG without anti-nAChR antibodies (thus without detectable auto-antibodies), but with the discovery of anti-MuSK antibodies (Hoch et al., 2001) this term has become confusing. We will use the term "idiopathic MG" (iMG) for the subgroup of MG patients without anti-nAChR or anti-MuSK antibodies (Gomez et al., 2010).

In addition, there is also the Lambert-Eaton myasthenic syndrome, which is caused by auto-antibodies against the P/Q-type calcium channels of the motor nerve ending. The neuromuscular junction is also affected by many different mutations affecting synaptic proteins, leading to congenital myasthenic syndromes. These are hereditary and not 
generally associated with auto-antibody production, and thus are not reviewed here. A few cases of familial autoimmune MG with AChR or MUSK antibodies have been reported (Bergoffen et al., 1994; Evoli et al., 1995; Lavrnic et al., 2008; Provenzano et al., 1988).

\section{Antibodies against the $\mathrm{nAChR}$}

Receptors for acetylcholine (ACh) can be divided into muscarinic and nicotinic AChRs. Muscarinic receptors (mAChRs) are G-protein-coupled receptors which react slowly and influence the membrane potential via activation of second messengers that modulate voltage-dependent ion channels. Nicotinic receptors (nAChRs), on the other hand, are fast-reacting ion channels opened by ACh (Figure 1). nACHRs can be subdivided into "muscular" types containing $\alpha 1, \beta 1, \gamma, \delta$ and $\varepsilon$ subunits, and "neuronal" types consisting of $\alpha_{2}-\alpha_{10}$ and $\beta_{2}-\beta_{4}$ subunits (Millar and Gotti, 2009). The AChR, with its 5 subunits (two $\alpha$ subunits and one $\beta, \gamma$ and $\delta$ subunit), was first isolated from the electric organ of the electric ray (Popot and Changeux, 1984). The AChR in adult skeletal muscle, however, is different in the sense that the $\gamma$ subunit is replaced by an $\varepsilon$ subunit, thus forming the pentameric channel $(\alpha, \varepsilon, \alpha, \beta, \delta)$, whereas in foetal, denervated or regenerating muscle the $\gamma$-type predominates (Mishina et al., 1986).The $\alpha$-subunits contain the binding sites for ACh at the interface with adjacent subunits ( $\varepsilon$ and $\delta$ ) (Sine, 2002) near Cys192 and Cys193 (Noda et al., 1982; Sumikawa et al., 1982).

The antibodies in $90 \%$ of MG patients are directed against the nAChR (nAChR-MG) and their presence is thus an important diagnostic feature (Lefvert et al., 1978; Lindstrom, 1977; Lindstrom, 2000b; Lindstrom et al., 1976; Vincent and Newsom-Davis, 1985). The anti-nAChR antibodies mostly bind to the main immunogenic region (MIR), which is located on the extracellular part of the $\alpha$-subunit (Mamalaki and Tzartos, 1994; Tzartos and Lindstrom, 1980), and they mainly belong to the immunoglobulin $\mathrm{G}$ (IgG) subclass 1 and 3 (Rodgaard et al., 1987).

The anti-nAChR antibodies are pathogenic because they reduce the number of nAChRs at the NMJ. Three mechanisms are involved. First, they bind and crosslink the nAChRs, resulting in an increased endocytosis and degradation of nAChRs by the muscle cell, a process that is termed "antigenic modulation" (Drachman et al., 1978; Heinemann et al., 1977; Losen et al., 2008; Loutrari et al., 1992; van der Neut Kolfschoten et al., 2007). Second, and most importantly, they bind complement factors at the postsynaptic membrane, leading to a focal lysis of the postsynaptic folds at the NMJ by the membrane attack complex (Chamberlain-Banoub et al., 2006; Engel et al., 1977; van der Neut Kolfschoten et al., 2007). Third, the destruction of nAChR-associated proteins, including utrophin, rapsyn and voltage-gated sodium channels, impairs neuromuscular transmission 
as well (Ito et al., 1996; Losen et al., 2005; Martinez-Martinez et al., 2007; MartinezMartinez et al., 2009; Slater et al., 1997), since these proteins are involved in NMJ formation and maintenance. Consequently, it is conceivable that the very ability of the muscle to compensate for the loss of nAChR and its associated proteins during the attack by anti-nAChR antibodies ultimately influences the severity of the disease (De Baets et al., 2003). In general, antibodies do not interfere with the function of the muscle nAChR, but a few exceptions have been reported where the antibody blocks the binding of ACh (Almon et al., 1974; Gomez and Richman, 1983) or affects the opening of the ion channel (Lang et al., 1988; Wintzen et al., 1998).

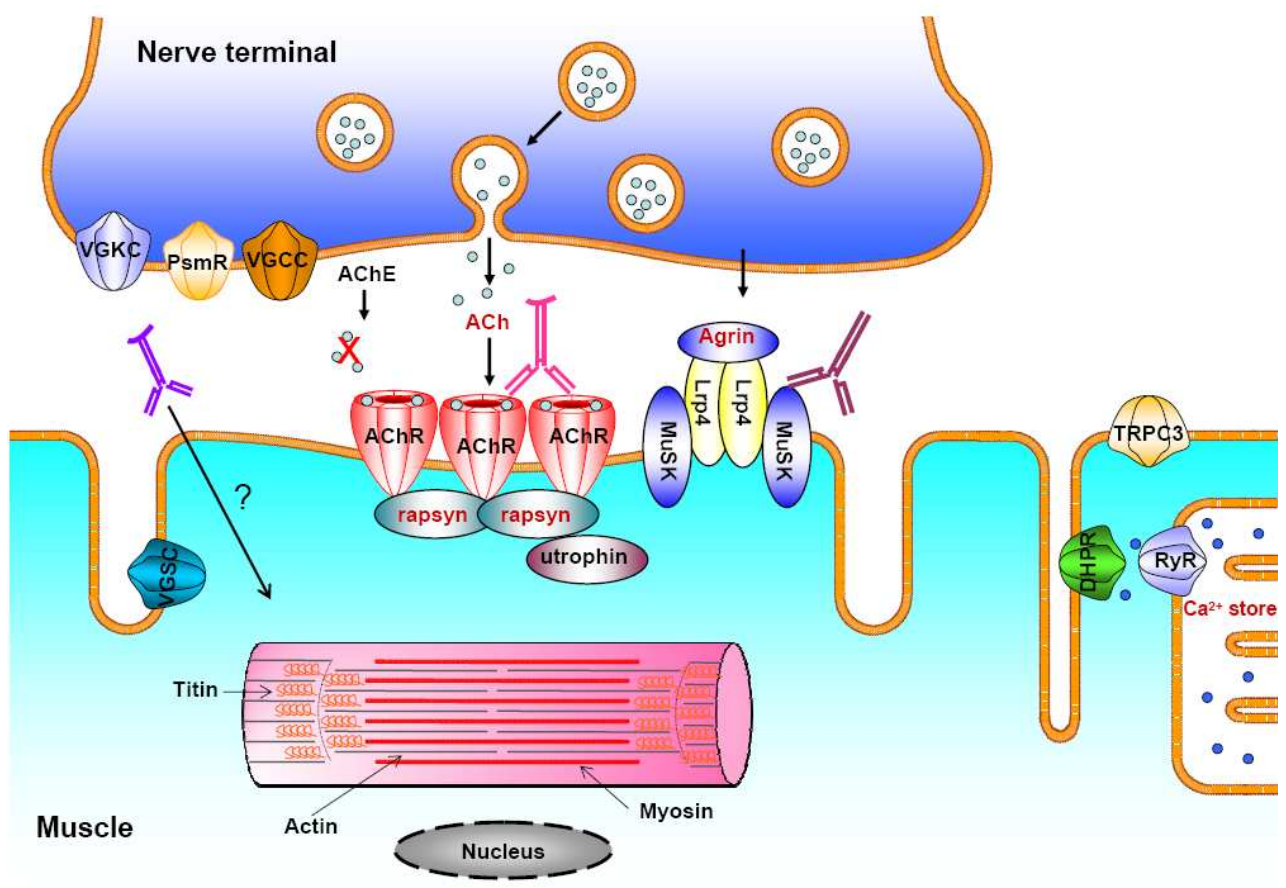

Figure 1. Auto-antigens of muscle tissue in MG patients. The presynaptic, synaptic and postsynaptic parts of the NMJ are shown, in addition to the extra-synaptical T-tubuli. The main pathological antibodies in MG patients target the nAChR and MuSK, but all other auto-antigens at the NMJ are depicted as well. Auto-antibodies also bind non-NMJ proteins that are crucial for muscle contraction, such as intracellular myofibrillar proteins and proteins involved in the excitation-contraction coupling. 
Although MG is usually caused by anti-nAChR antibodies, as such it is still a very heterogeneous disease that can be categorized according to the clinical symptoms and pathogenesis (Table 1). The muscle weakness remains localized to the eye muscles in the (purely) "ocular" form of AChR-MG. When other skeletal muscles are affected, the term "generalized" AChR-MG is used. In about $60 \%$ of generalized AChR-MG, the disease begins before the age of 40 . These "early-onset" patients usually have a hyperplastic thymus, containing germinal centers that may be sites of intense B-cell responses against the nAChR (Alpert et al., 1971). In the "late-onset" MG subgroup, beginning after 40 years of age, the patients mostly have a normal (i.e. atrophic) thymus (Myking et al., 1998). Finally, approximately $10 \%$ of generalized MG patients have a thymoma. Their age at onset varies considerably (Gilhus, 2009; Romi et al., 2005; Vincent, 2002; Vincent et al., 2001). The association between MG and thymic pathology, in addition to the fact that thymic lymphocytes produce anti-nAChR antibodies in vitro (Scadding et al., 1981), and that thymectomy improves the clinical symptoms in some MG patients (Kuks et al., 1991), suggests that the thymus has a special role in the ontogenesis or triggering of anti-nAChR antibody production in MG patients (reviewed by (Le Panse et al., 2010)). Further studies are needed to identify the initial trigger for antibody production in MG and to confirm a role of the thymus in this process.

Besides the need for making subdivisions among patient groups, other factors cause heterogeneity as well. For instance, the anti-nAChR antibodies can highly differ in their subclass, type of light chain, affinity and specificity to different nAChR epitopes (Andrews et al., 1994; Andrews et al., 1993; Chiu et al., 1987; Demaine et al., 1992; Oosterhuis et al., 1983; Tindall, 1981a; Tindall, 1981b). Moreover, no correlation exists between the nAChR antibody levels and severity of the disease (Lefvert et al., 1978; Lindstrom et al., 1976; Oosterhuis et al., 1983; Vincent and Newsom Davis, 1980), although in individual AChRMG patients (Newsom-Davis and Vincent, 1979) and in the experimental autoimmune MG model (Janssen et al., 2008) such correlations have been found. In addition, compensatory mechanisms that change the expression levels of the nAChR after antibody-mediated damage may vary between individuals, which might contribute to the great variability of the severity of the disease (Guyon et al., 1994; Moulian et al., 1998). Finally, the simultaneous presence of auto-antibodies against other antigens can cause additional heterogeneity in the nAChR-MG patients. 


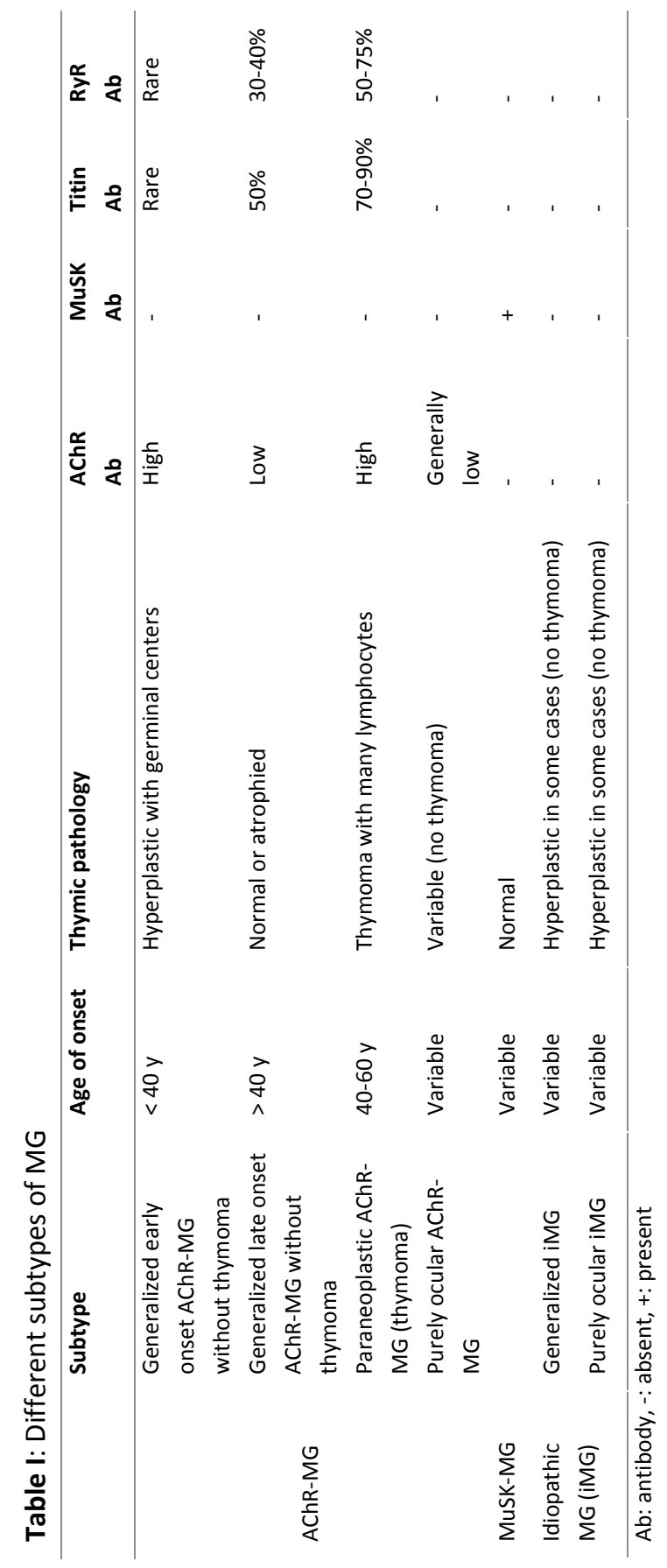




\section{Antibodies against MuSK}

In about $10 \%$ of MG patients, no anti-nAChR antibodies can be detected (seronegative MG). In this subgroup, Hoch et al. identified antibodies to muscle-specific kinase (MuSK) (Hoch et al., 2001), which is a transmembrane protein located at the postsynaptic membrane of the NMJ (Figure 1). Together with the NMJ protein Lrp4, it functions as a receptor for agrin, a nerve-derived extracellular protein (Kim et al., 2008; Zhang et al., 2008). When agrin is released by the nerve terminal during synapse development, it activates MuSK, which leads to clustering of nAChRs (Glass et al., 1996). MuSK is also expressed at the mature NMJ, but its role there is much less understood. Mutations in MuSK are associated with the occurrence of small, undeveloped NMJs in adult mice and humans (Chevessier et al., 2004; Chevessier et al., 2008), which indicates that the trophic influence of MUSK is important for the maintenance of the NMJ in mature muscles.

The number of patients positive for anti-MuSK antibodies (MuSK-MG) highly varies worldwide and approximately represents $50 \%$ of the anti-nAChR antibody negative MG patients (Diaz-Manera et al., 2007; Hoch et al., 2001; McConville et al., 2004; Niks et al., 2007; Ohta et al., 2004; Padua et al., 2006; Yeh et al., 2004; Zhou et al., 2004). Except for one case report, anti-MuSK antibodies have never been described in nAChR-MG patients (Diaz-Manera et al., 2007; Hoch et al., 2001; McConville et al., 2004; Niks et al., 2007; Ohta et al., 2004; Padua et al., 2006; Yeh et al., 2004; Zhou et al., 2004). The MuSK antibodies specifically bind to the N-terminal half of the extracellular domains of MuSK, and they functionally affect the agrin-induced nAChR clustering in vitro (Hoch et al., 2001). In addition, mice (Jha et al., 2006) and rabbits (Shigemoto et al., 2008; Shigemoto et al., 2006) immunized with domains of MuSK protein show less nAChR clustering at the NMJ and develop myasthenic symptoms, although it should be borne in mind that these immunization procedures elicit antibodies with the ability to activate complement, as anti-nAChR antibodies do, in contrast to human anti-MuSK antibodies that mostly lack this function (see below). Passive transfer of human anti-MuSK antibodies influences the activity of MuSK in regenerating endplates in mice, but without reducing MuSK levels, and thereby diminishes the size of the endplate affecting the functioning of AChRs (ter Beek et al., 2009). Nevertheless, the exact pathways leading to disturbed neuromuscular transmission in MuSK-MG patients are still unclear and need further investigation. It has been reported that dimerization, endocytosis and autophosphorylation of MuSK is required for its physiologic function (Zhu et al., 2008), and it is therefore conceivable that binding the MuSK antibody blocks these processes. 
Important differences have been described between MuSK-MG and AChR-MG patients. The pattern of weakness is different in MuSK-MG patients, with prominent muscle atrophy, especially of the tongue, with prevalent involvement of bulbar, respiratory, and neck muscles. MuSK-MG patients present with different features when examined with clinical neurophysiology (Lavrnic et al., 2005; Padua et al., 2006). Additionally, the MuSK antibody titer and disease severity are significantly correlated (Bartoccioni et al., 2006; Evoli et al., 2003; Niks et al., 2008), in contrast to AChR-MG as aforementioned above. The anti-MuSK antibodies belong predominantly to the IgG4 subclass and thus are devoid of the ability to activate the classical cascade of the complement system (McConville et al., 2004; Niks et al., 2008). The thymus is atrophied with age in a normal way, with no thymic germinal centers or lymphocyte infiltrates (Evoli et al., 1996; Lauriola et al., 2005; Leite et al., 2005), and MuSK-MG patients do not benefit from thymectomy (Evoli et al., 2003). These findings contrast with the thymic changes often seen in nAChR-MG patients and argue against a role for the thymus in the pathogenesis of MuSK-MG. All these signs indicate that MuSK-MG is clearly a distinct disease subtype of MG.

\section{Antibodies in idiopathic MG}

The cause of MG in approximately $10 \%$ of patients is unknown. It seems possible that some patients diagnosed with MG based solely on clinical characteristics actually suffer from an unrecognized form of a congenital myasthenic syndrome. However, MG patients without anti-AChR and MuSK antibodies (iMG) potentially have antibodies directed to unidentified neuromuscular proteins, since many benefit from immunosuppression or plasmapheresis.

Alternatively, the elusive autoantigen in iMG might be the AChR or MuSK after all, because the conventional techniques used to measure the anti-nAChR and anti-MuSK antibodies may lack sensitivity. It has been suggested that many iMG patients have nAChR antibodies with a very low affinity or at a low level. Indeed, there is recent evidence that $50 \%$ of iMG sera react positively when tested on human embryonic kidney cells where AChR subunits are expressed at high density together with rapsyn; these antibodies even exhibit the ability to activate complement (Leite et al., 2008; Leite et al., 2010), whereas these sera do not react positively in conventional solution phase assays for anti-nAChR antibodies. Furthermore, iMG patient sera also reduce the amount of AChR in TE671 cells and upregulate the nAChR $\gamma$-subunit expression (Farrugia et al., 2007), which suggests that the iMG antibodies affect nAChR-associated pathways. 
In addition, the nAChR or MuSK antibodies may all remain bound to their antigen at the NMJ, not leaving any detectable levels of circulating antibodies in the blood. Also, patients receiving immunosuppressive treatment have been included in several studies, which might have caused the levels of antibodies to drop to undetectably low levels. Nevertheless, the presence of many miscellaneous auto-antibodies in iMG patients and the clinical improvement after immunosuppressive treatment, the similarity to nAChRMG in clinical features, the response to treatment and thymic pathology all suggest that these patients also have an autoimmune basis to their disease (Chan et al., 2007; Hayashi et al., 2007; Lauriola et al., 2005; Leite et al., 2005).

\section{Acquired slow channel syndrome with antibodies against the $n A C h R \varepsilon$-subunit}

A case has been described that was negative for the standard test for $n A C h R$ antibodies, based on solubilised $\gamma$-subunit containing $n-A C h R$, but was found positive when $\varepsilon$-subunit containing $\mathrm{nAChR}$ was used instead for the antibody assay. Apparently, the antibody was directed to the $\varepsilon$-subunit of the adult nAChR or its interface with neighboring subunits (Wintzen et al., 1998).

Although some symptoms and features were reminiscent of nAChR-MG, such as fluctuating generalized weakness including extra-ocular, bulbar and limb muscles, hyperplastic thymus and decremental response in the electromyography at low frequency of stimulation, other aspects were atypical for MG. First, the electromyography revealed incremental responses at high frequencies, and single stimuli evoked repetitive compound muscle action potentials. As in MuSK-MG, the postsynaptic sensitivity was decreased but the number of AChRs was unchanged. As a result of the antibody- $\varepsilon$-subunit interaction, the opened AChR channels close abnormally slowly after stimulation, which is very similar to the hereditary form of the slow channel syndrome where $\varepsilon$-subunits are mutated and also $\beta$ - and $\gamma$-subunits (Engel et al., 1982; Gomez et al., 1996; Ohno et al., 1995; Oosterhuis et al., 1987; Sine et al., 1995).

Apparently the action of the antibody in the slow channel syndrome is completely different from that in n-AChR-MG, although other antibodies against the $\varepsilon$-subunit have been reported in patients with symptoms that are more typical for nAChR-MG (Beeson et al., 1996).

\section{Antibodies against the P/Q-type $\mathrm{Ca}^{2+}$ channel}

Historically, the Lambert-Eaton myasthenic syndrome (LEMS) branched off quite early from the main stem of MG, and has never been regarded as "seronegative" because early on, before the anti-nAChR antibody test became available, it was evident that the pattern 
of weakness and the results from in vitro electrophysiology of biopsied material were substantially different from MG (Lambert and Elmqvist, 1971). The autoreactive antibody in LEMS is directed against the P/Q-type calcium channels (Lennon et al., 1995), which are located on cholinergic nerve terminals and are responsible for ACh release. Binding of antibody leads to an insufficiency of inward calcium current, causing weakness and also autonomic dysfunction, since P/Q-type channels are also present on nerve terminals of the parasympathetic system.

So while the defect in MG is primarily postsynaptic, the defect in LEMS is caused by a pre-synaptic abnormality, because the quantal content (i.e. the number of ACh packets, or quanta released from the motor nerve terminals by the nerve action potential) is considerably reduced (Cull-Candy et al., 1980; Lambert and Elmqvist, 1971), as well as the resting release of ACh (Molenaar et al., 1982). Nerve terminals exhibit a paucity and disorganisation of the active zone particles, which presumably contain the calcium channels (Engel et al., 1989; Fukunaga et al., 1983).

Weakness in LEMS is usually proximal, particularly affecting the legs (Vincent et al., 1989; Wirtz et al., 2002). The reason is not understood, but could be related to the pattern of usage of the fast muscles of the leg or to some preference of anti-P/Q-type antibodies to pre-synaptic calcium channels of fast leg muscles.

\section{Non-MG specific antibodies}

Although the anti-nAChR and anti-MuSK antibodies are the only pathological autoantibodies in MG patients, various other auto-antibodies can also be found which are frequently associated with thymic abnormalities (Table 2). However, they are not specific to MG, because they are also found in patients with other diseases, and even in healthy individuals. We separated the non-MG specific antibodies into categories: striational antibodies, NMJ antibodies, and antibodies associated with other autoimmune diseases. Auto-antibodies not belonging to one of these subgroups are described as "other autoantibodies".

\section{Striational antibodies}

Already in 1960, sera of MG patients were shown to contain antibodies reacting to several skeletal muscle components (Strauss AJL, 1960). Because of their cross-striational staining pattern of sarcomeres (Strauss and Kemp, 1967), they were called striational antibodies. They have also been termed anti-striated muscle antibodies, muscle striation antibodies, citric acid antigen antibodies, and non-receptor muscle antibodies. They comprise 
antibodies against titin, the ryanodine receptor (RyR) and its related proteins, and antibodies against other myofibrillar proteins. Many of these proteins are located intracellularly and are therefore not directly accessible to auto-antibodies. Although some of them are correlated to MG severity, it is unlikely that they directly damage the NMJ. Diagnosis of striational antibodies is, however, an important diagnostic tool which reflects thymic pathology (reviewed by (Marx et al., 2010)).

\section{Antibodies against titin}

One of the striational antibody targets is titin, an intracellularly located protein of the skeletal muscle sarcomere (Wang et al., 1979). Titin, also known as connectin, extends along the muscle sarcomere from the Z-disc to the M-line and has a length of more than 1 $\mu \mathrm{m}$, making it the largest known protein (Figure 1). By interacting with other muscle proteins including actin, $\alpha$-actinin and myosin, titin mainly plays a role in sarcomere assembly and providing muscle cells with elasticity. Auto-antibodies against titin mainly bind to the main immunogenic region (MIR) of titin, named the myasthenia gravis titin 30 kDa (MGT-30), which is situated near the A-I band junction on the muscle sarcomere (Gautel et al., 1993). In addition to the MIR epitope, some MG patient sera bind a distinct epitope located more centrally on the I-band of titin (Lubke et al., 1998), indicating epitope spreading in MG patients.

Titin antibodies vary among the different MG subgroups. They are present in $70-90 \%$ of the thymoma MG patients, and in about $50 \%$ of late-onset AChR-MG patients without thymoma. Since titin antibodies are rarely present in early-onset AChR-MG patients, their presence is considered to be the main immunological difference between early- and lateonset MG patients. Finally, no titin antibodies are found in iMG or MuSK-MG patients, or in patients with muscle destruction after cardiac infarction, myositis or other causes (Aarli et al., 1990; Buckley et al., 2001; Gautel et al., 1993; Lubke et al., 1998; Romi et al., 2000a). However, the exact mechanisms leading to the titin antibody production in MG patients are not fully understood. Since titin antibodies can hardly be found in early-onset MG patients or myositis patients, it is unlikely that their production is initially triggered by muscle damage caused by the nAChR antibodies or by inflammation. The expression of titin mRNA and titin epitopes in thymoma tissue could suggest that a primary autosensitization against titin antigens occurs inside the thymoma (Romi et al., 2002a). However, this cannot explain the presence of titin antibodies in the late-onset MG patients without a thymoma. In addition, a hyperplastic thymus also contains both titin mRNA and titin itself (Skeie et al., 1997), but patients with early-onset MG and thymus hyperplasia do not develop titin antibodies. These contradictory findings suggest that the 
thymic abnormalities are not the only reason for the production of anti-titin antibodies in MG patients.

Important clinical characteristics have been assigned to the anti-titin antibodies. Firstly, their presence correlates with MG disease severity in the different MG subgroups (Romi et al., 2000b). Secondly, they mainly belong to the IgG1 subclass and can activate complement in vitro (Romi et al., 2000c). Thirdly, anti-titin positive MG patients benefit less from thymectomy compared to anti-titin antibody negative patients (Romi et al., 2002b).

\section{Antibodies against the ryanodine receptor}

The muscle ryanodine receptor (RyR1) is another important antigen to which striational antibodies bind. It is located intracellularly in the membrane of the sarcoplasmatic reticulum (SR) of skeletal muscle cells (Figure 1). It plays an important role in excitationcontraction coupling by functioning as a calcium $\left(\mathrm{Ca}^{2+}\right)$ release channel (Takeshima et al., 1994). Depolarization of the sarcolemma in the T-tubules of the muscle fibers triggers an interaction between L-type calcium channels (dihydropyridine receptor, DHPR) and RyR1 channels. The RyR channels open and release $\mathrm{Ca}^{2+}$ from the SR into the cytoplasma, leading to muscle contraction. This $\mathrm{Ca}^{2+}$ release activity can be affected by the binding of the plant alkaloid ryanodine (Williams, 1992). Auto-antibodies against the RyR1 mainly bind close to the $\mathrm{N}$-terminus (Skeie et al., 2003), but some RyR1 antibodies bind near the C-terminus (Takamori et al., 2004). RyR1 antibodies inhibit binding of ryanodine to the RyR1 in vitro and functionally affect the $\mathrm{Ca}^{2+}$ release from the SR (Skeie et al., 1998a; Skeie et al., 2003). Like the titin antibodies, the RyR1 antibodies are also differentially present in distinct MG subgroups, and they have remarkable features. RyR1 antibodies are detected in $50-75 \%$ of thymoma MG patients and in $30-40 \%$ of late-onset MG patients, whereas they are absent in ocular, early-onset, and MuSK-MG patients (Mygland et al., 1992a; Mygland et al., 1992b; Romi et al., 2000a; Takamori et al., 2004). In addition, they can bind to both the skeletal (RyR1) and cardiac isoforms (RyR2) of ryanodine receptors (Mygland et al., 1994). The presence of RyR1 antibodies is associated with more severe MG symptoms, frequently characterized by defects in bulbar, respiratory, and neck muscles (Romi et al., 2007; Romi et al., 2000b), but the reason for this selective muscle involvement, which is similar to that in MuSK-MG patients, is unknown. The presence of antibodies directed to the ryanodine binding site of the RyR1 is associated with severe MG symptoms (Skeie et al., 1998b). Finally, the presence of RyR1 antibodies in MG patients is correlated with a decreased chance of a positive thymectomy outcome (Romi et al., 2002b). 
The immune reactivity against RyR1 in MG patients is possibly caused by thymic pathology. RyR1 epitopes and co-stimulatory molecules have been found together in thymoma tissue, suggesting that the autoimmunization is actively triggered inside the pathological thymus (Romi et al., 2002a). Obviously, the presence of RyR1 antibodies in late-onset MG patients without thymoma must have another, unknown etiology. The antibodies mainly belong to the complement-activating IgG1 and IgG3 isotypes (Mygland et al., 1993; Romi et al., 2000a).

It seems unlikely that the anti-RyR1 antibodies (or anti-titin antibodies for that matter) can play a role in the pathophysiology of MG, because anti-RyR1 antibodies are not expected to have direct access to the intracellularly located RyR1. Primary damage to subsynaptic T-tubules, initialized by anti-nAChR antibodies and complement reactions, could however facilitate auto-antibody access to the RyR1 molecules. An interesting but puzzling observation is a rat model with spontaneous thymoma and "MG" without AChR antibodies (Iwasa et al., 1998). These rats have anti-RyR1 antibodies, suggesting that RyR1 antibodies per se may cause weakness, by interference with excitation-contraction coupling. Obviously, such weakness must be of a different nature than the myasthenic weakness, where neuromuscular transmission is affected, but it could attribute to contractile abnormalities in MG.

\section{Antibodies against RyR-related proteins}

Besides the RyR, the other $\mathrm{Ca}^{2+}$ channels involved in excitation-contraction coupling have also been described as auto-antigens in MG patients. Both the DHPR and the transient receptor potential canonical type 3 (TRPC3) function as $\mathrm{Ca}^{2+}$ release or modulation channels and participate in the excitation-contraction coupling. In contrast with the RyR, both these receptors have extracellular domains, thus making them directly accessible to auto-antibodies. Antibodies against DHPR (Maruta et al., 2009) or TRPC3 (Takamori, 2008) are found in almost $40 \%$ of MG patients. Whereas the DHPR antibodies are only detectable in thymoma-MG patients, TRPC3 antibodies also occur in patients with thymic hyperplasia. Both types of auto-antibodies are present in patients with more severe myasthenia and might therefore be correlated with increased muscle dysfunction in MG (Maruta et al., 2009; Takamori, 2008). The pathogenic effect of these auto-antibodies on the excitation-contraction coupling in MG patients needs to be further investigated, as well as their possible association with anti-RyR1 antibodies. 


\section{Antibodies against other myofibrillar proteins}

Striational auto-antibodies also target several other myofibrillar proteins, which play the key role in muscle contraction. The first identification of non-nAChR muscle antigens in MG patients was published by Williams and Lennon (Williams and Lennon, 1986). They showed that monoclonal antibodies produced by thymic B cells were able to bind the myofibrillar proteins myosin, actin and $\alpha$-actinin specifically. Later, other studies demonstrated antibodies in the sera of MG patients against myosin (Mohan et al., 1994; Ohta et al., 1990; Takaya et al., 1992), tropomyosin (Takaya et al., 1992; Yamamoto et al., 1987), actomyosin (Ohta et al., 1990), actin (Ohta et al., 1990; Takaya et al., 1992), $\alpha$ actinin (Ohta et al., 1990; Takaya et al., 1992), filamin (Lin, 1992; Yamamoto et al., 1987), troponin (Takaya et al., 1992), and vinculin (Yamamoto et al., 1987), and their level was significantly different when compared to healthy controls. Contradictory findings have however been reported about the correlation between the presence of anti-myofibrillar antibodies and the MG severity or thymic pathology (Mohan et al., 1994; Ohta et al., 1990; Yamamoto et al., 1987).

\section{Antibodies against other NMJ proteins}

Besides the striational antigens, non-MG specific auto-antibodies also bind to other NMJ proteins. Rapsyn is an intracellular postsynaptic membrane-associated protein, which is clustered at a ratio of approximaldy $1: 1$ to the $n A C h R$ and necessary to group nAChRs at high density at the postsynaptic folds of the NMJ (Gautam et al., 1995). Anti-rapsyn antibodies have been detected in almost $15 \%$ of MG patients, but not in healthy controls. However, patients with other autoimmune diseases, such as lupus or chronic procainamide-associated myopathy, also have anti-rapsyn antibodies, rendering these antibodies unspecific for MG (Agius et al., 1998a; Agius et al., 1998b).

Auto-antibodies can also arise against proteins in the basal lamina of the synaptic cleft, and anti-acetylcholinesterase (AChE) antibodies have been reported in 5-36\% of MG patients (Geen et al., 2004; Mappouras et al., 1995; Phillips et al., 1981; Tang et al., 1997). The enzyme AChE catalyzes the breakdown of $\mathrm{ACh}$ at the synaptic cleft, thereby preventing persistent depolarization and desensitization of the AChRs. Antibodies targeting the AChE might disturb the ACh breakdown. The potential function of anti-AChE antibodies in the pathophysiology of MG is contradictory, since they are also present in healthy controls and patients with other autoimmune diseases (Geen et al., 2004; Mappouras et al., 1995). An interesting rat model has been described in which injection of 
monoclonal antibodies to neuronal AChE caused pre-ganglionic sympathectomy, apparently without effects on the neuromuscular junction (Brimijoin and Lennon, 1990).

Finally, auto-antibodies are also reactive towards pre-synaptic membrane proteins, namely the pre-synaptic ACh membrane receptor (PsmR) and the voltage-gated potassium channel (VGKC). Antibodies against the PsmR, which can be isolated from crude receptor using beta-bungarotoxin instead of alpha-bungarotoxin, are found in approximately $50 \%$ of MG patients (Lu et al., 1991). Low levels of the antibodies are also detected in $6 \%$ of patients with other neurological diseases, but not in healthy control subjects. The PsmR antibodies cross-react with nAChR-antibodies, and both antibody levels strongly correlate with each other, but not with the disease severity (Lu et al., 1991; Xiao et al., 1991). Moreover, peripheral blood and bone marrow cells from MG patients, both with and without nAChR antibodies, secrete antibodies against PsmR (Link et al., 1992; Lu et al., 1993). Finally, when injected into mice, PsmR antibodies induce changes in neuromuscular transmission ( $\mathrm{Xu}$ et al., 1998b). These results suggest that the PsmR antibodies might also contribute to the pathophysiology of MG, but mainly by damaging the pre-synaptic membrane instead of the postsynaptic membrane.

The VGKC ion channel functions in repolarizing the nerve terminal and the nodes of Ranvier at the motor nerve after an action potential. Auto-antibodies to the VGKCs are primarily associated with acquired neuromyotonia, which is caused by high frequency after-discharges and spontaneous depolarizations (Shillito et al., 1995). Neuromyotonia is characterized by muscle twitching, cramps, pseudomyotonia and weakness (Hart et al., 1997). However, spontaneous polarizations can sometimes also be found in MG patients without clinical symptoms of acquired neuromyotonia (Mygland et al., 2000). Antibodies to the Kv1.4 subfamily of VGKCs are identified in 12-28\% of MG patients, but not in healthy controls (Suzuki et al., 2005; Suzuki et al., 2007). The anti-Kv1.4 antibodies are associated with a bulbar involvement, myasthenic crisis, myocarditis and thymoma; thus relating them to a more severe form of MG (Suzuki et al., 2005). The reason why these antibodies are present in MG patients without acquired neuromyotonia is still unclear. It should be remembered that muscle fibers also contain VGKCs, responsible for repolarization and maintenance of the resting potential of the muscle membrane. However, these are of a different type and neuromyotonia antibodies predominantly bind to the neuronal VGKCs.

All together, these findings clearly demonstrate that many proteins, all in functional connection with the $\mathrm{nAChR}$, can also be targeted by auto-antibodies in MG patients. This raises the interesting question of whether the autoimmunization processes against the 
different muscle antigens are triggered by the same factors, or whether different aspects cause the production of these auto-antibodies.

\section{Antibodies associated with other auto-immune diseases}

Several of the non-specific auto-antibodies found in MG patients are clearly associated with other autoimmune diseases, such as antibodies reactive to the thyroid gland, nuclear antigens or phospholipids.

Auto-antibodies against the thyroid gland, which regulates the general metabolism rate by the production of hormones, characterize autoimmune diseases such as Hashimoto's thyroiditis or Graves's disease. It has been shown that thyroid diseases are significantly more prevalent in MG patients (Toth et al., 2006). In addition, anti-thyroid antibodies can be detected in $30-40 \%$ of MG patients, and they occur more frequently in purely ocular MG compared to generalized MG (Cojocaru et al., 2000; Kiessling et al., 1981; Sagar et al., 1980). They are also present in healthy individuals (Weissel et al., 2000) and patients with other autoimmune disorders (Nakamura et al., 2008). Anti-thyroid antibodies have been demonstrated to bind to thyroglobulin (Chan et al., 2007; Kiessling et al., 1981; Mappouras et al., 1995; Weissel et al., 2000), thyroid peroxidase (Chan et al., 2007), and thyroid stimulating hormone (Kiessling et al., 1982).

Auto-antibodies directed against nuclear antigens occur with high prevalence in systemic lupus erythematosus (SLE), a chronic autoimmune connective tissue disease that affects multiple organs. The anti-nuclear antibodies have also been reported in variable numbers of MG patients, ranging from 6-60\% (Oosterhuis et al., 1976; Shoenfeld et al., 1988; White and Marshall, 1962). The high co-morbidity of MG and SLE might explain the increased amounts of SLE-related auto-antibodies in MG patients (Sthoeger et al., 2006). Additionally, the anti-nuclear antibodies cross-react with anti-phospholipid antibodies, and these antibodies often occur in SLE and MG patients as well (Colaco et al., 1987). Anti-nuclear antibody production might be triggered by thymic tumor tissue, since a correlation has been described between thymoma and anti-nuclear antibodies (Warlow et al., 1985). However, the significance of anti-nuclear antibodies in general is not yet clear, and their contribution to the pathology of MG and other autoimmune disorders needs further investigation.

Antibodies against phospholipids are associated with both SLE and the antiphospholipid syndrome. The phospholipid cardiolipin, a kind of diphosphatidylglycerol, is located at the inner membrane of mitochondria in metabolically active cells of heart and skeletal muscle. Antibodies against cardiolipin belong to a large family of antiphospholipid and anti-mitochondrial antibodies, and are found in $20-40 \%$ of $\mathrm{MG}$ 
patients(Colaco et al., 1987; Kinoshita et al., 1994; Sanmarco and Bernard, 1994). The anti-cardiolipin antibodies are not correlated with the severity of MG or with anti-nAChR antibody levels (Kinoshita et al., 1994), but they are significantly associated with thymic abnormalities (Sanmarco and Bernard, 1994). Thus, a disturbed self-tolerance due to thymic alterations might cause the production of anti-cardiolipin antibodies in some MG patients.

\section{Other auto-antibodies}

Besides the many auto-antibodies reacting to muscle antigens or to auto-antigens associated with other autoimmune diseases, various other auto-antibodies have been described in MG patients and will be briefly summarized here.

\section{Antibodies against other AChRs}

Although the muscle nicotinic AChR is the main target for antibodies in MG, autoantibodies are also reactive against other subfamilies of the AChR. The M1-type presynaptic muscarinic AChR (M1 mAChR) is expressed in the pre-synaptic membrane at the NMJ, where it might modulate the neuromuscular transmission (Garcia et al., 2005). Antibodies against M1 mAChR are frequently present in Lambert-Eaton myasthenic syndrome patients (LEMS), but can also be detected in almost $30 \%$ of MG patients (Takamori et al., 2007). In MG patients, anti-nAChR antibodies impair the neuromuscular transmission, which leads to an upregulation of the ACh release from the nerve terminal (Plomp et al., 1995). Blocking muscarinic receptors by atropine also increases ACh release in the autonomic parasympathetic nervous system and in the brain, but has no effect on ACh release at the NMJ.

In addition to muscle AChRs, the neuronal AChRs can also be targeted by autoantibodies, although infrequently in MG patients. Antibodies against the $\alpha 7$-subunit of the neuronal nAChR are found in only $8 \%$ of MG patients, and antibodies against the $\alpha 3$ subunit are detectable in less than $5 \%$ of MG patients (Balestra et al., 2000; Gotti et al., 2001). The fact that antibodies recognize these nAChRs might partly explain the autonomic dysfunctions seen in some of the patients, since these nAChRs play key roles in controlling the neuronal transmission in autonomic ganglia. However, many patients with other immune-mediated disorders, such as autoimmune autonomic ganglionopathy (AAG), also express these antibodies (Vernino et al., 2008). The structural and functional homologies between muscle and neuronal nAChR subtypes (Lindstrom, 2000a) raises the possibility that some muscle nAChR antibodies cross-react with the neuronal nAChRs. Another possibility is that a thymoma might be the cause of antibody production, since it 
is known to contain transcripts for neuronal nAChR subunits (Mihovilovic and Roses, 1993). It is also possible that neuronal antigens themselves originally trigger the autoimmune response. Thus, the origin and especially the extent of the contribution of these antibodies to the clinical symptoms of MG remain unclear. Nevertheless, these studies have led to the conclusion that all members of the AChR family are potential targets for an autoimmune attack.

\section{Antibodies against B-adrenergic receptors}

$\beta$-adrenergic receptors are present on skeletal muscle cells, but also on cardiomyocytes and lymphocytes, and they modulate the function of these organs by reacting to adrenaline (epinephrine) and noradrenaline (norepinephrine). Anti- $\beta$-adrenergic receptor antibodies may functionally interfere with the $\beta$-adrenergic regulation of both muscle and heart function by blocking or down-regulating the receptors, thereby impairing muscle contraction force, e.g. by interfering with the glycogenolysis, and aggravating the disease severity in some MG patients. Antibodies against the $\beta$-adrenergic receptors ( $\beta 1$ and $\beta 2$ ) exist in nearly $20-30 \%$ of MG patients, but not in healthy control subjects (Eng et al., 1992; Xu et al., 1998a), and immune cells reactive to $\beta$-adrenergic receptors are even shown to be present in almost all MG patients (Yi et al., 1996). However, these autoantibodies have also been found in more than $30 \%$ of patients with idiopathic dilated cardiomyopathy, a disease that primarily affects the myocardium (Magnusson et al., 1990). The prevalence of clinical heart disease does not differ in MG patients with or without $\beta$-adrenergic receptor antibodies, but MG patients with co-occurrence of heart disease have significantly higher levels of anti- $\beta$-adrenergic receptor antibodies than patients without heart diseases (Xu et al., 1998a).

\section{Antibodies against cytokines}

Cytokines are immune-modulating molecules that function in cellular communication, and their expression is drastically influenced by all events that affect the immune system, such as infection and injury. The production of auto-antibodies against cytokines can occur spontaneously in healthy individuals (Watanabe et al., 2007), but it is mainly associated with chronic infections and autoimmune diseases (Meager et al., 1999). In MG patients, increased numbers of antibodies have been described against several cytokines, such as granulocyte macrophage colony-stimulating factor (GM-CSF) (Meager et al., 1999), interferon-alpha (IFN- $\alpha$ ) (Buckley et al., 2001; Meager et al., 1999), interferonomega (IFN- $\omega$ ) (Meager et al., 2003), and interleukin 12 (IL-12) (Buckley et al., 2001; Meager et al., 1999; Yoshikawa et al., 2006). In addition, some of the antibodies have a 
neutralizing effect on their respective cytokine in vitro (Buckley et al., 2001; Meager et al., 1997; Meager et al., 2003). The anti-cytokine antibodies are closely related with thymoma, since they occur more often in thymoma-MG patients compared to nonthymoma MG patients, and these antibodies even occur in thymoma patients without MG. Moreover, their levels increase when thymomas recur, and thymoma cells spontaneously produce anti-cytokine antibodies in vitro, whereas they only produce anti$\mathrm{nAChR}$ antibodies after pokeweed mitogen stimulation. This might even suggest a direct autoimmunization in thymomas against the cytokines, rather more than against the nAChR (Shiono et al., 2003). However, this cannot explain the increased anti-cytokine antibody levels detected in late-onset MG patients without thymoma or patients with chronic infections (Buckley et al., 2001; Meager et al., 2003; Shiono et al., 2003). Anticytokine antibodies are not specific to $M G$, and no correlations exist between anticytokine antibody levels and clinical severity or AChR-antibody titer (Yoshikawa et al., 2006). They might suppress the pro-inflammatory properties of the cytokines (Wildbaum et al., 2003), thereby playing a role in the regulation of the immune system, but their specific effects on the pathogenesis of MG and autoimmunity in general are not completely understood.

\section{Antibodies against heat shock proteins}

Heat shock proteins (HSPs) are highly conserved intracellular proteins functioning as chaperones during intracellular folding, assembly and translocations of other proteins. Their expression greatly increases when cells are exposed to heat, inflammatory mediators or other forms of physiological stress (Hartl, 1996). In MG, auto-antibodies against the HSP are present in up to $80 \%$ of patients (Astarloa and Martinez Castrillo, 1996; Munakata et al., 2008). The anti-HSP antibody titers do not correlate with antiAChR antibodies or disease duration (Astarloa and Martinez Castrillo, 1996), but they do reflect the clinical course of MG patients as well as the efficacy of treatment (Munakata et al., 2008). However, the antibodies are not specific for MG, because they have also been reported in several other autoimmune diseases, such as SLE (Minota et al., 1988), multiple sclerosis (Gao et al., 1994) and rheumatoid arthritis (Hayem et al., 1999), and even in around 5\% of healthy controls (Astarloa and Martinez Castrillo, 1996; Hayem et al., 1999). This does not support a direct role of the anti-HSP antibodies in the pathogenesis of MG, but it relates more to a general dysfunction of the immune system. 


\section{Rarely studied auto-antibodies in MG}

A variety of other auto-antibodies have been demonstrated in MG patients, but otherwise, they are rather infrequently studied:

1.) auto-antibodies against complement factor $\mathrm{C} 1 \mathrm{q}$ are present in MG patients, but they are not inversely correlated with the muscle strength of the patients (Tuzun et al., 2006). Probably, these antibodies may further damage the neuromuscular transmission by binding to the C1q deposits at the NMJ thereby potentiating the complement activation process;

2.) auto-antibodies against thrombocytes occur in about $20 \%$ of MG patients, but since they are also present in about half of the SLE patients (Leone et al., 1978), they are not specific for MG;

3.) auto-antibodies to growth hormone have been detected in one MG patient who had never been prescribed growth hormone, but they were not present in the other MG patients studied (Okada et al., 1990);

4.) auto-antibodies against neuroblastoma cell lines, which are often used to determine antibodies against neural antigenic targets, are present in $40-60 \%$ of MG patients. However, low titers have also been observed in more than $10 \%$ of healthy individuals (Muller, 1989; Muller and Andersson, 1984; Muller et al., 1991). The presence of these antibodies provides evidence for autoimmunization against antigens of neural origin in MG;

5.) anti-thymus antibodies have been found in $45 \%$ of $M G$ patients with a normal or hyperplastic thymus (Safar et al., 1991);

6.) auto-antibodies against alkaline phosphatase (AP) have been reported in almost $10 \%$ of MG patients, but not in iMG or non-MG patients (Konishi et al., 2007). AP is a membrane-bound enzyme that dephosphorylates cellular molecules, and increased AP isoforms have been detected in distinct autoimmune disorders (Hanna et al., 1997). The anti-AP antibodies do not cross-react or correlate with anti-nAChR antibodies, but their presence does correlate with a more severe form of MG (Konishi et al., 2007);

7.) in $20-30 \%$ of MG patients, antibodies against gravin are present (Gordon et al., 1992; Sasaki et al., 2001), which is a cell- and tissue-type specific kinase scaffold protein (Nauert et al., 1997) that is not present at the NMJ (Grove et al., 1994). Apart from a single patient with rheumatoid arthritis, no anti-gravin antibodies have been detected in patients with other autoimmune diseases or in healthy controls, which makes this antibody specific to MG. The anti-gravin antibodies are, in addition, more strongly expressed in younger and non-thymoma patients (Sasaki et al., 2001), but their levels do not correlate with the anti- 
nAChR antibody levels (Gordon et al., 1992; Sasaki et al., 2001).

Despite the limited knowledge about the role of all these auto-antibodies, they might be of importance in MG and other autoimmune disorders. To accomplish the auto-antibody repertoire in MG, it would be important to include these antigens in future studies as well.

\section{Significance of the auto-antibodies in MG}

Because no correlation exists between the anti-nAChR antibody titer and the severity of MG, many studies have investigated whether other auto-antibodies might also be involved. Even though MG is a prototypic organ-specific autoimmune disorder, it is found to be accompanied by multiple auto-antibodies, which shows the degree of heterogeneity of this disease. The fact that many of these auto-antibodies are also present in patients with other autoimmune diseases or in healthy individuals raises the question of why so many different auto-antibodies are present in the human body, and if they play some role in the pathology or are merely bystanders.

In healthy individuals, antibodies are produced independently of known immunization, and they are termed natural antibodies. They can bind to a variety of exogenous antigens and are thought to play an important role in the primary defense against infections (Baxendale et al., 2008; Zhou et al., 2007). However, they also recognize multiple self-antigens, which suggests that they have an additional role in the homeostasis of the immune system (Yurasov and Nussenzweig, 2007). It is important to emphasize that natural antibodies also react to self-antigens that are targets for autoantibodies in autoimmune diseases, which may explain why many of the auto-antibodies found in MG patients are also present in healthy individuals. However, the subclass, affinity and specificity of natural antibodies are usually significantly different from pathological auto-antibodies (Elkon and Casali, 2008; Lacroix-Desmazes et al., 1998), leading most likely to distinct effects on the auto-antigen in healthy individuals as compared to autoimmune patients. 


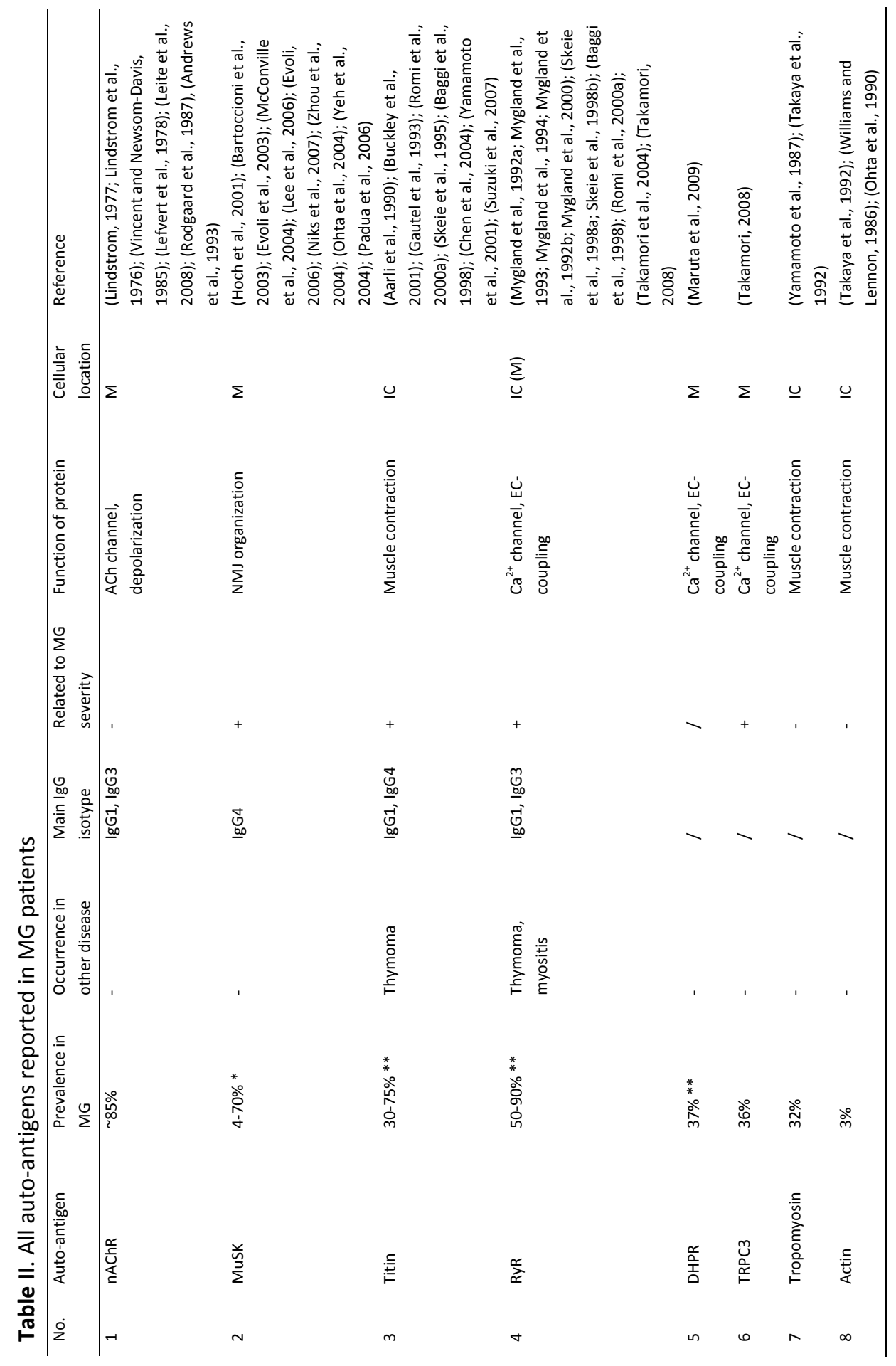




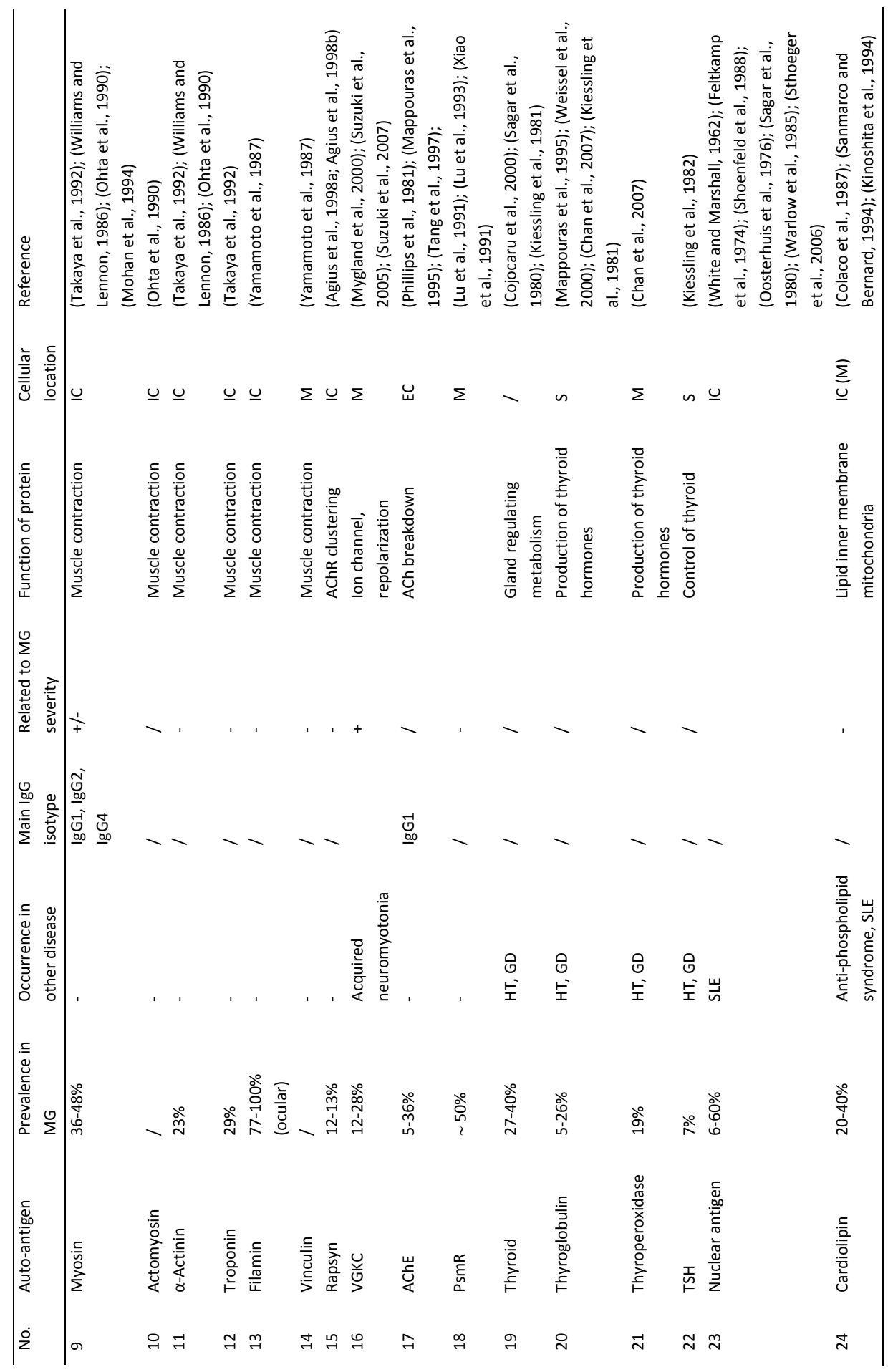




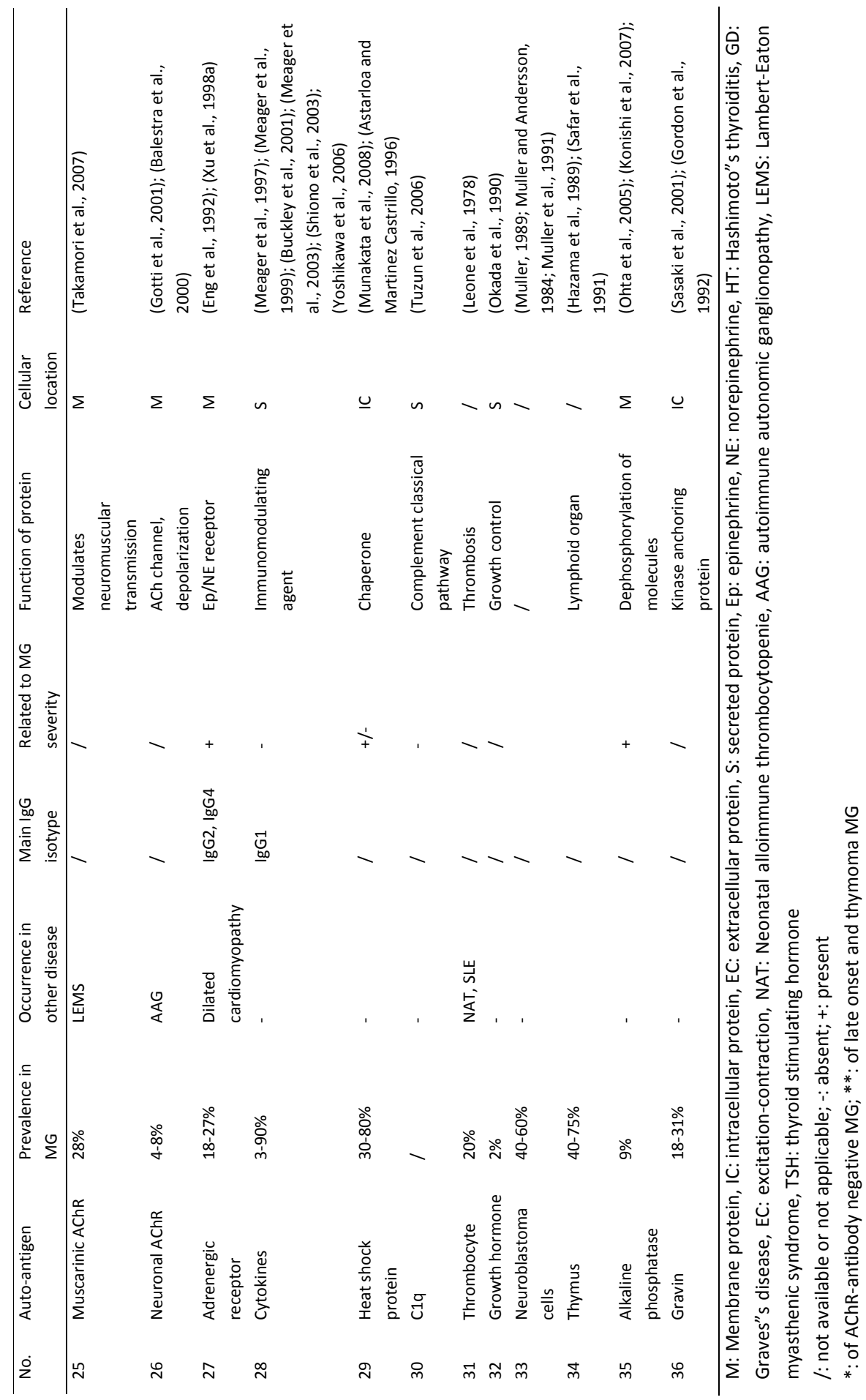


Autoimmunity usually occurs when the maintenance of self-tolerance is disturbed due to dysregulated immune mechanisms, but it is incompletely understood which factors exactly break down the self-tolerance. Molecular changes in the antigen can elicit the production of auto-antibodies, but deficiencies in the immune system itself facing an intact antigen can also give rise to autoimmunity. In addition, the self-tolerance can be influenced by inflammatory processes, molecular mimicry of pathogens, vaccination, environmental factors and genetic background (Atassi and Casali, 2008; Shoenfeld et al., 2008). A general dysfunction of the immune system might explain the increased cooccurrence of different autoimmune diseases and the simultaneous presence of distinct auto-antibodies in MG patients. Although the main auto-antigens in MG are well characterized, the most intriguing question that remains is how the self-tolerance breaks down and why so many antigens are selected as a target for the auto-antibodies. Promiscuous expression of tissue-restricted auto-antigens in the thymus provides protection from autoimmune diseases, and mutations in the autoimmune regulator AIRE protein cause a breakdown of central tolerance associated with decreased expression of these self-antigens in the thymus. Differences in the expression level of the autoimmune regulator AIRE, together with genetic variances in AChR genes, influence the expression levels of this self-antigen in MG, which might trigger the autoimmune response (Giraud et al., 2007). Even though the thymus is thought to be involved in the initial steps of MG pathogenesis in some patients, it is still not clear whether the thymus or other factors are the primary cause of the auto-antibody production (reviewed by (Le Panse et al., 2010)). Since MG is a prototypical and well-characterized autoimmune disease, it could serve a role as a model disorder for investigating the early steps in the pathogenesis that are still unknown in almost all autoimmune diseases.

It is also important to know whether and by what mechanism auto-antibodies exert pathological effects on their targets. How anti-nAChR antibodies cause muscle weakness is well-described, but the pathophysiological mechanisms of anti-MuSK antibodies are much less understood. Furthermore, it is not known if antibodies against particular proteins such as titin and RyR contribute to more severe symptoms, or whether the many other auto-antibodies present in MG patients have neutral, beneficial or harmful consequences. Some of these antibodies belong to the IgG1 subclass, so they might damage their targets by activating the complement system, which leads to additional inflammation. However, many studies do not describe the subclass of the particular antibody or its capacity to activate complement. It has become clear that this is important for the occurrence or the absence of the immunopathological effects, e.g. cross-linking and complement activation. The pathogenicity of auto-antibodies can be tested using 
human monoclonal antibodies, which can be produced by an efficient method of immortalizing human B cells (Fraussen et al., 2009; Traggiai et al., 2004). Moreover, it should be emphasized that many auto-antigens, in contrast to the nAChR and MuSK, are located intracellularly, which raises the question if they can be reached and attacked by auto-antibodies. It has long been thought that auto-antibodies exclusively reacted with antigens in the extracellular compartment, and that they were only able to bind to intracellular antigens after other mechanisms had damaged the cell membrane. However, auto-antibodies have been shown to be able to actively cross the cell membrane (AlarconSegovia et al., 1978; Deng et al., 2000; Yanase and Madaio, 2005), providing evidence that auto-antibodies against intracellular antigens could in principle exert functional effects. On the other hand, it is unknown whether complement factors can reach cytosolic targets and, if they do, cause damage there if there are no membranes to attack. The mechanisms by which the antibodies cross the cell membrane and travel through the cytoplasm to reach their targets are still unclear, although particular conformational motifs in the heavy chain CDR3 region (Yanase et al., 1997) and electrostatic interactions (Song et al., 2008) have been demonstrated to serve as localization signals in the intracellular directed transport. It is not known yet whether these characteristics are also present in auto-antibodies of MG patients, and if so, whether these antibodies have detrimental effects on their intracellular targets. Investigating these mechanisms will help to clarify the function of auto-antibodies against intracellular targets in MG.

Finally, it is important to realize that the knowledge of the auto-antibody repertoire of MG patients known so far might have been limited in previously performed studies. First of all, the sensitivity of many different techniques used to identify auto-antibodies may have been different, leading to variations in the published results. Moreover, many techniques have remained limited by the small number of purified proteins that were available as sources of self-antigens. In addition, many studies were performed before the identification of anti-MuSK antibodies, which makes it now difficult to attribute the results to either the MuSK-MG or the iMG group. Furthermore, results might have been biased, because the different MG subtypes were not taken into account, or because low numbers of patients were included in a study. Therefore, it would be highly desirable, if practically possible, that future studies should aim to include larger numbers of MG patients from different countries and subdivide them based on the MG subtype to obtain more significant, specific information. In addition, the development of new devices to perform large-scale and high-throughput auto-antibody analysis will increase our knowledge about the auto-antibody repertoire in MG. Further investigations should also consider which Ig subclass the antibodies belong, and whether they are associated with 
other auto-antibodies or other auto-immune diseases. Finally, it would be useful to study when the auto-antibodies appear in the disease course and whether they are reduced after immunosuppressive treatment.

This review underscores that in autoimmune diseases, antibodies against a whole array of antigens are present in patients, rather than against a single pathophysiological target. MG patients probably have many more auto-antibodies than described in the literature up until now, and the clarification of the complete auto-antibody repertoire is likely to contribute to a better understanding of the principle of autoimmune diseases in general. In this connection, one might wonder why the neuromuscular transmission is targeted and affected in autoimmune diseases such as MG, because it has a great inherent safety factor; three to five times more transmitter is released than is necessary for the successful and rapid transmission of impulses from nerve to muscle. In this way, the muscle function is heavily protected against the grave consequences that would entail failure of the system. However, the very nature of the chemical synapse, with receptors that are highly specific for neurotransmitters, makes neuromuscular transmission vulnerable for specialized "pharmacological" attacks, as witnessed by the action of curare poison arrows, the venoms of cobra and krait snakes, sea snail (conus) venoms and botulinum toxins, which all block or inactivate different proteins of the neuromuscular junction. Similarly, in autoimmune diseases, once self-protection breaks down and an array of antibodies is produced against self-proteins, MG is a logical consequence if the anti-AChR happens to be among the autoantibodies in the autoimmune repertoire. Other antigens may also be "attacked" by antibodies, but this may not have pathological consequences, because the proteins are intracellularly located, extracellularly located but not in membranes, or in membranes with a too low density for cross-linking or complement reactions to occur. According to this view, paradoxically, we have to seek the original cause of MG in the nature of the chemical synapse transmission itself, because of its vulnerability which depends on the precise function and irreplacability of the organspecific membrane proteins MuSK and AChR. In other words, the cause does not necessarily lie in a predetermined specificity of the immune system, e.g. by specific presentation of muscle proteins when autoimmune reactions are initiated. It is thus predicted that any membrane protein with a vitally important physiologic function that cannot be taken over or compensated by other proteins might sooner or later become subject to autoimmune attack and disease, albeit in a small number of patients. 


\section{References}

Aarli, J.A., Stefansson, K., Marton, L.S., Wollmann, R.L., 1990. Patients with myasthenia gravis and thymoma have in their sera IgG autoantibodies against titin. Clin Exp Immunol 82, 284-288.

Agius, M.A., Zhu, S., Aarli, J.A., 1998a. Antirapsyn antibodies occur commonly in patients with lupus. Ann N Y Acad Sci $841,525-526$.

Agius, M.A., Zhu, S., Kirvan, C.A., Schafer, A.L., Lin, M.Y., Fairclough, R.H., Oger, J.J., Aziz, T., Aarli, J.A., 1998b. Rapsyn antibodies in myasthenia gravis. Ann N Y Acad Sci 841, 516-521.

Alarcon-Segovia, D., Ruiz-Arguelles, A., Fishbein, E., 1978. Antibody to nuclear ribonucleoprotein penetrates live human mononuclear cells through Fc receptors. Nature 271, 67-69.

Almon, R.R., Andrew, C.G., Appel, S.H., 1974. Serum globulin in myasthenia gravis: inhibition of alpha-bungarotoxin binding to acetylcholine receptors. Science 186, 55-57.

Alpert, L.I., Papatestas, A., Kark, A., Osserman, R.S., Osserman, K., 1971. A histologic reappraisal of the thymus in myasthenia gravis. A correlative study of thymic pathology and response to thymectomy. Arch Pathol 91, 55-61.

Andrews, P.I., Massey, J.M., Howard, J.F., Jr., Sanders, D.B., 1994. Race, sex, and puberty influence onset, severity, and outcome in juvenile myasthenia gravis. Neurology 44, 1208-1214.

Andrews, P.I., Massey, J.M., Sanders, D.B., 1993. Acetylcholine receptor antibodies in juvenile myasthenia gravis. Neurology 43, 977-982.

Astarloa, R., Martinez Castrillo, J.C., 1996. Humoral response to the human heat shock $60 \mathrm{kDa}$ protein in myasthenia gravis. J Neurol Sci 135, 182-183.

Atassi, M.Z., Casali, P., 2008. Molecular mechanisms of autoimmunity. Autoimmunity 41, 123-132.

Baggi, F., Andreetta, F., Antozzi, C., Simoncini, O., Confalonieri, P., Labeit, S., Cornelio, F., Mantegazza, R., 1998. Antititin and antiryanodine receptor antibodies in myasthenia gravis patients with thymoma. Ann N Y Acad Sci 841, 538-541.

Balestra, B., Moretti, M., Longhi, R., Mantegazza, R., Clementi, F., Gotti, C., 2000. Antibodies against neuronal nicotinic receptor subtypes in neurological disorders. J Neuroimmunol 102, 89-97.

Bartoccioni, E., Marino, M., Evoli, A., Ruegg, M.A., Scuderi, F., Provenzano, C., 2003. Identification of disease-specific autoantibodies in seronegative myasthenia gravis. Ann N Y Acad Sci 998, 356-358.

Bartoccioni, E., Scuderi, F., Minicuci, G.M., Marino, M., Ciaraffa, F., Evoli, A., 2006. Anti-MuSK antibodies: correlation with myasthenia gravis severity. Neurology 67, 505-507.

Baxendale, H.E., Johnson, M., Stephens, R.C., Yuste, J., Klein, N., Brown, J.S., Goldblatt, D., 2008. Natural human antibodies to pneumococcus have distinctive molecular characteristics and protect against pneumococcal disease. Clin Exp Immunol 151, 51-60.

Beeson, D., Jacobson, L., Newsom-Davis, J., Vincent, A., 1996. A transfected human muscle cell line expressing the adult subtype of the human muscle acetylcholine receptor for diagnostic assays in myasthenia gravis. Neurology 47, $1552-1555$

Bergoffen, J., Zmijewski, C.M., Fischbeck, K.H., 1994. Familial autoimmune myasthenia gravis. Neurology 44, 551-554.

Brimijoin, S., Lennon, V.A., 1990. Autoimmune preganglionic sympathectomy induced by acetylcholinesterase antibodies. Proc Natl Acad Sci U S A 87, 9630-9634.

Buckley, C., Newsom-Davis, J., Willcox, N., Vincent, A., 2001. Do titin and cytokine antibodies in MG patients predict thymoma or thymoma recurrence? Neurology 57, 1579-1582.

Chamberlain-Banoub, J., Neal, J.W., Mizuno, M., Harris, C.L., Morgan, B.P., 2006. Complement membrane attack is required for endplate damage and clinical disease in passive experimental myasthenia gravis in Lewis rats. Clin Exp Immunol 146, 278-286.

Chan, K.H., Lachance, D.H., Harper, C.M., Lennon, V.A., 2007. Frequency of seronegativity in adult-acquired generalized myasthenia gravis. Muscle Nerve 36, 651-658.

Chen, X.J., Qiao, J., Xiao, B.G., Lu, C.Z., 2004. The significance of titin antibodies in myasthenia gravis--correlation with thymoma and severity of myasthenia gravis. J Neurol 251, 1006-1011. 
Chevessier, F., Faraut, B., Ravel-Chapuis, A., Richard, P., Gaudon, K., Bauche, S., Prioleau, C., Herbst, R., Goillot, E., loos, C., Azulay, J.P., Attarian, S., Leroy, J.P., Fournier, E., Legay, C., Schaeffer, L., Koenig, J., Fardeau, M., Eymard, B., Pouget, J., Hantai, D., 2004. MUSK, a new target for mutations causing congenital myasthenic syndrome. Hum Mol Genet 13, 3229-3240.

Chevessier, F., Girard, E., Molgo, J., Bartling, S., Koenig, J., Hantai, D., Witzemann, V., 2008. A mouse model for congenital myasthenic syndrome due to MuSK mutations reveals defects in structure and function of neuromuscular junctions. Hum Mol Genet 17, 3577-3595.

Chiu, H.C., Vincent, A., Newsom-Davis, J., Hsieh, K.H., Hung, T., 1987. Myasthenia gravis: population differences in disease expression and acetylcholine receptor antibody titers between Chinese and Caucasians. Neurology 37, 1854-1857.

Cojocaru, I.M., Cojocaru, M., Musuroi, C., 2000. Study of anti-striational and anti-thyroid antibodies in patients with myasthenia gravis. Rom J Intern Med 38-39, 111-120.

Colaco, C.B., Scadding, G.K., Lockhart, S., 1987. Anti-cardiolipin antibodies in neurological disorders: cross-reaction with anti-single stranded DNA activity. Clin Exp Immunol 68, 313-319.

Cull-Candy, S.G., Miledi, R., Trautmann, A., Uchitel, O.D., 1980. On the release of transmitter at normal, myasthenia gravis and myasthenic syndrome affected human end-plates. J Physiol 299, 621-638.

De Baets, M., Stassen, M., Losen, M., Zhang, X., Machiels, B., 2003. Immunoregulation in experimental autoimmune myasthenia gravis--about T cells, antibodies, and endplates. Ann N Y Acad Sci 998, 308-317.

Demaine, A., Willcox, N., Janer, M., Welsh, K., Newsom-Davis, J., 1992. Immunoglobulin heavy chain gene associations in myasthenia gravis: new evidence for disease heterogeneity. J Neurol 239, 53-56.

Deng, S.X., Hanson, E., Sanz, I., 2000. In vivo cell penetration and intracellular transport of anti-Sm and anti-La autoantibodies. Int Immunol 12, 415-423.

Diaz-Manera, J., Rojas-Garcia, R., Gallardo, E., Juarez, C., Martinez-Domeno, A., Martinez-Ramirez, S., Dalmau, J., Blesa, R., Illa, I., 2007. Antibodies to AChR, MuSK and VGKC in a patient with myasthenia gravis and Morvan's syndrome. Nat Clin Pract Neurol 3, 405-410.

Drachman, D.B., Angus, C.W., Adams, R.N., Michelson, J.D., Hoffman, G.J., 1978. Myasthenic antibodies cross-link acetylcholine receptors to accelerate degradation. N Engl J Med 298, 1116-1122.

Elkon, K., Casali, P., 2008. Nature and functions of autoantibodies. Nat Clin Pract Rheumatol 4, 491-498.

Eng, H., Magnusson, Y., Matell, G., Lefvert, A.K., Saponja, R., Hoebeke, J., 1992. Beta 2-adrenergic receptor antibodies in myasthenia gravis. J Autoimmun 5, 213-227.

Engel, A.G., Lambert, E.H., Howard, F.M., 1977. Immune complexes (IgG and C3) at the motor end-plate in myasthenia gravis: ultrastructural and light microscopic localization and electrophysiologic correlations. Mayo Clin Proc 52, 267-280.

Engel, A.G., Lambert, E.H., Mulder, D.M., Torres, C.F., Sahashi, K., Bertorini, T.E., Whitaker, J.N., 1982. A newly recognized congenital myasthenic syndrome attributed to a prolonged open time of the acetylcholine-induced ion channel. Ann Neurol 11, 553-569.

Engel, A.G., Nagel, A., Fukuoka, T., Fukunaga, H., Osame, M., Lang, B., Newsom-Davis, J., Vincent, A., Wray, D.W., Peers, C., 1989. Motor nerve terminal calcium channels in Lambert-Eaton myasthenic syndrome. Morphologic evidence for depletion and that the depletion is mediated by autoantibodies. Ann N Y Acad Sci 560, 278-290.

Evoli, A., 2006. Clinical aspects of neuromuscular transmission disorders. Acta Neurol Scand Suppl 183, 8-11.

Evoli, A., Batocchi, A.P., Lo Monaco, M., Servidei, S., Padua, L., Majolini, L., Tonali, P., 1996. Clinical heterogeneity of seronegative myasthenia gravis. Neuromuscul Disord 6, 155-161.

Evoli, A., Batocchi, A.P., Zelano, G., Uncini, A., Palmisani, M.T., Tonali, P., 1995. Familial autoimmune myasthenia gravis: report of four families. J Neurol Neurosurg Psychiatry 58, 729-731.

Evoli, A., Tonali, P.A., Padua, L., Monaco, M.L., Scuderi, F., Batocchi, A.P., Marino, M., Bartoccioni, E., 2003. Clinical correlates with anti-MuSK antibodies in generalized seronegative myasthenia gravis. Brain 126, 2304-2311.

Farrugia, M.E., Bonifati, D.M., Clover, L., Cossins, J., Beeson, D., Vincent, A., 2007. Effect of sera from AChR-antibody negative myasthenia gravis patients on AChR and MuSK in cell cultures. J Neuroimmunol 185, 136-144.

Feltkamp, T.E., van den Berg-Loonen, P.M., Nijenhuis, L.E., Engelfriet, C.P., van Rossum, A.L., van Loghem, J.J., Oosterhuis, H.J., 1974. Myasthenia gravis, autoantibodies, and HL-A antigens. Br Med J 1, 131-133. 
Fraussen, J., Vrolix, K., Martinez-Martinez, P., Losen, M., De Baets, M.H., Stinissen, P., Somers, V., 2009. B cell characterization and reactivity analysis in multiple sclerosis. Autoimmun Rev 8, 654-658.

Fukunaga, H., Engel, A.G., Lang, B., Newsom-Davis, J., Vincent, A., 1983. Passive transfer of Lambert-Eaton myasthenic syndrome with IgG from man to mouse depletes the presynaptic membrane active zones. Proc Natl Acad Sci U S A 80, 7636-7640.

Gao, Y.L., Raine, C.S., Brosnan, C.F., 1994. Humoral response to hsp 65 in multiple sclerosis and other neurologic conditions. Neurology 44, 941-946.

Garcia, N., Santafe, M.M., Salon, I., Lanuza, M.A., Tomas, J., 2005. Expression of muscarinic acetylcholine receptors (M1M2-, M3- and M4-type) in the neuromuscular junction of the newborn and adult rat. Histol Histopathol 20, 733743.

Gautam, M., Noakes, P.G., Mudd, J., Nichol, M., Chu, G.C., Sanes, J.R., Merlie, J.P., 1995. Failure of postsynaptic specialization to develop at neuromuscular junctions of rapsyn-deficient mice. Nature 377, 232-236.

Gautel, M., Lakey, A., Barlow, D.P., Holmes, Z., Scales, S., Leonard, K., Labeit, S., Mygland, A., Gilhus, N.E., Aarli, J.A., 1993. Titin antibodies in myasthenia gravis: identification of a major immunogenic region of titin. Neurology 43, $1581-1585$

Geen, J., Howells, R.C., Ludgate, M., Hullin, D.A., Hogg, S.I., 2004. The prevalence of anti-acetylcholinesterase antibodies in autoimmune disease. Autoimmunity 37, 579-585.

Gilhus, N.E., 2009. Autoimmune myasthenia gravis. Expert Rev Neurother 9, 351-358.

Giraud, M., Taubert, R., Vandiedonck, C., Ke, X., Levi-Strauss, M., Pagani, F., Baralle, F.E., Eymard, B., Tranchant, C., Gajdos, P., Vincent, A., Willcox, N., Beeson, D., Kyewski, B., Garchon, H.J., 2007. An IRF8-binding promoter variant and AIRE control CHRNA1 promiscuous expression in thymus. Nature 448, 934-937.

Glass, D.J., Bowen, D.C., Stitt, T.N., Radziejewski, C., Bruno, J., Ryan, T.E., Gies, D.R., Shah, S., Mattsson, K., Burden, S.J., DiStefano, P.S., Valenzuela, D.M., DeChiara, T.M., Yancopoulos, G.D., 1996. Agrin acts via a MuSK receptor complex. Cell 85, 513-523.

Gomez, A.M., Van Den Broeck, J., Vrolix, K., Janssen, S.P., Lemmens, M.A., Van Der Esch, E., Duimel, H., Frederik, P., Molenaar, P.C., Martinez-Martinez, P., De Baets, M.H., Losen, M., 2010. Antibody effector mechanisms in myasthenia gravis-pathogenesis at the neuromuscular junction. Autoimmunity 43, 353-370.

Gomez, C.M., Maselli, R., Gammack, J., Lasalde, J., Tamamizu, S., Cornblath, D.R., Lehar, M., McNamee, M., Kuncl, R.W., 1996. A beta-subunit mutation in the acetylcholine receptor channel gate causes severe slow-channel syndrome. Ann Neurol 39, 712-723.

Gomez, C.M., Richman, D.P., 1983. Anti-acetylcholine receptor antibodies directed against the alpha-bungarotoxin binding site induce a unique form of experimental myasthenia. Proc Natl Acad Sci U S A 80, 4089-4093.

Gordon, T., Grove, B., Loftus, J.C., O'Toole, T., McMillan, R., Lindstrom, J., Ginsberg, M.H., 1992. Molecular cloning and preliminary characterization of a novel cytoplasmic antigen recognized by myasthenia gravis sera. J Clin Invest 90 , 992-999.

Gotti, C., Moretti, M., Mantegazza, R., Fornasari, D., Tsouloufis, T., Clementi, F., 2001. Anti-neuronal nicotinic receptor antibodies in MG patients with thymoma. J Neuroimmunol 113, 142-145.

Grove, B.D., Bowditch, R., Gordon, T., del Zoppo, G., Ginsberg, M.H., 1994. Restricted endothelial cell expression of gravin in vivo. Anat Rec 239, 231-242.

Guyon, T., Levasseur, P., Truffault, F., Cottin, C., Gaud, C., Berrih-Aknin, S., 1994. Regulation of acetylcholine receptor alpha subunit variants in human myasthenia gravis. Quantification of steady-state levels of messenger RNA in muscle biopsy using the polymerase chain reaction. J Clin Invest 94, 16-24.

Hanna, A.N., Waldman, W.J., Lott, J.A., Koesters, S.C., Hughes, A.M., Thornton, D.J., 1997. Increased alkaline phosphatase isoforms in autoimmune diseases. Clin Chem 43, 1357-1364.

Hart, I.K., Waters, C., Vincent, A., Newland, C., Beeson, D., Pongs, O., Morris, C., Newsom-Davis, J., 1997. Autoantibodies detected to expressed $\mathrm{K}+$ channels are implicated in neuromyotonia. Ann Neurol 41, 238-246.

Hartl, F.U., 1996. Molecular chaperones in cellular protein folding. Nature 381, 571-579.

Hayashi, A., Shiono, H., Ohta, M., Ohta, K., Okumura, M., Sawa, Y., 2007. Heterogeneity of immunopathological features of AChR/MuSK autoantibody-negative myasthenia gravis. J Neuroimmunol 189, 163-168. 
Hayem, G., De Bandt, M., Palazzo, E., Roux, S., Combe, B., Eliaou, J.F., Sany, J., Kahn, M.F., Meyer, O., 1999. Anti-heat shock protein $70 \mathrm{kDa}$ and $90 \mathrm{kDa}$ antibodies in serum of patients with rheumatoid arthritis. Ann Rheum Dis 58, 291-296.

Hazama, T., Takahashi, M., Ueno, S., Tarui, S., 1989. Electrophoretic immunoblotting analysis of anti-thymus microsome antibodies in patients with myasthenia gravis. Acta Neurol Scand 79, 88-96.

Heinemann, S., Bevan, S., Kullberg, R., Lindstrom, J., Rice, J., 1977. Modulation of acetylcholine receptor by antibody against the receptor. Proc Natl Acad Sci U S A 74, 3090-3094.

Hoch, W., McConville, J., Helms, S., Newsom-Davis, J., Melms, A., Vincent, A., 2001. Auto-antibodies to the receptor tyrosine kinase MuSK in patients with myasthenia gravis without acetylcholine receptor antibodies. Nat Med 7, 365-368.

Ito, H., Yoshimura, T., Satoh, A., Takino, H., Tsujihata, M., Nagataki, S., 1996. Immunohistochemical study of utrophin and dystrophin at the motor end-plate in myasthenia gravis. Acta Neuropathol 92, 14-18.

Iwasa, K., Komai, K., Takamori, M., 1998. Spontaneous thymoma rat as a model for myasthenic weakness caused by anti-ryanodine receptor antibodies. Muscle Nerve 21, 1655-1660.

Janssen, S.P., Phernambucq, M., Martinez-Martinez, P., De Baets, M.H., Losen, M., 2008. Immunosuppression of experimental autoimmune myasthenia gravis by mycophenolate mofetil. J Neuroimmunol 201-202, 111-120.

Jha, S., Xu, K., Maruta, T., Oshima, M., Mosier, D.R., Atassi, M.Z., Hoch, W., 2006. Myasthenia gravis induced in mice by immunization with the recombinant extracellular domain of rat muscle-specific kinase (MuSK). J Neuroimmunol $175,107-117$.

Kiessling, W.R., Finke, R., Kotulla, P., Schleusener, H., 1982. Circulating TSH-binding inhibiting immunoglobulins in myasthenia gravis. Acta Endocrinol (Copenh) 101, 41-46.

Kiessling, W.R., Pflughaupt, K.W., Ricker, K., Haubitz, I., Mertens, H.G., 1981. Thyroid function and circulating antithyroid antibodies in myasthenia gravis. Neurology 31, 771-774.

Kim, N., Stiegler, A.L., Cameron, T.O., Hallock, P.T., Gomez, A.M., Huang, J.H., Hubbard, S.R., Dustin, M.L., Burden, S.J., 2008. Lrp4 is a receptor for Agrin and forms a complex with MuSK. Cell 135, 334-342.

Kinoshita, I., Motomura, M., Nagasato, K., Ichinose, K., Ohishi, K., Takeo, G., Satoh, A., Nakamura, T., Yoshimura, T., Tsujihata, M., Nagataki, S., 1994. Antiphospholipid antibodies in patients with myastenia gravis. Acta Med. Nagasaki 39, 41-44.

Konishi, T., Ohta, K., Shigemoto, K., Ohta, M., 2007. Anti-alkaline phosphatase antibody positive myasthenia gravis. J Neurol Sci 263, 89-93.

Kuks, J.B., Oosterhuis, H.J., Limburg, P.C., The, T.H., 1991. Anti-acetylcholine receptor antibodies decrease after thymectomy in patients with myasthenia gravis. Clinical correlations. J Autoimmun 4, 197-211.

Lacroix-Desmazes, S., Kaveri, S.V., Mouthon, L., Ayouba, A., Malanchere, E., Coutinho, A., Kazatchkine, M.D., 1998. Selfreactive antibodies (natural autoantibodies) in healthy individuals. J Immunol Methods 216, 117-137.

Lambert, E.H., Elmqvist, D., 1971. Quantal components of end-plate potentials in the myasthenic syndrome. Ann N Y Acad Sci 183, 183-199.

Lang, B., Richardson, G., Rees, J., Vincent, A., Newsom-Davis, J., 1988. Plasma from myasthenia gravis patients reduces acetylcholine receptor agonist-induced $\mathrm{Na}+$ flux into TE671 cell line. J Neuroimmunol 19, 141-148.

Lauriola, L., Ranelletti, F., Maggiano, N., Guerriero, M., Punzi, C., Marsili, F., Bartoccioni, E., Evoli, A., 2005. Thymus changes in anti-MuSK-positive and -negative myasthenia gravis. Neurology 64, 536-538.

Lavrnic, D., Losen, M., Vujic, A., De Baets, M., Hajdukovic, L.J., Stojanovic, V., Trikic, R., Djukic, P., Apostolski, S., 2005. The features of myasthenia gravis with autoantibodies to MuSK. J Neurol Neurosurg Psychiatry 76, 1099-1102.

Lavrnic, D., Nikolic, A., De Baets, M., Verschuuren, J., Verduyn, W., Losen, M., Stojanovic, V., Stevic, Z., Hajdukovic, L., Apostolski, S., 2008. Familial occurrence of autoimmune myasthenia gravis with different antibody specificity. Neurology 70, 2011-2013.

Le Panse, R., Bismuth, J., Cizeron-Clairac, G., Weiss, J.M., Cufi, P., Dartevelle, P., De Rosbo, N.K., Berrih-Aknin, S., 2010. Thymic remodeling associated with hyperplasia in myasthenia gravis. Autoimmunity 43, 401-412.

Lee, J.Y., Sung, J.J., Cho, J.Y., Oh, D.H., Kim, H.J., Park, J.H., Lee, K.W., Choi, Y.C., Vincent, A., 2006. MuSK antibodypositive, seronegative myasthenia gravis in Korea. J Clin Neurosci 13, 353-355. 
Lefvert, A.K., Bergstrom, K., Matell, G., Osterman, P.O., Pirskanen, R., 1978. Determination of acetylcholine receptor antibody in myasthenia gravis: clinical usefulness and pathogenetic implications. J Neurol Neurosurg Psychiatry 41, 394-403.

Leite, M.I., Jacob, S., Viegas, S., Cossins, J., Clover, L., Morgan, B.P., Beeson, D., Willcox, N., Vincent, A., 2008. IgG1 antibodies to acetylcholine receptors in 'seronegative' myasthenia gravis. Brain 131, 1940-1952.

Leite, M.I., Strobel, P., Jones, M., Micklem, K., Moritz, R., Gold, R., Niks, E.H., Berrih-Aknin, S., Scaravilli, F., Canelhas, A., Marx, A., Newsom-Davis, J., Willcox, N., Vincent, A., 2005. Fewer thymic changes in MuSK antibody-positive than in MuSK antibody-negative MG. Ann Neurol 57, 444-448.

Leite, M.I., Waters, P., Vincent, A., 2010. Diagnostic use of autoantibodies in myasthenia gravis. Autoimmunity 43, $371-$ 379.

Lennon, V.A., Kryzer, T.J., Griesmann, G.E., O'Suilleabhain, P.E., Windebank, A.J., Woppmann, A., Miljanich, G.P., Lambert, E.H., 1995. Calcium-channel antibodies in the Lambert-Eaton syndrome and other paraneoplastic syndromes. N Engl J Med 332, 1467-1474.

Leone, G., Breda, M., Accorra, F., Bizzi, B., 1978. Platelet antibody determination by platelet factor 3 assay (comparison with radiolabelled serotonin release and platelet aggregometry). Ric Clin Lab 8, 141-147.

Lin, H., 1992. [ELISA for detection of anti-filamin antibody in sera from patient with myasthenia gravis]. Zhonghua Shen Jing Jing Shen Ke Za Zhi 25, 281-283, 316-287.

Lindstrom, J., 1977. An assay for antibodies to human acetylcholine receptor in serum from patients with myasthenia gravis. Clin Immunol Immunopathol 7, 36-43.

Lindstrom, J., 2000a. The structure of nAChRs. In: Clementi, F., Fornasari, D., Gotti, C. (Ed.), Neuronal nicotinic receptors, Handbook of experimental pharmacology Vol. 144, Springer-Verlag, Berlin, pp. 101-147.

Lindstrom, J.M., 2000b. Acetylcholine receptors and myasthenia. Muscle Nerve 23, 453-477.

Lindstrom, J.M., Seybold, M.E., Lennon, V.A., Whittingham, S., Duane, D.D., 1976. Antibody to acetylcholine receptor in myasthenia gravis. Prevalence, clinical correlates, and diagnostic value. Neurology 26, 1054-1059.

Link, H., Sun, J.B., Lu, C.Z., Xiao, B.G., Fredrikson, S., Hojeberg, B., Olsson, T., 1992. Myasthenia gravis: T and B cell reactivities to the beta-bungarotoxin binding protein presynaptic membrane receptor. J Neurol Sci 109, 173-181.

Losen, M., Martinez-Martinez, P., Phernambucq, M., Schuurman, J., Parren, P.W., De Baets, M.H., 2008. Treatment of myasthenia gravis by preventing acetylcholine receptor modulation. Ann N Y Acad Sci 1132, 174-179.

Losen, M., Stassen, M.H., Martinez-Martinez, P., Machiels, B.M., Duimel, H., Frederik, P., Veldman, H., Wokke, J.H., Spaans, F., Vincent, A., De Baets, M.H., 2005. Increased expression of rapsyn in muscles prevents acetylcholine receptor loss in experimental autoimmune myasthenia gravis. Brain 128, 2327-2337.

Loutrari, H., Kokla, A., Tzartos, S.J., 1992. Passive transfer of experimental myasthenia gravis via antigenic modulation of acetylcholine receptor. Eur J Immunol 22, 2449-2452.

Lu, C.Z., Link, H., Mo, X.A., Xiao, B.G., Zhang, Y.L., Qin, Z., 1991. Anti-presynaptic membrane receptor antibodies in myasthenia gravis. J Neurol Sci 102, 39-45.

Lu, C.Z., Lu, L., Hao, Z.S., Xia, D.G., Qain, J., Arnason, B.G., 1993. Antibody-secreting cells to acetylcholine receptor and to presynaptic membrane receptor in seronegative myasthenia gravis. J Neuroimmunol 43, 145-149.

Lubke, E., Freiburg, A., Skeie, G.O., Kolmerer, B., Labeit, S., Aarli, J.A., Gilhus, N.E., Wollmann, R., Wussling, M., Ruegg, J.C., Linke, W.A., 1998. Striational autoantibodies in myasthenia gravis patients recognize I-band titin epitopes. J Neuroimmunol 81, 98-108.

Magnusson, Y., Marullo, S., Hoyer, S., Waagstein, F., Andersson, B., Vahlne, A., Guillet, J.G., Strosberg, A.D., Hjalmarson, A., Hoebeke, J., 1990. Mapping of a functional autoimmune epitope on the beta 1-adrenergic receptor in patients with idiopathic dilated cardiomyopathy. J Clin Invest 86, 1658-1663.

Mamalaki, A., Tzartos, S.J., 1994. Nicotinic acetylcholine receptor: structure, function and main immunogenic region. Adv Neuroimmunol 4, 339-354.

Mappouras, D.G., Philippou, G., Haralambous, S., Tzartos, S.J., Balafas, A., Souvatzoglou, A., Lymberi, P., 1995. Antibodies to acetylcholinesterase cross-reacting with thyroglobulin in myasthenia gravis and Graves's disease. Clin Exp Immunol 100, 336-343.

Martinez-Martinez, P., Losen, M., Duimel, H., Frederik, P., Spaans, F., Molenaar, P., Vincent, A., De Baets, M.H., 2007. Overexpression of rapsyn in rat muscle increases acetylcholine receptor levels in chronic experimental autoimmune myasthenia gravis. Am J Pathol 170, 644-657. 
Martinez-Martinez, P., Phernambucq, M., Steinbusch, L., Schaeffer, L., Berrih-Aknin, S., Duimel, H., Frederik, P., Molenaar, P., De Baets, M.H., Losen, M., 2009. Silencing rapsyn in vivo decreases acetylcholine receptors and augments sodium channels and secondary postsynaptic membrane folding. Neurobiol Dis 35, 14-23.

Maruta, T., Yoshikawa, H., Fukasawa, S., Umeshita, S., Inaoka, Y., Edahiro, S., Kado, H., Motozaki, Y., Iwasa, K., Yamada, M., 2009. Autoantibody to dihydropyridine receptor in myasthenia gravis. J Neuroimmunol 208, 125-129.

Marx, A., Willcox, N., Leite, M.I., Chuang, W.Y., Schalke, B., Nix, W., Strobel, P., 2010. Thymoma and paraneoplastic myasthenia gravis. Autoimmunity 43, 413-427.

McConville, J., Farrugia, M.E., Beeson, D., Kishore, U., Metcalfe, R., Newsom-Davis, J., Vincent, A., 2004. Detection and characterization of MuSK antibodies in seronegative myasthenia gravis. Ann Neurol 55, 580-584.

Meager, A., Vincent, A., Newsom-Davis, J., Willcox, N., 1997. Spontaneous neutralising antibodies to interferon--alpha and interleukin-12 in thymoma-associated autoimmune disease. Lancet 350, 1596-1597.

Meager, A., Wadhwa, M., Bird, C., Dilger, P., Thorpe, R., Newsom-Davis, J., Willcox, N., 1999. Spontaneously occurring neutralizing antibodies against granulocyte-macrophage colony-stimulating factor in patients with autoimmune disease. Immunology 97, 526-532.

Meager, A., Wadhwa, M., Dilger, P., Bird, C., Thorpe, R., Newsom-Davis, J., Willcox, N., 2003. Anti-cytokine autoantibodies in autoimmunity: preponderance of neutralizing autoantibodies against interferon-alpha, interferon-omega and interleukin-12 in patients with thymoma and/or myasthenia gravis. Clin Exp Immunol 132, 128-136.

Mihovilovic, M., Roses, A.D., 1993. Expression of alpha-3, alpha-5, and beta-4 neuronal acetylcholine receptor subunit transcripts in normal and myasthenia gravis thymus. Identification of thymocytes expressing the alpha-3 transcripts. J Immunol 151, 6517-6524.

Millar, N.S., Gotti, C., 2009. Diversity of vertebrate nicotinic acetylcholine receptors. Neuropharmacology 56, $237-246$.

Minota, S., Cameron, B., Welch, W.J., Winfield, J.B., 1988. Autoantibodies to the constitutive 73-kD member of the hsp70 family of heat shock proteins in systemic lupus erythematosus. J Exp Med 168, 1475-1480.

Mishina, M., Takai, T., Imoto, K., Noda, M., Takahashi, T., Numa, S., Methfessel, C., Sakmann, B., 1986. Molecular distinction between fetal and adult forms of muscle acetylcholine receptor. Nature 321, 406-411.

Mohan, S., Barohn, R.J., Jackson, C.E., Krolick, K.A., 1994. Evaluation of myosin-reactive antibodies from a panel of myasthenia gravis patients. Clin Immunol Immunopathol 70, 266-273.

Molenaar, P.C., Newsom-Davis, J., Polak, R.L., Vincent, A., 1982. Eaton-Lambert syndrome: acetylcholine and choline acetyltransferase in skeletal muscle. Neurology 32, 1061-1065.

Moulian, N., Wakkach, A., Guyon, T., Poea, S., Aissaoui, A., Levasseur, P., Cohen-Kaminsky, S., Berrih-Aknin, S., 1998. Respective role of thymus and muscle in autoimmune myasthenia gravis. Ann N Y Acad Sci 841, 397-406.

Muller, K.M., 1989. Anti-neuroblastoma antibodies in myasthenia gravis: clinical and immunological correlations. J Neurol Sci 93, 263-275.

Muller, K.M., Andersson, L.C., 1984. Antibodies against human neuroblastoma cells in the sera of patients with myasthenia gravis. J Neuroimmunol 7, 97-105.

Muller, K.M., Nykyri, E., Andersson, L.C., 1991. Effect of thymectomy and immunosuppressive therapy on antineuroblastoma antibody levels in patients with myasthenia gravis. Acta Neurol Scand 83, 336-342.

Munakata, S., Chen, M., Aosai, F., Kawaguchi, N., Nemoto, Y., Norose, K., Hattori, T., Yano, A., 2008. The clinical significance of anti-heat shock cognate protein 71 antibody in myasthenia gravis. J Clin Neurosci 15, 158-165.

Mygland, A., Tysnes, O.B., Aarli, J.A., Flood, P.R., Gilhus, N.E., 1992a. Myasthenia gravis patients with a thymoma have antibodies against a high molecular weight protein in sarcoplasmic reticulum. J Neuroimmunol 37, 1-7.

Mygland, A., Tysnes, O.B., Aarli, J.A., Matre, R., Gilhus, N.E., 1993. IgG subclass distribution of ryanodine receptor autoantibodies in patients with myasthenia gravis and thymoma. J Autoimmun 6, 507-515.

Mygland, A., Tysnes, O.B., Matre, R., Aarli, J.A., Gilhus, N.E., 1994. Anti-cardiac ryanodine receptor antibodies in thymoma-associated myasthenia gravis. Autoimmunity 17, 327-331.

Mygland, A., Tysnes, O.B., Matre, R., Volpe, P., Aarli, J.A., Gilhus, N.E., 1992b. Ryanodine receptor autoantibodies in myasthenia gravis patients with a thymoma. Ann Neurol 32, 589-591. 
Mygland, A., Vincent, A., Newsom-Davis, J., Kaminski, H., Zorzato, F., Agius, M., Gilhus, N.E., Aarli, J.A., 2000. Autoantibodies in thymoma-associated myasthenia gravis with myositis or neuromyotonia. Arch Neurol 57, 527531.

Myking, A., Skeie, G.O., Varhaug, J.E., Andersen, K.S., Gilhus, N.E., Aarli, J.A., 1998. The histomorphology of the thymus in late onset, non-thymoma myasthenia gravis. European Journal of Neurology 5, 401-405.

Nakamura, H., Usa, T., Motomura, M., Ichikawa, T., Nakao, K., Kawasaki, E., Tanaka, M., Ishikawa, K., Eguchi, K., 2008. Prevalence of interrelated autoantibodies in thyroid diseases and autoimmune disorders. J Endocrinol Invest 31, 861-865.

Nauert, J.B., Klauck, T.M., Langeberg, L.K., Scott, J.D., 1997. Gravin, an autoantigen recognized by serum from myasthenia gravis patients, is a kinase scaffold protein. Curr Biol 7, 52-62.

Newsom-Davis, J., Pinching, A.J., Vincent, A., Wilson, S.G., 1978. Function of circulating antibody to acetylcholine receptor in myasthenia gravis: investigation by plasma exchange. Neurology 28, 266-272.

Newsom-Davis, J., Vincent, A., 1979. Combined plasma exchange and immunosuppression in myasthenia gravis. Lancet $2,688$.

Niks, E.H., Kuks, J.B., Verschuuren, J.J., 2007. Epidemiology of myasthenia gravis with anti-muscle specific kinase antibodies in The Netherlands. J Neurol Neurosurg Psychiatry 78, 417-418.

Niks, E.H., van Leeuwen, Y., Leite, M.I., Dekker, F.W., Wintzen, A.R., Wirtz, P.W., Vincent, A., van Tol, M.J., Jol-van der Zijde, C.M., Verschuuren, J.J., 2008. Clinical fluctuations in MuSK myasthenia gravis are related to antigenspecific IgG4 instead of IgG1. J Neuroimmunol 195, 151-156.

Noda, M., Takahashi, H., Tanabe, T., Toyosato, M., Furutani, Y., Hirose, T., Asai, M., Inayama, S., Miyata, T., Numa, S., 1982. Primary structure of alpha-subunit precursor of Torpedo californica acetylcholine receptor deduced from cDNA sequence. Nature 299, 793-797.

Ohno, K., Hutchinson, D.O., Milone, M., Brengman, J.M., Bouzat, C., Sine, S.M., Engel, A.G., 1995. Congenital myasthenic syndrome caused by prolonged acetylcholine receptor channel openings due to a mutation in the $M 2$ domain of the epsilon subunit. Proc Natl Acad Sci U S A 92, 758-762.

Ohta, K., Shigemoto, K., Kubo, S., Maruyama, N., Abe, Y., Ueda, N., Fujinami, A., Ohta, M., 2005. MuSK Ab described in seropositive MG sera found to be Ab to alkaline phosphatase. Neurology 65, 1988.

Ohta, K., Shigemoto, K., Kubo, S., Maruyama, N., Abe, Y., Ueda, N., Ohta, M., 2004. MuSK antibodies in AChR Abseropositive MG vs AChR Ab-seronegative MG. Neurology 62, 2132-2133.

Ohta, M., Ohta, K., Itoh, N., Kurobe, M., Hayashi, K., Nishitani, H., 1990. Anti-skeletal muscle antibodies in the sera from myasthenic patients with thymoma: identification of anti-myosin, actomyosin, actin, and alpha-actinin antibodies by a solid-phase radioimmunoassay and a western blotting analysis. Clin Chim Acta 187, 255-264.

Okada, S., Saito, E., Oshima, H., Kinoshita, M., 1990. Autoantibody to growth hormone in a patient with myasthenia gravis. J Endocrinol 127, 533-538.

Oosterhuis, H.J., Feltkamp, T.E., van Rossum, A.L., van den Berg-Loonen, P.M., Nijenhuis, L.E., 1976. HL-A antigens, autoantibody production, and associated diseases in thymoma patients, with and without myasthenia gravis. Ann N Y Acad Sci 274, 468-474.

Oosterhuis, H.J., Limburg, P.C., Hummel-Tappel, E., The, T.H., 1983. Anti-acetylcholine receptor antibodies in myasthenia gravis. Part 2. Clinical and serological follow-up of individual patients. J Neurol Sci 58, 371-385.

Oosterhuis, H.J., Newsom-Davis, J., Wokke, J.H., Molenaar, P.C., Weerden, T.V., Oen, B.S., Jennekens, F.G., Veldman, H., Vincent, A., Wray, D.W., et al., 1987. The slow channel syndrome. Two new cases. Brain 110 ( Pt 4), 1061-1079.

Padua, L., Tonali, P., Aprile, I., Caliandro, P., Bartoccioni, E., Evoli, A., 2006. Seronegative myasthenia gravis: comparison of neurophysiological picture in MuSK+ and MuSK- patients. Eur J Neurol 13, 273-276.

Patrick, J., Lindstrom, J., 1973. Autoimmune response to acetylcholine receptor. Science 180, 871-872.

Phillips, T.M., Manz, H.J., Smith, F.A., Jaffe, H.A., Cohan, S.L., 1981. The detection of anti-cholinesterase antibodies in myasthenia gravis. Ann N Y Acad Sci 377, 360-371.

Plomp, J.J., Van Kempen, G.T., De Baets, M.B., Graus, Y.M., Kuks, J.B., Molenaar, P.C., 1995. Acetylcholine release in myasthenia gravis: regulation at single end-plate level. Ann Neurol 37, 627-636.

Popot, J.L., Changeux, J.P., 1984. Nicotinic receptor of acetylcholine: structure of an oligomeric integral membrane protein. Physiol Rev 64, 1162-1239. 
Provenzano, C., Arancio, O., Evoli, A., Rocca, B., Bartoccioni, E., de Grandis, D., Tonali, P., 1988. Familial autoimmune myasthenia gravis with different pathogenetic antibodies. J Neurol Neurosurg Psychiatry 51, 1228-1230.

Rodgaard, A., Nielsen, F.C., Djurup, R., Somnier, F., Gammeltoft, S., 1987. Acetylcholine receptor antibody in myasthenia gravis: predominance of IgG subclasses 1 and 3. Clin Exp Immunol 67, 82-88.

Romi, F., Aarli, J.A., Gilhus, N.E., 2007. Myasthenia gravis patients with ryanodine receptor antibodies have distinctive clinical features. Eur J Neurol 14, 617-620.

Romi, F., Bo, L., Skeie, G.O., Myking, A., Aarli, J.A., Gilhus, N.E., 2002a. Titin and ryanodine receptor epitopes are expressed in cortical thymoma along with costimulatory molecules. J Neuroimmunol 128, 82-89.

Romi, F., Gilhus, N.E., Aarli, J.A., 2005. Myasthenia gravis: clinical, immunological, and therapeutic advances. Acta Neurol Scand 111, 134-141.

Romi, F., Gilhus, N.E., Varhaug, J.E., Myking, A., Skeie, G.O., Aarli, J.A., 2002b. Thymectomy and anti-muscle autoantibodies in late-onset myasthenia gravis. Eur J Neurol 9, 55-61.

Romi, F., Skeie, G.O., Aarli, J.A., Gilhus, N.E., 2000a. Muscle autoantibodies in subgroups of myasthenia gravis patients. J Neurol 247, 369-375.

Romi, F., Skeie, G.O., Aarli, J.A., Gilhus, N.E., 2000b. The severity of myasthenia gravis correlates with the serum concentration of titin and ryanodine receptor antibodies. Arch Neurol 57, 1596-1600.

Romi, F., Skeie, G.O., Vedeler, C., Aarli, J.A., Zorzato, F., Gilhus, N.E., 2000c. Complement activation by titin and ryanodine receptor autoantibodies in myasthenia gravis. A study of IgG subclasses and clinical correlations. J Neuroimmunol 111, 169-176.

Safar, D., Aime, C., Cohen-Kaminsky, S., Berrih-Aknin, S., 1991. Antibodies to thymic epithelial cells in myasthenia gravis. J Neuroimmunol 35, 101-110.

Sagar, H.J., Gelsthorpe, K., Milford-Ward, A., Davies-Jones, G.A., 1980. Clinical and immunological associations in myasthenia gravis. 1: Autoantibodies. J Neurol Neurosurg Psychiatry 43, 967-970.

Sanmarco, M., Bernard, D., 1994. Studies of IgG-class anticardiolipin antibodies in myasthenia gravis. Autoimmunity 18 , 57-63.

Sasaki, H., Kunimatsu, M., Fujii, Y., Yamakawa, Y., Fukai, I., Kiriyama, M., Nonaka, M., Sasaki, M., 2001. Autoantibody to gravin is expressed more strongly in younger and nonthymomatous patients with myasthenia gravis. Surg Today 31, 1036-1037.

Scadding, G.K., Vincent, A., Newsom-Davis, J., Henry, K., 1981. Acetylcholine receptor antibody synthesis by thymic lymphocytes: correlation with thymic histology. Neurology 31, 935-943.

Shigemoto, K., Kubo, S., Jie, C., Hato, N., Abe, Y., Ueda, N., Kobayashi, N., Kameda, K., Mominoki, K., Miyazawa, A., Ishigami, A., Matsuda, S., Maruyama, N., 2008. Myasthenia gravis experimentally induced with muscle-specific kinase. Ann N Y Acad Sci 1132, 93-98.

Shigemoto, K., Kubo, S., Maruyama, N., Hato, N., Yamada, H., Jie, C., Kobayashi, N., Mominoki, K., Abe, Y., Ueda, N., Matsuda, S., 2006. Induction of myasthenia by immunization against muscle-specific kinase. J Clin Invest 116, 1016-1024.

Shillito, P., Molenaar, P.C., Vincent, A., Leys, K., Zheng, W., van den Berg, R.J., Plomp, J.J., van Kempen, G.T., Chauplannaz, G., Wintzen, A.R., et al., 1995. Acquired neuromyotonia: evidence for autoantibodies directed against $\mathrm{K}+$ channels of peripheral nerves. Ann Neurol 38, 714-722.

Shiono, H., Wong, Y.L., Matthews, I., Liu, J.L., Zhang, W., Sims, G., Meager, A., Beeson, D., Vincent, A., Willcox, N., 2003. Spontaneous production of anti-IFN-alpha and anti-IL-12 autoantibodies by thymoma cells from myasthenia gravis patients suggests autoimmunization in the tumor. Int Immunol 15, 903-913.

Shoenfeld, Y., Ben-Yehuda, O., Messinger, Y., Bentwitch, Z., Rauch, J., Isenberg, D.I., Gadoth, N., 1988. Autoimmune diseases other than lupus share common anti-DNA idiotypes. Immunol Lett 17, 285-291.

Shoenfeld, Y., Blank, M., Abu-Shakra, M., Amital, H., Barzilai, O., Berkun, Y., Bizzaro, N., Gilburd, B., Zandman-Goddard, G., Katz, U., Krause, I., Langevitz, P., Mackay, I.R., Orbach, H., Ram, M., Sherer, Y., Toubi, E., Gershwin, M.E., 2008. The mosaic of autoimmunity: prediction, autoantibodies, and therapy in autoimmune diseases--2008. Isr Med Assoc J 10, 13-19.

Sine, S.M., 2002. The nicotinic receptor ligand binding domain. J Neurobiol 53, 431-446. 
Sine, S.M., Ohno, K., Bouzat, C., Auerbach, A., Milone, M., Pruitt, J.N., Engel, A.G., 1995. Mutation of the acetylcholine receptor alpha subunit causes a slow-channel myasthenic syndrome by enhancing agonist binding affinity. Neuron 15, 229-239.

Skeie, G.O., Freiburg, A., Kolmerer, B., Labeit, S., Aarli, J.A., Appiah-Boadu, S., Gilhus, N.E., 1997. Titin transcripts in thymomas. J Autoimmun 10, 551-557.

Skeie, G.O., Lunde, P.K., Sejersted, O.M., Mygland, A., Aarli, J.A., Gilhus, N.E., 1998a. Myasthenia gravis-associated ryanodine receptor antibodies inhibit binding of ryanodine to sarcoplasmic reticulum. Ann N Y Acad Sci 841, 530533.

Skeie, G.O., Lunde, P.K., Sejersted, O.M., Mygland, A., Aarli, J.A., Gilhus, N.E., 1998b. Myasthenia gravis sera containing antiryanodine receptor antibodies inhibit binding of [3H]-ryanodine to sarcoplasmic reticulum. Muscle Nerve 21, 329-335.

Skeie, G.O., Mygland, A., Aarli, J.A., Gilhus, N.E., 1995. Titin antibodies in patients with late onset myasthenia gravis: clinical correlations. Autoimmunity 20, 99-104.

Skeie, G.O., Mygland, A., Treves, S., Gilhus, N.E., Aarli, J.A., Zorzato, F., 2003. Ryanodine receptor antibodies in myasthenia gravis: epitope mapping and effect on calcium release in vitro. Muscle Nerve 27, 81-89.

Slater, C.R., Young, C., Wood, S.J., Bewick, G.S., Anderson, L.V., Baxter, P., Fawcett, P.R., Roberts, M., Jacobson, L., Kuks, J., Vincent, A., Newsom-Davis, J., 1997. Utrophin abundance is reduced at neuromuscular junctions of patients with both inherited and acquired acetylcholine receptor deficiencies. Brain 120 ( Pt 9), 1513-1531.

Song, Y.C., Sun, G.H., Lee, T.P., Huang, J.C., Yu, C.L., Chen, C.H., Tang, S.J., Sun, K.H., 2008. Arginines in the CDR of antidsDNA autoantibodies facilitate cell internalization via electrostatic interactions. Eur J Immunol 38, 3178-3190.

Sthoeger, Z., Neiman, A., Elbirt, D., Zinger, H., Magen, E., Burstein, R., Eitan, S., Abarbanel, J., Mozes, E., 2006. High prevalence of systemic lupus erythematosus in 78 myasthenia gravis patients: a clinical and serologic study. Am J Med Sci 331, 4-9.

Strauss, A.J., Kemp, P.G., Jr., 1967. Serum autoantibodies in myasthenia gravis and thymoma: selective affinity for Ibands of striated muscle as a guide to identification of antigen(s). J Immunol 99, 945-953.

Strauss AJL, S.B., Hsu KC, Burkholder PM, Nastuk WL, Osserman KE, 1960. Immunofluorescence demonstration of a muscle binding, complement-fixing serum globulin fraction in mysthenia gravis. Proceedings of the society for experimental biology and medicine 105, 184.

Sumikawa, K., Houghton, M., Smith, J.C., Bell, L., Richards, B.M., Barnard, E.A., 1982. The molecular cloning and characterisation of cDNA coding for the alpha subunit of the acetylcholine receptor. Nucleic Acids Res 10, 58095822.

Suzuki, S., Satoh, T., Yasuoka, H., Hamaguchi, Y., Tanaka, K., Kawakami, Y., Suzuki, N., Kuwana, M., 2005. Novel autoantibodies to a voltage-gated potassium channel Kv1.4 in a severe form of myasthenia gravis. J Neuroimmunol 170, 141-149.

Suzuki, S., Utsugisawa, K., Nagane, Y., Satoh, T., Terayama, Y., Suzuki, N., Kuwana, M., 2007. Classification of myasthenia gravis based on autoantibody status. Arch Neurol 64, 1121-1124.

Takamori, M., 2008. Autoantibodies against TRPC3 and ryanodine receptor in myasthenia gravis. J Neuroimmunol 200, 142-144.

Takamori, M., Motomura, M., Fukudome, T., Yoshikawa, H., 2007. Autoantibodies against M1 muscarinic acetylcholine receptor in myasthenic disorders. Eur J Neurol 14, 1230-1235.

Takamori, M., Motomura, M., Kawaguchi, N., Nemoto, Y., Hattori, T., Yoshikawa, H., Otsuka, K., 2004. Anti-ryanodine receptor antibodies and FK506 in myasthenia gravis. Neurology 62, 1894-1896.

Takaya, M., Kawahara, S., Namba, T., Grob, D., 1992. Antibodies against myofibrillar proteins in myasthenia gravis patients. Tokai J Exp Clin Med 17, 35-39.

Takeshima, H., lino, M., Takekura, H., Nishi, M., Kuno, J., Minowa, O., Takano, H., Noda, T., 1994. Excitation-contraction uncoupling and muscular degeneration in mice lacking functional skeletal muscle ryanodine-receptor gene. Nature 369, 556-559.

Tang, J., Yuan, J., Hao, H., 1997. Anti-acetylcholinesterase antibody in myasthenic syndrome. Chin Med J (Engl) 110, 698700. 
ter Beek, W.P., Martinez-Martinez, P., Losen, M., de Baets, M.H., Wintzen, A.R., Verschuuren, J.J., Niks, E.H., van Duinen, S.G., Vincent, A., Molenaar, P.C., 2009. The effect of plasma from muscle-specific tyrosine kinase myasthenia patients on regenerating endplates. Am J Pathol 175, 1536-1544.

Tindall, R.S., 1981a. Humoral immunity in myasthenia gravis: biochemical characterization of acquired antireceptor antibodies and clinical correlations. Ann Neurol 10, 437-447.

Tindall, R.S., 1981b. Humoral immunity in myasthenia gravis: clinical correlations of anti-receptor antibody avidity and titer. Ann N Y Acad Sci 377, 316-331.

Toth, C., McDonald, D., Oger, J., Brownell, K., 2006. Acetylcholine receptor antibodies in myasthenia gravis are associated with greater risk of diabetes and thyroid disease. Acta Neurol Scand 114, 124-132.

Toyka, K.V., Drachman, D.B., Griffin, D.E., Pestronk, A., Winkelstein, J.A., Fishbeck, K.H., Kao, I., 1977. Myasthenia gravis. Study of humoral immune mechanisms by passive transfer to mice. N Engl J Med 296, 125-131.

Traggiai, E., Becker, S., Subbarao, K., Kolesnikova, L., Uematsu, Y., Gismondo, M.R., Murphy, B.R., Rappuoli, R., Lanzavecchia, A., 2004. An efficient method to make human monoclonal antibodies from memory $B$ cells: potent neutralization of SARS coronavirus. Nat Med 10, 871-875.

Tuzun, E., Saini, S.S., Ghosh, S., Rowin, J., Meriggioli, M.N., Christadoss, P., 2006. Predictive value of serum anti-C1q antibody levels in experimental autoimmune myasthenia gravis. Neuromuscul Disord 16, 137-143.

Tzartos, S.J., Lindstrom, J.M., 1980. Monoclonal antibodies used to probe acetylcholine receptor structure: localization of the main immunogenic region and detection of similarities between subunits. Proc Natl Acad Sci U S A 77, 755-759.

van der Neut Kolfschoten, M., Schuurman, J., Losen, M., Bleeker, W.K., Martinez-Martinez, P., Vermeulen, E., den Bleker, T.H., Wiegman, L., Vink, T., Aarden, L.A., De Baets, M.H., van de Winkel, J.G., Aalberse, R.C., Parren, P.W., 2007. Anti-inflammatory activity of human IgG4 antibodies by dynamic Fab arm exchange. Science 317, 1554-1557.

Vernino, S., Sandroni, P., Singer, W., Low, P.A., 2008. Invited Article: Autonomic ganglia: target and novel therapeutic tool. Neurology 70, 1926-1932.

Verschuuren, J.J., Palace, J., Gilhus, N.E., 2010. Clinical aspects of myasthenia explained. Autoimmunity 43, 344-352.

Vincent, A., 2002. Unravelling the pathogenesis of myasthenia gravis. Nat Rev Immunol 2, 797-804.

Vincent, A., Lang, B., Newsom-Davis, J., 1989. Autoimmunity to the voltage-gated calcium channel underlies the Lambert-Eaton myasthenic syndrome, a paraneoplastic disorder. Trends Neurosci 12, 496-502.

Vincent, A., Newsom-Davis, J., 1985. Acetylcholine receptor antibody as a diagnostic test for myasthenia gravis: results in 153 validated cases and 2967 diagnostic assays. J Neurol Neurosurg Psychiatry 48, 1246-1252.

Vincent, A., Newsom Davis, J., 1980. Anti-acetylcholine receptor antibodies. J Neurol Neurosurg Psychiatry 43, 590-600.

Vincent, A., Palace, J., Hilton-Jones, D., 2001. Myasthenia gravis. Lancet 357, 2122-2128.

Wang, K., McClure, J., Tu, A., 1979. Titin: major myofibrillar components of striated muscle. Proc Natl Acad Sci U S A 76, 3698-3702.

Warlow, R., Garlepp, M., Dawkins, R., 1985. Extractable nuclear antigen autoantibodies and their association with other autoantibodies and thymoma in myasthenia gravis. J Neuroimmunol 8, 185-197.

Watanabe, M., Uchida, K., Nakagaki, K., Kanazawa, H., Trapnell, B.C., Hoshino, Y., Kagamu, H., Yoshizawa, H., Keicho, N., Goto, H., Nakata, K., 2007. Anti-cytokine autoantibodies are ubiquitous in healthy individuals. FEBS Lett 581, 2017-2021.

Weissel, M., Mayr, N., Zeitlhofer, J., 2000. Clinical significance of autoimmune thyroid disease in myasthenia gravis. Exp Clin Endocrinol Diabetes 108, 63-65.

White, R.G., Marshall, A.H., 1962. The autoimmune response in myasthenia gravis. Lancet 2, 120-123.

Wildbaum, G., Nahir, M.A., Karin, N., 2003. Beneficial autoimmunity to proinflammatory mediators restrains the consequences of self-destructive immunity. Immunity 19, 679-688.

Williams, A.J., 1992. Ion conduction and discrimination in the sarcoplasmic reticulum ryanodine receptor/calciumrelease channel. J Muscle Res Cell Motil 13, 7-26.

Williams, C.L., Lennon, V.A., 1986. Thymic B lymphocyte clones from patients with myasthenia gravis secrete monoclonal striational autoantibodies reacting with myosin, alpha actinin, or actin. J Exp Med 164, 1043-1059. 
Wintzen, A.R., Plomp, J.J., Molenaar, P.C., van Dijk, J.G., van Kempen, G.T., Vos, R.M., Wokke, J.H., Vincent, A., 1998. Acquired slow-channel syndrome: a form of myasthenia gravis with prolonged open time of the acetylcholine receptor channel. Ann Neurol 44, 657-664.

Wirtz, P.W., Sotodeh, M., Nijnuis, M., Van Doorn, P.A., Van Engelen, B.G., Hintzen, R.Q., De Kort, P.L., Kuks, J.B., Twijnstra, A., De Visser, M., Visser, L.H., Wokke, J.H., Wintzen, A.R., Verschuuren, J.J., 2002. Difference in distribution of muscle weakness between myasthenia gravis and the Lambert-Eaton myasthenic syndrome. J Neurol Neurosurg Psychiatry 73, 766-768.

Xiao, B.G., Lu, C.Z., Hojeberg, B., Link, H., 1991. Immunological specificity and cross-reactivity of anti-acetylcholine receptor and anti-presynaptic membrane receptor antibodies in myasthenia gravis. J Neurol Sci 105, 118-123.

Xu, B.Y., Pirskanen, R., Lefvert, A.K., 1998a. Antibodies against beta1 and beta2 adrenergic receptors in myasthenia gravis. J Neuroimmunol 91, 82-88.

Xu, K., Shu, X.Q., Zhuo, X.L., Lu, C.Z., 1998b. Presynaptic changes of neuromuscular transmission in mice induced by passive transfer of plasma with anti-presynaptic membrane receptor antibodies from a patient with myasthenia gravis. J Peripher Nerv Syst 3, 103-109.

Yamamoto, A.M., Gajdos, P., Eymard, B., Tranchant, C., Warter, J.M., Gomez, L., Bourquin, C., Bach, J.F., Garchon, H.J., 2001. Anti-titin antibodies in myasthenia gravis: tight association with thymoma and heterogeneity of nonthymoma patients. Arch Neurol 58, 885-890.

Yamamoto, T., Sato, T., Sugita, H., 1987. Antifilamin, antivinculin, and antitropomyosin antibodies in myasthenia gravis. Neurology 37, 1329-1333.

Yanase, K., Madaio, M.P., 2005. Nuclear localizing anti-DNA antibodies enter cells via caveoli and modulate expression of caveolin and p53. J Autoimmun 24, 145-151.

Yanase, K., Smith, R.M., Puccetti, A., Jarett, L., Madaio, M.P., 1997. Receptor-mediated cellular entry of nuclear localizing anti-DNA antibodies via myosin 1. J Clin Invest 100, 25-31.

Yeh, J.H., Chen, W.H., Chiu, H.C., Vincent, A., 2004. Low frequency of MuSK antibody in generalized seronegative myasthenia gravis among Chinese. Neurology 62, 2131-2132.

Yi, Q., He, W., Matell, G., Pirskanen, R., Magnusson, Y., Eng, H., Lefvert, A.K., 1996. T and B lymphocytes reacting with the extracellular loop of the beta 2-adrenergic receptor (beta 2AR) are present in the peripheral blood of patients with myasthenia gravis. Clin Exp Immunol 103, 133-140.

Yoshikawa, H., Sato, K., Edahiro, S., Furukawa, Y., Maruta, T., Iwasa, K., Watanabe, H., Takaoka, S., Suzuki, Y., Takamori, M., Yamada, M., 2006. Elevation of IL-12 p40 and its antibody in myasthenia gravis with thymoma. J Neuroimmunol 175, 169-175.

Yurasov, S., Nussenzweig, M.C., 2007. Regulation of autoreactive antibodies. Curr Opin Rheumatol 19, 421-426.

Zhang, B., Luo, S., Wang, Q., Suzuki, T., Xiong, W.C., Mei, L., 2008. LRP4 serves as a coreceptor of agrin. Neuron 60, 285297.

Zhou, L., McConville, J., Chaudhry, V., Adams, R.N., Skolasky, R.L., Vincent, A., Drachman, D.B., 2004. Clinical comparison of muscle-specific tyrosine kinase (MuSK) antibody-positive and -negative myasthenic patients. Muscle Nerve 30, 55-60.

Zhou, Z.H., Zhang, Y., Hu, Y.F., Wahl, L.M., Cisar, J.O., Notkins, A.L., 2007. The broad antibacterial activity of the natural antibody repertoire is due to polyreactive antibodies. Cell Host Microbe 1, 51-61.

Zhu, D., Yang, Z., Luo, Z., Luo, S., Xiong, W.C., Mei, L., 2008. Muscle-specific receptor tyrosine kinase endocytosis in acetylcholine receptor clustering in response to agrin. J Neurosci 28, 1688-1696. 


\section{Chapter 2}

Antibody effector mechanisms in

myasthenia gravis - pathogenesis at the neuromuscular junction

Vrolix K*, Gomez AM*, Van den Broeck J*, Janssen SP, Lemmens MAM, van der Esch E, Duimel H, Frederik P, Molenaar PC, Martínez-Martínez P, De Baets MH and Losen M *These authors contributed equally to the work.

Published in: Autoimmunity 2010, 43 (5-6): 353-370. 


\section{Abstract}

Myasthenia gravis (MG) is an autoimmune disorder caused by autoantibodies that are either directed to the muscle nicotinic acetylcholine receptor (AChR) or to the muscle specific tyrosine kinase (MUSK). These autoantibodies define two distinct subforms of the disease: AChR-MG and MuSK-MG. Both AChR and MuSK are expressed on the postsynaptic membrane of the neuromuscular junction (NMJ), which is a highly specialized region of the muscle dedicated to receive and process signals from the motor nerve. Autoantibody binding to proteins of the postsynaptic membrane leads to impaired neuromuscular transmission and muscle weakness. Pro-inflammatory antibodies of the human IgG1 and IgG3 subclass modulate the AChR, cause complement activation and attract lymphocytes; together acting to decrease levels of the AChR and AChR-associated proteins and to reduce postsynaptic folding. In patients with anti-MuSK antibodies there is no evidence of loss of junctional folds and no apparent loss of AChR density. Anti-MuSK antibodies are predominantly of the IgG4 isotype which functionally differs from other IgG subclasses in its anti-inflammatory activity. Moreover, IgG4 undergoes a posttranslational modification termed Fab arm exchange which prevents cross-linking of antigens. These findings suggest that MuSK-MG may be different in etiological and pathological mechanisms from AChR-MG. The effector functions of IgG subclasses on synapse structure and function are discussed in this review. 


\section{Introduction}

Myasthenia gravis (MG) is an autoimmune disease caused by autoantibodies against proteins in the postsynaptic membrane of the neuromuscular junction (NMJ) (Hoch et al., 2001; Lindstrom et al., 1976b). Several lines of evidence have clearly demonstrated that antibodies against the acetylcholine receptor $(\mathrm{AChR})$ cause the disease in approximately $85 \%$ of MG patients (Lindstrom et al., 1976b). Autoantibodies against the muscle specific tyrosine kinase (MuSK) have been detected in up to $70 \%$ of MG patients without autoantibodies against the AChR (Hoch et al., 2001). MuSK is essential for the development and maintenance of the NMJ (Evoli et al., 2003; Hoch et al., 2001; Kong et al., 2004) since it is required for AChR clustering. Together, AChR-MG and MuSK-MG cover more than $90 \%$ of MG cases. The remaining patients also have an autoimmune disorder, since they, too, benefit from immunosuppression or plasmapheresis (Sanders and Evoli, 2010). Historically, the term "seronegative MG" was used for MG without antiAChR antibodies, but with the discovery of MuSK antibodies in many seronegative patients, this term has become confusing. Therefore, we will use the following nomenclature in this review: "AChR-MG" for myasthenia gravis with anti-AChR antibodies; "MuSK-MG" for myasthenia gravis with anti-MuSK antibodies; "idiopathic MG" for patients with (autoimmune) myasthenia gravis, but (so-far) undetectable levels of anti-AChR or anti-MuSK antibodies (Table 1).

In AChR-MG patients, antibodies against many other antigens can be found (Vrolix et al., 2010). Their role in the pathogenesis and their contribution to the clinical symptoms of MG are not completely understood yet. Many of these antibodies are not specific for MG and they also occur in patients with other autoimmune diseases. Some autoantibodies are associated with malignancies of the thymus (Marx et al., 2010). Thymic abnormalities such as hyperplasia and thymoma are significant risk factors for AChR-MG (Le Panse et al., 2010; Shiono et al., 2003).

Idiopathic MG is more similar to AChR-MG than to MuSK-MG regarding thymic pathology (Leite et al., 2005) and clinical features (Romi et al., 2005). Since idiopathic MG patients have the same clinical presentation as patients with AChR-MG, it is possible that they produce $A C h R$ autoantibodies at a very low level or with low affinity, which makes these autoantibodies undetectable for conventional AChR antibody assays (Leite et al., 2008; Leite et al., 2010; Vincent and Leite, 2005). Alternatively, autoantibodies might be directed against other neuromuscular proteins in idiopathic MG patients. 
Table I. Myasthenia gravis and related animal models

\begin{tabular}{lllll}
\hline MG in humans & & MG in animals & Animal models & \\
\hline Chronic & Transient & Chronic & Active immunization & Passive immunization \\
\hline AChR-MG & Neonatal & AChR-MG & AChR-EAMG & passive transfer AChR-MG \\
human IgG1, & AChR-MG & cats (g) & Rabbit (i), rats, & mice $(\mathrm{n})$ \\
human IgG3 & (a-d) & dogs (h) & guinea pigs (j) & rhesus monkeys (o) \\
& & & rhesus monkeys (k) & rats (p) \\
MuSK-MG & Neonatal & & MuSK-EAMG & passive transfer MuSK-MG \\
human IgG4 & MuSK-MG & & Rabbits (I) & mice (q) \\
& (e-f) & & Mice (m) & \\
Idiopathic MG & & & & \\
"seronegative & & & & \\
MG" & & & & \\
\hline
\end{tabular}

(a) (Eymard et al., 1991), (b) (Morel et al., 1988) (c) (Papazian, 1992) (d) (Vernet-der Garabedian et al., 1994), (e) (Behin et al., 2008), (f) (Niks et al., 2008), (g) (Shelton, 1999), (h) (Shelton et al., 1997), (i) (Patrick and Lindstrom, 1973), (j) (Lennon et al., 1975), (k) (Tarrab-Hazdai et al., 1975), (I) (Shigemoto et al., 2006), (m) (Jha et al., 2006), (n) (Toyka et al., 1975), (o) (van der Neut Kolfschoten et al., 2007), (p) (Lindstrom et al., 1976a), (q) (Cole et al., 2008)

The structure and physiology of the NMJ is complex, but well understood. The pathogenic changes at the NMJ in MG are interesting also from an immunological point of view, since it provides a clear example of autoantibody effector-functions on the target tissue. Immunotherapies for MG patients do not only depend on suppressing or modulating the autoimmune processes, but also on the repair processes and plasticity of the NMJ. Therefore, we first review the normal structure and function of the NMJ and secondly discuss the changes at the NMJ as a function of IgG isotype and specificity.

\section{Organization and physiology of the neuromuscular junction}

For understanding the pathophysiology in MG it will be useful to recall some basic facts of neuromuscular transmission. The NMJ is a chemical synapse that transmits a signal from the motor nerve to the postsynaptic region of the muscle fiber (Figure 1 and 2). The postsynaptic membrane contains a high density of AChR (Figure 3) which is a ligand-gated ion channel (Changeux et al., 1984). The impairment of the neuromuscular function in MG is a result of changes in the physiology, biochemistry and structure of the NMJ. 

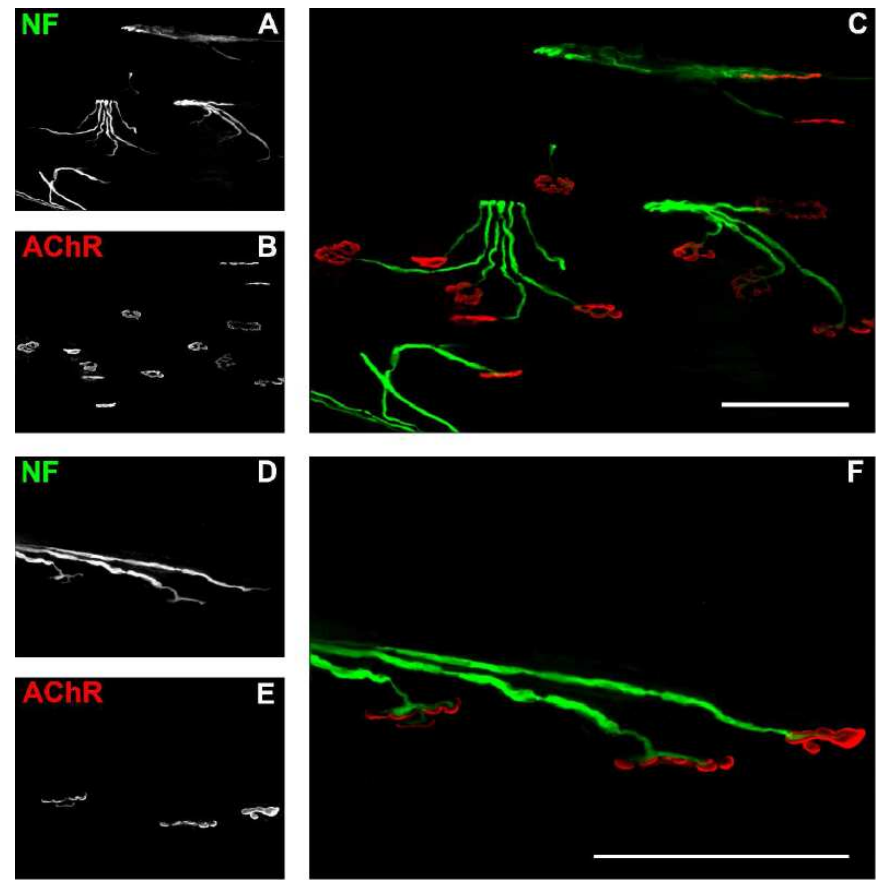

Figure 1. Immunohistochemical staining of $\mathbf{2 0 0} \boldsymbol{\mu m}$ cryosections of rat tibialis anterior muscle. Nerves are stained with mouse anti-neurofilament $A b(A, D)$ and $A C h R s$ are stained with Alexa $594 \alpha$-bungarotoxin (B, E). Merged pictures (C, F) show the AChR clusters (red) at the site of contact with the nerve terminals (green). Generally, each muscle fiber is only innervated by a single nerve branch. Scale bars are $100 \mu \mathrm{m}$.

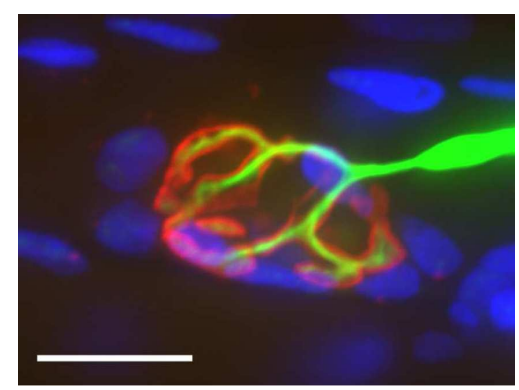

Figure 2. High power confocal photomicrograph of a rat neuromuscular junction. The AChR is stained in red with Alexa 594-labelled $\alpha$-bungarotoxin and the nerve terminal is stained in green (Alexa 488) with an antibody directed against neurofilament and synaptic vesicle protein 2 (SV2). Nuclei are labeled with Hoechst DNA stain in blue. The image was taken with a MBF Bioscience Stereo Investigator Confocal Spinning Disk (SI-SD) system (MBF Bioscience, Williston, VT), with a modified Olympus BX51 fluorescence microscope (Olympus, Tokyo, Japan). Scale bar is $20 \mu \mathrm{m}$. 


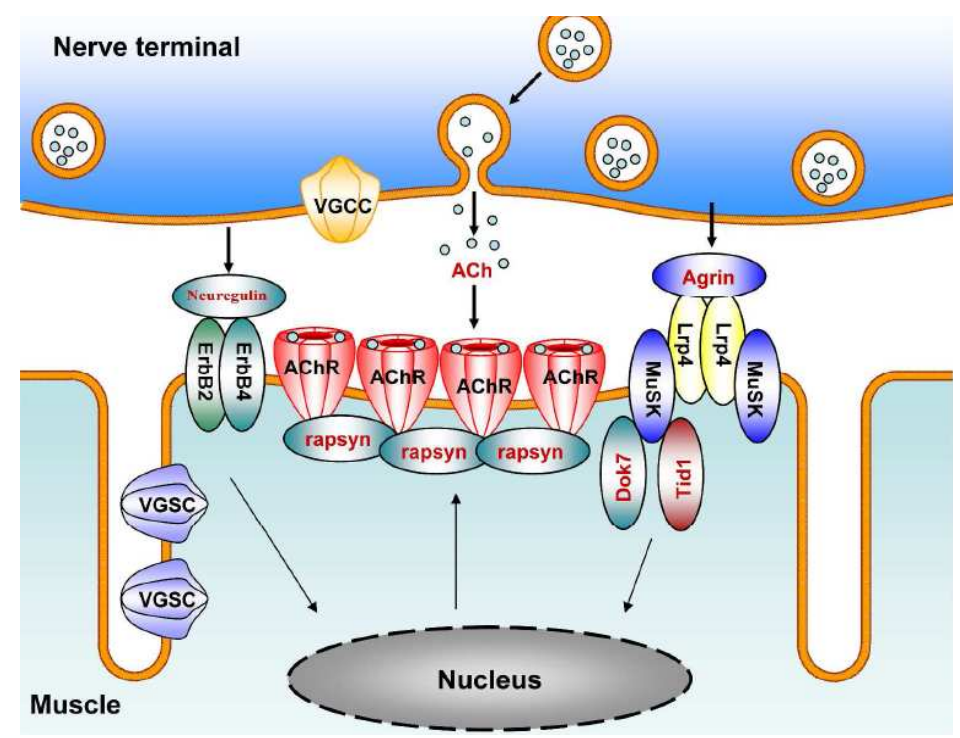

Figure 3. Scheme of the neuromuscular junction. ACh, neuregulin and agrin are released form the nerve terminal. ACh is a neurotransmitter that binds and opens the AChR ion channel, inducing depolarization of the membrane. Neuregulins bind to ErbB receptors and enhance the transcription of AChR, utrophin and acetylcholine esterase genes at the postsynaptic nuclei. Lrp4-MuSK-Dok-7-Tid1 are the main mediators of agrinsignaling in the postsynaptic membrane, activating intracellular cascades that lead to dense AChR clustering at the top of the junctional folds. ACh - acetylcholine; AChR-acetylcholine receptor; Dok7 - docking protein 7; ErbB2/4 erythroblastic leukemia viral oncogene homolog 2/4; Lrp4 - low density lipoprotein receptor-related protein 4; MuSK - muscle specific tyrosine kinase; rapsyn - receptor associated protein of the synapse; Tid1 tumorous imaginal discs; VGSC - voltage gated sodium channel; VGCC - voltage gated calcium channel.

\section{Physiology}

At the nerve terminal, ACh is stored in synaptic vesicles. Occasionally a vesicle undergoes spontaneous exocytosis so that a so-called quantum of released ACh, consisting of about 10,000 molecules, causes a miniature endplate potential (MEPP), about 1 millivolt in amplitude, by interaction with the AChRs. MEPPs occur in the human endplate at a frequency of a few per minute and their amplitude is a good measure of the density of the AChRs.

When a nerve action potential reaches the nerve terminal, P/Q-type calcium channels open and as a result of inflowing calcium ions a number of vesicles release their ACh into the synaptic cleft. The evoked release of ACh is thus dependent on the presence of calcium in the surrounding medium. The number of ACh quanta released by the nerve 
action potential is called the quantal content. The value of the quantal content is in human muscle around 30 whereas in rodents it is between 50 and 100 .

The ACh that is released upon a stimulus (in man $30 * 10,000=300,000$ molecules of ACh) causes a depolarization called the endplate potential or EPP. The EPP has a more or less constant value since the nerve action potential is a standard event causing a standard inflow of calcium into the nerve terminal. The EPP shows a little variation, however, which is largely dependent on the variation in the quantal content and the variation in diameter of the muscle fiber.

Normally the EPP is so large that surrounding voltage-gated sodium channels (VGSC) in the muscle membrane near the endplate are activated so that the muscle action potential is generated (Katz and Miledi, 1964). As soon as the action potential is generated it completely overshadows the EPP (Figure 4). If EPPs have to be recorded, this can only be done after blocking specifically the sodium channels of the muscle. Neuromuscular transmission has a large so-called safety factor, meaning that the EPP is considerably larger than the threshold membrane potential for opening of VGSC, so that nerve stimuli elicit muscle action potentials with $100 \%$ efficiency. This safety factor is about 3 in human muscle and about 5 in rodents (Wood and Slater, 2001).

The muscle action potential spreads along the muscle fiber from the endplate area towards the tendons. The action potential activates L-type calcium channels causing the release of calcium from intracellular stores though ryanodine-type calcium channels. As a result the concentration of cytosolic calcium rises dramatically which leads finally to the contraction of the muscle fiber.

\section{Biochemistry and structure}

The nerve terminal produces agrin and neuregulin which induce expression of postsynaptic proteins in subsynaptic nuclei (Figure 2 and 3) of the muscle fiber. Among the molecules that are concentrated at the endplate are the acetylcholine esterase, the membrane receptors for agrin (MUSK and Lrp4) and the cytoskeletal-associated proteins utrophin and rapsyn (Schaeffer et al., 2001). During development, AChRs are diffusely distributed on embryonic myotubes but become highly concentrated (approximately $10,000 / \mu \mathrm{m}^{2}$ ) in the postsynaptic membrane a few weeks after birth, whereas the density of the extra-synaptical AChRs falls to $\sim 10 / \mu \mathrm{m}^{2}$ (Bevan and Steinbach, 1977). At least two distinct processes contribute to this accumulation. First, subsynaptic muscle nuclei transcribe AChR subunit genes at higher rates than extra-synaptic nuclei, so AChR messenger RNA is concentrated near synaptic sites (Goldman and Staple, 1989; Jessell et al., 1979). Second, once AChRs have been inserted into the membrane, they form high- 
density clusters by tethering to a subsynaptic cytoskeletal complex. A key component of this complex is rapsyn, a $43 \mathrm{kDa}$ membrane-associated protein, which is precisely colocalized with AChRs at synaptic sites (Figure 5) as soon as clusters form (Gautam et al., 1995). Rapsyn anchors the AChR via ß-dystroglycan and utrophin to the contractile protein F-actin and is thus essential for the AChR clustering in the endplate region (Cartaud et al., 1998; Glass et al., 1996; Moransard et al., 2003; Phillips et al., 1997; Rybakova et al., 2006; Wang et al., 1999). No AChR clusters are formed in muscles of rapsyn-deficient mice or in myotubes cultured from the mutants (Gautam et al., 1995).

The structure of the postsynaptic membrane is also highly specialized. The nerve and the nerve terminal area are covered by Schwann cells as shown in the scanning electron micrograph in Figure 6A. Chemical removal of the Schwann cell and partial removal of the nerve (Figure $6 \mathrm{~B}$ ) reveals that the branched nerve endings are embedded in the gutterlike depression of the muscle plasma membrane (sarcolemma). Between the nerve endings (synaptic boutons) and the sarcolemma lies the primary synaptic cleft. Adjacent to synaptic boutons the sarcolemma is folded and thereby creates secondary clefts (hereafter referred to as synaptic folds of the postsynaptic membrane, Figure 6B, arrowhead). The postsynaptic folds enlarge the surface and contain a high density of AChR at the top of the folds facing the nerve and voltage gated sodium channels in the troughs of the secondary folds.

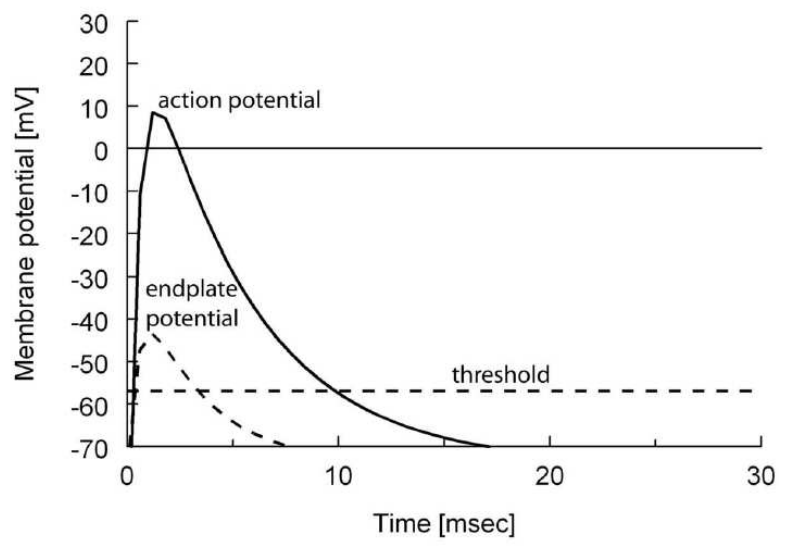

Figure 4. Schematic representation of an intracellular microelectrode recording at the endplate of the muscle action potential. The stippled line indicates the shape of the endplate potential (EPP, which can only be seen after blocking the action potential of the muscle with $\mu$-conotoxin). The firing threshold of the muscle is indicated by the horizontal stippled line. Nota bene: in most recordings the electrode is dislodged from the cell because of the contraction of the muscle, but sometimes it stays put and it is possible, as illustrated in this chart, to follow the whole event of the muscle action potential. 

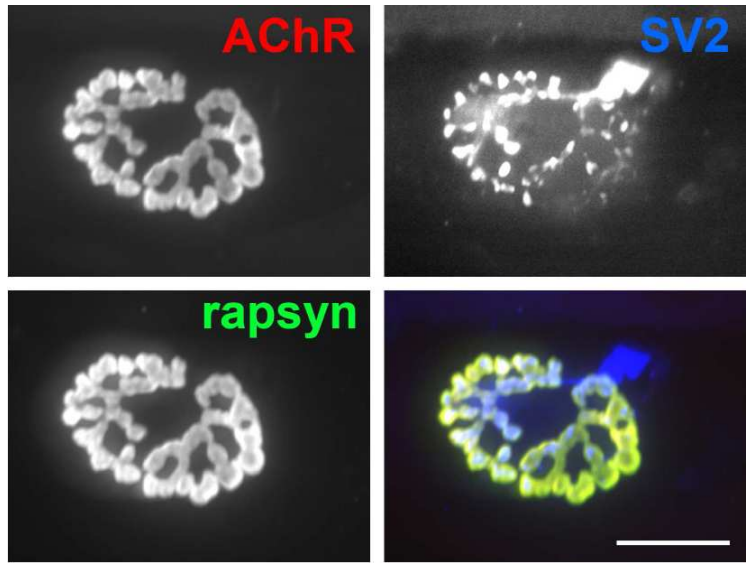

Figure 5. Confocal photomicrographs demonstrating colocalization of rapsyn and the AChR. (A) Rat tibialis anterior cryosections of $30 \mu \mathrm{m}$ were stained with Alexa $594 \alpha$-bungarotoxin for the AChR in red, (B) mouse antirapsyn mAb 1234 in green, (C) SV2 for the nerve terminal in blue. (D) The merged picture shows the precise colocalization of rapsyn and the AChR (yellow color). Images were taken with a MBF Bioscience Stereo Investigator Confocal Spinning Disk (SI-SD) system (MBF Bioscience, Williston, VT) with a modified Olympus BX51 fluorescence microscope (Olympus, Tokyo, Japan). Scale bar is $20 \mu \mathrm{m}$.
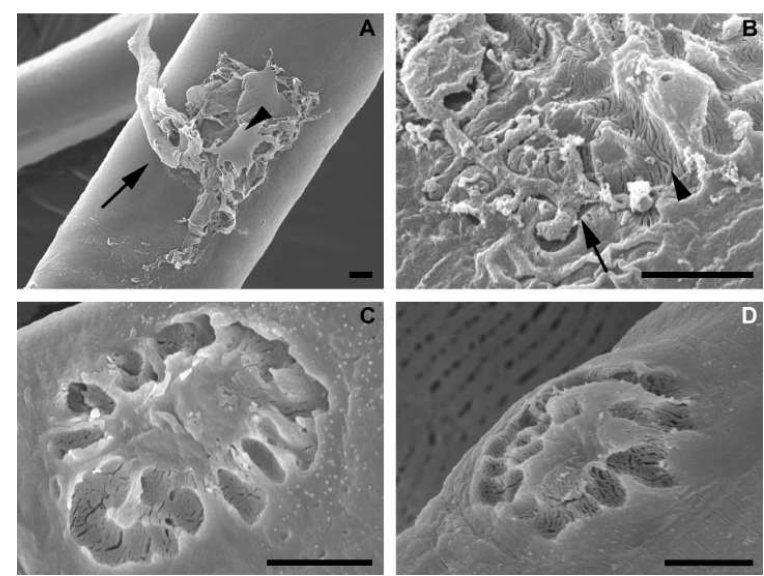

Figure 6. Scanning electron micrographs of the NMJ of a rat. (A) The myelinated motor axon (arrow) branches at the NMJ. The NMJ is covered by perisynaptic ("terminal") Schwann cells (arrowhead). (B) Chemical removal of the Schwann cells exposes the nerve terminals (arrow) which are embedded in gutter-like depressions. Where the nerve terminal is removed as well, the folded postsynaptic membrane is visible (arrowhead). (C) Complete chemical removal of the presynaptic structures reveals the postsynaptic structure of a normal rat NMJ. (D) Postsynaptic membrane with slightly widened postsynaptic clefts in a rat with EAMG. Scale bars are 5 $\mu \mathrm{m}$. 


\section{Pathophysiology of the neuromuscular junction in AChR-MG}

Anti-AChR antibodies induce loss of the AChRs, leading to an impaired neuromuscular transmission with muscle weakness as a result (Drachman, 1994). Due to the reduced number of AChRs, the sensitivity of the endplate to released ACh is reduced. Consequently, the amplitude of the MEPPs is reduced with approximately the same proportion as the loss of the AChRs. However, the loss of AChRs is partly compensated by an increase of ACh release in AChR-MG (Molenaar et al., 1979; Plomp et al., 1995).

As a consequence of the reduced AChR levels in MG, the EPPs can be so low that the threshold for activating voltage-gated sodium channels is not reached and consequently no action potential is generated (blocking of neuromuscular transmission; Figure 7D). If the EPP is just above the threshold, a delayed action potential is produced because the threshold is reached later. The reduced AChR levels, in combination with the variability of the quantal content, leads to a variation of the time at which an action potential is generated after motor nerve stimulation. This variation (jitter) can be measured by single fiber electromyography and is a sensitive measure for impaired neuromuscular transmission (Figure 7B). This method also allows the detection of neuromuscular blockings.

The quantal content decreases as a function of time (and frequency) during repetitive stimulation. Due to the great safety factor of the NMJ, this does not normally impair neuromuscular transmission; but in MG, because of the decreased sensitivity of the endplate to ACh, this decreased output leads to an increased likelihood of neuromuscular blockings. In electromyography recordings in MG patients, the decreasing amount of released $\mathrm{ACh}$ during repetitive nerve stimulation (generally measured at $3 \mathrm{~Hz}$ ) leads to increased number of neuromuscular blockings and to decrementing amplitudes of the compound muscle action potentials (CMAPs). 

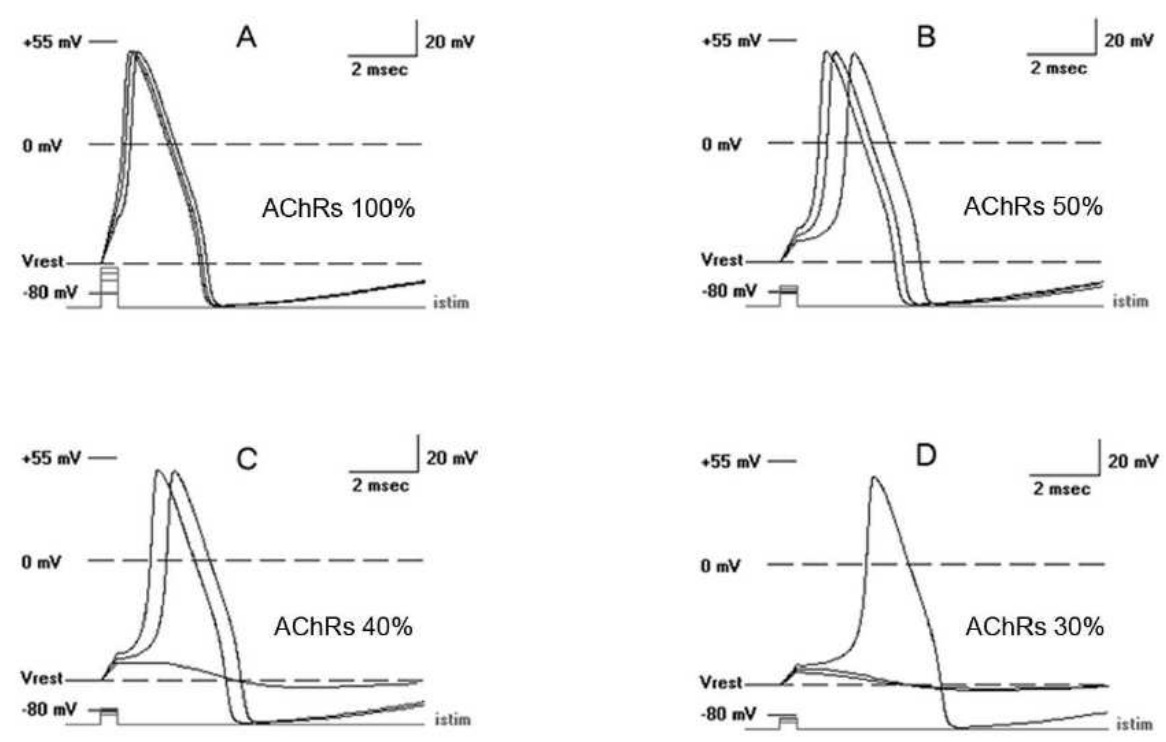

Figure 7. Computer simulation of muscle action potentials. Action potentials are elicited by nerve stimulation under conditions of increasing degree of AChR loss using the program NeuralSim/APSimv1.0 by Steven A. Siegelbaum. The basis of the simulation settings is the assumption of the value of the safety factor 3.0 for neuromuscular transmission in man. In each frame, A-D, three traces are shown to indicate the variability of the quantal output of ACh upon each stimulus: the mean, the mean minus 1 standard deviation and the mean +1 standard deviation (the coefficient of variation of the transmitter release of the human endplate with a quantal content of 30 is 0.18 ). Panel A, $100 \%$ AChRs. Panel B, 50\% AChRs; notice the increased delay in response time to the nerve stimulus and also the greater variation of response time (jitter). Panel C, $40 \%$ AChRs; notice the further delay in response time and one failure ("blocking") where stimulation failed to elicit an action potential. Panel D, $30 \%$ AChRs; a further delay in response time and two failures.

\section{Ultrastructural changes at the neuromuscular junction in AChR-MG}

In transmission electron micrographs, the ultrastructure of the postsynaptic membrane can be analyzed in detail. Normal NMJs show a complex pattern of postsynaptic folds near the nerve bouton (Figure 8). In contrast, a high concentration of anti-AChR antibodies causes lysis of the postsynaptic membrane. Figure 9A shows this lysis after passive transfer of the anti-AChR monoclonal antibody (mAb) 35. In this model, also infiltration of granulocytes occurs (Figure 9B). Ultimately, the chronic exposure of the NMJ to anti-AChR antibodies leads to a simplified postsynaptic membrane without postsynaptic folds. This change also occurs in experimental autoimmune myasthenia gravis (EAMG) model (Figure 9C), as discussed below. 

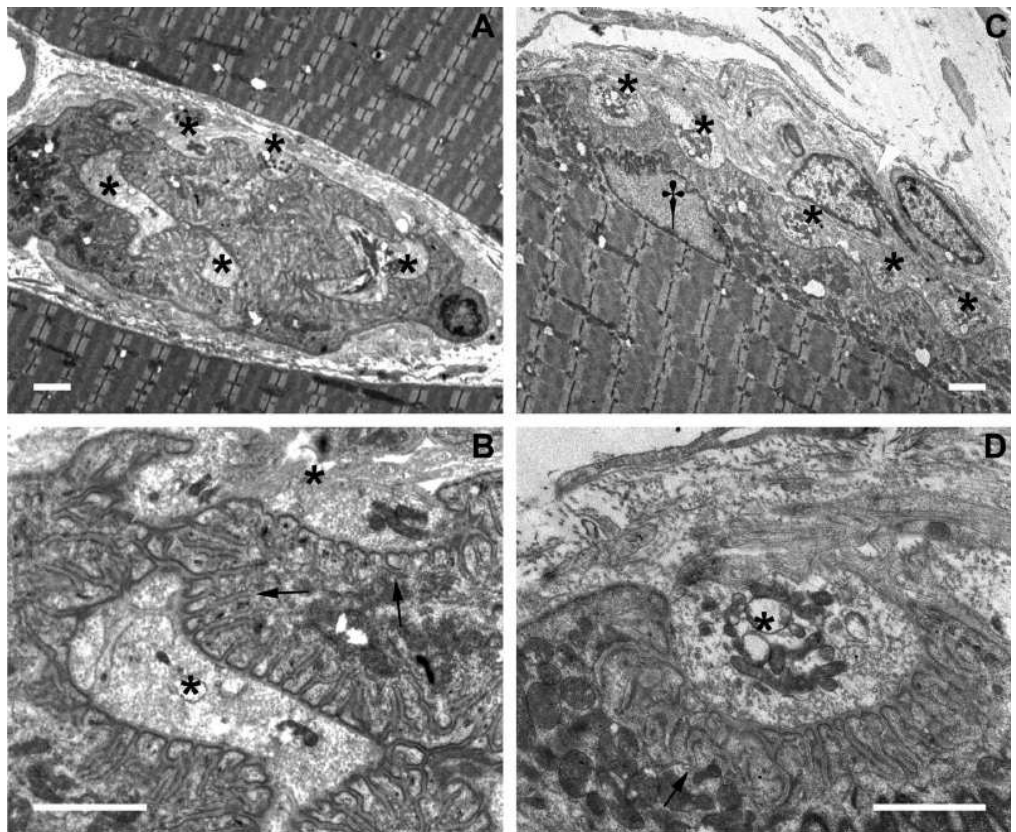

Figure 8. Transmission electron micrographs of the NMJ in rat tibialis anterior muscles. The asterisks indicate nerve terminals, the arrows point at the poststnaptic membrane (A, B) Section cutting the NMJ parallel to the muscle fiber surface (i.e. similar to the orientation of the scanning electron micrographs shown in Figure 6). Abundant postsynaptic membrane folds are arranged around multiple nerve boutons. (C,D) Section cutting parallel to the axis of the muscle fiber. In this orientation both the subsynaptic nuclei (dagger) as well as the perisynaptic Schwann cell (arrowhead) covering the nerve terminal. Scale bars are $2 \mu \mathrm{m}$.

\section{Pathophysiology of the neuromuscular junction in MuSK-MG}

The main effect of MuSK antibodies at the endplate is still unclear. MuSK is known to initiate aggregation of the AChR during synapse formation via the agrin/Lrp4/MuSK/rapsyn/AChR clustering pathway (Figure 3), but MuSK is also expressed at the mature NMJ. MuSK autoantibodies have the potential to alter MuSK function at the adult NMJ, and they may not only inhibit MuSK function directly, but also increase the turnover of MuSK, thereby further reducing its activity (Evoli et al., 2003; Hoch et al., 2001). In contrast with AChR antibody-positive patients, there is no evidence of loss of junctional folds, no apparent loss of AChR density and generally no complement deposition (Selcen et al., 2004; Shiraishi et al., 2005) in muscle biopsies of MuSK-MG patients. These findings suggest that MuSK-MG may be different in etiological and pathological mechanisms, compared to AChR-MG (McConville et al., 2004). 
While some muscles may remain unaffected, other, particularly facial, muscles show abnormalities such as increased jitter and atrophy (Farrugia et al., 2006; Kuwabara et al., 2007; Stickler et al., 2005). In vitro investigations revealed reduced amplitudes of MEPPs but no concomitant reduction in the number of AChRs (Selcen et al., 2004; Shiraishi et al., 2005). Studies using active immunization with MuSK or passive transfer of anti-MuSK antibodies from MuSK-MG patients to mice have shed some light into the effects on the NMJ and are discussed below.

\section{IgG isotypes in MG}

MG is mediated by circulating antibodies of the IgG class directed to the AChR, MuSK or possibly other, still unidentified autoantigens in the NMJ of striated muscle.

In humans, four different IgG isotypes exist which have very similar amino acid sequences, but differ in their ability to activate the complement system. IgG1 and IgG3 are effective complement activators, IgG2 poorly fixes complement and IgG4 is completely deficient in the ability to activate complement via the classical pathway (Bruggemann et al., 1987; Dangl et al., 1988). The structure mainly responsible for the differential ability of human IgG isotypes to activate complement is located at the carboxy-terminal part (residues 292-340) of the $\mathrm{CH} 2$ domain (Tao et al., 1991) (Figure $10 \mathrm{~A})$, but the hinge region also has a minor contribution to the complement activation (Tan et al., 1990).

In AChR-MG patients, the complement-fixing IgG1 and IgG3 isotype AChR-specific antibodies predominate, whereas IgG2 and IgG4 are only present in lower concentrations (Lefvert et al., 1981; Rodgaard et al., 1987; Vincent and Newsom-Davis, 1982). Generally, the anti-AChR autoantibody concentration does not correlate well with the severity of disease (Takeo et al., 1993), although in individual patients there is a relation between antibody titer and clinical condition after immunosuppression (Newsom-Davis et al., 1979). Since IgG autoantibody subclasses have distinct immunological properties, a possible explanation for this weak correlation could be found in variations in the isotype distribution. Interestingly, anti-AChR IgG1 (but not IgG2, IgG3 and IgG4) concentration was found to be significantly correlated to severity of disease (Rodgaard et al., 1987). These results suggest that binding of IgG1 may play a key role in the pathogenesis of AChR-MG (Rodgaard et al., 1987). In rhesus monkeys, passive transfer of human IgG1, but not IgG4 anti-AChR antibodies caused MG (van der Neut Kolfschoten et al., 2007). 

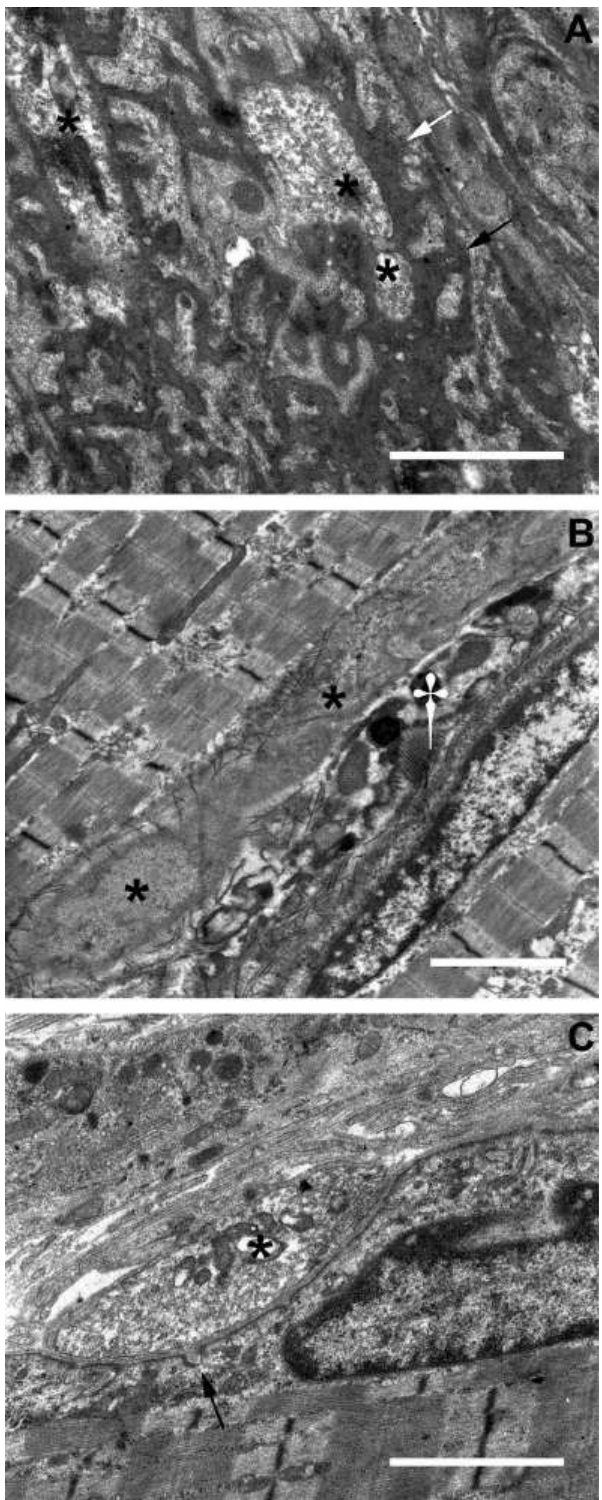

Figure 9. Morphological changes at the postsynaptic membrane after autoantibody attack. Transmission electron microscopy pictures of the NMJ in tibialis anterior sections. The asterisks indicate nerve terminals, the arrows point at the poststnaptic membrane. (A) Lysis of postsynaptic structure after passive transfer of antiAChR mAb 35. (B) Infiltrating granulocyte (see dagger) at the NMJ after passive transfer of mAb 35 . The synaptic boutons are dislocated from the sarcolemma. (C) In chronic AChR-EAMG, many endplates show a simplified postsynaptic membrane with a few shallow postsynaptic folds. Scale bars are $2 \mu \mathrm{m}$. 
In contrast to the anti-AChR antibodies, anti-MuSK antibodies are predominantly of the IgG4 isotype (McConville et al., 2004) and therefore they do not cause substantial complement deposition, morphological damage or AChR loss at the NMJ (Selcen et al., 2004; Shiraishi et al., 2005). These findings imply important differences between MuSKMG and AChR-MG in their pathological mechanisms. The mechanism in MuSK-MG may involve downstream changes in the function and distribution of key molecules at the NMJ. Based on cell culture using AChR-expressing rhabdomyosarcoma cells, it has been suggested that the postsynaptic machinery becomes structurally and functionally disorganized by a significant reduction of AChR clustering (Boneva et al., 2006).

Finally, in idiopathic MG patients, it has been shown that the autoantibodies belong to the IgG1 subclass. In addition, they induced complement deposition on the AChR clusters which demonstrates $\mathrm{C} 1 \mathrm{q}$ binding and activation of the classical complement pathway (Leite et al., 2008). This strongly suggests that the autoantibodies of idiopathic MG can be directed towards the AChR, but bind only when the AChRs are clustered densely (Leite et al., 2008).

\section{IgG4 Fab arm exchange}

All IgGs are composed of two heavy chain / light chain pairs (half-molecules), which are connected via inter-heavy chain disulfide bonds situated in the hinge region (Figure 10A), as well as by non-covalent bonds mostly situated between the third constant domains (CH3). IgG antibodies mediate pro-inflammatory activities, with the exception of IgG4 which has anti-inflammatory activities. IgG4 represents approximately $4 \%$ of the total IgG in serum of adults and significant IgG4 titers are generated by prolonged antigenic stimulation (Schuurman et al., 1999). The anti-inflammatory activity includes a poor ability to induce complement and cell activation because of a low affinity for C1q and Fc receptors. Moreover, IgG4 does not form immune complexes due to a posttranslational modification, known as Fab-arm exchange. IgG4 exchanges Fab arms by swapping a heavy chain and attached light chain with a half-molecule from another antibody (Figure 10B). Antibodies from the IgG4 subclass have been shown to be dynamic molecules, undergoing Fab arm exchange both in vivo and in vitro. The ability to engage in Fab arm exchange appears to be an inherent feature of IgG4 that involves the third constant domain in addition to the hinge region and this posttranslational modification only requires a reducing environment to be activated (van der Neut Kolfschoten et al., 2007).

Kinetic studies on the inter-heavy chain disulfide bond formation of the IgG4 molecule showed that these bonds were formed slowly and that they were unstable (Petersen and Dorrington, 1974). Inter- and intra-heavy chain disulfide bonds are in 
equilibrium. This phenomenon is facilitated by a substitution of single amino acid in the hinge of IgG4 compared to IgG1: a proline in IgG1 is replaced by a serine in IgG4 (Angal et al., 1993). Nevertheless, simply mixing IgG4 molecules in vitro does not result in Fab arm exchange. The mechanism by which IgG4 Fab arm exchange occurs in vivo likely requires the reducing environment in blood or at cell surfaces to facilitate the breaking of bonds between half-molecules (van der Neut Kolfschoten et al., 2007).

A

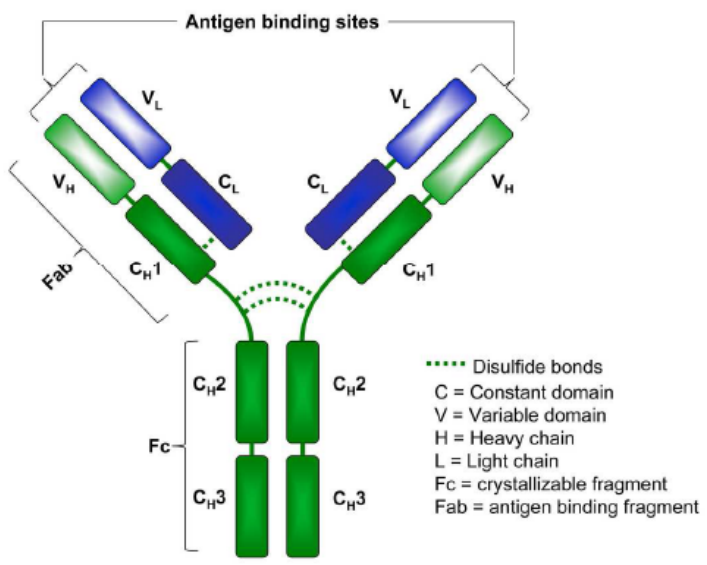

B

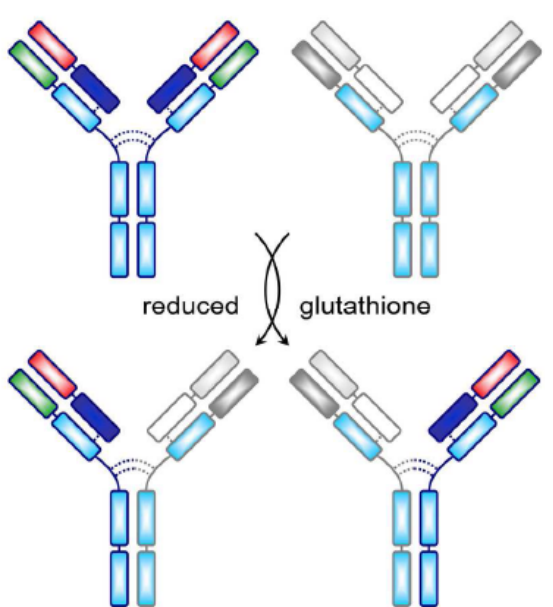

Figure 10. A) Structure of IgG. B) Fab arm exchange reaction. IgG4 molecules with different specificity interchange half-molecules resulting in chimeric bispecific antibodies.

When polyclonal IgG4 is derived from plasma, the Fab arm exchange reaction usually produces IgG4 molecules with two different antigen-binding sites. The resulting asymmetric antibodies are bispecific, and thus are directed against two different and generally unrelated antigens. Moreover, they are unable to cross-link two identical antigens (van der Zee et al., 1986) and are therefore functionally monovalent (Schuurman et al., 1999). Fab arm exchange, furthermore, is dynamic, and combinations of certain specific Fab arms are therefore expected to exist only transiently. This protein modification challenges the commonly accepted one antibody-one antigen paradigm and redefines our thinking about the role of $\operatorname{lgG} 4$ in antibody-mediated immunity and the application of IgG4 monoclonal antibodies to immunotherapy. 
Functionally monovalent IgG4 antibodies directed to the AChR that do not modulate the AChR or block the ACh binding are not pathogenic. Moreover they have the potential to protect the NMJ against complement fixing IgG1 anti-AChR-autoantibodies (van der Neut Kolfschoten et al., 2007) by competition for binding. Therefore, IgG4 has an important anti-inflammatory property and protects tissues against the biological effects of the complement-fixing IgG subclasses (van der Zee et al., 1986).

\section{Effector functions of IgG autoantibody subclasses in AChR-MG}

The breakdown of the AChR is mainly caused by complement-mediated lysis of the postsynaptic membrane (Sahashi et al., 1980) and by cross-linking of AChRs in the membrane. Cross-linking antibodies are believed to initiate a conformational change of the AChR (antigenic modulation) which induces accelerated AChR internalization and degradation (Drachman et al., 1978). The different properties and effector functions of IgG antibodies are discussed below.

\section{Antigenic modulation}

Antibodies from patients with AChR-MG accelerate the degradation of AChRs in cultured muscles and in vivo at intact NMJs (Drachman et al., 1978; Kao and Drachman, 1977; Stanley and Drachman, 1978). The antibody-accelerated degradation of the AChR by antigenic modulation is a consequence of the bivalent nature of the IgG1, IgG2 and IgG3 autoantibodies. These AChR-specific antibodies are able to cross-link adjacent AChR molecules which are rapidly internalized by endocytosis and then degraded (Pumplin and Drachman, 1983). Serum IgG from approximately $90 \%$ of patients increased the degradation rate of the AChR two to three fold (Drachman et al., 1982). Thus, if accelerated degradation is not sufficiently compensated by increased AChR synthesis, it will lead to a reduction of the available AChR molecules at the NMJ. This reduction of AChR at the NMJ can be used as a useful diagnostic test for MG (Howard et al., 1987). However, not all anti-AChR antibodies cause antigenic modulation. The epitope location on the AChR surface may restrict the ability of antibodies to cross-link a second AChR molecule (Conti-Tronconi et al., 1981). Moreover, IgG4 antibodies are functionally monovalent, which means that they do not cross-link two identical antigens.

\section{Complement activation}

Binding of anti-AChR antibodies to the tightly packed AChRs in the postsynaptic membrane folds results in very high density of bound antibody and, hence, very tightly 
packed Fc regions of these antibodies. Since anti-AChR antibodies belong mainly to the IgG1 and IgG3 class, this causes a highly efficient activation of the complement system and consequently the formation of the membrane attack complex (MAC) in the postsynaptic membrane. In combination with antigenic modulation of the AChR, MAC causes the severe endplate membrane damage (Corey et al., 1987; Engel and Arahata, 1987). Stabilization of the AChR by increasing rapsyn expression prevents modulation of the AChR, even in the presence of activated complement (Losen et al., 2008; Losen et al., 2005).

Different lines of indirect evidence support complement activation at the NMJ as a fundamental cause of AChR loss and failure of neuromuscular transmission: complement depletion with cobra venom factor (Lennon et al., 1978), administration of antibodies that block a complement component (Biesecker and Gomez, 1989), complement inhibitors (Piddlesden et al., 1996) or genetic deficits of complement components (Christadoss, 1988) make animals resistant or less susceptible to EAMG. IL-12 deficient mice develop minimal EAMG symptoms after AChR immunization in spite of robust anti-AChR antibody synthesis (Karachunski et al., 2000). The lack of IL-12 prevents the production of the complement fixing IgG2a antibodies in the mouse (Table 2). NMJs in these mice contain only IgG1 antibodies, which unlike human IgG1 antibodies do not activate complement; indicating that anti-AChR antibodies, which do not activate complement, do not effectively compromise neuromuscular transmission.

Complement activation damages the postsynaptic membrane by multiple mechanisms. The membrane attack complex leads to loss of postsynaptic folding (Engel et al., 1977), loss of membrane potential (Mozrzymas et al., 1993) and, in conjunction with antigenic modulation of the AChR, to loss of AChR-associated proteins (Martinez-Martinez et al., 2007).

\section{Functional AChR blockade}

Serum IgG from 50 to $88 \%$ of patients with MG has been shown to block the ACh-binding sites of AChRs in cultured mammalian muscle cells (Howard et al., 1987). Antibodies with the ability to block the ACh-binding site of the AChR cause acute and severe muscle weakness in rodents without inflammation or necrosis at the NMJ (Gomez and Richman, 1983). Many MG patients have low levels of these antibodies. They might block the AChR in spite of their low concentrations and contribute to acute myasthenic crisis (Whiting et al., 1983). 


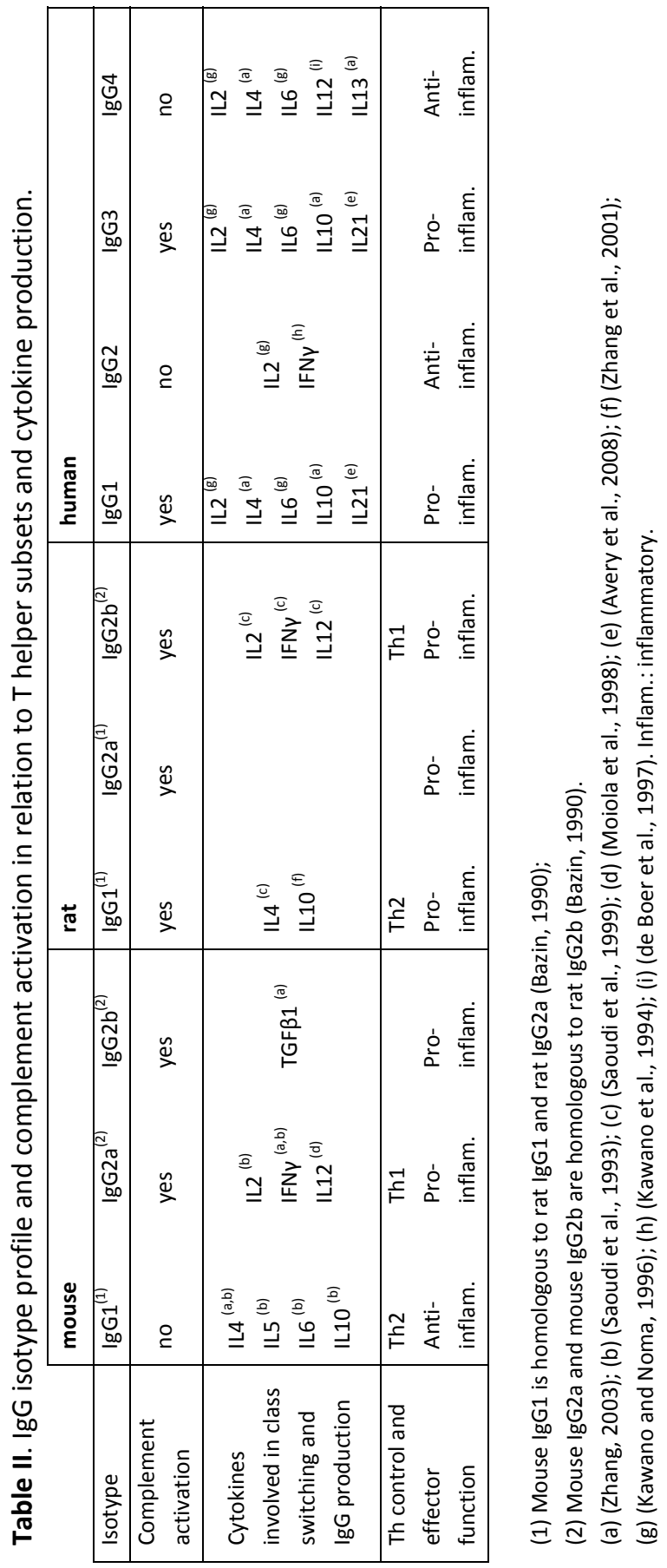




\section{Loss of AChR-associated proteins}

The attack of anti-AChR antibodies at the NMJ does not only lead to a reduction of the density of AChR, but also affects other AChR-associated proteins (Ito et al., 1996; Slater et al., 1997). Research on the significance of postsynaptic proteins for the maintenance of the adult endplate and the reorganization of the NMJ after injuries is promising, showing that some postsynaptic proteins are not just crucial for fetal development but also play an important role in the dynamics of the organization of adult endplates. This premise is in agreement with the deterioration of neuromuscular transmission observed in patients with mutations in genes of the NMJ. This group of patients is gathered under the term "congenital myasthenic syndromes" (CMS) (Engel and Sine, 2005). CMS mutations can occur in genes of presynaptic, synaptic or postsynaptic proteins, though the latter is far more common (Palace and Beeson, 2008).

The importance of the synaptic proteins is further illustrated in the knock-down models for MuSK (DeChiara et al., 1996), rapsyn (Gautam et al., 1995), Dok-7 (Okada et al., 2006), Lrp4 (Weatherbee et al., 2006) or agrin (Glass et al., 1996), where animals die prematurely around birth, primarily due to respiratory distress, and with a severely underdeveloped NMJ.

Among the NMJ proteins affected in CMS patients, the AChR is the most prominent, with mutations in $\alpha, \beta, \delta$ or $\varepsilon$ subunits that generate an MG-like clinical picture of the patients. Several mutations that lead to muscular weakness have been identified in rapsyn, MuSK, laminin and Dok-7 genes (Beeson et al., 2006; Burke et al., 2003; Chevessier et al., 2004; Maselli et al., 2009; Noakes et al., 1995). CMS patients display a variable range of MG-like symptoms that are normally present at birth or develop during early life.

In AChR-MG, it seems likely that loss of AChR-associated proteins, including rapsyn, utrophin and voltage gated sodium channels aggravate the disease and delay repair processes (Martinez-Martinez et al., 2007; Martinez-Martinez et al., 2009). The function of key postsynaptic proteins is reviewed below, because we believe that this knowledge is helpful for evaluating the possible consequences resulting from loss of these proteins in AChR-MG.

\section{Utrophin}

Utrophin is localized primarily at the NMJ (Tanaka et al., 1991), while the homologous protein dystrophin (Tinsley et al., 1992) is expressed throughout the muscle fiber (Huard et al., 1991). Utrophin is found closely colocalized to the AChR both in the adult NMJ 
(Bewick et al., 1992) and throughout development (Bewick et al., 1996), suggesting that it helps to stabilize the AChR clusters (Phillips et al., 1993). However, studies of utrophindeficient mice indicate that utrophin is not essential for NMJ formation or for precise localization of AChRs at the NMJ (Deconinck et al., 1997; Grady et al., 1997). The reduction of utrophin in MG patients is probably secondary to the loss of AChR, but in the presence of autontibodies against the $A C h R$, it is likely that utrophin-loss curbs anchoring of newly produced AChRs to the cytoskeleton (Martinez-Martinez et al., 2007).

\section{Rapsyn}

Rapsyn is required for anchoring and stabilizing the AChR in the postsynaptic membrane of the NMJ during development. The AChR clustering by rapsyn is activated by agrin (Brockhausen et al., 2008), which acts via Lrp4 and MuSK (Kim et al., 2008). The expression of rapsyn increases with age and thereby stabilizes the AChR (Gervasio and Phillips, 2005). In a passive-transfer rat model for MG, increased expression of rapsyn at the NMJ induced resistance against anti-AChR antibodies (Losen et al., 2005) by reducing antibody-induced AChR internalization. Conversely, rapsyn overexpression has a detrimental effect in chronic EAMG where endplates are already substantially damaged. In chronic EAMG, increased rapsyn expression increases the postsynaptic membrane turnover by anti-AChR antibodies (Martinez-Martinez et al., 2007). It is of interest that a modest reduction of rapsyn expression already causes substantial changes, showing that the amount of rapsyn is critically related to the AChR levels and to the structure of the endplate (Martinez-Martinez et al., 2009). These findings support the idea of rapsyn as a stabilizing protein for the AChR in the membrane, as previously shown in vitro when AChR half-life was increased and its degradation rate reduced by the presence of rapsyn in cultured myotubes (Phillips et al., 1997) or when AChR turnover was augmented in rapsyn-deficient myotubes (Wang et al., 1999). In intercostal muscle biopsies from AChRMG patients rapsyn levels are significantly reduced relative to control biopsies (unpublished results).

\section{MUSK}

The role of MuSK has been discussed above. In addition it is important to mention the findings of Hesser and colleagues (Hesser et al., 2006) who demonstrated the relevance of MuSK for the maintenance of the postsynaptic structure by using a transgenic mouse model with a conditional knock-out of MuSK. Upon inactivation of MuSK expression, the AChR clusters became disassembled with evident disorganization of the NMJ and sprouting of the nerve terminals. This further supports the notion that, MuSK expression 
is necessary for maintaining the integrity of the NMJ (Kong et al., 2004).

\section{Lrp4}

Lrp4 is localized in the postsynaptic membrane and has a large extracellular region (Johnson et al., 2005; Tian et al., 2006). New born mice with null alleles of Lrp4 are cyanotic, unable to breathe and have defects in distal limbs, indicating that Lrp4 is required for the development of the NMJ (Weatherbee et al., 2006). The absence of AChR clusters at the postsynaptic membrane of Lrp4 null mutant animals resemble the phenotype observed in MUSK -/- mice and suggest a role for Lrp4 upstream or at the same level of MuSK. Lrp4 selectively binds to neural agrin (Kim et al., 2008; Zhang et al., 2008), which is necessary for the activation of MuSK.

\section{Dok-7}

The family of Dok proteins work as docking platforms for the formation of signaling complexes at the cell membrane. They actively regulate signal transduction and recruit other proteins by their phosphotyrosine binding (PTB) domain and a C-terminal domain, that contains multiple potential tyrosine phosphorylation sites and proline-rich sequences for SH2 and SH3-containing proteins (Zhang et al., 2004). Dok-7 interacts with the cytoplasmic domain of MuSK and induces its autophosphorylation. MuSK-deficient myotubes do not form AChR clusters when mutated forms of MuSK, which cannot interact with Dok-7, are re-introduced (Okada et al., 2006). Silencing of Dok-7 in C2 myotubes suppressed MuSK phosphorylation and, therefore, impaired the formation of AChR clusters. Dok-7 knock-out mice are immobile and die at birth. No detectable AChR clusters on the endplate area are developed in these mice, which resembles the phenotype of MuSK -/- mice (Okada et al., 2006).

Tid1

When screening for proteins that interact with MuSK, Linnoila and colleagues (Linnoila et al., 2008) encountered a rat homolog of the Drosophila tumor suppressor Tid56 and the heat shock protein hsp40 that was constitutively associated with MuSK, and was denominated tumorous imaginal disk 1 (Tid1). Tid1 is colocalized with MuSK and the AChR at the postsynaptic membrane. The relevance of Tid1 for AChR clustering was demonstrated when silencing of Tid1 expression in cultured myotubes caused a marked disruption in the AChR clusters, a situation that could be rescued by transfecting the normal Tid1 gene (Linnoila et al., 2008). However, transfection of a mutated variant of Tid1 did not rescue AChR clustering. These findings suggest that Tid1 orchestrates the cascade that leads to $A C h R$ clustering by interactions with other regulatory proteins 
downstream of MuSK, since Tid1 had been documented to activate a variety of intracellular mediators like the small GTPases RAc1 and RhoA (Trentin et al., 2001) or NFKB (Cheng et al., 2002). Some of these mediators were directly related with AChR phosphorylation and rapsyn stabilization like Hsp90 $\beta$ (Luo et al., 2008) and, therefore, it is likely that the effect of Tid1 on the AChR clustering occurs downstream of MuSK (Linnoila et al., 2008; Song and Balice-Gordon, 2008).

In vivo studies have also supported the importance of Tid1 for the development and maintenance of the NMJ. Tid1 knock-out mice die at embryonic day 7. Since Tid1 is localized in many cells types and tissues (Yin and Rozakis-Adcock, 2001) and is involved in a wide collection of intracellular processes like DNA repair (Catlett and Forsburg, 2003) and senescence (Tarunina et al., 2004) or signaling pathways like those of NFKB (Cheng et al., 2002), interferon (Sarkar et al., 2001) and ras (Trentin et al., 2001), it is not surprising that suppression of this gene resulted in death at an early developmental stage. On the other hand, focalized siRNA-mediated down-regulation of Tid1 in adult mouse muscles led to a profound disorganization of the AChR clusters at the NMJ and also impaired the neuromuscular transmission, showing that Tid1 expression is essential for the maintenance of normal endplates (Linnoila et al., 2008).

Although MuSK still remains a key molecule for AChR clustering, it is more adequate at the moment to refer to a MuSK-Dok7-Tid1 complex in the agrin induced pathway for synapse development.

\section{IgG isotypes in animal models for MG}

Animal models have contributed significantly to elucidate the pathogenesis of MG. AChRimmunization is used as an MG animal model termed experimental autoimmune myasthenia gravis (EAMG). Moreover, injection of MG patient sera or monoclonal antiAChR antibodies also induce muscle weakness in animals and this model is termed passive transfer MG (Toyka et al., 1975).

Similarly, MG can be induced in animals by active immunization with MuSK (Jha et al., 2006; Shigemoto et al., 2006) or by passive transfer with serum from MuSK-MG patients (Cole et al., 2008; ter Beek et al., 2009). Here, we refer to these models as "MuSK-EAMG" and "passive transfer MuSK-MG", respectively (Table 1).

MG models have been crucial for understanding the role of the different IgG isotypes in the pathology and severity of MG. This knowledge provides a basis to improve the current therapies for MG patients and to develop more specific treatment approaches 
(Souroujon et al., 2010). Strategies that use this knowledge to curb the pathogenic effects of pro-inflammatory IgG subclasses are briefly discussed below.

\section{AChR-EAMG}

Patrick and Lindstrom were the first to induce MG in rabbits by immunization with AChR from the electric organ of electric eels (Electrophorus electricus) in complete Freund's adjuvant. They immunized these rabbits with purified AChR to obtain antibodies for the biochemical analysis of the AChR but all animals became paralyzed and eventually died (Patrick and Lindstrom, 1973). Active immunization of experimental animals (including mice, rats, guinea pigs and monkeys) with AChR -with or without adjuvant- induced chronic EAMG within 30 days after immunization (Berman and Patrick, 1980; Lennon et al., 1975; Tarrab-Hazdai et al., 1975). The animals mount an active immune response against injected AChR. The disease is caused by antibodies cross-reacting with the animals' own muscle AChR.

The production of the pathogenic antibodies by $B$ cells depends on $T$ helper cells. The pathogenic anti-AChR antibodies are high affinity IgGs, whose synthesis requires interaction of activated T cells with B cells (Conti-Fine et al., 2008). T cells can be divided into T helper-one (Th1) and T helper-two cells (Th2) depending upon their cytokine profile. Cytokine signaling is crucial for development, modulation and downregulation of immune responses, and therefore influences the initiation and evolution of the anti-AChR response in EAMG. The regulation of Th cells by cytokines is important, because it affects the isotype profile of stimulated B-cells. Th1 cells have a pathogenic role in EAMG because they stimulate the synthesis of anti-AChR antibodies that fix complement and therefore cause destruction of the NMJ (Balasa et al., 1997). In contrast, Th2 cells induce anti-AChR antibodies that do not fix complement in mice (Table 2). In rats, both Th1 and Th2 cells are able to induce pathogenic anti-AChR antibodies (Saoudi et al., 1999).

In AChR-EAMG models the isotype profile of autoantibodies can be altered by experimental treatments. Cytokines such as IL-4 stimulate Th2 cells and antagonize the action of Th1 cells, possibly by inducing regulatory T-cells (Ostlie et al., 2003). In mice, manipulation of the balance in favor of Th2 cells protects against EAMG (Moiola et al., 1998), because only Th1 related cytokines induce the complement activating IgG2b antibodies. In rats, both Th1 and Th2 cells are able to induce pathogenic anti-AChR antibodies (see Table 2) and manipulation of the Th1/Th2 balance does not affect the severity of disease (Saoudi et al., 1999). The different requirements for Th1-dependent responses in rats and mice are therefore correlated to the capacity of complement activation by antibody subclasses. In humans, it is not yet clear if the Th1/Th2 balance 
affects the production of complement-binding antibodies. It would be interesting to study how an isotype switch of IgG1 towards IgG4 can be induced in autoreactive B-cells for the treatment of AChR-MG.

\section{Passive transfer AChR-MG}

Toyka and colleagues have transferred purified IgG from MG patients to mice, which subsequently developed MG symptoms (Toyka et al., 1975). This passive transfer EAMG model is relevant for MG in order to study the effector phase of the disease. Antibodies against the main immunogenic region (MIR) of the AChR induce myasthenia within 8 to 48 hours, depending on the dose and affinity of the antibody for AChR (Hoedemaekers et al., 1997). The source of antibodies can be serum of MG patients, serum from chronic EAMG animals or monoclonal antibodies produced in cell culture (Richman et al., 1980). The immunopathological mechanisms are antigenic modulation (Tzartos et al., 1985) and complement-mediated focal lysis of the postsynaptic membrane for anti-MIR antibodies (Lennon et al., 1978). Antibodies against the ACh-binding sites induce an acute paralysis within 15 to 30 minutes (Balass et al., 1993). It has been shown that also anti-MIR antibodies can functionally inhibit AChR (Sterz et al., 1986) and the role of the MIR for AChR activity has recently been demonstrated (Luo et al., 2009).

Monovalent anti-AChR antibodies or antibody fragments without complement binding capacity are not pathogenic. Since they can compete with pathogenic autoantibodies for binding to the AChR, they can prevent autoantibody binding at the NMJ (Lagoumintzis et al., 2010). In passive transfer AChR-MG mouse models, monovalent Fab fragments have been demonstrated to protect the AChR against the action of intact pathogenic antibodies (Papanastasiou et al., 2000; Toyka et al., 1980). Monovalent binding to antigens is not limited to Fab fragments, but also human IgG4 antibodies are functionally monovalent. IgG4 has favorable properties for potential immunotherapy, such as long half-life in vivo, low immunogenicity, no capacity of complement activation and inability to cross-link antigens. In a passive transfer MG model in rhesus monkeys, a monoclonal human anti-AChR IgG4 antibody derived from an MG patient (Graus et al., 1997) was not pathogenic, while the corresponding IgG1 isotype induced muscle weakness (van der Neut Kolfschoten et al., 2007). Interestingly, also Fab arm exchange of IgG4 anti-AChR antibodies occurred in this model, suggesting that the rhesus monkey has an IgG4 like subclass. 


\section{MUSK-EAMG}

Mice actively immunized with MuSK also showed the characteristic symptoms of MG (Jha et al., 2006). However, the pro-inflammatory (i.e. complement-fixing and cross-linking) anti-MuSK antibodies that are produced in MuSK-EAMG do not closely resemble human MuSK-MG with anti-inflammatory IgG4 antibodies. Therefore, the pathological mechanisms of the MuSK-EAMG model might differ from MuSK-MG.

\section{Passive transfer MuSK-MG}

The presence of a pathogenic antibody in MuSK-MG was demonstrated by a passive transfer of IgG from anti-MuSK-positive MG patients into adult mice. In this passive transfer model, reduced levels of AChRs were observed at the postsynaptic membrane and changes in the presynaptic and postsynaptic elements of the synapse led to muscle weakness (Cole et al., 2008). In addition, passive transfer caused a decrease of the safety factor of neuromuscular transmission and the size of endplates in regenerating muscles of adult mice (ter Beek et al., 2009).

Treatment of mice with IgG or blood plasma from MuSK patients led to reduced endplate sizes and caused a decrease in the safety factor of neuromuscular transmission of regenerating adult muscles (ter Beek et al., 2009). With high doses of anti-MuSK IgG in passive transfer experiments, the number of AChRs is reduced as well (Cole et al., 2008). It is possible that MuSK antibodies in patients primarily cause a reduction of the size of the presynaptic ending while leaving the postsynaptic part and the AChRs intact, although the function of the AChRs may be altered (ter Beek et al., 2009). In this case the value of the quantal content would be decreased leading to increased jitter in single fiber EAMG. Reduced endplate sizes have been observed in pathogenic mutations of both MuSK and Dok-7 (Beeson et al., 2006; Chevessier et al., 2004) which predict that the pathophysiological cause of muscle weakness is primarily a small value of the quantal content because of small nerve terminals.

\section{Conclusion}

The symptoms of AChR-MG and MuSK-MG are a result of dysregulation of the immune system and the NMJ. Antigen-specific therapies for MG can make use of biological mechanisms such as the Th1/Th2 balance or the IgG1/IgG4 antibody isotype distribution, for example. Similarly, the NMJ offers potential therapeutic targets to make the postsynaptic membrane more resilient to autoantibody attack. Hopefully, a better 
understanding of the mechanisms of immune regulation in MG and the pathogenesis at the NMJ as a result of autoantibody attack will lead to the development of antigenspecific therapies.

\section{Acknowledgements}

The micrographs in this paper were taken with a confocal spinning disk microscope financed by The Netherlands Organisation for Scientific Research (NWO), grant number 911-06-003. The authors' experimental work was supported by grants from the Prinses Beatrix Fonds, L'Association Française contre les Myopathies, the European Union Sixth Framework Program (FP6) MYASTAID LSHM-CT-2006-037833, Genmab and Aspreva.

\section{References}

Angal, S., King, D.J., Bodmer, M.W., Turner, A., Lawson, A.D., Roberts, G., Pedley, B., Adair, J.R., 1993. A single amino acid substitution abolishes the heterogeneity of chimeric mouse/human (IgG4) antibody. Mol Immunol 30, 105108.

Avery, D.T., Bryant, V.L., Ma, C.S., de Waal Malefyt, R., Tangye, S.G., 2008. IL-21-induced isotype switching to IgG and IgA by human naive B cells is differentially regulated by IL-4. J Immunol 181, 1767-1779.

Balasa, B., Deng, C., Lee, J., Bradley, L.M., Dalton, D.K., Christadoss, P., Sarvetnick, N., 1997. Interferon gamma (IFNgamma) is necessary for the genesis of acetylcholine receptor-induced clinical experimental autoimmune myasthenia gravis in mice. J Exp Med 186, 385-391.

Balass, M., Heldman, Y., Cabilly, S., Givol, D., Katchalski-Katzir, E., Fuchs, S., 1993. Identification of a hexapeptide that mimics a conformation-dependent binding site of acetylcholine receptor by use of a phage-epitope library. Proc Natl Acad Sci U S A 90, 10638-10642.

Bazin, H., 1990. Rat Immunoglobulins. In: Bazin, H. (Ed.), Rat Hybridomas and Rat Monoclonal Antibodies, CRC press, Boca Raton, pp. 5-42.

Beeson, D., Higuchi, O., Palace, J., Cossins, J., Spearman, H., Maxwell, S., Newsom-Davis, J., Burke, G., Fawcett, P., Motomura, M., Muller, J.S., Lochmuller, H., Slater, C., Vincent, A., Yamanashi, Y., 2006. Dok-7 mutations underlie a neuromuscular junction synaptopathy. Science 313, 1975-1978.

Behin, A., Mayer, M., Kassis-Makhoul, B., Jugie, M., Espil-Taris, C., Ferrer, X., Chatenoud, L., Laforet, P., Eymard, B., 2008. Severe neonatal myasthenia due to maternal anti-MuSK antibodies. Neuromuscul Disord 18, 443-446.

Berman, P.W., Patrick, J., 1980. Experimental myasthenia gravis. A murine system. J Exp Med 151, 204-223.

Bevan, S., Steinbach, J.H., 1977. The distribution of alpha-bungarotoxin binding sites of mammalian skeletal muscle developing in vivo. J Physiol 267, 195-213.

Bewick, G.S., Nicholson, L.V., Young, C., O'Donnell, E., Slater, C.R., 1992. Different distributions of dystrophin and related proteins at nerve-muscle junctions. Neuroreport 3, 857-860.

Bewick, G.S., Young, C., Slater, C.R., 1996. Spatial relationships of utrophin, dystrophin, beta-dystroglycan and betaspectrin to acetylcholine receptor clusters during postnatal maturation of the rat neuromuscular junction. J Neurocytol 25, 367-379.

Biesecker, G., Gomez, C.M., 1989. Inhibition of acute passive transfer experimental autoimmune myasthenia gravis with Fab antibody to complement C6. J Immunol 142, 2654-2659.

Boneva, N., Frenkian-Cuvelier, M., Bidault, J., Brenner, T., Berrih-Aknin, S., 2006. Major pathogenic effects of anti-MuSK antibodies in myasthenia gravis. J Neuroimmunol 177, 119-131. 
Brockhausen, J., Cole, R.N., Gervasio, O.L., Ngo, S.T., Noakes, P.G., Phillips, W.D., 2008. Neural agrin increases postsynaptic $\mathrm{ACh}$ receptor packing by elevating rapsyn protein at the mouse neuromuscular synapse. Dev Neurobiol 68, 1153-1169.

Bruggemann, M., Williams, G.T., Bindon, C.I., Clark, M.R., Walker, M.R., Jefferis, R., Waldmann, H., Neuberger, M.S., 1987. Comparison of the effector functions of human immunoglobulins using a matched set of chimeric antibodies. J Exp Med 166, 1351-1361.

Burke, G., Cossins, J., Maxwell, S., Owens, G., Vincent, A., Robb, S., Nicolle, M., Hilton-Jones, D., Newsom-Davis, J., Palace, J., Beeson, D., 2003. Rapsyn mutations in hereditary myasthenia: distinct early- and late-onset phenotypes. Neurology 61, 826-828.

Cartaud, A., Coutant, S., Petrucci, T.C., Cartaud, J., 1998. Evidence for in situ and in vitro association between betadystroglycan and the subsynaptic $43 \mathrm{~K}$ rapsyn protein. Consequence for acetylcholine receptor clustering at the synapse. J Biol Chem 273, 11321-11326.

Catlett, M.G., Forsburg, S.L., 2003. Schizosaccharomyces pombe Rdh54 (TID1) acts with Rhp54 (RAD54) to repair meiotic double-strand breaks. Mol Biol Cell 14, 4707-4720.

Changeux, J.P., Devillers-Thiery, A., Chemouilli, P., 1984. Acetylcholine receptor: an allosteric protein. Science 225, $1335-1345$

Cheng, H., Cenciarelli, C., Tao, M., Parks, W.P., Cheng-Mayer, C., 2002. HTLV-1 Tax-associated hTid-1, a human DnaJ protein, is a repressor of Ikappa B kinase beta subunit. J Biol Chem 277, 20605-20610.

Chevessier, F., Faraut, B., Ravel-Chapuis, A., Richard, P., Gaudon, K., Bauche, S., Prioleau, C., Herbst, R., Goillot, E., loos, C., Azulay, J.P., Attarian, S., Leroy, J.P., Fournier, E., Legay, C., Schaeffer, L., Koenig, J., Fardeau, M., Eymard, B., Pouget, J., Hantai, D., 2004. MUSK, a new target for mutations causing congenital myasthenic syndrome. Hum Mol Genet 13, 3229-3240.

Christadoss, P., 1988. C5 gene influences the development of murine myasthenia gravis. J Immunol 140, 2589-2592.

Cole, R.N., Reddel, S.W., Gervasio, O.L., Phillips, W.D., 2008. Anti-MuSK patient antibodies disrupt the mouse neuromuscular junction. Ann Neurol 63, 782-789.

Conti-Fine, B.M., Milani, M., Wang, W., 2008. CD4+ T cells and cytokines in the pathogenesis of acquired myasthenia gravis. Ann N Y Acad Sci 1132, 193-209.

Conti-Tronconi, B., Tzartos, S., Lindstrom, J., 1981. Monoclonal antibodies as probes of acetylcholine receptor structure. 2. Binding to native receptor. Biochemistry 20, 2181-2191.

Corey, A.L., Richman, D.P., Agius, M.A., Wollmann, R.L., 1987. Refractoriness to a second episode of experimental myasthenia gravis. Correlation with AChR concentration and morphologic appearance of the postsynaptic membrane. J Immunol 138, 3269-3275.

Dangl, J.L., Wensel, T.G., Morrison, S.L., Stryer, L., Herzenberg, L.A., Oi, V.T., 1988. Segmental flexibility and complement fixation of genetically engineered chimeric human, rabbit and mouse antibodies. Embo J 7, 1989-1994.

de Boer, B.A., Kruize, Y.C., Rotmans, P.J., Yazdanbakhsh, M., 1997. Interleukin-12 suppresses immunoglobulin E production but enhances immunoglobulin G4 production by human peripheral blood mononuclear cells. Infect Immun 65, 1122-1125.

DeChiara, T.M., Bowen, D.C., Valenzuela, D.M., Simmons, M.V., Poueymirou, W.T., Thomas, S., Kinetz, E., Compton, D.L., Rojas, E., Park, J.S., Smith, C., DiStefano, P.S., Glass, D.J., Burden, S.J., Yancopoulos, G.D., 1996. The receptor tyrosine kinase MuSK is required for neuromuscular junction formation in vivo. Cell 85, 501-512.

Deconinck, A.E., Potter, A.C., Tinsley, J.M., Wood, S.J., Vater, R., Young, C., Metzinger, L., Vincent, A., Slater, C.R., Davies, K.E., 1997. Postsynaptic abnormalities at the neuromuscular junctions of utrophin-deficient mice. J Cell Biol 136, 883-894.

Drachman, D.B., 1994. Myasthenia gravis. N Engl J Med 330, 1797-1810.

Drachman, D.B., Adams, R.N., Josifek, L.F., Self, S.G., 1982. Functional activities of autoantibodies to acetylcholine receptors and the clinical severity of myasthenia gravis. N Engl J Med 307, 769-775.

Drachman, D.B., Angus, C.W., Adams, R.N., Michelson, J.D., Hoffman, G.J., 1978. Myasthenic antibodies cross-link acetylcholine receptors to accelerate degradation. N Engl J Med 298, 1116-1122.

Engel, A.G., Arahata, K., 1987. The membrane attack complex of complement at the endplate in myasthenia gravis. Ann N Y Acad Sci 505, 326-332. 
Engel, A.G., Lambert, E.H., Howard, F.M., 1977. Immune complexes (IgG and C3) at the motor end-plate in myasthenia gravis: ultrastructural and light microscopic localization and electrophysiologic correlations. Mayo Clin Proc 52, 267-280.

Engel, A.G., Sine, S.M., 2005. Current understanding of congenital myasthenic syndromes. Curr Opin Pharmacol 5, 308321.

Evoli, A., Tonali, P.A., Padua, L., Monaco, M.L., Scuderi, F., Batocchi, A.P., Marino, M., Bartoccioni, E., 2003. Clinical correlates with anti-MuSK antibodies in generalized seronegative myasthenia gravis. Brain 126, 2304-2311.

Eymard, B., Vernet-der Garabedian, B., Berrih-Aknin, S., Pannier, C., Bach, J.F., Morel, E., 1991. Anti-acetylcholine receptor antibodies in neonatal myasthenia gravis: heterogeneity and pathogenic significance. J Autoimmun 4, 185-195.

Farrugia, M.E., Kennett, R.P., Newsom-Davis, J., Hilton-Jones, D., Vincent, A., 2006. Single-fiber electromyography in limb and facial muscles in muscle-specific kinase antibody and acetylcholine receptor antibody myasthenia gravis. Muscle Nerve 33, 568-570.

Gautam, M., Noakes, P.G., Mudd, J., Nichol, M., Chu, G.C., Sanes, J.R., Merlie, J.P., 1995. Failure of postsynaptic specialization to develop at neuromuscular junctions of rapsyn-deficient mice. Nature 377, 232-236.

Gervasio, O.L., Phillips, W.D., 2005. Increased ratio of rapsyn to ACh receptor stabilizes postsynaptic receptors at the mouse neuromuscular synapse. J Physiol 562, 673-685.

Glass, D.J., Bowen, D.C., Stitt, T.N., Radziejewski, C., Bruno, J., Ryan, T.E., Gies, D.R., Shah, S., Mattsson, K., Burden, S.J., DiStefano, P.S., Valenzuela, D.M., DeChiara, T.M., Yancopoulos, G.D., 1996. Agrin acts via a MuSK receptor complex. Cell 85, 513-523.

Goldman, D., Staple, J., 1989. Spatial and temporal expression of acetylcholine receptor RNAs in innervated and denervated rat soleus muscle. Neuron 3, 219-228.

Gomez, C.M., Richman, D.P., 1983. Anti-acetylcholine receptor antibodies directed against the alpha-bungarotoxin binding site induce a unique form of experimental myasthenia. Proc Natl Acad Sci U S A 80, 4089-4093.

Grady, R.M., Merlie, J.P., Sanes, J.R., 1997. Subtle neuromuscular defects in utrophin-deficient mice. J Cell Biol 136, 871882.

Graus, Y.F., de Baets, M.H., Parren, P.W., Berrih-Aknin, S., Wokke, J., van Breda Vriesman, P.J., Burton, D.R., 1997. Human anti-nicotinic acetylcholine receptor recombinant Fab fragments isolated from thymus-derived phage display libraries from myasthenia gravis patients reflect predominant specificities in serum and block the action of pathogenic serum antibodies. J Immunol 158, 1919-1929.

Hesser, B.A., Henschel, O., Witzemann, V., 2006. Synapse disassembly and formation of new synapses in postnatal muscle upon conditional inactivation of MuSK. Mol Cell Neurosci 31, 470-480.

Hoch, W., McConville, J., Helms, S., Newsom-Davis, J., Melms, A., Vincent, A., 2001. Auto-antibodies to the receptor tyrosine kinase MuSK in patients with myasthenia gravis without acetylcholine receptor antibodies. Nat Med 7, 365-368.

Hoedemaekers, A.C., van Breda Vriesman, P.J., De Baets, M.H., 1997. Myasthenia gravis as a prototype autoimmune receptor disease. Immunol Res 16, 341-354.

Howard, F.M., Jr., Lennon, V.A., Finley, J., Matsumoto, J., Elveback, L.R., 1987. Clinical correlations of antibodies that bind, block, or modulate human acetylcholine receptors in myasthenia gravis. Ann N Y Acad Sci 505, 526-538.

Huard, J., Fortier, L.P., Labrecque, C., Dansereau, G., Tremblay, J.P., 1991. Is dystrophin present in the nerve terminal at the neuromuscular junction? An immunohistochemical study of the heterozygote dystrophic (mdx) mouse. Synapse 7, 135-140.

Ito, H., Yoshimura, T., Satoh, A., Takino, H., Tsujihata, M., Nagataki, S., 1996. Immunohistochemical study of utrophin and dystrophin at the motor end-plate in myasthenia gravis. Acta Neuropathol 92, 14-18.

Jessell, T.M., Siegel, R.E., Fischbach, G.D., 1979. Induction of acetylcholine receptors on cultured skeletal muscle by a factor extracted from brain and spinal cord. Proc Natl Acad Sci U S A 76, 5397-5401.

Jha, S., Xu, K., Maruta, T., Oshima, M., Mosier, D.R., Atassi, M.Z., Hoch, W., 2006. Myasthenia gravis induced in mice by immunization with the recombinant extracellular domain of rat muscle-specific kinase (MuSK). J Neuroimmunol 175, 107-117.

Johnson, E.B., Hammer, R.E., Herz, J., 2005. Abnormal development of the apical ectodermal ridge and polysyndactyly in Megf7-deficient mice. Hum Mol Genet 14, 3523-3538. 
Kao, I., Drachman, D.B., 1977. Myasthenic immunoglobulin accelerates acetylcholine receptor degradation. Science 196, 527-529.

Karachunski, P.I., Ostlie, N.S., Monfardini, C., Conti-Fine, B.M., 2000. Absence of IFN-gamma or IL-12 has different effects on experimental myasthenia gravis in C57BL/6 mice. J Immunol 164, 5236-5244.

Katz, B., Miledi, R., 1964. Further Observations on the Distribution of Actylcholine-Reactive Sites in Skeletal Muscle. J Physiol 170, 379-388.

Kawano, Y., Noma, T., 1996. Role of interleukin-2 and interferon-gamma in inducing production of IgG subclasses in lymphocytes of human newborns. Immunology 88, 40-48.

Kawano, Y., Noma, T., Yata, J., 1994. Regulation of human IgG subclass production by cytokines. IFN-gamma and IL-6 act antagonistically in the induction of human IgG1 but additively in the induction of IgG2. J Immunol 153, 49484958.

Kim, N., Stiegler, A.L., Cameron, T.O., Hallock, P.T., Gomez, A.M., Huang, J.H., Hubbard, S.R., Dustin, M.L., Burden, S.J., 2008. Lrp4 is a receptor for Agrin and forms a complex with MuSK. Cell 135, 334-342.

Kong, X.C., Barzaghi, P., Ruegg, M.A., 2004. Inhibition of synapse assembly in mammalian muscle in vivo by RNA interference. ЕMBO Rep 5, 183-188.

Kuwabara, S., Nemoto, Y., Misawa, S., Takahashi, H., Kawaguchi, N., Hattori, T., 2007. Anti-MuSK-positive myasthenia gravis: neuromuscular transmission failure in facial and limb muscles. Acta Neurol Scand 115, 126-128.

Lagoumintzis, G., Zisimopoulou, P., Kordas, G., Lazaridis, K., Poulas, K., Tzartos, S.J., 2010. Recent approaches to the development of antigen-specific immunotherapies for myasthenia gravis. Autoimmunity 43, 436-445.

Le Panse, R., Bismuth, J., Cizeron-Clairac, G., Weiss, J.M., Cufi, P., Dartevelle, P., De Rosbo, N.K., Berrih-Aknin, S., 2010. Thymic remodeling associated with hyperplasia in myasthenia gravis. Autoimmunity 43, 401-412.

Lefvert, A.K., Cuenoud, S., Fulpius, B.W., 1981. Binding properties and subclass distribution of anti-acetylcholine receptor antibodies in myasthenia gravis. J Neuroimmunol 1, 125-135.

Leite, M.I., Jacob, S., Viegas, S., Cossins, J., Clover, L., Morgan, B.P., Beeson, D., Willcox, N., Vincent, A., 2008. IgG1 antibodies to acetylcholine receptors in 'seronegative' myasthenia gravis. Brain 131, 1940-1952.

Leite, M.I., Strobel, P., Jones, M., Micklem, K., Moritz, R., Gold, R., Niks, E.H., Berrih-Aknin, S., Scaravilli, F., Canelhas, A., Marx, A., Newsom-Davis, J., Willcox, N., Vincent, A., 2005. Fewer thymic changes in MuSK antibody-positive than in MuSK antibody-negative MG. Ann Neurol 57, 444-448.

Leite, M.I., Waters, P., Vincent, A., 2010. Diagnostic use of autoantibodies in myasthenia gravis. Autoimmunity 43, 371379.

Lennon, V.A., Lindstrom, J.M., Seybold, M.E., 1975. Experimental autoimmune myasthenia: A model of myasthenia gravis in rats and guinea pigs. J Exp Med 141, 1365-1375.

Lennon, V.A., Seybold, M.E., Lindstrom, J.M., Cochrane, C., Ulevitch, R., 1978. Role of complement in the pathogenesis of experimental autoimmune myasthenia gravis. J Exp Med 147, 973-983.

Lindstrom, J.M., Engel, A.G., Seybold, M.E., Lennon, V.A., Lambert, E.H., 1976a. Pathological mechanisms in experimental autoimmune myasthenia gravis. II. Passive transfer of experimental autoimmune myasthenia gravis in rats with anti-acetylcholine recepotr antibodies. J Exp Med 144, 739-753.

Lindstrom, J.M., Seybold, M.E., Lennon, V.A., Whittingham, S., Duane, D.D., 1976b. Antibody to acetylcholine receptor in myasthenia gravis. Prevalence, clinical correlates, and diagnostic value. Neurology 26, 1054-1059.

Linnoila, J., Wang, Y., Yao, Y., Wang, Z.Z., 2008. A mammalian homolog of Drosophila tumorous imaginal discs, Tid1, mediates agrin signaling at the neuromuscular junction. Neuron 60, 625-641.

Losen, M., Martinez-Martinez, P., Phernambucq, M., Schuurman, J., Parren, P.W., De Baets, M.H., 2008. Treatment of myasthenia gravis by preventing acetylcholine receptor modulation. Ann N Y Acad Sci 1132, 174-179.

Losen, M., Stassen, M.H., Martinez-Martinez, P., Machiels, B.M., Duimel, H., Frederik, P., Veldman, H., Wokke, J.H., Spaans, F., Vincent, A., De Baets, M.H., 2005. Increased expression of rapsyn in muscles prevents acetylcholine receptor loss in experimental autoimmune myasthenia gravis. Brain 128, 2327-2337.

Luo, J., Taylor, P., Losen, M., de Baets, M.H., Shelton, G.D., Lindstrom, J., 2009. Main immunogenic region structure promotes binding of conformation-dependent myasthenia gravis autoantibodies, nicotinic acetylcholine receptor conformation maturation, and agonist sensitivity. J Neurosci 29, 13898-13908. 
Luo, S., Zhang, B., Dong, X.P., Tao, Y., Ting, A., Zhou, Z., Meixiong, J., Luo, J., Chiu, F.C., Xiong, W.C., Mei, L., 2008. HSP90 beta regulates rapsyn turnover and subsequent AChR cluster formation and maintenance. Neuron 60, 97-110.

Martinez-Martinez, P., Losen, M., Duimel, H., Frederik, P., Spaans, F., Molenaar, P., Vincent, A., De Baets, M.H., 2007. Overexpression of rapsyn in rat muscle increases acetylcholine receptor levels in chronic experimental autoimmune myasthenia gravis. Am J Pathol 170, 644-657.

Martinez-Martinez, P., Phernambucq, M., Steinbusch, L., Schaeffer, L., Berrih-Aknin, S., Duimel, H., Frederik, P., Molenaar, P., De Baets, M.H., Losen, M., 2009. Silencing rapsyn in vivo decreases acetylcholine receptors and augments sodium channels and secondary postsynaptic membrane folding. Neurobiol Dis 35, 14-23.

Marx, A., Willcox, N., Leite, M.I., Chuang, W.Y., Schalke, B., Nix, W., Strobel, P., 2010. Thymoma and paraneoplastic myasthenia gravis. Autoimmunity 43, 413-427.

Maselli, R.A., Ng, J.J., Anderson, J.A., Cagney, O., Arredondo, J., Williams, C., Wessel, H.B., Abdel-Hamid, H., Wollmann, R.L., 2009. Mutations in LAMB2 causing a severe form of synaptic congenital myasthenic syndrome. J Med Genet 46, 203-208.

McConville, J., Farrugia, M.E., Beeson, D., Kishore, U., Metcalfe, R., Newsom-Davis, J., Vincent, A., 2004. Detection and characterization of MuSK antibodies in seronegative myasthenia gravis. Ann Neurol 55, 580-584

Moiola, L., Galbiati, F., Martino, G., Amadio, S., Brambilla, E., Comi, G., Vincent, A., Grimaldi, L.M., Adorini, L., 1998. IL-12 is involved in the induction of experimental autoimmune myasthenia gravis, an antibody-mediated disease. Eur J Immunol 28, 2487-2497.

Molenaar, P.C., Polak, R.L., Miledi, R., Alema, S., Vincent, A., Newsom-Davis, J., 1979. Acetylcholine in intercostal muscle from myasthenia gravis patients and in rat diaphragm after blockade of acetylcholine receptors. Prog Brain Res 49, 449-458.

Moransard, M., Borges, L.S., Willmann, R., Marangi, P.A., Brenner, H.R., Ferns, M.J., Fuhrer, C., 2003. Agrin regulates rapsyn interaction with surface acetylcholine receptors, and this underlies cytoskeletal anchoring and clustering. J Biol Chem 278, 7350-7359.

Morel, E., Eymard, B., Vernet-der Garabedian, B., Pannier, C., Dulac, O., Bach, J.F., 1988. Neonatal myasthenia gravis: a new clinical and immunologic appraisal on 30 cases. Neurology 38, 138-142.

Mozrzymas, J.W., Lorenzon, P., Riviera, A.P., Tedesco, F., Ruzzier, F., 1993. An electrophysiological study of the effects of myasthenia gravis sera and complement on rat isolated muscle fibres. J Neuroimmunol 45, 155-162.

Newsom-Davis, J., Wilson, S.G., Vincent, A., Ward, C.D., 1979. Long-term effects of repeated plasma exchange in myasthenia gravis. Lancet 1, 464-468.

Niks, E.H., Verrips, A., Semmekrot, B.A., Prick, M.J., Vincent, A., van Tol, M.J., Jol-van der Zijde, C.M., Verschuuren, J.J., 2008. A transient neonatal myasthenic syndrome with anti-musk antibodies. Neurology 70, 1215-1216.

Noakes, P.G., Gautam, M., Mudd, J., Sanes, J.R., Merlie, J.P., 1995. Aberrant differentiation of neuromuscular junctions in mice lacking s-laminin/laminin beta 2 . Nature 374, 258-262.

Okada, K., Inoue, A., Okada, M., Murata, Y., Kakuta, S., Jigami, T., Kubo, S., Shiraishi, H., Eguchi, K., Motomura, M., Akiyama, T., Iwakura, Y., Higuchi, O., Yamanashi, Y., 2006. The muscle protein Dok-7 is essential for neuromuscular synaptogenesis. Science 312, 1802-1805.

Ostlie, N., Milani, M., Wang, W., Okita, D., Conti-Fine, B.M., 2003. Absence of IL-4 facilitates the development of chronic autoimmune myasthenia gravis in C57BL/6 mice. J Immunol 170, 604-612.

Palace, J., Beeson, D., 2008. The congenital myasthenic syndromes. J Neuroimmunol 201-202, 2-5.

Papanastasiou, D., Poulas, K., Kokla, A., Tzartos, S.J., 2000. Prevention of passively transferred experimental autoimmune myasthenia gravis by Fab fragments of monoclonal antibodies directed against the main immunogenic region of the acetylcholine receptor. J Neuroimmunol 104, 124-132.

Papazian, O., 1992. Transient neonatal myasthenia gravis. J Child Neurol 7, 135-141.

Patrick, J., Lindstrom, J., 1973. Autoimmune response to acetylcholine receptor. Science 180, 871-872.

Petersen, J.G., Dorrington, K.J., 1974. An in vitro system for studying the kinetics of interchain disulfide bond formation in immunoglobulin G. J Biol Chem 249, 5633-5641.

Phillips, W.D., Noakes, P.G., Roberds, S.L., Campbell, K.P., Merlie, J.P., 1993. Clustering and immobilization of acetylcholine receptors by the $43-\mathrm{kD}$ protein: a possible role for dystrophin-related protein. J Cell Biol 123, 729740. 
Phillips, W.D., Vladeta, D., Han, H., Noakes, P.G., 1997. Rapsyn and agrin slow the metabolic degradation of the acetylcholine receptor. Mol Cell Neurosci 10, 16-26.

Piddlesden, S.J., Jiang, S., Levin, J.L., Vincent, A., Morgan, B.P., 1996. Soluble complement receptor 1 (sCR1) protects against experimental autoimmune myasthenia gravis. J Neuroimmunol 71, 173-177.

Plomp, J.J., Van Kempen, G.T., De Baets, M.B., Graus, Y.M., Kuks, J.B., Molenaar, P.C., 1995. Acetylcholine release in myasthenia gravis: regulation at single end-plate level. Ann Neurol 37, 627-636.

Pumplin, D.W., Drachman, D.B., 1983. Myasthenic patients' IgG causes redistribution of acetylcholine receptors: freezefracture studies. J Neurosci 3, 576-584.

Richman, D.P., Gomez, C.M., Berman, P.W., Burres, S.A., Fitch, F.W., Arnason, B.G., 1980. Monoclonal anti-acetylcholine receptor antibodies can cause experimental myasthenia. Nature 286, 738-739.

Rodgaard, A., Nielsen, F.C., Djurup, R., Somnier, F., Gammeltoft, S., 1987. Acetylcholine receptor antibody in myasthenia gravis: predominance of IgG subclasses 1 and 3. Clin Exp Immunol 67, 82-88.

Romi, F., Skeie, G.O., Gilhus, N.E., Aarli, J.A., 2005. Striational antibodies in myasthenia gravis: reactivity and possible clinical significance. Arch Neurol 62, 442-446.

Rybakova, I.N., Humston, J.L., Sonnemann, K.J., Ervasti, J.M., 2006. Dystrophin and utrophin bind actin through distinct modes of contact. J Biol Chem 281, 9996-10001.

Sahashi, K., Engel, A.G., Lambert, E.H., Howard, F.M., Jr., 1980. Ultrastructural localization of the terminal and lytic ninth complement component (C9) at the motor end-plate in myasthenia gravis. J Neuropathol Exp Neurol 39, 160-172.

Sanders, D.B., Evoli, A., 2010. Immunosuppressive therapies in myasthenia gravis. Autoimmunity 43, 428-435.

Saoudi, A., Bernard, I., Hoedemaekers, A., Cautain, B., Martinez, K., Druet, P., De Baets, M., Guery, J.C., 1999. Experimental autoimmune myasthenia gravis may occur in the context of a polarized Th1- or Th2-type immune response in rats. J Immunol 162, 7189-7197.

Saoudi, A., Kuhn, J., Huygen, K., de Kozak, Y., Velu, T., Goldman, M., Druet, P., Bellon, B., 1993. Role of the TH1-TH2 balance in the development of autoimmunity in rats. Transplant Proc 25, 2824-2825.

Sarkar, S., Pollack, B.P., Lin, K.T., Kotenko, S.V., Cook, J.R., Lewis, A., Pestka, S., 2001. hTid-1, a human DnaJ protein, modulates the interferon signaling pathway. J Biol Chem 276, 49034-49042.

Schaeffer, L., de Kerchove d'Exaerde, A., Changeux, J.P., 2001. Targeting transcription to the neuromuscular synapse. Neuron 31, 15-22.

Schuurman, J., Van Ree, R., Perdok, G.J., Van Doorn, H.R., Tan, K.Y., Aalberse, R.C., 1999. Normal human immunoglobulin G4 is bispecific: it has two different antigen-combining sites. Immunology 97, 693-698.

Selcen, D., Fukuda, T., Shen, X.M., Engel, A.G., 2004. Are MuSK antibodies the primary cause of myasthenic symptoms? Neurology 62, 1945-1950.

Shelton, G.D., 1999. Acquired myasthenia gravis: what we have learned from experimental and spontaneous animal models. Vet Immunol Immunopathol 69, 239-249.

Shelton, G.D., Schule, A., Kass, P.H., 1997. Risk factors for acquired myasthenia gravis in dogs: 1,154 cases (1991-1995). J Am Vet Med Assoc 211, 1428-1431.

Shigemoto, K., Kubo, S., Maruyama, N., Hato, N., Yamada, H., Jie, C., Kobayashi, N., Mominoki, K., Abe, Y., Ueda, N., Matsuda, S., 2006. Induction of myasthenia by immunization against muscle-specific kinase. J Clin Invest 116, 1016-1024.

Shiono, H., Wong, Y.L., Matthews, I., Liu, J.L., Zhang, W., Sims, G., Meager, A., Beeson, D., Vincent, A., Willcox, N., 2003. Spontaneous production of anti-IFN-alpha and anti-IL-12 autoantibodies by thymoma cells from myasthenia gravis patients suggests autoimmunization in the tumor. Int Immunol 15, 903-913.

Shiraishi, H., Motomura, M., Yoshimura, T., Fukudome, T., Fukuda, T., Nakao, Y., Tsujihata, M., Vincent, A., Eguchi, K., 2005. Acetylcholine receptors loss and postsynaptic damage in MuSK antibody-positive myasthenia gravis. Ann Neurol 57, 289-293.

Slater, C.R., Young, C., Wood, S.J., Bewick, G.S., Anderson, L.V., Baxter, P., Fawcett, P.R., Roberts, M., Jacobson, L., Kuks, J., Vincent, A., Newsom-Davis, J., 1997. Utrophin abundance is reduced at neuromuscular junctions of patients with both inherited and acquired acetylcholine receptor deficiencies. Brain 120 ( Pt 9), 1513-1531.

Song, Y., Balice-Gordon, R., 2008. New dogs in the dogma: Lrp4 and Tid1 in neuromuscular synapse formation. Neuron 60, 526-528. 
Souroujon, M.C., Brenner, T., Fuchs, S., 2010. Development of novel therapies for MG: Studies in animal models. Autoimmunity $43,446-460$.

Stanley, E.F., Drachman, D.B., 1978. Effect of myasthenic immunoglobulin on acetylcholine receptors of intact mammalian neuromuscular junctions. Science 200, 1285-1287.

Sterz, R., Hohlfeld, R., Rajki, K., Kaul, M., Heininger, K., Peper, K., Toyka, K.V., 1986. Effector mechanisms in myasthenia gravis: end-plate function after passive transfer of IgG, Fab, and $F\left(a b^{\prime}\right) 2$ hybrid molecules. Muscle Nerve 9, 306312.

Stickler, D.E., Massey, J.M., Sanders, D.B., 2005. MuSK-antibody positive myasthenia gravis: clinical and electrodiagnostic patterns. Clin Neurophysiol 116, 2065-2068.

Takeo, G., Motomura, M., Mats, H., Ohishi, K., Yoshimura, T., Tsujihata, M., Nagataki, S., 1993. Effect of myasthenic IgG on degradation of junctional acetylcholine receptor. Muscle Nerve 16, 840-848.

Tan, L.K., Shopes, R.J., Oi, V.T., Morrison, S.L., 1990. Influence of the hinge region on complement activation, C1q binding, and segmental flexibility in chimeric human immunoglobulins. Proc Natl Acad Sci U S A 87, 162-166.

Tanaka, H., Ishiguro, T., Eguchi, C., Saito, K., Ozawa, E., 1991. Expression of a dystrophin-related protein associated with the skeletal muscle cell membrane. Histochemistry 96, 1-5.

Tao, M.H., Canfield, S.M., Morrison, S.L., 1991. The differential ability of human IgG1 and IgG4 to activate complement is determined by the $\mathrm{COOH}$-terminal sequence of the $\mathrm{CH} 2$ domain. J Exp Med 173, 1025-1028.

Tarrab-Hazdai, R., Aharonov, A., Silman, I., Fuchs, S., Abramsky, O., 1975. Experimental autoimmune myasthenia induced in monkeys by purified acetylcholine receptor. Nature 256, 128-130.

Tarunina, M., Alger, L., Chu, G., Munger, K., Gudkov, A., Jat, P.S., 2004. Functional genetic screen for genes involved in senescence: role of Tid1, a homologue of the Drosophila tumor suppressor I(2)tid, in senescence and cell survival. Mol Cell Biol 24, 10792-10801.

ter Beek, W.P., Martinez-Martinez, P., Losen, M., de Baets, M.H., Wintzen, A.R., Verschuuren, J.J., Niks, E.H., van Duinen, S.G., Vincent, A., Molenaar, P.C., 2009. The effect of plasma from muscle-specific tyrosine kinase myasthenia patients on regenerating endplates. Am J Pathol 175, 1536-1544.

Tian, Q.B., Suzuki, T., Yamauchi, T., Sakagami, H., Yoshimura, Y., Miyazawa, S., Nakayama, K., Saitoh, F., Zhang, J.P., Lu, Y., Kondo, H., Endo, S., 2006. Interaction of LDL receptor-related protein 4 (LRP4) with postsynaptic scaffold proteins via its C-terminal PDZ domain-binding motif, and its regulation by Ca/calmodulin-dependent protein kinase II. Eur J Neurosci 23, 2864-2876.

Tinsley, J.M., Blake, D.J., Roche, A., Fairbrother, U., Riss, J., Byth, B.C., Knight, A.E., Kendrick-Jones, J., Suthers, G.K., Love, D.R., et al., 1992. Primary structure of dystrophin-related protein. Nature 360, 591-593.

Toyka, K.V., Brachman, D.B., Pestronk, A., Kao, I., 1975. Myasthenia gravis: passive transfer from man to mouse. Science 190, 397-399.

Toyka, K.V., Lowenadler, B., Heininger, K., Besinger, U.A., Birnberger, K.L., Fateh-Moghadam, A., Heilbronn, E., 1980. Passively transferred myasthenia gravis: protection of mouse endplates by Fab fragments from human myasthenic IgG. J Neurol Neurosurg Psychiatry 43, 836-842.

Trentin, G.A., Yin, X., Tahir, S., Lhotak, S., Farhang-Fallah, J., Li, Y., Rozakis-Adcock, M., 2001. A mouse homologue of the Drosophila tumor suppressor I(2)tid gene defines a novel Ras GTPase-activating protein (RasGAP)-binding protein. J Biol Chem 276, 13087-13095.

Tzartos, S.J., Sophianos, D., Efthimiadis, A., 1985. Role of the main immunogenic region of acetylcholine receptor in myasthenia gravis. An Fab monoclonal antibody protects against antigenic modulation by human sera. J Immunol 134, 2343-2349.

van der Neut Kolfschoten, M., Schuurman, J., Losen, M., Bleeker, W.K., Martinez-Martinez, P., Vermeulen, E., den Bleker, T.H., Wiegman, L., Vink, T., Aarden, L.A., De Baets, M.H., van de Winkel, J.G., Aalberse, R.C., Parren, P.W., 2007. Anti-inflammatory activity of human IgG4 antibodies by dynamic Fab arm exchange. Science 317, 1554-1557.

van der Zee, J.S., van Swieten, P., Aalberse, R.C., 1986. Inhibition of complement activation by IgG4 antibodies. Clin Exp Immunol 64, 415-422.

Vernet-der Garabedian, B., Lacokova, M., Eymard, B., Morel, E., Faltin, M., Zajac, J., Sadovsky, O., Dommergues, M., Tripon, P., Bach, J.F., 1994. Association of neonatal myasthenia gravis with antibodies against the fetal acetylcholine receptor. J Clin Invest 94, 555-559. 
Vincent, A., Leite, M.I., 2005. Neuromuscular junction autoimmune disease: muscle specific kinase antibodies and treatments for myasthenia gravis. Curr Opin Neurol 18, 519-525.

Vincent, A., Newsom-Davis, J., 1982. Acetylcholine receptor antibody characteristics in myasthenia gravis. I. Patients with generalized myasthenia or disease restricted to ocular muscles. Clin Exp Immunol 49, 257-265.

Vrolix, K., Fraussen, J., Molenaar, P.C., Losen, M., Somers, V., Stinissen, P., De Baets, M.H., Martinez-Martinez, P., 2010. The auto-antigen repertoire in myasthenia gravis. Autoimmunity 43, 380-400.

Wang, Z.Z., Mathias, A., Gautam, M., Hall, Z.W., 1999. Metabolic stabilization of muscle nicotinic acetylcholine receptor by rapsyn. J Neurosci 19, 1998-2007.

Weatherbee, S.D., Anderson, K.V., Niswander, L.A., 2006. LDL-receptor-related protein 4 is crucial for formation of the neuromuscular junction. Development 133, 4993-5000.

Whiting, P.J., Vincent, A., Newsom-Davis, J., 1983. Acetylcholine receptor antibody characteristics in myasthenia gravis. Fractionation of alpha-bungarotoxin binding site antibodies and their relationship to IgG subclass. J Neuroimmunol 5, 1-9.

Wood, S.J., Slater, C.R., 2001. Safety factor at the neuromuscular junction. Prog Neurobiol 64, 393-429.

Yin, X., Rozakis-Adcock, M., 2001. Genomic organization and expression of the human tumorous imaginal disc (TID1) gene. Gene 278, 201-210.

Zhang, B., Luo, S., Wang, Q., Suzuki, T., Xiong, W.C., Mei, L., 2008. LRP4 serves as a coreceptor of agrin. Neuron 60, 285297.

Zhang, G.X., Xiao, B.G., Yu, L.Y., van der Meide, P.H., Link, H., 2001. Interleukin 10 aggravates experimental autoimmune myasthenia gravis through inducing Th2 and B cell responses to AChR. J Neuroimmunol 113, 10-18.

Zhang, K., 2003. Accessibility control and machinery of immunoglobulin class switch recombination. J Leukoc Biol 73, 323-332.

Zhang, Y., Yan, Z., Farooq, A., Liu, X., Lu, C., Zhou, M.M., He, C., 2004. Molecular basis of distinct interactions between Dok1 PTB domain and tyrosine-phosphorylated EGF receptor. J Mol Biol 343, 1147-1155. 


\section{Chapter}

A novel method for making

human monoclonal antibodies

Fraussen J, Vrolix K, Martinez-Martinez P, Losen M, Meulemans E, De Baets MH, Stinissen

$\mathrm{P}$ and Somers V

Published in: Journal of Autoimmunity 2010, 35 (2), 130-4. 


\section{Abstract}

We have developed a B cell immortalization method for low B cell numbers per well using simultaneous B cell stimulation by CpG2006 and B cell infection by Epstein-Barr virus (EBV), followed by an additional CpG2006 and interleukin-2 (IL-2) stimulus. Using this method, immunoglobulin $G$ (IgG) producing immortalized B cell lines were generated from peripheral blood $\operatorname{IgG}^{+} \mathrm{CD} 22^{+}$B cells with an efficiency of up to $83 \%$. Antibody can already be obtained from the culture supernatant after 3-4 weeks. Moreover, clonality analysis demonstrated monoclonality in $87 \%$ of the resulting immortalized B cell lines. Given the high immortalization efficiency and monoclonality rate, evidence is provided that no further subcloning is necessary. An important application of this B cell immortalization method is the characterization of (autoreactive) antibodies from patients with autoimmune disease. This could eventually lead to the identification of new autoantigens, disease markers or targets for therapy. 


\section{Introduction}

B cell immortalization by Epstein-Barr virus (EBV) is an established method for antibody production. EBV infects B cells via their CD21 receptor (Martin et al., 1994) and subsequently transforms them into continually dividing, lymphoblastoid cell lines that produce antibodies representing the humoral immune response in vivo. Antibodies can be generated against an infectious agent or tumour cells, rendering the resulting antibodies attractive for therapy. In addition, B cell immortalization can be a valuable tool for the production and characterization of autoreactive antibodies from patients with autoimmune diseases. This can provide more insight into the underlying mechanisms of humoral immune responses in autoimmunity and can lead to the identification of new autoantigens, disease markers or targets for therapy (Govarts et al., 2009; Somers et al., 2009; Somers et al., 2008). The major advantage of B cell immortalization, when compared to other antibody producing techniques (Carter, 2006; Kohler and Milstein, 1975; Levy and Dilley, 1978; McCafferty et al., 1990; Meijer et al., 2006; Olsson and Kaplan, 1980), is the generation of fully human antibodies that truly reflect both the specificity and diversity of the human immune response, generated from the human $B$ cell repertoire, without the need for specific immunization.

The original B cell immortalization technology, first described in 1977, was performed by culturing $B$ cells in the presence of EBV, obtained from the marmoset lymphocyte cell line B95-8 (Rosen et al., 1977; Steinitz et al., 1977). The resulting immortalized B cell lines were mainly unstable immunoglobulin $\mathrm{M}$ (IgM) producing clones with low affinity. Various adjustments to the procedure have been tried since then, but immortalization and $B$ cell growth rate remained inefficient. More recently, antibodies neutralizing SARS coronavirus and cytomegalovirus (CMV) were produced successfully by the introduction of the polyclonal B cell activator CpG2006 in the B cell immortalization process or by B cell activation prior to EBV infection, respectively (Funaro et al., 2008; Traggiai et al., 2004). In our hands, these methods resulted in a low reproducibility. The current study was aimed at developing a B cell immortalization procedure with a high efficiency and reproducibility when seeding low B cell numbers per well, that could easily be adopted for the production of (autoreactive) antibodies from patients with autoimmune disease. Such a method can be especially advantageous when autoreactive B cells are not easily available, for example in the cerebrospinal fluid (CSF) of multiple sclerosis (MS) patients or the synovial fluid of rheumatoid arthritis (RA) patients. Moreover, seeding low B cell numbers per well limits the bias towards the preferential outgrowth of fast growing immortalized B cells. 


\section{Materials and methods}

\section{B cell immortalization procedure}

Peripheral blood from healthy donors was obtained with informed consent. Peripheral blood mononuclear cells (PBMC) were isolated by Ficoll Hypaque density gradient centrifugation (Sigma-Aldrich). To isolate $\operatorname{IgG}^{+} \mathrm{CD} 22^{+} \mathrm{B}$ cells, $\mathrm{PBMC}$ were stained with $\mathrm{PE}-$ Cy5-labelled anti-CD22 antibodies (Ab) and PE-labelled anti-IgG Ab for 30 min at $4^{\circ} \mathrm{C}$ and subsequently enriched by means of FACS sorting using a FACSAria II cell sorter (all from BD Biosciences). The FACS sorted cells were immediately used for B cell immortalization assays. $\operatorname{IgG}^{+} \mathrm{CD} 22^{+} \mathrm{B}$ cells were cultured in U-bottom 96-well plates (Nunc) at 50 cells per well in RPMI 1640 medium supplemented with L-glutamine, $10 \mathrm{mM}$ HEPES buffer, $1 \mathrm{mM}$ sodium pyruvate, $50 \mathrm{U} / \mathrm{ml}$ penicillin, $50 \mu \mathrm{g} / \mathrm{ml}$ streptomycin (all from Invitrogen Life Technologies) and $10 \%$ heat-inactivated fetal bovine serum (FBS, HyClone). All immortalization experiments were started in 30 wells for each tested condition. The isolated B cells were immortalized during 2 weeks in the presence of $1 \times 10^{5}$ autologous irradiated (83 Gy) feeder cells, 30\% v/v EBV-containing supernatant $\left(3.4 \times 10^{8}\right.$ viral copies/ml) of the B95-8 cell line (ATCC) and $1 \mu \mathrm{g} / \mathrm{ml} \mathrm{CpG2006}$ (ODN2006, 5'tcgtcgttttgtcgttttgtcgtt-3', InvivoGen) (Fig. 1). Next, cells were restimulated during 7 days

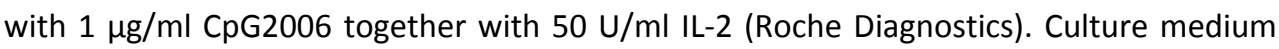
was then replaced and cells were continuously cultured without extra stimuli. Immortalization was verified 28 days after seeding by screening the culture supernatant for antibody production using dot blot analysis and by light microscopic examination of cell growth. Both parameters were included since positive antibody measurements were sometimes observed in the absence of B cell growth, due to B cell activation at the start of the culture.

\section{Dot blot analysis for antibody production}

Culture supernatant $(5 \mu \mathrm{l})$ of potentially immortalized B cells was spotted on a nitrocellulose blotting membrane (Protran BA-85, VWR International). After drying, blots were blocked with $5 \%(\mathrm{w} / \mathrm{v})$ non-fat dry milk (NFDM) in PBS (blocking buffer) during 30 min on a shaker. Membranes were then incubated for 1 hour with HRP-labelled rabbit anti-human IgG (Dako) $1 / 100$ in blocking buffer and extensively washed in PBS supplemented with $0.05 \%(\mathrm{v} / \mathrm{v})$ Triton X-100. Antibody production was detected using $3,3^{\prime}$ deaminobenzidine (DAB) substrate (Sigma-Aldrich). Serial dilutions of human IgG (Zymed, Invitrogen) ranging from $500 \mu \mathrm{g} / \mathrm{ml}$ to $0.5 \mu \mathrm{g} / \mathrm{ml}$ were included as a positive control. Culture medium was used as a negative control. 


\section{Isolation of $\operatorname{lgG}{ }^{+} \mathrm{CD} 22^{+}$cells by FACS sorting}

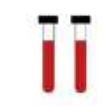

PBMC

$\downarrow$

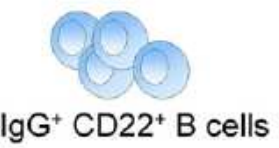

$\downarrow$

$50 \mathrm{~B}$ cells

100,000 feeder cells

$1 \mu \mathrm{g} / \mathrm{ml} \mathrm{CpG2006}$

$30 \% \mathrm{v} / \mathrm{V} \mathrm{EBV}$

- EBV

B cell

3. Restimulation

Day 14 Addition of $1 \mu \mathrm{g} / \mathrm{ml} \mathrm{CpG} 2006$ and $50 \mathrm{U} / \mathrm{ml} \mathrm{IL-2}$

Day 21

Further culture without stimuli

4. Verification of $B$ cell
immortalization

Day 28
Dot blot analysis for $\mathrm{Ab}$ production and examination of cell growth

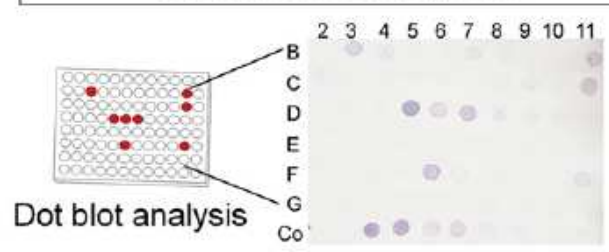

Figure 1. B cell immortalization procdure. $\operatorname{IgG}^{+} C D 22^{+} \mathrm{B}$ cells are isolated from PBMC by FACS sorting (1) and thereafter immortalized using simultaneous B cell stimulation and infection. B cells are cultured during 2 weeks in microtiter plates at 50 cells per well in the presence of $1 \times 10^{5}$ autologous irradiated feeder cells, $1 \mu \mathrm{g} / \mathrm{ml}$ CpG2006 and 30\% v/v EBV containing supernatant of the B95-8 cell line (2). After this immortalization phase, the cells are restimulated during 1 week with $1 \mu \mathrm{g} / \mathrm{ml} \mathrm{CpG2006}$ in combination with $50 \mathrm{U} / \mathrm{ml} \mathrm{IL}-2$ (3). The culture medium is then replaced and cultures are continued without the addition of stimuli for 1 week. Immortalization status is verified after 28 days of culture by performing dot blot analysis for antibody production and by light microscopic examination of cell growth (4). 
Table I. Sequences of VH and J gene-specific primers.

\begin{tabular}{ll}
\hline Target region & Sequence \\
\hline VH1-FR1 & 5' GGCCTCAGTGAAGGTCTCCTGCAAG 3' \\
VH2-FR1 & 5' GTCTGGTCCTACGCTGGTGAAACCC 3' \\
VH3-FR1 & 5' CTGGGGGGTCCCTGAGACTCTCCTG 3' \\
VH4-FR1 & 5' CTTCGGAGACCCTGTCCCTCACCTG 3' \\
VH5-FR1 & 5' CGGGGAGTCTCTGAAGATCTCCTGT 3' \\
VH6-FR1 & 5' TCGCAGACCCTCTCACTCACCTGTG 3' \\
\hline VH1-FR2 & 5' CTGGTGCGACAGGCCCCTGGACAA 3' \\
VH2-FR2 & 5' TGGATCCGTCAGCCCCCAGGGAAGG 3' \\
VH3-FR2 & 5' GGTCCGCCAGGCTCCAGGAA 3' \\
VH4-FR2 & 5' TGGATCCGCCAGCCCCCAGGAAGG 3' \\
VH5-FR2 & 5' GGGTGCGCCAGATGCCCGGGAAAGG 3' \\
VH6-FR2 & 5' TGGATCAGGCAGTCCCCATCGAGAG 3' \\
VH7-FR2 & 5' TTGGGTGCGACAGGCCCCTGGACAA 3' \\
\hline VH1-FR3 & 5' TGGAGCTGAGCAGCCTGAGATCTGA 3' \\
VH2-FR3 & 5' CAATGACCAACATGGACCCTGTGGA 3' \\
VH3-FR3 & 5' TCTGCAAATGAACAGCCTGAGAGCC 3' \\
VH4-FR3 & 5' GAGCTCTGTGACCGCCGCGGACACG 3' \\
VH5-FR3 & 5' CAGCACCGCCTACCTGCAGTGGAGC 3' \\
VH6-FR3 & 5' GTTCTCCCTGCAGCTGAACTCTGTG 3' \\
VH7-FR3 & 5' CAGCACGGCATATCTGCAGATCAG 3' \\
J 5' CTTACCTGAGGAGACGGTGACC 3' \\
\hline
\end{tabular}

\section{B cell spectratyping}

B cell spectratyping was performed on 34 randomly selected B cell lines to determine monoclonality rates of the resulting immortalized B cell populations. Genomic DNA was isolated from immortalized antibody-producing and growth-positive $B$ cells present in single wells. The variable region of the $B$ cell receptor heavy chain $(\mathrm{HC})$ locus was amplified from 100 ng DNA using the IdentiClone ${ }^{\mathrm{TM}}$ IGH Gene Clonality Assay (Invivoscribe Technologies) according to the manufacturer's recommendations. This standardized assay was extensively validated using Revised European/American Lymphoma (REAL) Classification (van Dongen et al., 2003). Primers that target the conserved framework regions (FR) were used in combination with a FAM-labelled consensus primer targeting the conserved joining region $(\mathrm{J})$ in order to amplify the variable region in which genetic rearrangements occur during B cell development. The B cell receptor genes are highly polymorphic and subject to diversity and mutations. To maximize identification of the clonal rearrangements, a polymerase chain reaction (PCR) was performed for each FR using VH family-specific forward primers (Table 1). Analysis of the resulting fragments was 
accomplished using automatic capillary electrophoresis (ABI3730, Applied Biosystems). Polyclonal populations resulted in a Gaussian distribution of amplification products with different lengths, while a monoclonal population yielded a single amplification product. This spectratyping procedure can detect clonal populations with a sensitivity of $0.5-5 \%$.

\section{Statistics}

All statistical analyses were performed using Prism software version 4.00 (Graphpad). We analyzed the data using unpaired Student's t-test. A $p$ value of $<0.05$ was considered statistically significant.

\section{Results and discussion}

An improved $B$ cell immortalization method was developed for the fast generation of IgGproducing $\mathrm{B}$ cell lines from $\operatorname{IgG}^{+} \mathrm{CD} 22^{+}$peripheral blood $\mathrm{B}$ cells. This procedure is characterized by simultaneous B cell stimulation by CpG2006 and B cell infection by EBV during 2 weeks at 50 cells per well (Fig. 1). After this immortalization phase, the cells are restimulated during 7 days by CpG2006 and IL-2.

FACS sorting for the isolation of $\operatorname{lgG}^{+} \mathrm{CD} 22^{+}$cells resulted in the highest yield $(1.4 \mathrm{x}$ $10^{4}$ cells out of $\left.1 \times 10^{7} \mathrm{PBMC}\right)$, purity (>99\%) and immortalization efficiency (83\%, donor 3 in Fig. 2a) when compared to magnetic selection alone or in combination with FACS sorting (data not shown). No $\operatorname{IgM}^{+}$immortalized B cell lines were recovered after FACS sorting, although several $\operatorname{IgM}^{+}$wells could be found after magnetic selection. Consequently, $\operatorname{lgG}^{+} \mathrm{CD} 22^{+}$FACS sorting was proven to be the best choice for $\operatorname{lgG}^{+} \mathrm{B}$ cell isolation prior to $B$ cell immortalization. This enrichment of $\operatorname{lgG}^{+} B$ cells before immortalization was performed to select for IgG-producing immortalized B cell lines. Autoantibodies of the IgG isotype are mostly implicated in the pathogenesis of autoimmune diseases. For example, oligoclonal IgG bands (OCB) have been described in the CSF of patients with MS and are used as a diagnostic indicator (Cross et al., 2001; Kabat et al., 1948). In several autoimmune diseases, including myasthenia gravis (MG) (Graus et al., 1997; Vrolix et al., 2010), systemic lupus erythematosus (SLE) and RA (Weissmann, 2009), IgG responses against autoantigenic targets are present. Therefore, it is interesting to focus on IgG responses when examining humoral immunity in autoimmune diseases.

The high immortalization efficiency on FACS sorted cells (83\%) was confirmed on 2 other healthy donors (donors 1-2 Fig. 2a). Considering all 3 individual immortalization experiments, an immortalization efficiency of $53-83 \%$ could be achieved (Fig. 2a). 
Variations in culture conditions were tested together with the immortalization experiments in donors 1 and 2 (Fig. 2b). A mean immortalization efficiency of 55\% was hereby obtained for the improved method, as indicated by the mean percentage of IgGand growth-positive wells (Fig. 2b). Variation in CpG2006 and IL-2 concentration revealed that the most efficient $B$ cell stimulation and immortalization could be obtained with 1

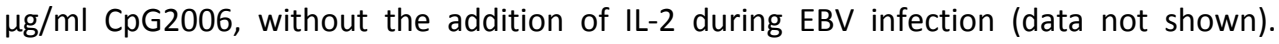
CpG2006 was used for B cell stimulation during immortalization as it was previously shown that this ligand of Toll-like receptor 9 (TLR9) (Hurst and von Landenberg, 2008) increases immortalization efficiency when administered during EBV infection (Traggiai et al., 2004) and causes polyclonal B cell activation and proliferation (Bernasconi et al., 2002; Hanten et al., 2008; Hartmann et al., 2000). Some studies revealed that CpG2006 suppresses viral infection as it protects against several viruses (Luganini et al., 2008; Schlaepfer et al., 2004) and induces the production of anti-viral cytokines and other proteins (Kato et al., 2003; Ladell et al., 2007). Concerning EBV, CpG2006 has only been shown to suppress the initiation of lytic EBV infection via inhibition of lytic gene expression (Ladell et al., 2007). Such connection, however, has never been demonstrated for latent EBV infection during B cell immortalization in vitro. Moreover, we have shown a positive effect of CpG2006 on B cell activation and a higher immortalization efficiency when CpG2006 is administered to cells when immortalization is in progress (data not shown). In contrast to the increase that has been described in CpG2006 elicited B cell activation (Liang et al., 1996) or immortalization (Lanzavecchia and inventors, 2004) by IL2 , we could not detect an amplification of $B$ cell immortalization when IL-2 was administered during the B cell immortalization phase (data not shown). Since the IL-2 receptor is mainly present on activated B cells (Muraguchi et al., 1985), it is likely that IL-2 exerts a stimulating effect on B cell proliferation and growth rather than on $B$ cell activation. This is also reflected in the higher immortalization efficiency when CpG2006 and IL-2 are combined for restimulation in comparison with the addition of CpG2006 or IL-2 alone (Fig. 2a), although the difference was not statistically significant. Addition of CpG2006 increases the effect of IL-2 given that TLR9 expression is elevated after EBV infection and CpG2006 stimulation (Bourke et al., 2003), rendering the immortalized cells even more responsive to CpG2006. 
a

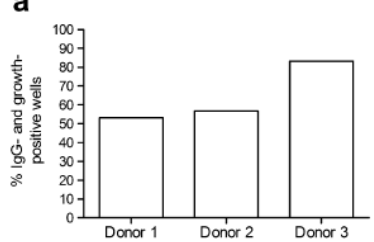

b

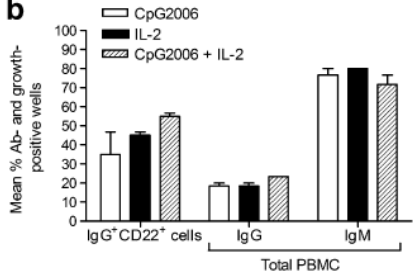

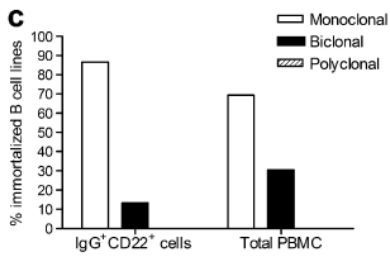

Figure 2. Immortalization efficiency and clonality on isolated IgG+ B cells or total PBMC. (a) Immortalization efficiency for isolated $\operatorname{IgG}^{+} \mathrm{CD} 22^{+}$cells using the improved $\mathrm{B}$ cell immortalization method was measured as the percentage of IgG- and growth-positive wells. IgG-producing immortalized B cell lines are shown 28 days after seeding for 3 healthy donors. (b) The mean percentage of immortalized B cell lines is shown after immortalization of isolated $\operatorname{IgG}^{+} \mathrm{CD} 22^{+}$cells and total PBMC using simultaneous $\mathrm{B}$ cell stimulation and infection with the addition of CpG2006, IL-2 or both after immortalization. Both IgG- and IgM-producing immortalized B cell lines are depicted for total PBMC. Results shown are the average of experiments in 2 healthy donors (donors 1 and 2 panel a). (c) Clonality of 34 randomly selected $\operatorname{~IgG~}^{+}$immortalized B cell lines was determined using $\mathrm{B}$ cell spectratyping for $\operatorname{IgG}^{+} \mathrm{CD} 22^{+}$cells and total PBMC. The percentage of monoclonal, biclonal and polyclonal immortalized $\mathrm{B}$ cell lines is shown.

B cell spectratyping provides further insights into the clonality of the resulting immortalized B cells, which can be useful to evaluate the need for cloning of the B cell lines. A monoclonality rate of $87 \%$ was demonstrated, while the remaining $13 \%$ of the investigated $B$ cell lines appeared to be biclonal (Fig. 2c). This preferential generation of monoclonal immortalized $B$ cell lines can be explained by the immortalization process itself. EBV-infected B cells undergo a proliferative crisis in which most of the cells die because of apoptosis. Surviving B cells become activated and eventually transform into lymphoblastoid immortalized cell lines (Sugimoto et al., 2004). Consequently, the outgrowth of multiple immortalized B cell lines is rare when starting with low B cell numbers per well. Nevertheless, the high monoclonality rate provides a major advantage for our B cell immortalization method in combination with the high immortalization efficiency. Subcloning using limiting dilution is no longer necessary, which considerably reduces the time span in which monoclonal antibodies can be produced.

The improved B cell immortalization procedure could also be successfully performed on total PBMC of 2 healthy donors with 95\% efficiency. To exclude differences in immortalization efficiency due to donor variability, the same donors were used as in previous experiments with isolated $\operatorname{IgG}^{+} \mathrm{CD} 22^{+} \mathrm{B}$ cells. However, the largest proportion of the resulting $B$ cell lines (72\%) appeared to be $\operatorname{IgM}^{+}$. Only $23 \%$ of the immortalized B cell lines was $\operatorname{lgG}^{+}$(Fig. 2b). This larger proportion of IgM-producing immortalized cells was reasonable, as most $B$ cells in the peripheral blood belong to the naïve $B$ cell population 
(Fraussen et al., 2009b). Naïve B cells also express the EBV receptor CD21 (unpublished results) and can be activated by CpG2006 to produce large amounts of IgM (Hanten et al., 2008). Moreover, the percentages of $\operatorname{IgM}^{+}$and $\operatorname{IgG}^{+}$immortalized $B$ cell lines that were produced from total PBMC, namely $72 \%$ and $23 \%$, resemble the proportion of naïve and memory B cells present in the peripheral blood (Chong et al., 2005). No significant difference could be observed when CpG2006, IL-2 or both were used during restimulation after B cell immortalization, although a trend towards a higher percentage of IgG $^{+}$ immortalized B cells was observed when both stimuli were added to the culture $(23 \%)$ compared to a single stimulus (18\%) (Fig. 2b). When immortalizing total PBMC, $250 \mathrm{ng} / \mathrm{ml}$ cyclosporine $A$ has to be added to suppress growth of (cytotoxic) $T$ cells that would otherwise target EBV-infected B cells, causing immortalization failure. B cell spectratyping of the generated immortalized $B$ cell lines resulted in $70 \%$ monoclonal $B$ cell lines and $30 \%$ biclonal B cell lines (Fig. 2c). This again emphasizes a high monoclonality rate when seeding low $B$ cell numbers per well.

Using this improved B cell immortalization method, we have successfully generated a large panel of immortalized B cell lines from the peripheral blood of MS patients (Fraussen et al., 2008; Fraussen et al., 2009a). Some B cell lines could also be recovered from the CSF of a MS patient. Preliminary screening demonstrated intracellular binding of antibodies from several B cell lines to a human oligodendroglia cell line, suggesting autoreactivity. In addition, autoreactivity against striated muscle proteins was shown for immortalized B cell lines that were recovered from MG patients (Vrolix et al., 2008). These are two examples of how possibly autoreactive antibodies can be produced from patients with autoimmune disease using B cell immortalization.

In summary, this study presents a reproducible B cell immortalization method with an efficiency of up to $83 \%$ for fast IgG production from $\mathrm{CD}_{2} 2^{+} \mathrm{IgG}{ }^{+}$peripheral blood $\mathrm{B}$ cells, by simultaneous B cell stimulation using CpG2006 and B cell infection by EBV followed by an additional stimulus of CpG2006 and IL-2. This immortalization procedure can in addition be used for IgM production from total PBMC with an efficiency of about $70 \%$. A detailed method description is provided to increase reproducibility of $B$ cell immortalization success rates. Moreover, B cell spectratyping demonstrated monoclonality in almost $90 \%$ of the immortalized $B$ cell lines originating from isolated IgG $^{+}$ $B$ cells. This unique combination of a high immortalization efficiency and a high monoclonality rate eliminates the need for further cloning of the immortalized cells. For the first time, a B cell immortalization procedure is introduced with high efficiency and reproducibility for low $B$ cell numbers that makes immediate generation of monoclonal antibodies possible. 


\title{
Acknowledgments
}

\author{
We thank Igna Rutten for technical assistance. This work was supported by grants from \\ Hasselt University and the Transnationale Universiteit Limburg.
}

\section{References}

Bernasconi, N.L., Traggiai, E., Lanzavecchia, A., 2002. Maintenance of serological memory by polyclonal activation of human memory B cells. Science 298, 2199-2202.

Bourke, E., Bosisio, D., Golay, J., Polentarutti, N., Mantovani, A., 2003. The toll-like receptor repertoire of human B lymphocytes: inducible and selective expression of TLR9 and TLR10 in normal and transformed cells. Blood 102, 956-963.

Carter, P.J., 2006. Potent antibody therapeutics by design. Nat Rev Immunol 6, 343-357.

Chong, Y., Ikematsu, H., Yamaji, K., Nishimura, M., Nabeshima, S., Kashiwagi, S., Hayashi, J., 2005. CD27(+) (memory) B cell decrease and apoptosis-resistant CD27(-) (naive) B cell increase in aged humans: implications for age-related peripheral B cell developmental disturbances. Int Immunol 17, 383-390.

Cross, A.H., Trotter, J.L., Lyons, J., 2001. B cells and antibodies in CNS demyelinating disease. J Neuroimmunol 112, 1-14.

Fraussen, J., Martinez-Martinez, P., De Baets, M.H., Van Diepen, A., Meulemans, E., Stinissen, P., 2008. Charaterizing autoantibodies in multiple sclerosis by B cell immortalization. Journal of neuroimmunology 203, 183-184.

Fraussen, J., Vrolix, K., Martinez-Martinez, P., Hupperts, R., Van Diepen, A., Meulemans, E., 2009a. Antibody-producing monoclonal $B$ cell lines from multiple sclerosis patients obtained by B cell immortalization. Clinical immunology 131, S129-S130.

Fraussen, J., Vrolix, K., Martinez-Martinez, P., Losen, M., De Baets, M.H., Stinissen, P., Somers, V., 2009b. B cell characterization and reactivity analysis in multiple sclerosis. Autoimmun Rev 8, 654-658.

Funaro, A., Gribaudo, G., Luganini, A., Ortolan, E., Lo Buono, N., Vicenzi, E., Cassetta, L., Landolfo, S., Buick, R., Falciola, L., Murphy, M., Garotta, G., Malavasi, F., 2008. Generation of potent neutralizing human monoclonal antibodies against cytomegalovirus infection from immune B cells. BMC Biotechnol 8, 85 .

Govarts, C., Somers, K., Hupperts, R., Stinissen, P., Somers, V., 2009. Analysis of antibody reactivity in paired cerebrospinal fluid and serum of a relapsing remitting multiple sclerosis patient. Autoimmunity 42, 699-704.

Graus, Y.F., de Baets, M.H., Parren, P.W., Berrih-Aknin, S., Wokke, J., van Breda Vriesman, P.J., Burton, D.R., 1997. Human anti-nicotinic acetylcholine receptor recombinant Fab fragments isolated from thymus-derived phage display libraries from myasthenia gravis patients reflect predominant specificities in serum and block the action of pathogenic serum antibodies. J Immunol 158, 1919-1929.

Hanten, J.A., Vasilakos, J.P., Riter, C.L., Neys, L., Lipson, K.E., Alkan, S.S., Birmachu, W., 2008. Comparison of human B cell activation by TLR7 and TLR9 agonists. BMC Immunol 9, 39.

Hartmann, G., Weeratna, R.D., Ballas, Z.K., Payette, P., Blackwell, S., Suparto, I., Rasmussen, W.L., Waldschmidt, M., Sajuthi, D., Purcell, R.H., Davis, H.L., Krieg, A.M., 2000. Delineation of a CpG phosphorothioate oligodeoxynucleotide for activating primate immune responses in vitro and in vivo. J Immunol 164, 1617-1624.

Hurst, J., von Landenberg, P., 2008. Toll-like receptors and autoimmunity. Autoimmun Rev 7, 204-208.

Kabat, E.A., Glusman, M., Knaub, V., 1948. Quantitative estimation of the albumin and gamma globulin in normal and pathologic cerebrospinal fluid by immunochemical methods. Am J Med 4, 653-662.

Kato, A., Homma, T., Batchelor, J., Hashimoto, N., Imai, S., Wakiguchi, H., Saito, H., Matsumoto, K., 2003. Interferonalpha/beta receptor-mediated selective induction of a gene cluster by CpG oligodeoxynucleotide 2006. BMC Immunol 4, 8 .

Kohler, G., Milstein, C., 1975. Continuous cultures of fused cells secreting antibody of predefined specificity. Nature 256, 495-497. 
Ladell, K., Dorner, M., Zauner, L., Berger, C., Zucol, F., Bernasconi, M., Niggli, F.K., Speck, R.F., Nadal, D., 2007. Immune activation suppresses initiation of lytic Epstein-Barr virus infection. Cell Microbiol 9, 2055-2069.

Lanzavecchia, A., inventors, 2004. Monoclonal antibody production by EBV transformation of B cells Vol. WO/2004/076677.

Levy, R., Dilley, J., 1978. Rescue of immunoglobulin secretion from human neoplastic lymphoid cells by somatic cell hybridization. Proc Natl Acad Sci U S A 75, 2411-2415.

Liang, H., Nishioka, Y., Reich, C.F., Pisetsky, D.S., Lipsky, P.E., 1996. Activation of human B cells by phosphorothioate oligodeoxynucleotides. J Clin Invest 98, 1119-1129.

Luganini, A., Caposio, P., Landolfo, S., Gribaudo, G., 2008. Phosphorothioate-modified oligodeoxynucleotides inhibit human cytomegalovirus replication by blocking virus entry. Antimicrob Agents Chemother 52, 1111-1120.

Martin, D.R., Marlowe, R.L., Ahearn, J.M., 1994. Determination of the role for CD21 during Epstein-Barr virus infection of B-lymphoblastoid cells. J Virol 68, 4716-4726.

McCafferty, J., Griffiths, A.D., Winter, G., Chiswell, D.J., 1990. Phage antibodies: filamentous phage displaying antibody variable domains. Nature 348, 552-554.

Meijer, P.J., Andersen, P.S., Haahr Hansen, M., Steinaa, L., Jensen, A., Lantto, J., Oleksiewicz, M.B., Tengbjerg, K., Poulsen, T.R., Coljee, V.W., Bregenholt, S., Haurum, J.S., Nielsen, L.S., 2006. Isolation of human antibody repertoires with preservation of the natural heavy and light chain pairing. J Mol Biol 358, 764-772.

Muraguchi, A., Kehrl, J.H., Longo, D.L., Volkman, D.J., Smith, K.A., Fauci, A.S., 1985. Interleukin 2 receptors on human B cells. Implications for the role of interleukin 2 in human B cell function. J Exp Med 161, 181-197.

Olsson, L., Kaplan, H.S., 1980. Human-human hybridomas producing monoclonal antibodies of predefined antigenic specificity. Proc Natl Acad Sci U S A 77, 5429-5431.

Rosen, A., Gergely, P., Jondal, M., Klein, G., Britton, S., 1977. Polyclonal Ig production after Epstein-Barr virus infection of human lymphocytes in vitro. Nature 267, 52-54.

Schlaepfer, E., Audige, A., von Beust, B., Manolova, V., Weber, M., Joller, H., Bachmann, M.F., Kundig, T.M., Speck, R.F., 2004. CpG oligodeoxynucleotides block human immunodeficiency virus type 1 replication in human lymphoid tissue infected ex vivo. J Virol 78, 12344-12354.

Somers, K., Govarts, C., Stinissen, P., Somers, V., 2009. Multiplexing approaches for autoantibody profiling in multiple sclerosis. Autoimmun Rev 8, 573-579.

Somers, V., Govarts, C., Somers, K., Hupperts, R., Medaer, R., Stinissen, P., 2008. Autoantibody profiling in multiple sclerosis reveals novel antigenic candidates. J Immunol 180, 3957-3963.

Steinitz, M., Klein, G., Koskimies, S., Makel, O., 1977. EB virus-induced B lymphocyte cell lines producing specific antibody. Nature 269, 420-422.

Sugimoto, M., Tahara, H., Ide, T., Furuichi, Y., 2004. Steps involved in immortalization and tumorigenesis in human Blymphoblastoid cell lines transformed by Epstein-Barr virus. Cancer Res 64, 3361-3364.

Traggiai, E., Becker, S., Subbarao, K., Kolesnikova, L., Uematsu, Y., Gismondo, M.R., Murphy, B.R., Rappuoli, R., Lanzavecchia, A., 2004. An efficient method to make human monoclonal antibodies from memory B cells: potent neutralization of SARS coronavirus. Nat Med 10, 871-875.

van Dongen, J.J., Langerak, A.W., Bruggemann, M., Evans, P.A., Hummel, M., Lavender, F.L., Delabesse, E., Davi, F., Schuuring, E., Garcia-Sanz, R., van Krieken, J.H., Droese, J., Gonzalez, D., Bastard, C., White, H.E., Spaargaren, M., Gonzalez, M., Parreira, A., Smith, J.L., Morgan, G.J., Kneba, M., Macintyre, E.A., 2003. Design and standardization of PCR primers and protocols for detection of clonal immunoglobulin and T-cell receptor gene recombinations in suspect lymphoproliferations: report of the BIOMED-2 Concerted Action BMH4-CT98-3936. Leukemia 17, 22572317.

Vrolix, K., Fraussen, J., Meulemans, E., Becker, P., Phernambucq, M., Somers, V., 2008. Monoclonal antibody production by immortalization of B cells from the thymus of myasthenia gravis patients. Journal of neuroimmunology 203, 258.

Vrolix, K., Fraussen, J., Molenaar, P.C., Losen, M., Somers, V., Stinissen, P., De Baets, M.H., Martinez-Martinez, P., 2010. The auto-antigen repertoire in myasthenia gravis. Autoimmunity $43,380-400$.

Weissmann, G., 2009. Rheumatoid arthritis and systemic lupus erythematosus as immune complex diseases. Bull NYU Hosp Jt Dis 67, 251-253. 


\section{Chapter 4}

Immortalization of thymic autoreactive B cells

and monoclonal antibody production from AChRantibody positive myasthenia gravis patients

Vrolix K, Fraussen J, Losen M, Van den Broeck J, Lazaridis K, Molenaar PC, Stinissen P, Tzartos S, Somers V, De Baets MH, Martínez-Martínez P 


\section{Abstract}

Autoreactive B cells have been found in the human thymus, but their contribution to autoimmune diseases is not well understood. Here, we investigated the thymus $B$ cell repertoire of myasthenia gravis (MG) patients with autoantibodies against the muscle acetylcholine receptor ( $A C h R$ ) by using a $B$ cell immortalization method based on infection of thymic B cells with the Epstein-Barr virus (EBV) in combination with polyclonal $B$ cell stimulation via Toll-like receptor 9 (TLR-9). We isolated several monoclonal B cell lines producing antibodies with reactivity against striated muscle proteins. One monoclonal antibody was directed against the gamma subunit of the fetal AChR. This antibody strongly modulated the AChR. The isolation of representative striational and anti-AChR antibodies from the MG thymus indicates that the EBV immortalization technique is suitable to study the $B$ cell repertoire in the autoimmune thymus. 


\section{Introduction}

Autoimmune diseases generally occur when the processes of central and peripheral tolerance have failed. Central tolerance primarily occurs in the thymus and is responsible for the elimination of potentially auto-reactive T lymphocytes. When auto-reactive $T$ cells escape tolerance, they can induce auto-immunity (Peterson et al., 2008; Takahama, 2006). Although the maintenance of $T$ cell tolerance is considered as the main function of the human thymus, autoreactive $B$ cells have also been found in thymuses from autoimmune patients (Alpert et al., 1971; Kendall, 1995). However their frequency is unknown and their contribution to the pathophysiology of the autoimmune reaction is poorly understood. Here, we used an improved Epstein-Barr virus (EBV) immortalization technique on human thymic B cells (Fraussen et al., 2010; Traggiai et al., 2004). In order to study the complete $B$ cell repertoire of the thymus, we characterized the antibodies that are produced by monoclonal immortalized B cells. We focused on acetylcholine receptor (AChR)-antibody positive myasthenia gravis (MG) (i.e. AChR-MG) because thymic $B$ cells have been implicated in its etiology as explained below.

AChR-MG is an auto-immune disease that is characterized by skeletal muscle weakness (Conti-Fine et al., 2006; Vincent et al., 2000) caused by auto-antibodies binding to $A C h R$ at the postsynaptic membrane of the neuromuscular junction (NMJ) (Lindstrom et al., 1976). The AChR in developing skeletal muscles is a pentameric ion channel with a composition of two alpha1 subunits and one beta1, one gamma and one delta subunit $\left(\alpha_{2} \beta \gamma \delta\right)$. In the mature NMJ the gamma subunit is replaced by an epsilon subunit yielding the adult AChR with a subunit composition of $\alpha_{2} \beta \varepsilon \delta$ (Hesselmans et al., 1993). After birth, expression of fetal $A C h R$ is restricted to few tissue forms including extraocular muscle fibers of unknown function, thymus myoid cells and skeletal muscles following denervation (Gattenloehner et al., 1998) and for this reason only antibodies directed against the adult form of the AChR are pathogenic in MG patients. However, anti-fetal AChR antibodies can also be very pathogenic for developing embryos and neonates by placental transfer. Anti-AChR antibodies can impair neuromuscular transmission by four mechanisms (reviewed in Gomez et al., 2010): antigenic modulation of the AChR (Drachman et al., 1978; Heinemann et al., 1977; Losen et al., 2008), complementmediated lysis of the postsynaptic membrane (Chamberlain-Banoub et al., 2006), loss of AChR associated proteins such as rapsyn, voltage-gated sodium channels and utrophin (Losen et al., 2005; Martinez-Martinez et al., 2007; Martinez-Martinez et al., 2009), and, less frequently, direct inhibition of AChRs (Almon et al., 1974; Lang et al., 1988). The majority of sera from AChR-MG patients also have antibodies against the gamma subunit 
of the fetal AChR $\left(\alpha_{2} \beta \gamma \delta\right)$. Antibody titers against the gamma subunit may even exceed titers against the other subunits of the adult AChR ( $\left.\alpha_{2} \beta \varepsilon \delta\right)$ (Polizzi et al., 2000).

The role of the thymus in MG has been suggested by several findings. Removing the thymus of AChR-MG patients often seems to cause a reduction of myasthenic symptoms (Gronseth and Barohn, 2000; Kuks et al., 1991). Indeed, autoantibody production observed in MG patients is generally thought to be associated with some remarkable abnormalities of the thymus. Approximately $70 \%$ of AChR-MG patients display thymic hyperplasia with the formation of abundant ectopic germinal centers (Alpert et al., 1971; Levinson and Wheatley, 1996). These germinal centers are sites of a high rate of $B$ cell differentiation, in which $B$ cells recognize the antigen on antigen-presenting cells, undergo somatic hypermutation of the immunoglobulin genes by interacting with $\mathrm{T}$ cells and differentiate into plasma cells producing high affinity antibodies (Hill et al., 2008). In AChR-MG, thymic B cells may recognize the fetal and adult AChR expressed by myoid and epithelial cells of the thymus (Leite et al., 2007; Wakkach et al., 1996; Wekerle et al., 1978) and they may be stimulated by anti-AChR autoreactive T cells which also have been detected in the MG thymus (Melms et al., 1988). In addition, B cells extracted from the thymus of AChR-MG patients produce anti-AChR antibodies in vitro (Graus et al., 1997; Scadding et al., 1981). The ratio of anti-AChR antibody to total Ig produced by thymic B cells is even about ten-fold higher than that from B cells of peripheral blood, bone marrow or lymph nodes of the same patients (Fujii et al., 1986). Thus, the evidence suggests that the thymus and thymic B cells play an important role in the pathophysiology of AChR-MG.

\section{Methods}

\section{Patient information}

MG patients underwent thymectomy at the Academic Hospital of Maastricht in the Netherlands. Informed consent was obtained from all patients and the study was approved by the local medical ethical committee (NL22271.068.08). Clinical data of MG patients are summarized in Table 1.

\section{Thymus tissue}

Thymus tissue obtained after thymectomy was mechanically disrupted by rubbing it through a nylon gauze or by using the gentleMACS Tissue Dissociator (Miltenyi Biotec, Bergisch Gladbach, Germany) according to the manufacturer's instructions. The crude cell 
suspension was collected in RPMI medium and passed through a $30 \mu \mathrm{m}$ cell strainer to remove large cell clumps and fat tissue. Single cell suspensions were used fresh (P90) or were stored in liquid $\mathrm{N}_{2}$ until experiments started (P21, P28, P42 and P82).

Table I. Clinical characteristics of AChR-MG patients and phenotype of their thymic B cells

\begin{tabular}{|c|c|c|c|c|c|}
\hline Patient & P21 & P28 & P42 & P82 & P90 \\
\hline Sex & female & female & female & female & female \\
\hline Disease severity (MGFA) & IIIa & I & $\mathrm{IVb}$ & $\mathrm{IIIb}$ & $\mathrm{IVb}$ \\
\hline Age at thymectomy (y) & 29 & 41 & 24 & 28 & 23 \\
\hline Thymic histology & $\mathrm{FH}$ & $\mathrm{FH}$ & $\mathrm{FH}$ & $\mathrm{FH}$ & $\mathrm{FH}$ \\
\hline Anti-AChR Ab titer (nM) & 104 & 90 & 24 & $>20$ & $>500$ \\
\hline Age at onset (years) & 26 & 38 & 23 & 28 & 23 \\
\hline MG symptoms & Generalized & $\begin{array}{l}\text { Ocular/ } \\
\text { bulbar }\end{array}$ & Generalized & Generalized & Generalized \\
\hline Treatment & Mestinon & Mestinon & Mestinon & Mestinon & Mestinon \\
\hline Comorbidities & RA & / & Diabetis & Scoliosis & / \\
\hline $\mathrm{CD}_{22}{ }^{+}$thymocytes & $36.61 \%$ & $11.0 \%$ & $8.13 \%$ & ND & ND \\
\hline $\mathrm{CD}_{22} 2^{+} \operatorname{IgG}{ }^{+}$thymocytes & $4.15 \%$ & $4.45 \%$ & $3.43 \%$ & $1.9 \% *$ & $1.6 \% *$ \\
\hline $\mathrm{CD} 21^{+}$of $\mathrm{CD} 22^{+}$thymocytes & $95.19 \%$ & $78.56 \%$ & $67.77 \%$ & ND & ND \\
\hline Immortalization method & 1 & 1 & 1 & 2 & 2 \\
\hline Immortalization efficiency ${ }^{\S}$ & $10.5 \%$ & $29 \%$ & $12.5 \%$ & $7.5 \%$ & $25 \%$ \\
\hline $\begin{array}{l}\text { Number of growth-positive } \\
\text { clones }\end{array}$ & 63 & 84 & 182 & 54 & 187 \\
\hline $\operatorname{lgG}^{+}$immortalized clones & $16 \%$ & $40 \%$ & $19 \%$ & $100 \%$ & $100 \%$ \\
\hline Monoclonality rate & $84 \%$ & $94 \%$ & $93 \%$ & $90 \%$ & $83 \%$ \\
\hline Anti-AChR reactivity & 0 & 0 & 0 & 0 & 2 \\
\hline
\end{tabular}

FH: follicular hyperplasia; RA: rheumatoid arthritis; ND: not determined. Disease severity is scored according to the Myasthenia Gravis Foundation of America (MGFA) clinical classification (Jaretzki et al., 2000). * Values were measured with FACSAria instead of the FACSCalibur system. ${ }^{\S}$ Immortalization efficiency represents the percentage of clones that became immortalized and could be kept in culture long enough to reach an estimated total number of 30 million cells.

\section{B cell immortalization}

$\mathrm{CD}_{2}{ }^{+} \mathrm{B}$ cells were isolated from the total thymocyte cell population by binding to CD22 microbeads (Miltenyi Biotec) and separating them on a magnetic column (P21, P28 and $\mathrm{P} 42$ ). Alternatively, $\mathrm{CD} 22^{+} \mathrm{IgG}^{+} \mathrm{B}$ cells were isolated by staining total thymocytes with antiCD22 and anti-lgG antibodies and subsequently enriching positively labeled cells using the FACSAria II cell sorter (all from BD Biosciences, San Jose, CA, USA) (P82 and P90). B cell 
immortalization was performed as described previously (Fraussen et al., 2010). In short, selected B cells were seeded in $96 \mathrm{U}$-bottom microwell plates in RPMI medium containing $10 \%$ fetal bovine serum (Bodinco, Alkmaar, The Netherlands), $1 \mathrm{mM}$ sodium pyruvate (Gibco Invitrogen, Carlsbad, USA), $50 \mathrm{U} / \mathrm{mL}$ penicillin, $50 \mu \mathrm{g} / \mathrm{mL}$ streptomycin, $1 \mu \mathrm{g} / \mathrm{mL}$ CpG 2006 (Invivogen, San Diego, USA) and $50 \mathrm{U} / \mathrm{mL}$ interleukin-2 (IL-2) (Roche, Basel, Switzerland), in the presence of EBV (supernatant of the B95-8 cell line; $30 \% \mathrm{v} / \mathrm{v}$ ). As feeder cells, $10^{5}$ irradiated ( $83 \mathrm{~Gy}$ ) PBMCs from healthy donors were used. After 2 weeks, EBV was removed and cells were restimulated with $1 \mu \mathrm{g} / \mathrm{mL}$ CpG 2006 and $50 \mathrm{U} / \mathrm{ml} \mathrm{IL-2}$ for another week, after which the immortalization was verified by microscopic examination of cell growth and by screening the culture supernatants for antibody production. Growth-positive and antibody-producing clones were kept in culture until they grew confluently in a $75 \mathrm{~cm}^{2}$ flask and could be frozen in $\mathrm{N}_{2}$. Figure 1 depicts the different procedures which were used to immortalize thymic B cells.

\section{Measurement of antibody production}

Dot blotting was used to measure the antibody production of immortalized B cell lines. Culture supernatants $(5 \mu \mathrm{L})$ of all B cell lines were spotted on a nitrocellulose membrane (Bio-Rad Laboratories, Hercules, USA), and allowed to dry for 15 minutes. After blocking the membrane with $5 \%$ non-fat dry milk in phosphate buffered saline (PBS) for 30 minutes at room temperature (RT), it was incubated for one hour with rabbit anti-human IgG labeled with horseradish peroxidase (HRP) (1/100 in blocking buffer; Dako, Glostrup, Denmark) or rabbit anti-human IgM HRP (1/50 in blocking buffer; Dako). Following 5 washing steps with $0.05 \%$ Triton X-100 in PBS, the membrane was incubated with substrate solution containing di-aminobenzidine (DAB, $1 \mathrm{mg} / \mathrm{mL})$, Tris- $\mathrm{HCl}(50 \mathrm{mmol} / \mathrm{L})$ and $0.03 \% \mathrm{H}_{2} \mathrm{O}_{2}$ until spots were visible. Human IgG (IgG1 637, (van der Neut Kolfschoten et al., 2007)) or IgM (Sigma Aldrich, St-Louis, USA) (ranging from $500 \mu \mathrm{g} / \mathrm{mL}$ to $0.5 \mu \mathrm{g} / \mathrm{mL}$ ) was included as a positive control, and culture medium was used as a negative control.

To determine the IgG isotype of B cell clone P90-131, the PeliClass human IgG subclass Plus kit (Sanquin, Amsterdam, The Netherlands) was used according to the manufacturer's instructions.

\section{Radioimmunoassay for anti-AChR antibodies}

Radioimmunoassays (RIA) were performed to measure anti-human AChR antibodies in culture supernatants of immortalized B cell clones. Culture supernatant was incubated with fetal AChR from the TE 671 human rhabdomyosarcoma cell line, ${ }^{125}$ lodine-labeled $\alpha$ bungarotoxin (1/250; PerkinElmer, Waltham, USA) and normal human serum overnight at 
$4^{\circ} \mathrm{C}$ as described previously (van der Neut Kolfschoten et al., 2007). For detection of antibodies binding to the $\varepsilon$-AChR subunit, the CN 21 cell line was used. The CN 21 has been produced by $D$. Beeson and colleagues by stable transfection of TE 671 cell with a plasmid driving the production of the AChR epsilon subunit, resulting in the predominant expression of adult AChR (Beeson et al., 1996). To determine the cross-reactivity of anti$A C h R$ antibodies between different species, rat and mouse denervated muscle tissue and the electric organ of Torpedo californica were used as source of AChR. Anti-AChR antibodies that bound the radioactively-labeled receptor in the antibody complex were measured with the Wizard2 automatic gamma counter (PerkinElmer).

Alternatively, anti-AChR antibodies in the culture supernatants of immortalized B cell clones were measured against $A C h R$ isolated from human amputated legs by using the commercially available AChR antibody kit (IBL, Hamburg, Germany) according to the manufacturer's instructions.

\section{Immunoabsorption of mAb by sepharose-immobilized ECDs and RIA}

Extracellular domains (ECDs) of the human AChR subunits $\alpha 1, \beta 1, \gamma$ and $\varepsilon$ were expressed as soluble proteins in $P$. pastoris (Kostelidou et al., 2006). After purification by nickelaffinity chromatography, they were individually immobilized on $\mathrm{CNBr}$ activated sepharose (GE Healthcare, Fairfield, CT, USA) to a ratio of $0.1 \mathrm{mg}$ protein / $0.1 \mathrm{~g}$ sepharose. A control column with immobilized bovine serum albumin (BSA) was also prepared. $10 \mu \mathrm{L}$ of the culture supernatant of P90-131 was incubated with $1 \mu \mathrm{g}$ of each of the sepharoseimmobilized ECDs, or sepharose-BSA (in a total volume of $160 \mu \mathrm{L}$ PBS, $\mathrm{pH} 7.4$ ), for $2 \mathrm{~h}$ at $4^{\circ} \mathrm{C}$. Then the samples were briefly centrifuged to pellet the sepharose. Unbound antiAChR antibodies in the supernatant (duplicate samples of $40 \mu \mathrm{L}$ each) were assayed by RIA (RSR, Cardiff, UK) according to the manufacturer's protocol. The antibodies detected after incubation with sepharose-BSA were taken as the $100 \%$ value. The immunoabsorptions were performed in three independent experiments.

\section{SDS-PAGE and Western blotting}

The ECDs (3-6 $\mu \mathrm{g})$ of the $\alpha 1, \beta 1, \gamma$ and $\varepsilon$ subunits were resolved by SDS-PAGE and then transferred onto a nitrocellulose membrane. The blot was blocked with $5 \%$ non-fat dry milk in PBS and then probed with the culture supernatant of P90-131 for $16 \mathrm{~h}$ at $4{ }^{\circ} \mathrm{C}$, followed by HRP-labeled rabbit anti-human IgG (1:1000 in PBS; Dako, Glostrup, Denmark). The molecular masses of proteins were estimated relatively to the electrophoretic mobility of cotransferred prestained molecular mass markers (Fermentas, USA). To visualize the $\alpha 1, \beta 1, \gamma$ and $\varepsilon$ subunits on the gel, a coomassie staining was performed. 


\section{Antigenic modulation of AChR}

Confluently grown TE 671 cells were incubated with culture supernatants of B cell lines, culture medium (negative control) or with monoclonal anti-AChR antibody IgG1 637 (10 nM, positive control)(van der Neut Kolfschoten et al., 2007) for three hours at $37^{\circ} \mathrm{C}$. The synthesis of new proteins was prevented by adding cycloheximide ( $40 \mu \mathrm{M})$. After washing with prewarmed PBS, the cells were incubated for one hour at $37^{\circ} \mathrm{C}$ with ${ }^{125} \mathrm{I}$ labeled $\alpha$-bungarotoxin ( $1 / 5000$ in culture medium; PerkinElmer) to label the remaining $\mathrm{AChR}$ on the cell surface. Following three washing steps, cells were lysed with $0.5 \mathrm{M}$ sodium hydroxide and the amount of labeled AChR was measured using the Wizard2 automatic gamma counter (PerkinElmer). The non-specific binding of ${ }^{125}$ I-labeled $\alpha$ bungarotoxin to TE 671 cells was measured in samples that had been pre-incubated with unlabeled $\alpha$-bungarotoxin. The amount of AChR on the cells was calculated by subtracting the non-specific radioactivity from each measurement $(\Delta \mathrm{cpm})$. The maximum amount of cell surface ${ }^{125} \mathrm{I}$ - $\alpha$-bungarotoxin labeled AChR ( $\Delta$ cpm max) is the cell-bound radioactivity on confluent cells where plain culture medium is maintained during the steps before labeling. The percentage of surface AChR was calculated as follows: \% AChR on cell surface $=(\Delta \mathrm{cpm}$ in the presence of $\mathrm{lg} / \Delta \mathrm{cpm} \max ) * 100$.

\section{Immunohistochemistry for anti-muscle antibodies}

The anti-striated monkey (macaques) muscle antibody immunofluorescence test system (ScimedX, Denville, USA) was used to detect striational antibodies in the culture supernatant of immortalized B cells. Stainings were performed according to the manufacturer's instructions. To detect antibodies that bind proteins of the NMJ, $30 \mu \mathrm{m}$ cryosections from intercostal monkey muscles were used instead. Sections were cut using the Leica CM3050 cryostate (Leica Microsystems $\mathrm{GmbH}$, Wetzlar, Germany), dried, fixed in acetone at $4^{\circ} \mathrm{C}$ for 10 minutes and dried again for 30 minutes. Subsequently, the sections were incubated with culture supernatants for three hours at RT. To confirm the localization of AChR in the rhesus muscle end-plates, sections were double stained with Alexa 594-conjugated $\alpha$-bungarotoxin (1/300 in PBS; Molecular Probes, Leiden, The Netherlands) for 30 minutes at RT. Then, they were incubated with sheep-anti-human IgG FITC (1/100 in PBS; The Binding Site, Birmingham, UK) for 60 minutes at RT. After washing with PBS, coverslips were mounted with $30 \%$ glycerol in PBS. 


\section{Spectratyping and sequencing analysis}

RNA was isolated from the immortalized B cells by using the high pure RNA isolation kit (Roche) according to the manufacturer's instructions. The isolated RNA was subsequently converted into cDNA with the Reverse transcription system kit (Promega) according to the manufacturer's instructions. To analyze the variable region of the B cell receptor heavy and light chain locus, a PCR was performed with the following reagents: PCR buffer (100 $\mathrm{mM}$ Tris- $\mathrm{HCl}, 500 \mathrm{mM} \mathrm{KCl}, 15 \mathrm{mM} \mathrm{MgCl}_{2}$ and $0.1 \%$ gelatine), $0.25 \mathrm{mM}$ dNTPs (GE Healthcare), 10 pmol FR1, FR2, and FR3 forward primer mix (Sigma Aldrich), 10 pmol Primer Biomed JH-con FAM (Sigma Aldrich), one unit Jumpstart Red Taq polymerase (Sigma Aldrich) and 100 ng cDNA, using the PTC200 DNA Engine Thermal Cycler PCR (Scientific Support, Hayward, USA). The primers used to amplify $V_{H}$ genes have been described previously (Fraussen et al., 2010). In the case of $V_{K}$ genes, the primers used in $5^{\prime}$ were as follows: $V_{k} 1$ : GAC ATC CAG ATG ACC CAG TCT CC; $V_{K} 2$ : GAT GTT GTG ATG ACT CAG TCT CC; $V_{K} 3$ : GAA ATT GTG TTG ACG CAG TCT CC; $V_{K} 4$ : GAC ATC GTG ATG ACC CAG TCT CC; $V_{K}$ 5: GAA ACG ACA CTC ACG CAG TCT CC; $\vee_{K} 6$ : GAA ATT GTG CTG ACT CAG TCT CC. In 3', the consensus $J_{K}$ primer CTT ACG TTT GAT CTC CAG CTT GGT CCC was used. PCR products were analyzed by electrophoresis on a $2 \%$ agarose gel and photographed by the Molecular Imager Gel Doc XR System (Bio-Rad Laboratories). To measure the length of different frameworks, the PCR-product was added to an internal size standard and formamide and analyzed by the genetic analyzer ABI3100 (Applied Biosystems, Foster City, USA) which detects the FAM-labels of the PCR-products in order to identify monoclonal or polyclonal B cell clones. This spectratyping procedure can detect clonal populations with a sensitivity of $0.5-5 \%$. To sequence the heavy and light chain of the antibody, the PCR-product was used as template for the sequence reaction, based on single strand primer extension by Taq-polymerase in a PCR-reaction. The mix for the sequence reaction contained PCR product $(10 \% \mathrm{v} / \mathrm{v}), \mathrm{J}_{\mathrm{H}}$ or $\mathrm{J}_{\mathrm{K}}$ con primer $(3.2 \mathrm{pmol} / \mu \mathrm{L})$ (Sigma Aldrich), Big Dye v1.1 (10\% v/v) (Applied Biosystems) and sequence buffer (15\% $\mathrm{v} / \mathrm{v}$ ). The PCR-product was amplified in a PE 9700 thermocycler (PerkinElmer) and analyzed by the genetic analyzer $\mathrm{ABI} 3100$ (Applied Biosystems). The $\operatorname{IgV}_{\mathrm{H}}$ and $\mathrm{IgV}_{\mathrm{L}}$ regions were subsequently sequenced in the forward direction by means of a $V_{H}$ and $V_{K}$ family specific forward primer using the same procedure. Forward and reverse sequences were aligned using the BLAST alignment tool (b/2seq, NCBI) in order to establish the complete $V(D) J$ region sequence. The obtained sequences were compared to the BLAST immunoglobulin database (NCBI). 


\section{Results}

\section{Phenotypic analysis and immortalization of thymic B cells}

To isolate human monoclonal anti-AChR antibodies from the thymus of AChR-MG patients, we used two different methods to immortalize thymic B cells (Fig. 1). Before the immortalization, we determined the phenotypic characteristics of $B$ cells from the MG thymus by FACS. Results are shown in Table 1 . We found that the percentage of CD22 ${ }^{+}$ cells (i.e. mature B cells) in total thymocytes highly varied between MG patients, ranging from 8 to $36 \%$. The percentage of $\mathrm{CD}_{2} 2^{+} \mathrm{IgG}^{+}$thymocytes ranged from 1.6 to $4.5 \%$, indicating that the majority of $\mathrm{CD}_{2} 2^{+}$thymic $\mathrm{B}$ cells express other immunoglobulin isotypes. The majority of $\mathrm{CD} 22^{+} \mathrm{B}$ cells, ranging from $68-95 \%$, were found to express the EBV receptor CD21, thereby suggesting that they would be susceptible to EBV immortalization.

CD22 ${ }^{+}$thymic B cells from 3 MG patients (P21, P28 and P42) were immortalized following isolation by magnetic cell sorting (Fig. 1, Method 1). Immortalization efficiencies, based on the amount of clones that actively grew until sufficient amounts of cells could be frozen, ranged from 10 to $29 \%$ (Table 1). The antibody production of growing B cell clones was measured by dot blot and more than $60 \%$ was found to produce IgM antibodies. Since pathogenic autoantibodies in MG sera belong to the IgG isotype, we then selectively enriched $\mathrm{CD}_{2} 2^{+} \mathrm{IgG}^{+} \mathrm{B}$ cells before immortalization. These were isolated from the thymus of 2 other MG patients (P82 and P90) using FACS sorting (Method 2). All $B$ cell clones immortalized by this method were positive for IgG production. Finally, we determined the monoclonality rate in the immortalized $B$ cell lines by spectratyping analysis. We obtained about $90 \%$ monoclonal and $10 \%$ biclonal B cell lines (data not shown), thereby eliminating the need for further subcloning.

\section{Immortalized B cell clones produce anti-human AChR antibodies}

The reactivity of immortalized B cell lines against human AChR was tested using RIAs. From the $B$ cell clones immortalized by Method 1, none produced antibodies with specific AChR reactivity. Conversely, Method 2 yielded two clones with reactivity against the human AChR. As shown in Figure 2, the AChR binding activity of P90-65 and P90-131 was confirmed by two different RIAs, using human AChR either from the TE 671 cell line (Fig. $2 A$ ) or from leg muscles (Fig. 2B). Unfortunately, P90-65 did not survive after freezing/thawing procedures, whereby only the AChR binding capacity of P90-131 could be further investigated. We studied the specificity of P90-131 against AChR from different 
species, but no reactivity against rat, mouse or Torpedo AChR was detected (Fig. 2C). In addition, P90-131 did not bind to AChRs on the NMJ of monkey muscle tissue in immunostainings (data not shown). Then, we investigated whether P90-131 recognized adult or fetal AChR, by using AChR extracted from the CN 21 or TE 671 cell line, respectively. P90-131 as well as the serum of patient P90 showed reactivity against the fetal AChR and P90-131 did not bind to the adult AChR (Fig. 3A). The immunoabsorption experiment (Fig. 3B) and Western blot (Fig. 3C) clearly showed binding of P90-131 to the gamma-AChR subunit only, thereby confirming its specific reactivity against the fetal $\operatorname{AChR}\left(\alpha_{2} \beta \gamma \delta\right)$.

\section{Isolated anti-AChR antibody modulates surface $A C h R$ in vitro}

Because the internalization of cell surface AChR is an important mechanism by which antiAChR antibodies exert their pathogenic effect in vivo (Drachman et al., 1978; Heinemann et al., 1977; Losen et al., 2005), we tested the modulating effect of P90-131 on cultured TE 671 cells. As shown in Figure 4, P90-131 effectively reduced surface AChR levels in a concentration-dependent manner, reaching a maximum reduction of $60 \%$ when a concentration of $\sim 6 \mathrm{nM}$ of IgG was used. Human mAb IgG1 637, which is directed against the human AChR alpha subunit and known to efficiently reduce surface AChR was used as a positive control (van der Neut Kolfschoten et al., 2007). As expected, two IgG-producing $B$ cell clones, negative for anti-AChR antibodies in the RIA, did not cause significant reduction in surface AChR levels. These results clearly show that P90-131 exerts pathogenic effects in vitro.

In addition, the isotyping assay determined that clone P90-131 produced IgG1 antibodies (data not shown). This means that P90-131 might activate the classical pathway of the complement system, thereby implying that P90-131 could also exert pathogenic effects in vivo, by activating the membrane attack complex of complement.

\section{Sequence analysis of monoclonal anti-AChR antibodies}

Sequence analysis of anti-AChR positive clones P90-65 and P90-131 revealed that their $\mathrm{V}_{\mathrm{H}}$ gene fragments had most likely differentiated from the germ-line genes V1-24*01 (M99642) and V3-30*02 (L26401) to which they showed $96.8 \%$ and $74.7 \%$ of homology, respectively (Fig. 5A). The high rate of mutations in mutational hot spots of P90-131 (data not shown) suggests that these $B$ cells have passed through a germinal center to undergo affinity maturation towards an antigen. In addition, the ratios of replacement to silent mutations $(R / S)$ observed in the complementarity determining regions (CDR) were higher than in the framework regions (FR) in both clones, indicating antigen-driven selection. 


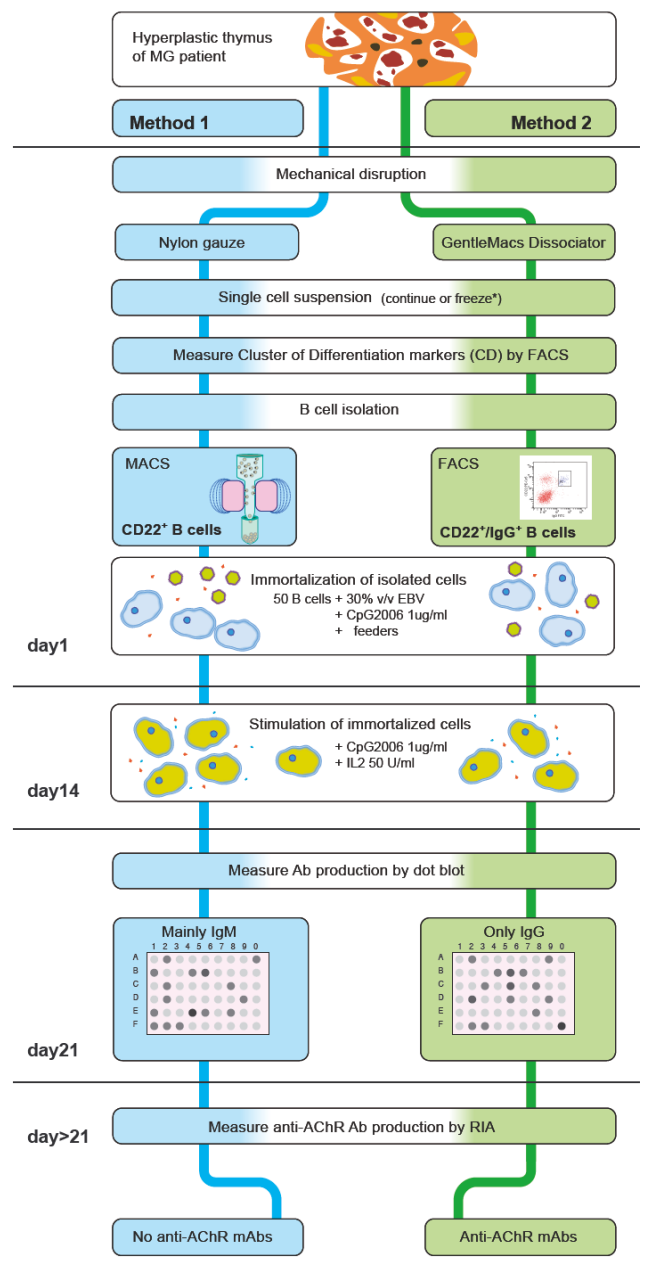

Figure 1. Schematic overview of thymic B cell immortalizations. Two different methods were used to immortalize B cells, represented in blue and green. The hyperplastic thymus of MG patients was mechanically disrupted using either nylon gauze or the GentleMacs dissociator. Single cell suspensions were used fresh or were frozen until later time points $\left(^{*}\right)$. Then, the expression of different B cell CD markers in total thymocytes was measured using FACS. $\mathrm{CD} 22^{+}$or $\mathrm{CD}_{2} 2^{+} \mathrm{IgG}{ }^{+} \mathrm{B}$ cells were isolated from total thymocytes by magnetic sorting or fluorescent sorting, respectively. Isolated B cells were simultaneously stimulated with CpG2006 and immortalized with $30 \%$ (v/v) EBV-containing supernatant. Following two weeks, EBV-containing supernatant was removed and B cells were stimulated with CpG2006 and IL-2 during 7 days. Immortalization efficiency was verified on day 21 by microscopic examination of cell growth and by measuring antibody production by dot blot. Immortalizing $\mathrm{CD} 22^{+}$thymic B cells mainly yielded IgM antibodies, while immortalizing $\mathrm{CD}_{22}{ }^{+} \operatorname{lgG}{ }^{+} \mathrm{B}$ cells only produced IgG antibodies. At later time points, the antibodies were screened for anti-AChR reactivity using RIA. Method 2 successfully resulted in the isolation of anti-AChR antibodies from the thymus of AChR-MG patients. 
A

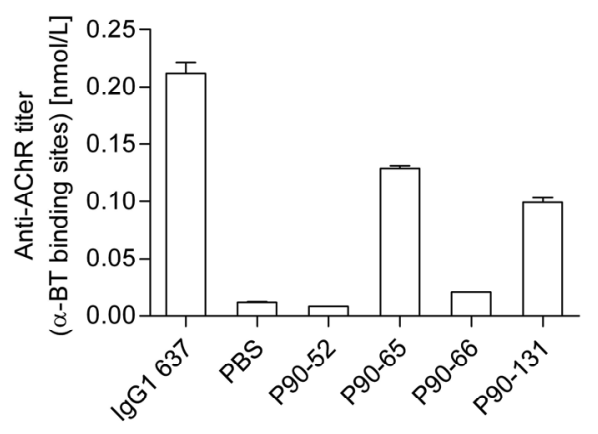

B

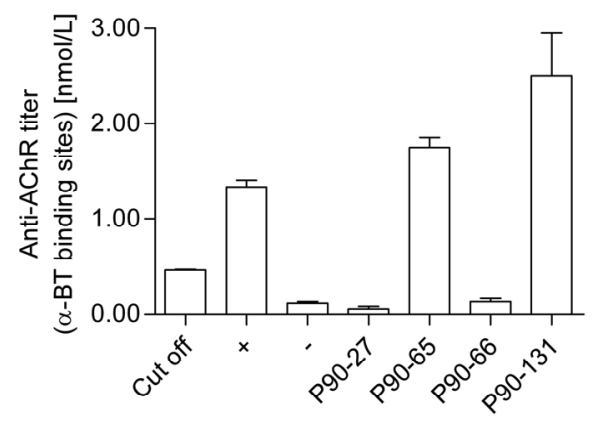

$\square$ Rat AChR

$\square$ Torpedo AChR

Mouse AChR

C

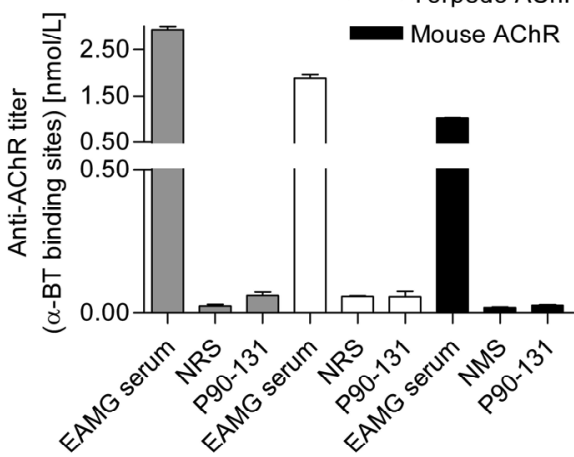

Figure 2. Immortalized B cell clones produce anti-human AChR antibodies. (A) Specificity of immortalized B cell clones against human AChR was tested by RIA using AChR isolated from the TE 671 cell line. mAb IgG1 637 [0.01 $\mathrm{g} / \mathrm{L}]$ was used as a positive control for AChR binding. Non-concentrated culture supernatant of the $B$ cell lines was used with a total Ig concentration of approximately $1 \mu \mathrm{g} / \mathrm{mL}$. Values represent the average of at least in triplo measurements. (B) Specificity of immortalized B cell clones against human AChR was tested using the IBL diagnostic kit. The first bar represents the cut-off value, as provided with the kit. Anti-AChR human serum ( + ) and normal human serum (-) were used as positive and negative controls, respectively. Values represent the average of in duplo measurements. (C) Specificity of P90-131 against non-human AChR was tested using AChR isolated from rat or mouse denervated muscle tissue or from the electric organ of Torpedo californica. AntiAChR antibody positive rat serum (EAMG serum) and normal rat or mouse serum (NRS/NMS) were used as positive and negative controls, respectively, for binding against rat, mouse and Torpedo AChR. Values represent the average of in duplo measurements. 
Comparison of $\mathrm{IgV}_{\mathrm{H}}$ nucleotide sequences of P90-65 with P90-131 did not show significant similarity. The $\mathrm{V}_{\mathrm{L}}$ sequences of $\mathrm{P} 90-65$ and $\mathrm{P} 90-131$ showed $96.5 \%$ and $89.1 \%$ homology, respectively, to their germ-line genes V3-15*01 (M23090) and V1-9*01 (K02096) (Fig. 5B). The $I g V_{L}$ nucleotide sequences of P90-65 and P90-131 display almost $75 \%$ of homology (data not shown). When comparing the $V_{H}$ and $V_{L}$ gene usage of P90-65 and P90-131 with previously published human anti-AChR antibodies (Table 2), no preferential usage of certain IgV genes was observed. Interestingly, the $V_{H}$ and $D_{H}$ gene family used in clone P90-131 matched with those used by anti-AChR Fabs that were published by Fostieri and colleagues (Fostieri et al., 2005).
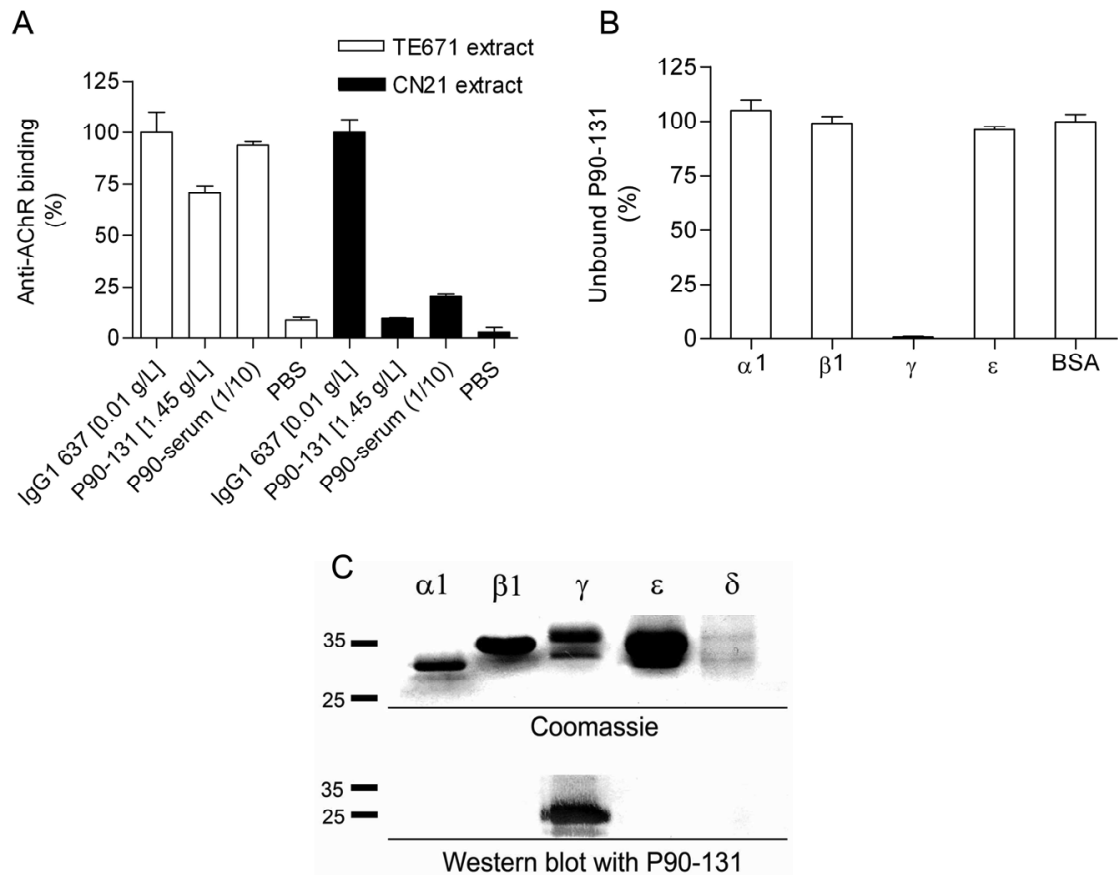

Figure 3. P90-131 specifically binds to the fetal AChR. (A) Specificity of P90-131 (concentrated culture supernatants) against fetal $\left(\alpha_{2} \beta \gamma \delta\right)$ and adult $\left(\alpha_{2} \beta \varepsilon \delta\right)$ AChR was tested using AChR isolated from TE 671 and CN 21 cell line, respectively. IgG1 637 was used as a positive control for both cell lines. The results are shown as percentage compared to $0.01 \mathrm{~g} / \mathrm{L}$ IgG1 637. Values represent the average of at least in duplo measurements. (B) Specificity of P90-131 (concentrated culture supernatants) was tested against extracellular domains of human AChR subunits using immunoabsorption. The results are shown as percentage compared to the BSA control. Values represent the average of in triplo measurements. (C) Specificity of P90-131 (concentrated culture supernatants) was tested against extracellular domains of human AChR subunits using Western blot. AChR subunits alpha, beta, gamma, epsilon and delta are visualized by Coomassie staining (upper panel). Incubation with culture supernatants of P90-131 specifically shows reactivity of P90-131 against the gamma-subunit of the AChR only (lower panel). 


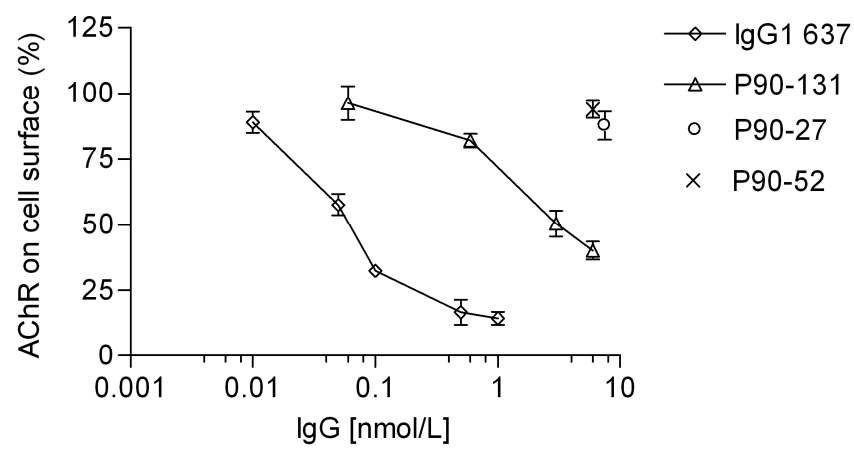

Figure 4. P90-131 modulates surface AChR on TE 671 cells. Confluent TE 671 cells were incubated with cycloheximide and culture supernatants of immortalized B cell clones. The percentage of AChR on cell surface is calculated as described in the materials and methods section. mAb IgG1 637 was used as a positive control for AChR internalization. Non-concentrated culture supernatant was used for all immortalized B cell lines. Values represent the average of in triplo measurements from three independent experiments.

\section{Immortalized B cell clones produce striational antibodies}

In addition to anti-AChR antibodies, MG patients often present with antibodies against striational muscle proteins (Vrolix et al., 2010). Therefore, we screened all immortalized B cells for striated muscle reactivity. Representative results of the immunohistochemical stainings are shown in Figure 6 . Approximately $25 \%$ of $\mathrm{CD}_{2} 2^{+} \mathrm{B}$ cell clones, immortalized by Method 1, showed reactivity against striational proteins (P21: 7/19; P28: 5/22; P42: $6 / 38$ ) both from the IgM (13 out of $18 ; 72 \%$ ) and IgG (5 out of $18 ; 28 \%$ ) subtype. Of the $\mathrm{CD}_{22} 2^{+} \mathrm{gG}^{+} \mathrm{B}$ cell clones immortalized by Method 2, only one monoclonal line against striational muscle proteins was identified (P82: 0/20; P90:1/30; 2\%). Different staining patterns that were observed suggested specificity for different striational antigens. Therefore, ELISAs were performed to identify antibodies against actin, myosin, alphaactinin and titin, but none of the striational antibodies showed specific reactivity against any of these proteins (data not shown). We also tested the anti-striated muscle reactivity of immortalized B cells isolated from PBMC's of multiple sclerosis (MS) patients and healthy individuals, but no striational antibodies were detected. 
A

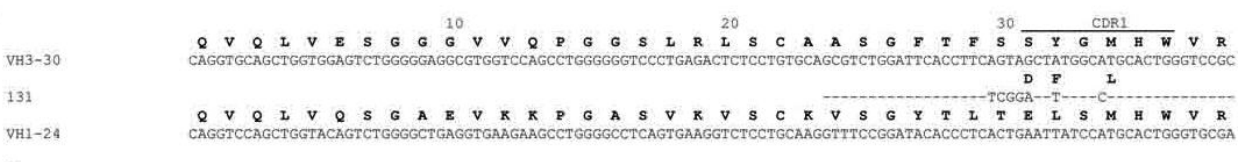
65 VH3-30 131 VH1-24 65 ขH 3-30 131

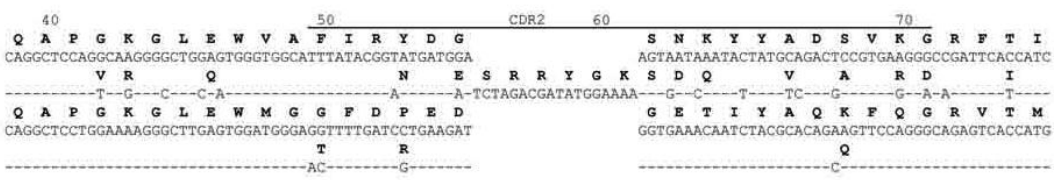

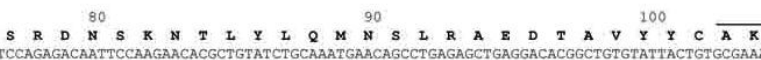

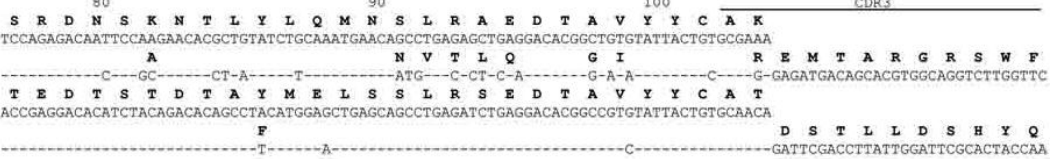

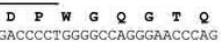

Y C S G C I Y Y Y W G Q G T I

B D I Q L T Q S P S F L S A S V G D R V T I T C R A S Q G I S S Y I A W Y Q $Q$

Figure 5. Sequence alignment of anti-AChR antibodies with germline sequences. Nucleotide sequence alignment of the $V_{H}$ and $V_{L}$ regions of clone 131 and 65 are shown together with the closest matching germline counterparts. Amino acids are shown in bold. Dashes represent nucleotide identity with the germline sequence. The CDR regions are indicated. (A) Heavy chain alignments. Clone 131 and 65 were closest related to V3-30 (L26401) and V1-24 (M99642) germline sequences, respectively. (B) Light chain alignments. $k$ light chains of clone 131 and 65 resembled KV1-9 (K02096) and KV3-15 (M23090) germline sequences, respectively. 


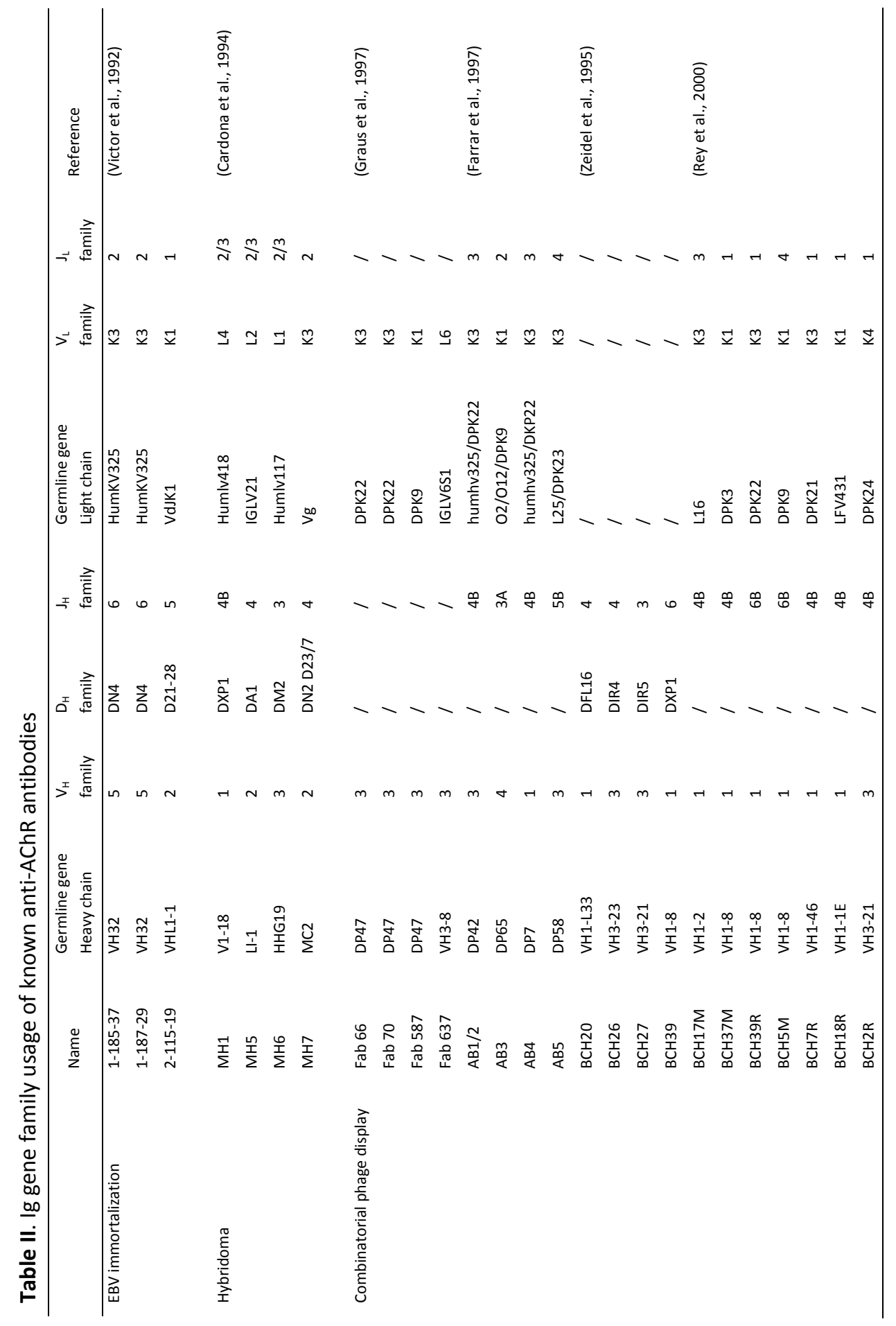




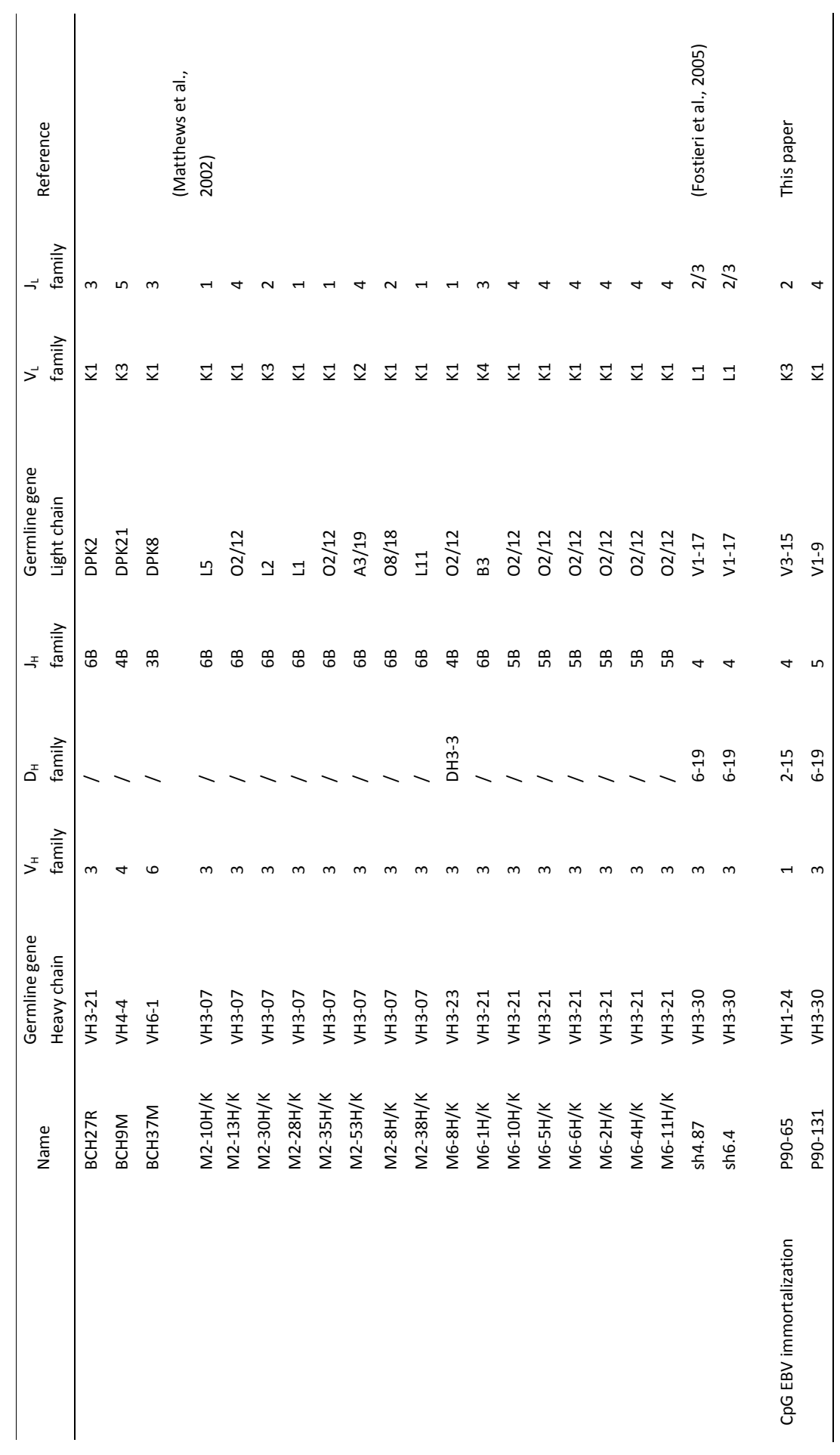




\section{Discussion}

Autoreactive B cells have been found in the human thymus, but their role in autoimmunity remains unclear in many aspects. To investigate the $B$ cell repertoire in the autoimmune thymus, we focused on AChR-MG, because thymic B cells have been implicated in its pathophysiology. By using an improved method of B cell immortalization, we isolated striational antibodies which were specifically produced by thymic B cells of MG patients. In addition, we isolated a full-size human monoclonal antibody directed against the gamma subunit of the AChR, which exerted pathogenic effects on the AChR in vitro.
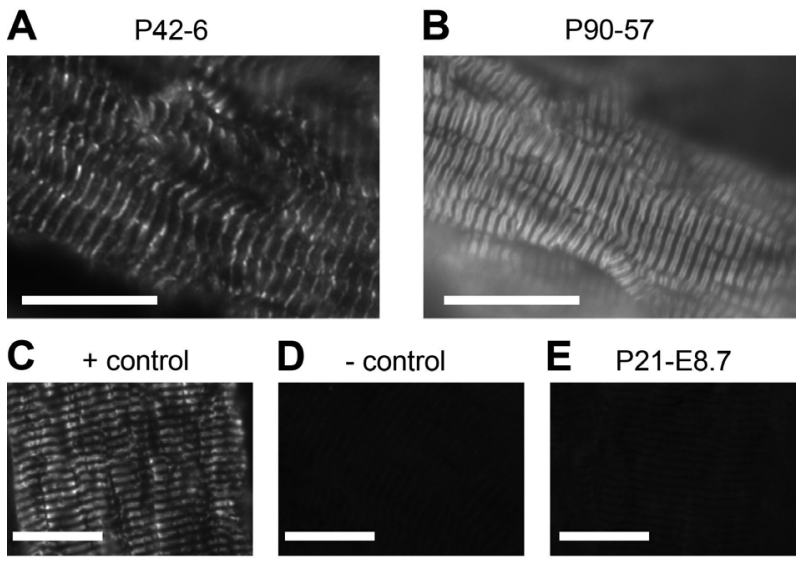

Figure 6. Immortalized B cell clones produces striational antibodies. Monkey muscle tissue was stained by immunofluorescence with culture supernatants (non-concentrated) of immortalized B cell clones. (A) Positive clone P42-6, (B) Positive clone P90-57, (C) Positive control provided with the testing system (ScimedX), (D) Negative control provided with the testing system (Scimedx), (E) Negative clone P21-E8.7. Scale bar represents $20 \mu \mathrm{m}$.

So far, the production of human monoclonal (auto-) antibodies has been proven to be difficult and only a small number of human monoclonal anti-AChR antibodies have been cloned from MG patients (supplemental Table 1). The majority of anti-AChR antibodies have been isolated using phage display libraries (Farrar et al., 1997; Fostieri et al., 2005; Graus et al., 1997; Matthews et al., 2002; Rey et al., 2000; Zeidel et al., 1995). However, the antibodies produced by phage display do not entirely reflect the natural human immune response because the original pairing of heavy and light chains is lost. 
Production of hybridomas with human B cells or EBV transformation overcomes this drawback and has previously been used to isolate anti-AChR antibodies from MG patients (Blair et al., 1986; Cardona et al., 1994; Kamo et al., 1982; Victor et al., 1992). Three monoclonal B cell lines, reacting with actin, alpha-actinin and the myosin heavy chain, respectively, have been previously isolated by using EBV immortalized $B$ cells from the MG thymus (Williams et al., 1987). Recently, a more efficient B cell immortalization procedure has been published (Traggiai et al., 2004), which we further improved for the characterization of autoimmune B cells (Fraussen et al., 2010). This enabled us to study the autoantibody repertoire from thymic B cells from AChR-MG patients. Using Method 1 (Figure 1), high amounts of anti-striated muscle reactive $B$ cells were isolated from the MG thymi, while Method 2, which is selective for IgG producing B cells, resulted in the isolation of 2 anti-AChR reactive monoclonal cell lines from 1 out of 2 MG patients.

Several reasons might have contributed to the fact why we failed to isolate AChRspecific B cell clones from patient P82. Firstly, although the thymus in MG patients has been described as a good source of anti-AChR reactive B cells (Hill et al., 2008; Safar et al., 1987), large variability exists in the ability of thymocytes from MG patients to produce anti-AChR antibodies in vitro. We only used a small piece of the thymus which might not have contained germinal centers. Secondly, the presence of the EBV receptor CD21 on thymic B cells of patient P82 was not determined, but its expression highly differs between patients (67-95\% in this study) and causes variation in immortalization susceptibility. Thirdly, except for P90, we used frozen thymocytes to perform the immortalizations. Freezing and thawing procedures might have influenced the viability and antibody production of thymic B cells. None of the 54 growing clones of patient P82 produced anti-AChR antibodies, but we isolated 2 clones with AChR reactivity out of a total of 187 clones from patient P90. This roughly correlated with the ratio of serum antiAChR antibodies (>500 $\mathrm{nM}$ ) to total IgG in the serum of this patient $(1 / 200)$, which indicates that thymic $B$ cells contribute to the autoantibody production in MG.

The observation of $B$ cell lines with reactivity against striated muscle proteins is in accordance with previous findings (Williams et al., 1987). To date, the pathological relevance of these antibodies in MG patients remains unknown, but they might be produced as a consequence of muscle damage at the postsynaptic region. More studies could be performed on these immortalized B cell lines to further investigate the characteristics of anti-striational muscle protein antibodies, since the identification of their target epitopes potentially leads to novel disease-relevant autoantigens.

The anti-AChR antibody positive clone P90-131 showed specificity for the human AChR isolated from TE 671 cells or amputated legs, and reduced AChR surface levels on TE 
671 cells. Three different techniques demonstrated the binding of P90-131 to the fetal AChR, and specifically to the gamma subunit. This may explain why P90-131 did not bind to the NMJ on monkey muscle tissue since that presumably contained only the adult AChRs. P90-131 did not show significant binding against AChR extracts from Torpedo or denervated rat and mouse muscle tissue. Since denervated muscles express the fetal AChR (Evans et al., 1987), this indicates that P90-131 does not cross-react with the AChR gamma-subunit from these species.

P90-131 belongs to the human IgG1 isotype, which means that it could potentially activate the complement system and cause damage at the NMJ in vivo if some gammatype AChRs were present between the adult AChRs (Reimann et al., 2009).

The majority of sera from AChR-MG patients contain antibodies against fetal AChR $\left(\alpha_{2} \beta \gamma \delta\right)$ (Matthews et al., 2002; Polizzi et al., 2000) and often at a higher titer compared to antibodies directed against the adult AChR (Polizzi et al., 2000). Since also high titers of anti-gamma AChR antibodies were present in the patient's P90 serum, it is understandable that we found a gamma subunit specific anti-AChR antibody in our screening. The low reactivity of the patient's serum that we observed against AChR from CN 21 cell extract (Fig $3 A$ ) can be partly attributed to low amounts of remaining fetal AChR in the cell line (Beeson et al., 1996). However, the ratio of binding against CN 21 cell line to TE 671 cell line was higher for the patient's serum (20\%) compared to the P90-131 (11\%) (based on Fig 3A), indicating that a minor fraction of the patient's antibodies are directed against the adult AChR. The fact that anti-gamma AChR antibodies often occur in MG patients and that a mixture of fetal and adult AChRs $\left(\alpha_{2} \beta \gamma \delta\right)$ are used in assays to determine anti-AChR antibodies in AChR-MG patients, might explain the well-known fact that there is no correlation between the overall anti-AChR antibody titer and AChR-MG severity.

Although not causing pathogenic effects in adults, a few anti-gamma AChR antibodies can occasionally complicate pregnancies when crossing the placenta by functionally inhibiting the AChRs of the fetus (Vincent et al., 1995). This leads to a lack of fetal movement in utero, and thereby, to the development of arthrogryposis multiplex congenital (AMC). In addition, sera of mothers with AMC babies can induce AMC-like deformities in mouse pups after injection into pregnant mice (Jacobson et al., 1999). Fetal AChR $\left(\alpha_{2} \beta \gamma \delta\right)$ inhibiting antibodies have even been shown to be more common in AChRMG patients sampled after pregnancy than in those who present before pregnancy, which suggests that the production of anti-gamma AChR antibodies is triggered by fetal immunization (Matthews et al., 2002). The patient of whom we isolated P90-131 presented AChR-MG without a previous pregnancy, suggesting other causes of anti- 
gamma AChR antibody production. To investigate the characteristics of anti-gamma AChR antibodies, Fabs have been cloned from the thymus of mothers with AMC babies. These Fabs displayed specific reactivity against fetal AChR $\left(\alpha_{2} \beta \gamma \delta\right)$ but did not cause their functional inhibition (Matthews et al., 2002). Mouse models have also been made, using sera of mothers with AMC babies, to study the role of anti-gamma AChR antibodies in the induction of AMC (Jacobson et al., 1999). Thus, our isolation of a full-size human antiAChR antibody, which specifically reacts to the fetal AChR $\left(\alpha_{2} \beta \gamma \delta\right)$, offers useful opportunities to study the role of anti-gamma AChR antibodies in AMC and in AChR-MG patients in general. In addition, P90-131 is the first anti-gamma AChR antibody to be described to exert pathogenic effects when gamma-subunit containing $A C h R s$ are present by inducing $A C h R$ internalization in vitro. Recently, the fetal AChR $\left(\alpha_{2} \beta \gamma \delta\right)$ has also been described as a specific marker of human rhabsomyosarcoma (RMS), and RMS cells have been shown to be destroyed by an immunotoxin-labeled human anti-gamma AChR Fab fragment (Gattenlohner et al., 2010). This indicates that our full-size anti-gamma AChR antibody, because of its strong binding and modulating effects, could potentially be used to refine this treatment strategy in RMS patients.

The isolation of representative striational and anti-AChR antibodies from the thymus of MG patients led to the conclusion that our improved method of B cell immortalization is a valuable tool to characterize the $B$ cell repertoire in the autoimmune thymus. An adaptation of our method to isolate specific antibodies at high throughput may even lead to the development of new antibodies with therapeutic characteristics.

\section{Acknowledgements}

We would like to thank Jonas Hummel for valuable practical assistance, and Els Meulemans, Guido Roemen and colleagues for helping us with spectratyping and sequencing experiments. We thank Prof. J Maessen and Dr. L Van Garsse for their help in the collection of thymic biopsies and Danielle Beckering for her help with the patient data. 


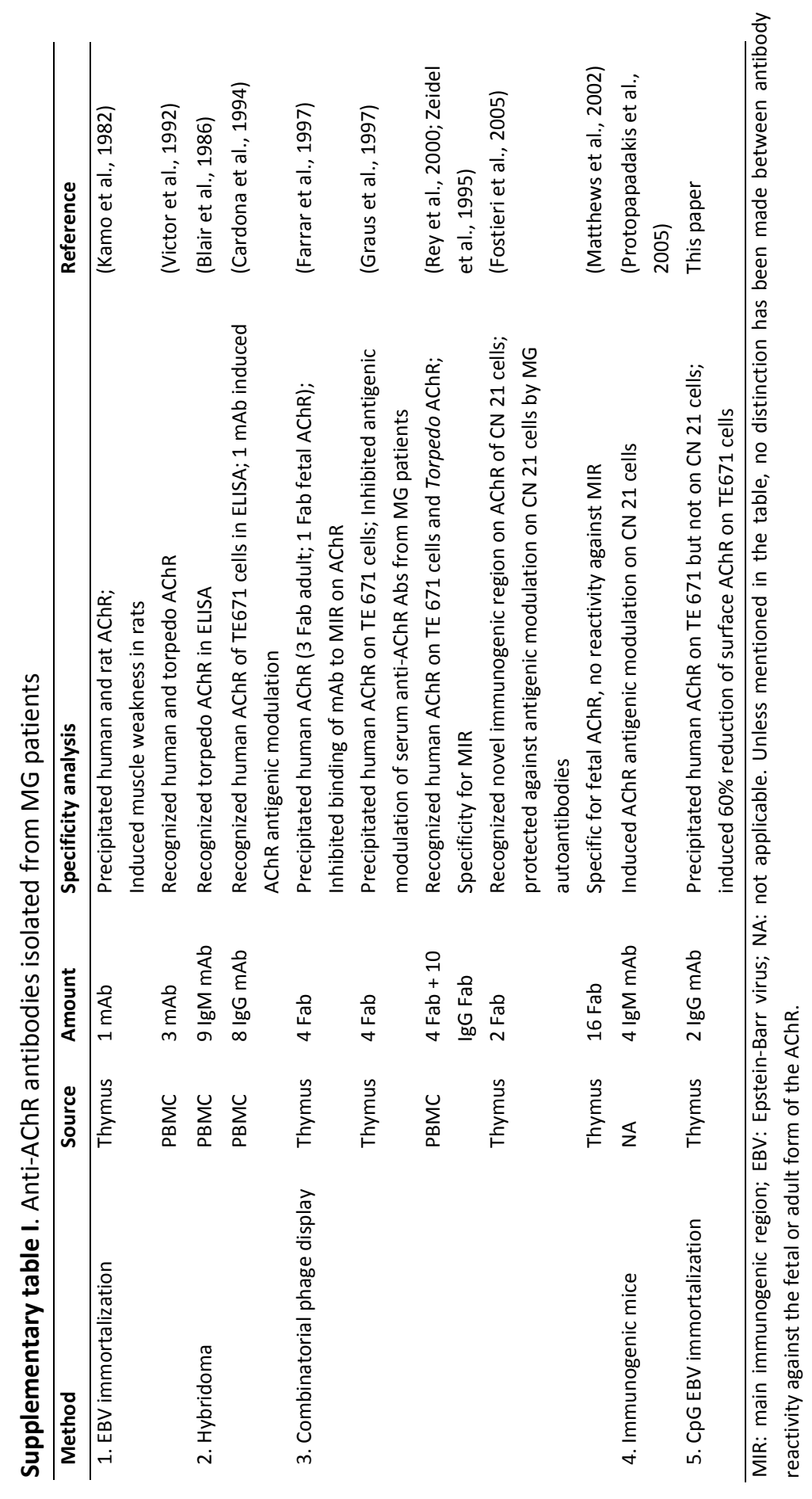




\section{References}

Almon, R.R., Andrew, C.G., Appel, S.H., 1974. Serum globulin in myasthenia gravis: inhibition of alpha-bungarotoxin binding to acetylcholine receptors. Science 186, 55-57.

Alpert, L.I., Papatestas, A., Kark, A., Osserman, R.S., Osserman, K., 1971. A histologic reappraisal of the thymus in myasthenia gravis. A correlative study of thymic pathology and response to thymectomy. Arch Pathol 91, 55-61.

Beeson, D., Jacobson, L., Newsom-Davis, J., Vincent, A., 1996. A transfected human muscle cell line expressing the adult subtype of the human muscle acetylcholine receptor for diagnostic assays in myasthenia gravis. Neurology 47, 1552-1555.

Blair, D.A., Richman, D.P., Taves, C.J., Koethe, S., 1986. Monoclonal antibodies to acetylcholine receptor secreted by human $\mathrm{x}$ human hybridomas derived from lymphocytes of a patient with myasthenia gravis. Immunol Invest 15, 351-364.

Cardona, A., Garchon, H.J., Vernet-der-Garabedian, B., Morel, E., Gajdos, P., Bach, J.F., 1994. Human IgG monoclonal autoantibodies against muscle acetylcholine receptor: direct evidence for clonal heterogeneity of the antiself humoral response in myasthenia gravis. J Neuroimmunol 53, 9-16.

Chamberlain-Banoub, J., Neal, J.W., Mizuno, M., Harris, C.L., Morgan, B.P., 2006. Complement membrane attack is required for endplate damage and clinical disease in passive experimental myasthenia gravis in Lewis rats. Clin Exp Immunol 146, 278-286.

Conti-Fine, B.M., Milani, M., Kaminski, H.J., 2006. Myasthenia gravis: past, present, and future. J Clin Invest 116, 28432854.

Drachman, D.B., Angus, C.W., Adams, R.N., Michelson, J.D., Hoffman, G.J., 1978. Myasthenic antibodies cross-link acetylcholine receptors to accelerate degradation. N Engl J Med 298, 1116-1122.

Evans, S., Goldman, D., Heinemann, S., Patrick, J., 1987. Muscle acetylcholine receptor biosynthesis. Regulation by transcript availability. J Biol Chem 262, 4911-4916.

Farrar, J., Portolano, S., Willcox, N., Vincent, A., Jacobson, L., Newsom-Davis, J., Rapoport, B., McLachlan, S.M., 1997. Diverse Fab specific for acetylcholine receptor epitopes from a myasthenia gravis thymus combinatorial library. Int Immunol 9, 1311-1318.

Fostieri, E., Tzartos, S.J., Berrih-Aknin, S., Beeson, D., Mamalaki, A., 2005. Isolation of potent human Fab fragments against a novel highly immunogenic region on human muscle acetylcholine receptor which protect the receptor from myasthenic autoantibodies. Eur J Immunol 35, 632-643.

Fraussen, J., Vrolix, K., Martinez-Martinez, P., Losen, M., Meulemans, E., De Baets, M.H., Stinissen, P., Somers, V., 2010. A novel method for making human monoclonal antibodies. J Autoimmun 35, 130-134.

Fujii, Y., Hashimoto, J., Monden, Y., Ito, T., Nakahara, K., Kawashima, Y., 1986. Specific activation of lymphocytes against acetylcholine receptor in the thymus in myasthenia gravis. J Immunol 136, 887-891.

Gattenloehner, S., Vincent, A., Leuschner, I., Tzartos, S., Muller-Hermelink, H.K., Kirchner, T., Marx, A., 1998. The fetal form of the acetylcholine receptor distinguishes rhabdomyosarcomas from other childhood tumors. Am J Pathol $152,437-444$.

Gattenlohner, S., Jorissen, H., Huhn, M., Vincent, A., Beeson, D., Tzartos, S., Mamalaki, A., Etschmann, B., MullerHermelink, H.K., Koscielniak, E., Barth, S., Marx, A., 2010. A human recombinant autoantibody-based immunotoxin specific for the fetal acetylcholine receptor inhibits rhabdomyosarcoma growth in vitro and in a murine transplantation model. J Biomed Biotechnol 2010, 187621.

Gomez, A.M., Van Den Broeck, J., Vrolix, K., Janssen, S.P., Lemmens, M.A., Van Der Esch, E., Duimel, H., Frederik, P., Molenaar, P.C., Martinez-Martinez, P., De Baets, M.H., Losen, M., 2010. Antibody effector mechanisms in myasthenia gravis-pathogenesis at the neuromuscular junction. Autoimmunity 43, 353-370.

Graus, Y.F., de Baets, M.H., Parren, P.W., Berrih-Aknin, S., Wokke, J., van Breda Vriesman, P.J., Burton, D.R., 1997. Human anti-nicotinic acetylcholine receptor recombinant Fab fragments isolated from thymus-derived phage display libraries from myasthenia gravis patients reflect predominant specificities in serum and block the action of pathogenic serum antibodies. J Immunol 158, 1919-1929. 
Gronseth, G.S., Barohn, R.J., 2000. Practice parameter: thymectomy for autoimmune myasthenia gravis (an evidencebased review): report of the Quality Standards Subcommittee of the American Academy of Neurology. Neurology 55, 7-15.

Heinemann, S., Bevan, S., Kullberg, R., Lindstrom, J., Rice, J., 1977. Modulation of acetylcholine receptor by antibody against the receptor. Proc Natl Acad Sci U S A 74, 3090-3094.

Hesselmans, L.F., Jennekens, F.G., Van den Oord, C.J., Veldman, H., Vincent, A., 1993. Development of innervation of skeletal muscle fibers in man: relation to acetylcholine receptors. Anat $\operatorname{Rec} 236,553-562$.

Hill, M.E., Shiono, H., Newsom-Davis, J., Willcox, N., 2008. The myasthenia gravis thymus: a rare source of human autoantibody-secreting plasma cells for testing potential therapeutics. J Neuroimmunol 201-202, 50-56.

Jacobson, L., Polizzi, A., Morriss-Kay, G., Vincent, A., 1999. Plasma from human mothers of fetuses with severe arthrogryposis multiplex congenita causes deformities in mice. J Clin Invest 103, 1031-1038.

Jaretzki, A., 3rd, Barohn, R.J., Ernstoff, R.M., Kaminski, H.J., Keesey, J.C., Penn, A.S., Sanders, D.B., 2000. Myasthenia gravis: recommendations for clinical research standards. Task Force of the Medical Scientific Advisory Board of the Myasthenia Gravis Foundation of America. Neurology 55, 16-23.

Kamo, I., Furukawa, S., Tada, A., Mano, Y., Iwasaki, Y., Furuse, T., Ito, N., Hayashi, K., Satoyoshi, E., 1982. Monoclonal antibody to acetylcholine receptor: cell line established from thymus of patient with Myasthenia gravis. Science 215, 995-997.

Kendall, M.D., 1995. Hemopoiesis in the thymus. Dev Immunol 4, 157-168.

Kostelidou, K., Trakas, N., Zouridakis, M., Bitzopoulou, K., Sotiriadis, A., Gavra, I., Tzartos, S.J., 2006. Expression and characterization of soluble forms of the extracellular domains of the beta, gamma and epsilon subunits of the human muscle acetylcholine receptor. FEBS J 273, 3557-3568.

Kuks, J.B., Oosterhuis, H.J., Limburg, P.C., The, T.H., 1991. Anti-acetylcholine receptor antibodies decrease after thymectomy in patients with myasthenia gravis. Clinical correlations. J Autoimmun 4, 197-211.

Lang, B., Richardson, G., Rees, J., Vincent, A., Newsom-Davis, J., 1988. Plasma from myasthenia gravis patients reduces acetylcholine receptor agonist-induced $\mathrm{Na}+$ flux into TE671 cell line. J Neuroimmunol 19, 141-148.

Leite, M.I., Jones, M., Strobel, P., Marx, A., Gold, R., Niks, E., Verschuuren, J.J., Berrih-Aknin, S., Scaravilli, F., Canelhas, A., Morgan, B.P., Vincent, A., Willcox, N., 2007. Myasthenia gravis thymus: complement vulnerability of epithelial and myoid cells, complement attack on them, and correlations with autoantibody status. Am J Pathol 171, 893905.

Levinson, A.I., Wheatley, L.M., 1996. The thymus and the pathogenesis of myasthenia gravis. Clin Immunol Immunopathol 78, 1-5.

Lindstrom, J.M., Seybold, M.E., Lennon, V.A., Whittingham, S., Duane, D.D., 1976. Antibody to acetylcholine receptor in myasthenia gravis. Prevalence, clinical correlates, and diagnostic value. Neurology 26, 1054-1059.

Losen, M., Martinez-Martinez, P., Phernambucq, M., Schuurman, J., Parren, P.W., De Baets, M.H., 2008. Treatment of myasthenia gravis by preventing acetylcholine receptor modulation. Ann N Y Acad Sci 1132, 174-179.

Losen, M., Stassen, M.H., Martinez-Martinez, P., Machiels, B.M., Duimel, H., Frederik, P., Veldman, H., Wokke, J.H., Spaans, F., Vincent, A., De Baets, M.H., 2005. Increased expression of rapsyn in muscles prevents acetylcholine receptor loss in experimental autoimmune myasthenia gravis. Brain 128, 2327-2337.

Martinez-Martinez, P., Losen, M., Duimel, H., Frederik, P., Spaans, F., Molenaar, P., Vincent, A., De Baets, M.H., 2007. Overexpression of rapsyn in rat muscle increases acetylcholine receptor levels in chronic experimental autoimmune myasthenia gravis. Am J Pathol 170, 644-657.

Martinez-Martinez, P., Phernambucq, M., Steinbusch, L., Schaeffer, L., Berrih-Aknin, S., Duimel, H., Frederik, P., Molenaar, P., De Baets, M.H., Losen, M., 2009. Silencing rapsyn in vivo decreases acetylcholine receptors and augments sodium channels and secondary postsynaptic membrane folding. Neurobiol Dis 35, 14-23.

Matthews, I., Sims, G., Ledwidge, S., Stott, D., Beeson, D., Willcox, N., Vincent, A., 2002. Antibodies to acetylcholine receptor in parous women with myasthenia: evidence for immunization by fetal antigen. Lab Invest 82,1407 1417.

Melms, A., Schalke, B.C., Kirchner, T., Muller-Hermelink, H.K., Albert, E., Wekerle, H., 1988. Thymus in myasthenia gravis. Isolation of T-lymphocyte lines specific for the nicotinic acetylcholine receptor from thymuses of myasthenic patients. J Clin Invest 81, 902-908. 
Peterson, P., Org, T., Rebane, A., 2008. Transcriptional regulation by AIRE: molecular mechanisms of central tolerance. Nat Rev Immunol 8, 948-957.

Polizzi, A., Huson, S.M., Vincent, A., 2000. Teratogen update: maternal myasthenia gravis as a cause of congenital arthrogryposis. Teratology 62, 332-341.

Protopapadakis, E., Kokla, A., Tzartos, S.J., Mamalaki, A., 2005. Isolation and characterization of human antiacetylcholine receptor monoclonal antibodies from transgenic mice expressing human immunoglobulin loci. Eur J Immunol 35, 1960-1968.

Reimann, J., Jacobson, L., Vincent, A., Kornblum, C., 2009. Endplate destruction due to maternal antibodies in arthrogryposis multiplex congenita. Neurology 73, 1806-1808.

Rey, E., Zeidel, M., Rhine, C., Tami, J., Krolick, K., Fischbach, M., Sanz, I., 2000. Characterization of human antiacetylcholine receptor monoclonal autoantibodies from the peripheral blood of a myasthenia gravis patient using combinatorial libraries. Clin Immunol 96, 269-279.

Safar, D., Berrih-Aknin, S., Morel, E., 1987. In vitro anti-acetylcholine receptor antibody synthesis by myasthenia gravis patient lymphocytes: correlations with thymic histology and thymic epithelial-cell interactions. J Clin Immunol 7, 225-234.

Scadding, G.K., Vincent, A., Newsom-Davis, J., Henry, K., 1981. Acetylcholine receptor antibody synthesis by thymic lymphocytes: correlation with thymic histology. Neurology 31, 935-943.

Takahama, Y., 2006. Journey through the thymus: stromal guides for T-cell development and selection. Nat Rev Immunol 6, 127-135.

Traggiai, E., Becker, S., Subbarao, K., Kolesnikova, L., Uematsu, Y., Gismondo, M.R., Murphy, B.R., Rappuoli, R., Lanzavecchia, A., 2004. An efficient method to make human monoclonal antibodies from memory B cells: potent neutralization of SARS coronavirus. Nat Med 10, 871-875.

van der Neut Kolfschoten, M., Schuurman, J., Losen, M., Bleeker, W.K., Martinez-Martinez, P., Vermeulen, E., den Bleker, T.H., Wiegman, L., Vink, T., Aarden, L.A., De Baets, M.H., van de Winkel, J.G., Aalberse, R.C., Parren, P.W., 2007. Anti-inflammatory activity of human IgG4 antibodies by dynamic Fab arm exchange. Science 317, 1554-1557.

Victor, K.D., Pascual, V., Lefvert, A.K., Capra, J.D., 1992. Human anti-acetylcholine receptor antibodies use variable gene segments analogous to those used in autoantibodies of various specificities. Mol Immunol 29, 1501-1506.

Vincent, A., Beeson, D., Lang, B., 2000. Molecular targets for autoimmune and genetic disorders of neuromuscular transmission. Eur J Biochem 267, 6717-6728.

Vincent, A., Newland, C., Brueton, L., Beeson, D., Riemersma, S., Huson, S.M., Newsom-Davis, J., 1995. Arthrogryposis multiplex congenita with maternal autoantibodies specific for a fetal antigen. Lancet 346, 24-25.

Vrolix, K., Fraussen, J., Molenaar, P.C., Losen, M., Somers, V., Stinissen, P., De Baets, M.H., Martinez-Martinez, P., 2010. The auto-antigen repertoire in myasthenia gravis. Autoimmunity $43,380-400$.

Wakkach, A., Guyon, T., Bruand, C., Tzartos, S., Cohen-Kaminsky, S., Berrih-Aknin, S., 1996. Expression of acetylcholine receptor genes in human thymic epithelial cells: implications for myasthenia gravis. J Immunol 157, 3752-3760.

Wekerle, H., Ketelsen, U.P., Zurn, A.D., Fulpius, B.W., 1978. Intrathymic pathogenesis of myasthenia gravis: transient expression of acetylcholine receptors on thymus-derived myogenic cells. Eur J Immunol 8, 579-582.

Williams, C.L., Lennon, V.A., Momoi, M.Y., Howard, F.M., Jr., 1987. Serum antibodies and monoclonal antibodies secreted by thymic B-cell clones from patients with myasthenia gravis define striational antigens. Ann $\mathrm{N} Y$ Acad Sci 505, 168-179.

Zeidel, M., Rey, E., Tami, J., Fischbach, M., Sanz, I., 1995. Genetic and functional characterization of human autoantibodies using combinatorial phage display libraries. Ann N Y Acad Sci 764, 559-564. 


\section{Chapter 5}

\section{Different B cell and antibody repertoire}

in thymus of myasthenia gravis patients compared to controls

Vrolix K, Fraussen J, Losen M, Molenaar P, Stinissen P, Somers V, Le Panse R, Berrih-Aknin S, Maessen JG, Van Garsse L, Somers V, De Baets MH, Martínez-Martínez P 


\section{Abstract}

Thymic B cells play an important role in the immune system, but still their contribution to autoimmunity remains unclear in many aspects. Myasthenia gravis (MG) with antibodies against the acetylcholine receptor (AChR) (i.e. AChR-MG) is considered as a prototypic antibody-mediated autoimmune disease, and in AChR-MG patients, the thymus and thymic B cells are thought to play a fundamental role in the pathophysiology of the disease. The antibody repertoire produced by the thymic B cells of AChR-MG patients, however, has never been directly compared to that of thymic B cells from healthy individuals. Previously, we have described an improved B cell immortalization method as a useful tool to characterize the thymic $B$ cell repertoire. We hypothesize that thymic $B$ cell and antibody repertoire of AChR-MG patients intrinsically differ from that of healthy individuals. We found a ten-fold increase in B cells, which were also phenotypically different, in the thymus of AChR-MG patients. In addition, we observed that $23 \%$ of $B$ cells of the AChR-MG thymus displayed reactivity against striated muscle proteins compared to $4 \%$ of $B$ cells of the control thymus. Despite these differences, gene sequence analysis of the immunoglobulin variable region heavy chain $\left(\operatorname{lgV}_{H}\right)$ sequences showed remarkable similarities, concerning $V_{H}$ family gene distribution, mutation frequency and CDR3 composition, between thymic B cells of controls and AChR-MG patients. However, we found more clonally expanded B cell clones in the thymus of AChRMG patients and noticed that specific anti-AChR antibodies displayed higher mutation frequencies compared to non anti-AChR immunoglobulin (Ig) $\mathrm{G}^{+}$antibodies. These results show that the B cell and antibody repertoire differs between AChR-MG patients and healthy controls, but these differences are not caused by intrinsic differences on Ig gene sequences. 


\section{Introduction}

The thymus plays a major role in the central immune tolerance, mainly by regulating the development and maturation of non self-reactive $T$ cells and the elimination of selfreactive T cells (von Boehmer and Kisielow, 1990). T cells are indeed in the majority in the thymus, but small numbers of B cells are also present (Isaacson et al., 1987). Thymic B cells are found mainly in the medulla of the normal human thymus from early in ontogeny through to adulthood. They have the phenotype of activated B cells (Isaacson et al., 1987; Spencer et al., 1992) and the presence of B cell progenitor cells in the thymus indicates that B cells can proliferate into mature and Ig-producing B cells within the thymus by endogenous stimuli (Mori et al., 1997). Because thymic B cells make close contacts with surrounding thymocytes by forming rosettes, they can act as antigen-presenting cells during the negative selection of autoreactive T cells, thereby playing a role in the process of central tolerance (Fukuba et al., 1994; Inaba et al., 1991; Zoller, 1990). In addition, thymic $B$ cells contribute to the expression of tissue restricted antigens on thymic epithelial cells (Akirav et al., 2011) and they have been reported as the first and main source of natural antibody production (Cukrowska B., 2002). These findings suggest that thymic B cells play a fundamental role in the immune system. Nevertheless, their contribution to autoimmunity is poorly understood.

Acetylcholine receptor (AChR) antibody positive myasthenia gravis (MG) (AChR-MG) is a prototypic B cell-mediated autoimmune disease which is characterized by skeletal muscle weakness (Conti-Fine et al., 2006; Lindstrom et al., 1976; Vincent et al., 2000). In AChR-MG patients, the thymus and thymic B cells are known to play a significant role in the pathophysiology of the disease. The number of B cells in the thymus of AChR-MG patients is highly increased compared to those of healthy individuals (Flores et al., 2001) and these B cells have been shown to produce anti-AChR antibodies in vitro (Yoshikawa and Lennon, 1997). $20 \%$ to $80 \%$ of AChR-MG patients improve after thymectomy (Gronseth and Barohn, 2000; Kuks et al., 1991). In addition, $60-70 \%$ of early-onset AChRMG patients have a hyperplastic thymus containing AChR-specific T cells and germinal centers (Levinson and Wheatley, 1996; Melms et al., 1988). These germinal centers may be sites of an intense $B$ cell activation and proliferation against the AChR. Moreover, muscle-like myoid cells and thymic epithelial cells specifically express AChRs in the MG thymus and might influence the anti-AChR antibody production by thymic B cells (Akirav et al., 2011; Kyewski and Taubert, 2008; Leite et al., 2007; Wakkach et al., 1996; Wekerle et al., 1978). These observations indicate that in AChR-MG patients, there is a specific differentiation of B cells in the thymus that produce anti-AChR antibodies. However, the 
antibody repertoire produced by thymic B cells of AChR-MG patients has not been fully characterized and has not so far been compared to that of healthy controls.

In this study, we focus on AChR-MG to elucidate the involvement of thymic B cells and their antibodies in autoimmunity. Our hypothesis is that the thymic B cell and antibody repertoires intrinsically differ between AChR-MG patients and healthy controls, thereby contributing to the autoimmune pathology. We have shown before that our improved method of EBV immortalization of B cells is very useful to study the thymic $B$ cell repertoire (Fraussen et al., 2010; Vrolix et al., Manuscript in preparation). Here, we used this method to investigate the antibody repertoire of thymic $B$ cells in more detail. Our results show that significantly more and phenotypically different $B$ cells are present in the thymus of AChR-MG patients compared to healthy controls. The EBV receptor CD21 was expressed on significantly more B cells of the MG thymus compared to the control thymus. For the first time, we also demonstrated that thymic B cells from controls produced antibodies against striated muscle proteins. Interestingly these antibodies were produced by significantly more thymic B cells of AChR-MG compared to those of healthy controls and more clonally expanded B cells were detected in the AChR-MG thymus compared to control thymuses.

\section{Materials and methods}

\section{Patients}

MG patients were thymectomized at the academical hospital of Maastricht (AZM) in the Netherlands, and thymic biopsies from non-MG patients undergoing cardiovascular surgery were obtained at the Marie Lannelongue Chirurgical Center in France. Informed consent was obtained from all patients and the studies were approved by the local medical ethical committee in the Netherlands (NL22271.068.08) and in France (CCPPRB, Kremlin-Bicêtre, France: agreement (18/10/1999)). Clinical data of MG patients are summarized in Table 1. Since the thymus of healthy individuals undergoes involution with age, normal thymus tissue was obtained from babies (i.e. control-young) and young adults (control-adults) instead of perfectly age-matched controls to obtain sufficient material to study the $B$ cell repertoire. The age of the healthy individuals is listed in table 2. 
Table I. Clinical characteristics and immortalization information of AChR-MG patients

\begin{tabular}{|c|c|c|c|c|c|c|}
\hline Patient & P21 & P28 & P42 & P82 & P90 & P53 \\
\hline Sex & female & female & female & female & female & female \\
\hline Disease severity & Illa & $\mathrm{Ilb}$ & $\mathrm{IVb}$ & Illb & $\mathrm{IVb}$ & $\mathrm{llb}$ \\
\hline Age at thymectomy (y) & 29 & 41 & 24 & 28 & 23 & 28 \\
\hline Thymic histology & $\mathrm{FH}$ & $\mathrm{FH}$ & $\mathrm{FH}$ & $\mathrm{FH}$ & $\mathrm{FH}$ & $\mathrm{FH}$ \\
\hline Anti-AChR Ab titer (nM) & 104 & 90 & 24 & $>20$ & $>500$ & 93 \\
\hline Age at onset (years) & 26 & 38 & 23 & 28 & 23 & 26 \\
\hline MG symptoms & Generalized & $\begin{array}{l}\text { Ocular/ } \\
\text { bulbar }\end{array}$ & Generalized & Generalized & Generalized & $\begin{array}{l}\text { Bulbar/ } \\
\text { generalized }\end{array}$ \\
\hline Treatment & Mestinon & Mestinon & Mestinon & Mestinon & Mestinon & Mestinon \\
\hline Comorbidities & RA & l & Diabetes & Scoliosis & / & Family diabetic \\
\hline B cell selection & $\mathrm{CD}_{22}{ }^{+}$ & $\mathrm{CD}_{22}{ }^{+}$ & $\mathrm{CD}_{22}{ }^{+}$ & ${\mathrm{CD} 22^{+} \operatorname{lgG}}^{+}$ & $\mathrm{CD}_{2} 2^{+} \operatorname{lgG}{ }^{+}$ & $\mathrm{NI}$ \\
\hline Number of sequences & 15 & 14 & 35 & 16 & 27 & $\mathrm{NI}$ \\
\hline
\end{tabular}

RA: rheumatoid arthritis; FH: follicular hyperplasia; NI: not immortalized.

Table II. Clinical characteristics and immortalization information of healthy controls

\begin{tabular}{lllllllll}
\hline Patient & C2 & C4 & C8 & C14 & C15 & C17 & C18 & C29 \\
\hline Age & $2 \mathrm{~m}$ & $4 \mathrm{~m}$ & $8 \mathrm{~m}$ & $14 \mathrm{y}$ & $15 \mathrm{y}$ & $17 \mathrm{y}$ & $18 \mathrm{y}$ & $29 \mathrm{y}$ \\
B cell selection & $\mathrm{CD} 22^{+}$ & $\mathrm{CD} 22^{+}$ & $\mathrm{CD} 22^{+}$ & $\mathrm{CD} 22^{+}$ & $\mathrm{CD} 22^{+}$ & $\mathrm{CD}_{2} 2^{+}$ & $\mathrm{NI}$ & $\mathrm{CD}_{22}{ }^{+}$ \\
Number of sequences & 1 & 28 & 6 & 45 & 5 & 2 & $\mathrm{NI}$ & 43 \\
\hline
\end{tabular}

M: months; y: years; NI: not immortalized.

\section{Thymus tissue}

Thymus tissue was mechanically disrupted immediately after surgical removal by rubbing it through a nylon gauze or by using the GentleMacs dissociator (Miltenyi Biotec, Bergisch Gladbach, Germany) according to the manufacturer's instructions. No distinction has been made between germinal centers, medullar or perivascular space regions when processing the thymus tissue. The crude cell suspension was collected in Roswell Park Memorial Institute (RPMI) medium and passed through a $30-\mu \mathrm{m}$ cell strainer to remove large cell clumps and fat tissue. Single cell suspensions were stored in liquid $\mathrm{N}_{2}$ except for cell suspensions from patient P90 which were processed immediately.

\section{Fluorescence activated cell sorting (FACS)}

The phenotype of thymic B cells from 4 MG patients and 7 healthy controls ( 3 young +4 adult) was analyzed by FACS. In short, thymocytes $\left(10^{5}\right.$ cells $/ 0.2 \mathrm{~mL} /$ tube) were washed with staining buffer ( $2 \%$ fetal bovine serum (FCS) and $0.1 \%$ sodium azide in phosphatebuffered saline (PBS)), and incubated for 30 minutes at $4^{\circ} \mathrm{C}$ with different combinations of 
antibody: CD19-PerCP Cy5.5, IgM-PE, IgG-FITC, CD22-PE-Cy5, CD21-PE and CD19-FITC (1/40 in staining buffer) (all from Becton Dickinson (BD) Biosciences, San Jose, USA). Cells were washed three times and measured on a FACSCalibur flow cytometer system (BD Biosciences). Analysis was performed using the CellQuest Pro software (BD Biosciences).

\section{B cell immortalization}

Mature $\left(\mathrm{CD}_{2} 2^{+}\right) \mathrm{B}$ cells were isolated from the total thymocyte cell population by binding to CD22 microbeads (Miltenyi Biotec) and separating on a magnetic column (P21, P28, P42 and all control patients), according to the manufacturer's instructions. Alternatively, $\mathrm{CD}_{22}{ }^{+} \mathrm{IgG}^{+} \mathrm{B}$ cells were isolated (for P82 and P90) by staining total thymocytes with antiCD22 and anti-IgG antibodies and subsequently enriching positively labeled cells using the FACSAria II cell sorter (all from BD Biosciences). Selected B cells were immortalized as described previously (Fraussen et al., 2010; Vrolix et al., Manuscript in preparation). The B cell selection method used for AChR-MG patients and controls are listed in table 1 and 2, respectively. Throughout the manuscript, AChR-MG patients are subdivided in two categories based on the $B$ cell selection method before immortalization: $A C h R-M G_{C D 22+}$ and $A C h R-M_{\mathrm{CD} 22+\operatorname{lgG}+}$.

\section{Measurement of antibody production}

Dot blotting was used to measure the antibody production of immortalized B cell lines as described before (Fraussen et al., 2010; Vrolix et al., Manuscript in preparation).

\section{Immunohistochemistry for anti-muscle antibodies}

The monkey anti-striated muscle antibody immunofluorescence test system (ScimedX, Denville, USA) was used to detect striational antibodies in culture supernatants of immortalized B cells. Stainings were performed according to the manufacturer's instructions. In short, muscle sections were incubated with culture supernatants of immortalized B cell lines for three hours at room temperature (RT). Sections were washed with PBS and incubated with conjugate solution for one hour at RT. After washing with PBS, coverslips were mounted with mounting medium.

\section{Spectratyping and sequencing analysis}

RNA was isolated from the immortalized B cells by using the high pure RNA isolation kit (Roche) according to the manufacturer's instructions. The isolated RNA was subsequently converted into cDNA with the Reverse transcription system kit (Promega) according to the manufacturer's instructions. To analyze the variable region of the B cell receptor heavy 
and light chain locus, PCR and sequencing reactions were performed as described before (Vrolix et al., Manuscript in preparation). Variable region heavy chain $\left(\mathrm{V}_{\mathrm{H}}\right)$ family usage was determined by comparing the nucleotide sequences to GenBank databases with the immunoglobulin (Ig) basic local alignment search tool of NCBI (IgBlast, NCBI). The IgV region was subsequently sequenced in the forward direction by means of a $V_{H}$ family specific forward primer using the same procedure. Forward and reverse sequences were aligned using the BLAST alignment tool (bl2seq, NCBI) in order to establish the complete VDJ region sequence. Flanking regions corresponding to the PCR amplification primers were not removed from the sequences prior to further analysis. The obtained sequences were run through the BLAST Ig database (IgBlast, NCBI) and analyzed with JOINSOLVER ${ }^{\circ}$ software (http://joinsolver.niams.nig.gov) (Souto-Carneiro et al., 2004), a software tool which was specifically developed to identify the $C D R 3_{H}$ region of Ig genes expressed by human $B$ cells. Genealogical trees showing the homology between amino acid sequences containing CDR1-3 regions from monoclonal antibodies produced by immortalized $B$ cell clones were constructed by analysis of shared and unshared mutation using phylogenetic analysis by Bosque (http://bosque.udec.cl) (Ramirez-Flandes and Ulloa, 2008). The number of sequences analyzed per patient are listed in Table 1 and 2.

\section{Statistics}

All statistical analyses were performed using Prism software version 4.00 (GraphPad). The distribution of $V_{H}$ gene family usage was assessed using $\chi^{2}$ analysis. Student's t-test or one-way ANOVA plus Bonferroni post-hoc testing were used to analyze other parameters. $P$ values equal or less than 0.05 were assumed to be significant.

\section{Results}

\section{The AChR-MG thymus contains more and phenotypically different B cells}

To investigate the hypothesis that the thymic B cell and antibody repertoire differs between healthy controls and AChR-MG patients, we first compared the phenotypic expression of different $B$ cell markers in their thymuses using flow cytometry. The results are summarized in Table 3 and Figure 1. Despite the trend for more B cells in the controladult compared to the control-young thymus (Fig. $1 \mathrm{~A}$ and $1 \mathrm{C}$ ), the differences were not significant and these groups were combined (i.e. control) for the analysis shown in Table 3. Comparing thymocytes of controls and AChR-MG patients, significantly higher percentages of $\mathrm{CD} 19^{+}$and $\mathrm{CD} 22^{+} \mathrm{B}$ cells were present in the AChR-MG thymus $(p<0.01$ 
for both parameters). The percentage of thymic $C D 19^{+} \operatorname{lgG}{ }^{+}$and $\mathrm{CD}_{2} 2^{+} \operatorname{IgG}{ }^{+}$B cells was significantly increased in AChR-MG patients compared to controls ( $p<0.001$ for both parameters). The percentage of $\mathrm{CD}^{2} 2^{+} \operatorname{IgG}{ }^{+}$(Fig. $1 \mathrm{~A}$ ) and $\mathrm{CD} 19^{+} \operatorname{IgG}{ }^{+} \mathrm{B}$ cells (data not shown) was also significantly higher in AChR-MG patients compared to both controlyoung and control-adult patients separately ( $p<0.001$ for all analyses). Then, we found an age-related increase of $C D 22^{+} B$ cells in the thymus of healthy individuals (Fig. 1B). No such age-related trend was observed in AChR-MG patients and their percentage of thymic $B$ cells highly varied. Despite the observed increase in percentage of $C D 22^{+}$thymic $B$ cells with age and with MG, the mean percentage of $C D 22^{+} B$ cells in AChR-MG thymus did not significantly differ from that of control-young or control-adult separately (data not shown), most probably because the high variation in the proportion of $\mathrm{CD}_{2} 2^{+}$cells in the AChR-MG thymus and because of low patient numbers per group. Finally, we determined the susceptibility of thymic B cells to EBV immortalization by measuring their expression of CD21, which functions as the receptor for EBV during EBV infection. In the literature, discrepancy exists on whether CD21 is expressed on control thymocytes or not (Flores et al., 2001; Isaacson et al., 1987; Spencer et al., 1992), but its expression on AChR-MG thymocytes has clearly been confirmed (Leprince 1990). We found an increased amount of $\mathrm{CD}_{21} 1^{+}$thymocytes in AChR-MG patients compared to controls $(p<0.05)$ (Table 3 and Fig. 1C). The proportion of $C D 22^{+} B$ cells that expressed $C D 21$ was even two-fold higher in the AChR-MG thymus. CD21 expression on thymocytes has never been directly compared between AChR-MG patients and controls, but these findings indicate that the specific phenotype of MG thymic $B$ cells might make them more susceptible to EBV immortalization compared to those of healthy individuals.

Table III. Phenotypic analysis of thymic B cells

\begin{tabular}{|c|c|c|}
\hline & Controls & AChR-MG \\
\hline${\mathrm{CD} 19^{+}}^{+}$ & $1.70 \pm 0.26$ & $17.74 \pm 6.43^{* *}$ \\
\hline $\mathrm{CD} 22^{+}$ & $1.40 \pm 0.29$ & $17.40 \pm 6.51 * *$ \\
\hline $\mathrm{CD} 21^{+}$ & $1.49 \pm 0.22$ & $16.73 \pm 6.77^{*}$ \\
\hline $\operatorname{lgM}^{+}$ & $0.49 \pm 0.14$ & $8.77 \pm 4.70 *$ \\
\hline $\operatorname{lgG}^{+}$ & $0.61 \pm 0.23$ & $4.03 \pm 0.22 * * *$ \\
\hline $\mathrm{CD}_{19}{ }^{+} \lg \mathrm{G}^{+}$ & $0.46 \pm 0.20$ & $3.64 \pm 0.40 * * *$ \\
\hline $\mathrm{CD}_{22}{ }^{+} \operatorname{IgG}^{+}$ & $0.47 \pm 0.20$ & $3.69 \pm 0.38 * * *$ \\
\hline $\mathrm{CD} 21^{+}$of $\mathrm{CD} 22^{+}$ & $42.44 \pm 4.82$ & $83.63 \pm 6.45 * * *$ \\
\hline $\operatorname{lgG}^{+}$of $\mathrm{CD} 22^{+}$ & $23.50 \pm 6.47$ & $26.64 \pm 6.82$ \\
\hline $\operatorname{lgM}^{+}$of $\mathrm{CD} 22^{+}$ & $31.51 \pm 9.14$ & $31.07 \pm 5.43$ \\
\hline
\end{tabular}

All numbers are shown as mean percentages \pm SEM of total thymocytes. Results of Control-young and Controladult groups were combined for analysis. Student's T-test has been used for statistical analysis. ${ }^{*} p<0.05$; $* * p<0.01 ; * * * p<0.001$ 
A

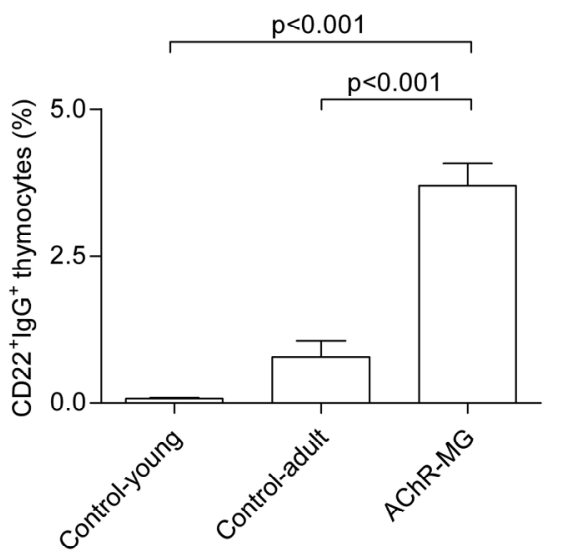

B

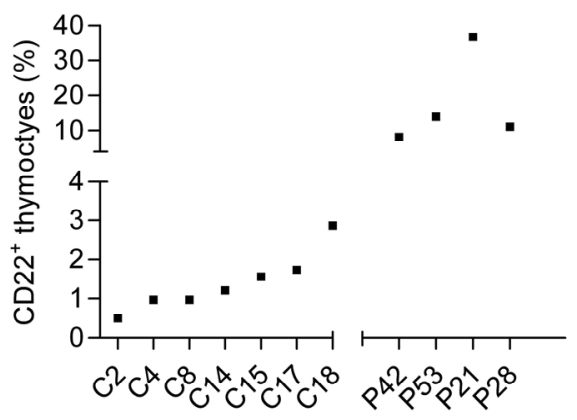

C

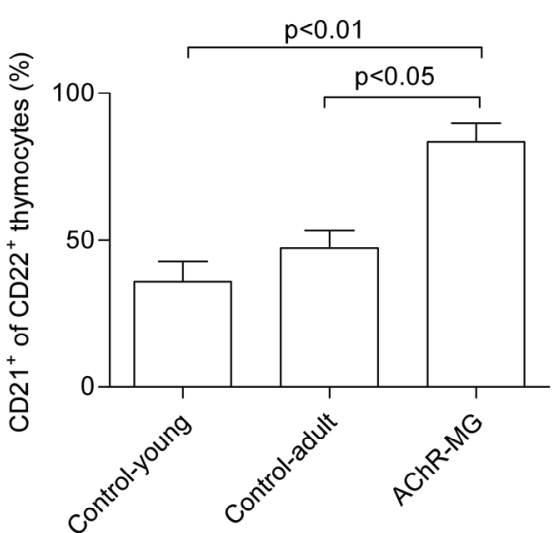

Figure 1. Phenotypic analysis of thymic B cells. (A) Mean percentage of $C D 22^{+} \operatorname{lgG}{ }^{+} B$ cells in the thymus of control-young, control-adult and AChR-MG patients. (B) Percentage of $C D 22^{+} B$ cells in the thymus of individual controls and AChR-MG patients. Both controls and AChR-MG patients are arranged by increasing age. The number of $\mathrm{CD} 22^{+} \mathrm{B}$ cells increases with age in the thymus of healthy individuals and highly varies in the thymus of AChR-MG patients. (C) Mean percentage of $C D 21^{+}$cells in $C D 22^{+}$thymic $B$ cell population of control-young, control-adult and AChR-MG patients. One-way ANOVA and Bonferroni post hoc testing were used for statistical analysis.

\section{Normal IgG to IgM ratio in thymic B cells of AChR-MG patients}

We investigated whether thymic B cells of controls and AChR-MG patients produced IgM ${ }^{+}$ and $\mathrm{IgG}^{+}$antibodies in different proportions. Before immortalization, significantly more AChR-MG thymocytes expressed IgM or IgG on their cell surface in comparison to control thymocytes ( $p<0.05$ and $p<0.0001$, respectively) (Table 3 ). The percentage of IgG $^{+}$or $\mathrm{IgM}^{+}$cells out of $\mathrm{CD} 22^{+} \mathrm{B}$ cells did not differ between the AChR-MG and control thymus. 
However, the ratio of $\operatorname{IgG}^{+}$to $\operatorname{IgM}^{+}$cells out of $\mathrm{CD} 22^{+} \mathrm{B}$ cells was significantly higher in control-adult compared to control-young thymus $(p<0.05)$ (Fig. $2 A)$. Only a trend for higher IgG/IgM ratio was observed in AChR-MG compared to control-young thymus, presumably because of the high variability between AChR-MG values. After immortalization, thymic B cells were screened for IgG or IgM secretion by dot blot (Fig. 2B). As expected, the immortalized B cell clones from AChR-MG patients which were selected for $\mathrm{CD}_{2} 2^{+} \operatorname{IgG}{ }^{+}$expression prior to immortalization (i.e. $A C h R-M_{\mathrm{CD22}+\mathrm{IgG}}$ ) all secreted $\operatorname{lgG}^{+}$antibodies, and therefore, they were omitted here from further analysis. In general, the majority of immortalized B cells, both from AChR-MG and control thymus, secreted antibodies of the IgM isotype. The ratio of $\operatorname{lgG} / \operatorname{IgM}$-producing $B$ cells only statistically differed between control-young and AChR-MG groups $(p<0.05)$. We also observed that the $\operatorname{lgG} / \lg M$ ratio in most patients slightly decreased due to immortalization (Fig. $2 \mathrm{~A}$ versus $2 \mathrm{~B}$ ).
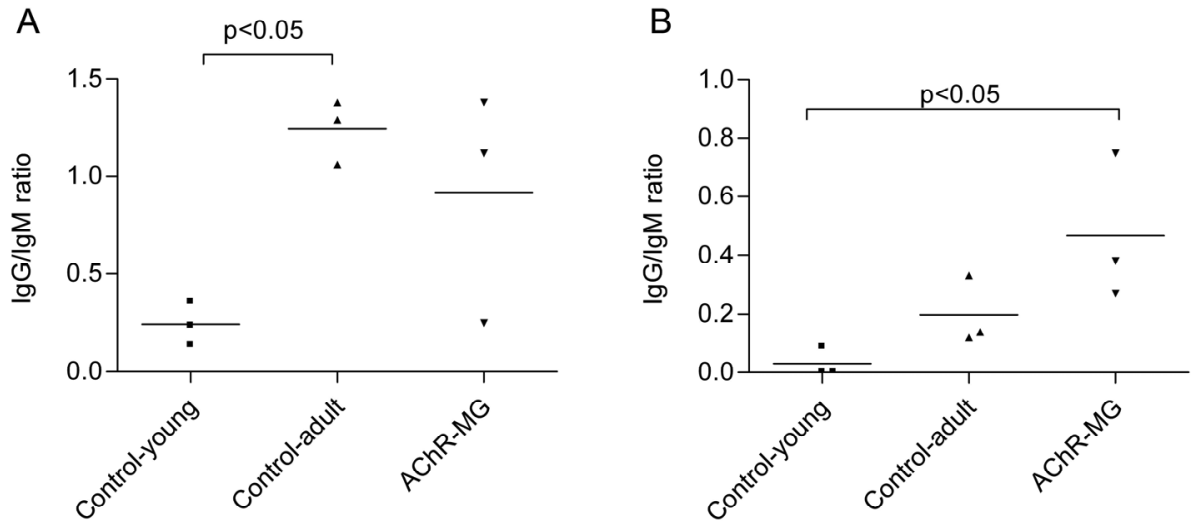

Figure 2. IgG and IgM antibody ratio in thymic B cells. (A) Ratio of IgG/IgM producing $B$ cells before immortalization was measured by flow cytometry. (B) Ratio of IgG/IgM producing B cells after immortalization was measured by dot blot. One-way ANOVA and Bonferroni post hoc testing were used for statistical analysis.

\section{More B cells of AChR-MG thymus produce striational antibodies}

It is known that striational antibodies occur in about $30 \%$ of AChR-MG patients (Vrolix et al., 2010a) and that thymic B cells of AChR-MG patients can produce striational antibodies in vitro (Vrolix et al., Manuscript in preparation; Williams and Lennon, 1986). Therefore, we investigated whether such antibodies can also be produced by control thymic $B$ cells. We found that thymic B cells of both controls and AChR-MG patients produced antibodies 
with anti-striated muscle protein reactivity and they displayed a similar staining pattern, which is shown previously (Vrolix et al., Manuscript in preparation). In addition, both IgM and IgG isotypes were detected among the striational antibodies (data not shown). The proportion of thymic $B$ cells with anti-striated muscle reactivity, however, was significantly higher in $A C h R-M G_{C D 22+} B$ cells $(23 \%)$ than in control $B$ cells $(6 \%)(p<0.001)$ (Fig.3). No differences were observed between control-young and control-adult thymic $B$ cells. Importantly, only $2 \%$ of the $A C h R-M_{C D 22+1 g G+}$ thymic $B$ cells produced striational antibodies (data not shown). This suggests that the higher percentage of striational antibodies in the MG thymus is not due to its higher ratio of IgG antibody producing $B$ cells and shows that the striational antibodies mainly belong to the IgM subtype. Indeed, we found that, when only taking the $\operatorname{IgM}^{+}$antibodies into account, the percentage of antibodies with anti-striated muscle reactivity was still significantly higher in the AChRMG than in the control thymus (data not shown). No differences were found when comparing the anti-striated muscle reactivity of $\mathrm{IgG}^{+}$antibodies between AChR-MG patients and controls.

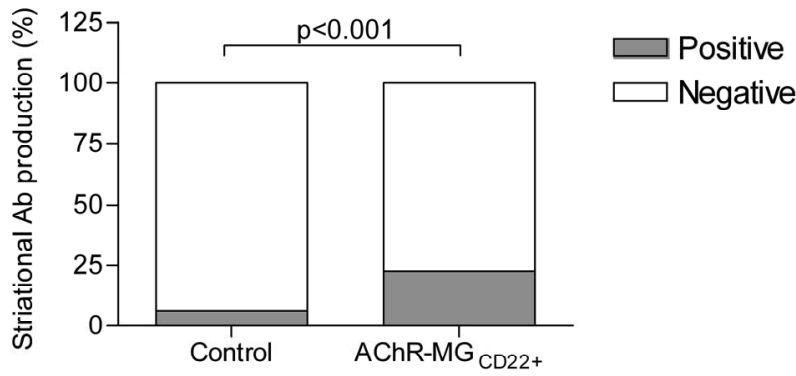

Figure 3. Striational antibody production by thymic B cells. Culture supernatants of immortalized B cells were tested for reactivity against monkey striated muscle tissue. The percentages of antibodies positive or negative for striated muscle binding are shown for control (young + adult) and $A C h R-M G_{C D 22}$ B cells. B cells from the $A C h R-M G_{C D 22+1 g G+}$ group were excluded from this analysis. Fisher's exact test was used for statistical analysis.

\section{Thymic B cells of AChR-MG patients display normal lgV $V_{H}$ gene characteristics}

In addition to the phenotypical and reactivity analyses that we performed on thymic $B$ cells, we also investigated the molecular characteristics of the variable regions of their Ig heavy chain genes $\left(\operatorname{lgV}_{H}\right)$. Genetic deviations in the generation of the $\operatorname{lgV}_{H}$ genes that create intrinsic $B$ cell abnormalities could potentially play a role in the emergence of autoimmune B cells. Among the 251 sequences examined from all controls and AChR-MG patients, 15 were nonfunctional (5.5\%) because of the presence of an out-of-frame 
reading frame, and therefore, these sequences were omitted from further analyses. The main results obtained by sequencing analysis are summarized in Table 4.

Table IV. Sequence analyis of $\mathrm{IgV}_{\mathrm{H}}$ gene rearrangements from thymic $\mathrm{B}$ cells

\begin{tabular}{|c|c|c|c|c|}
\hline & Control-young & Control-adult & AChR-MG $\mathrm{MD22+}_{\mathrm{C}}$ & AChR-MG CD22+lgG \\
\hline Number of sequences & 35 & 95 & 64 & 43 \\
\hline Mutation frequency (\%) & $1.50 \pm 0.22$ & $4.51 \pm 0.47^{* *}$ & $4.47 \pm 0.48^{*}$ & $7.22 \pm 1.05^{* * *, \# \#,+}$ \\
\hline WRCY mutations (\%) & $3.14 \pm 1.24$ & $10.48 \pm 1.47^{*}$ & $10.88 \pm 1.56^{*}$ & $17.16 \pm 2.51^{* * *}$ \\
\hline RGYW mutations (\%) & $3.49 \pm 1.39$ & $9.13 \pm 1.29$ & $9.73 \pm 1.78$ & $23.13 \pm 3.35^{* * *}$, \\
\hline Transitions & $31.93 \pm 5.60$ & $41.29 \pm 2.35$ & $47.01 \pm 2.93^{*}$ & $48.91 \pm 2.91^{*}$ \\
\hline RS mutations in FR & $1.00 \pm 0.22$ & $1.78 \pm 0.18$ & $2.12 \pm 0.26^{*}$ & $2.68 \pm 0.40^{* *}$ \\
\hline RS mutations in CDR & $0.36 \pm 0.21$ & $1.48 \pm 0.24$ & $1.24 \pm 0.21$ & $3.75 \pm 0.47 * * *$ \\
\hline CDR3 length (AA) & $14.77 \pm 0.61$ & $16.22 \pm 0.46$ & $15.77 \pm 0.56$ & $16.33 \pm 0.52$ \\
\hline VJ distance & $26.23 \pm 1.72$ & $28.06 \pm 1.08$ & $28.80 \pm 1.26$ & $29.91 \pm 1.67$ \\
\hline CDR3 charge: $-/ 0 /+(\%)$ & $51 / 23 / 26$ & $48 / 29 / 22$ & $39 / 31 / 30$ & $49 / 23 / 28$ \\
\hline
\end{tabular}

AA: amino acid. IgV $_{\mathrm{H}}$ gene sequences of immortalized $\mathrm{B}$ cells were analyzed using Joinsolver software. Results are shown as average values \pm SEM. Chi-square test was used for statistical analysis of CDR3 charge. One-way ANOVA analysis and Bonferroni post-hoc testing were used for other statistical analyses.

${ }^{*} p<0.05 ; * *<<0.01 ; * * *<<0.001$ when compared to Control-young

$\# p<0.05 ; "$ p $<0.01 ; \#$ p $<0.001$ when compared to Control-adult ${ }^{\dagger} \mathrm{p}<0.05 ;{ }^{++\dagger} \mathrm{p}<0.001$ when compared to MG-CD22

\section{Normal Ig $V_{H}$ gene family repertoire is displayed by sequences of AChR-MG thymic B cells}

We first determined whether the usage of particular $\lg \mathrm{V}_{\mathrm{H}}$ gene families was skewed in the thymus of AChR-MG patients compared to controls, because a non-random use of Ig gene segments might reflect an abnormal $B$ cell regulation. We did not observe any differences in $\operatorname{IgV}_{H} \mathrm{~V}, \mathrm{D}$ or $\mathrm{J}$ gene usage between control-young and control-adult or between AChR$M_{\mathrm{CD}_{2}+}$ and $A C h R-M_{\mathrm{CD22+IgG+}}$ thymocytes, and thus, these groups were combined for further analysis. Comparing both AChR-MG and control sequences to the germline complexity, no preferentially restricted $V$ gene usage was observed (data not shown), as previously reported (Flores et al., 2001; Guigou et al., 1991; Sims et al., 2001; Zuckerman et al., 2010). We noticed a greater usage of DH3 in AChR-MG sequences compared to germline complexity, which is in accordance to previously reported findings (Sims et al., 2001), and a greater usage of DH3 and DH6 and a lower usage of DH5 in control sequences. We also found a clear bias in AChR-MG sequences towards the JH4 gene segment at the expense of $\mathrm{JH} 1$ and $\mathrm{JH} 2$, which is consistent with previous findings (Sims et al., 2001). In control sequences, there was a bias towards the JH4 gene segment at the expense of JH1, JH2 and JH5. Despite the skewed Ig gene usage in both the AChR-MG and 
control thymus compared to the germline complexity, no significant differences were found between AChR-MG and control sequences (data not shown). These results indicate that thymic B cells of AChR-MG patients display a normal $\lg _{H}$ gene family usage, which is in accordance with previous data which showed a similar $\operatorname{lgV}_{\mathrm{H}}$ gene repertoire in germinal centers of the AChR-MG thymus and normal germinal centers (Zuckerman et al., 2010). Finally, the fact that a wide gene family repertoire was observed in both control and AChR-MG thymic B cells suggests a polyclonal origin of B cells in the autoimmune as well as the healthy thymus.

\section{Thymic B cells of AChR-MG patients exhibit normal characteristics of somatic hypermutation}

Studies concerning somatic hypermutation in $\operatorname{lgV}_{\mathrm{H}}$ sequences have shown that both healthy and AChR-MG thymus contain a heterogeneous population of $B$ cells, consisting of both $B$ cells with non-mutated $I_{\text {gV }}$ genes, characteristic of naïve $B$ cells, and $B$ cells with mutated $\operatorname{lgV}_{\mathrm{H}}$ genes, characteristic of post-germinal center B cells (Dunn-Walters et al., 1995; Sims et al., 2001). Since the pattern of somatic hypermutation in $\operatorname{lgV}_{H}$ sequences might contribute to the production of autoreactive $B$ cells, we compared the mutation frequency in $I_{\mathrm{H}} \mathrm{V}_{\mathrm{H}}$ sequences of control and AChR-MG thymic B cells. As shown in Figure 4, the mutation frequency in $A C h R-M_{\mathrm{CD} 22+\lg G+}$ sequences was significantly higher compared to $A C h R-M_{\mathrm{CD}_{22}+}$, control-young and control-adult sequences $(p<0.05, p<0.001$ and $p<0.01$, respectively). This result is caused by the fact that the $A C h R-M_{C D 22+1 g G+}$ group entirely consist of $\operatorname{IgG}^{+}$antibodies, which are known to contain higher mutation

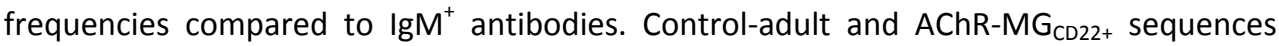
also contained significantly higher mutation frequencies than control-young sequences ( $p<0.01$ and $p<0.05$, respectively), of which the latter also have been shown before to be mainly unmutated (Dunn-Walters et al., 1995). Most importantly, no differences in mutation frequency were observed between $A C h R-M_{\mathrm{CD} 22+}$ and control-adult sequences. Moreover, no differences in mutation frequency were found between $\operatorname{IgG}^{+}$sequences of AChR-MG and control thymus or between $\operatorname{IgM}^{+}$sequences of AChR-MG and control thymus (data not shown), suggesting similarity in mutation rate between thymic $B$ cells of controls and AChR-MG patients. Finally, the considerable variation which was observed in mutation frequencies of both control and AChR-MG sequences, ranging from nonmutated to more than $40 \%$ mutated, confirms the presence of both naïve and postgerminal center $\mathrm{B}$ cells and suggests clonal heterogeneity in both healthy and autoimmune thymus. 


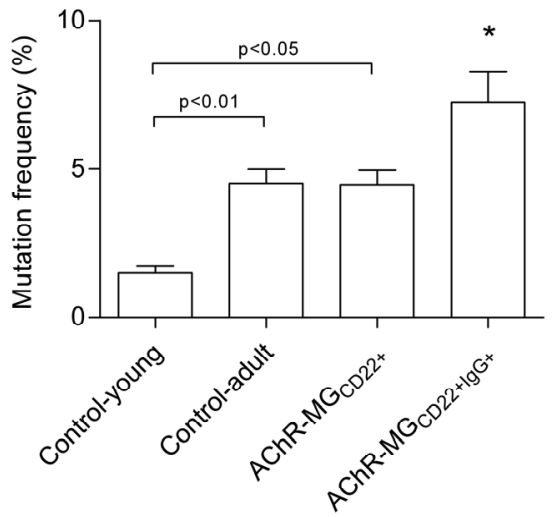

Figure 4. Mutation frequency in IgVH gene rearrangements of thymic B cells. Each rearrangement was compared to the closest matching germline $\mathrm{V}_{\mathrm{H}}$ gene to identify somatic mutations. The percentage of mutations was determined for all immortalized $B$ cell lines from control-young, control-adult, $A C h R-M_{\mathrm{CD22}}$ and $A C h R-$ $M_{\mathrm{CD}_{22+\lg +}}$ groups. * Significantly higher compared to all other groups. One-way ANOVA and Bonferroni post hoc testing were used for statistical analysis.

Previous studies have reported contradictory findings on the targeting of mutations to mutational hot spots, such as RGYW and WRCY motifs, in autoimmune diseases (Foreman et al., 2007). We observed significantly higher mutation frequencies in RGYW motifs of the $A C h R-M G_{\mathrm{CD} 22+1 \mathrm{gG}+}$ sequences compared to those of all other groups ( $p<0.001$ for all analyses), presumably because the $A C h R-M_{C D 22+1 g G+}$ group exclusively consists of $\mathrm{IgG}^{+}$antibodies (Table 3). The mutation frequencies in WRCY motifs of controlyoung sequences were significantly lower compared to those of control-adult, AChR$\mathrm{MG}_{\mathrm{CD} 22+}$ and $A C h R-\mathrm{MG}_{\mathrm{CD22}+\lg G+}$ sequences $(\mathrm{p}<0.05, \mathrm{p}<0.05, \mathrm{p}<0.001$, respectively). No differences in targeting of mutational hot spots were found between $A C h R-M_{\mathrm{CD} 22+}$ and control-adult sequences, which accords to the reported similarity in targeting RGYW and WRCY motifs between germinal centers of the AChR-MG thymus and normal germinal centers (Zuckerman et al., 2010). The high mutation frequencies observed in RGYW and WRCY motifs of several $\mathrm{IgV}_{\mathrm{H}}$ rearrangements from control and AChR-MG thymic $B$ cells (data not shown) indicates that at least part of the thymic $B$ cells have passed through germinal centers. Finally, we analyzed whether the mutations were either transition or transversion mutations and found a significantly higher percentage of transitions in the AChR-MG $\mathrm{MD22}_{\mathrm{C} 2}$ and $\mathrm{AChR}-\mathrm{MG}_{\mathrm{CD} 22+}$ sequences compared to control-young ( $\mathrm{p}<0.05$ for both analyses) but not to control-adult sequences. 
Analyzing the number of replacement (R) and silent (S) mutations in $\operatorname{lgV}_{H}$ sequences can also give more information on $B$ cell selection mechanisms, because a higher proportion of $\mathrm{R}$ mutations in the CDR compared to the FR is a typical feature of antibodies that were affinity matured in germinal centers following antigenic stimulation. In this study, the R/S ratio in the $F R$, responsible for the structural integrity of the $B C R$, was significantly lower in the control-young sequences compared to $A C h R-M_{C D 22}$ and $A C h R-$ $M G_{C D 22+1 g G+}$ sequences ( $p<0.05$ and $p<0.01$, respectively) (Table 4). The $R / S$ ratio in the $C D R$, responsible for antigen binding, was significantly higher in the $A C h R-M G_{C D 22+1 g G+}$ group compared to all other groups ( $p<0.001$ for each comparison), thereby displaying a similar pattern as the general mutation frequency. These data indicate that the general mutation pattern is mainly caused by $R$ mutations in the mutational hot spots of the CDR regions. In addition, the ratio of $R / S$ mutations was significantly higher in the FR regions of $A C h R-M_{C_{222}+}$ sequences than in the CDR regions $(p<0.05)$ (data not shown), and a similar trend was observed in control sequences, which indicates that the antibody structure might be affected in both AChR-MG and control antibodies. In contrast, AChR-MG ${ }_{\mathrm{CD} 22+\operatorname{IgG}+}$ sequences displayed significantly higher $\mathrm{R} / \mathrm{S}$ ratios in the CDR compared to the FR regions $(p<0.05)$ (data not shown), emphasizing that they underwent significantly more affinity maturation of their CDR regions to be highly antigen-specific.

Altogether, the mutational analysis of $\mathrm{IgV}_{\mathrm{H}}$ antibody sequences from control and AChR-MG thymic B cells mainly showed differences that were due to the age of controlyoung sequences or to the exclusive presence of $\mathrm{IgG}^{+}$antibodies in the $A C h R-M_{\mathrm{CD} 22+\mid \mathrm{gG}+}$ group. High levels of similarity were observed between $A C h R-M_{\mathrm{CD} 22+}$ and control-adult sequences, suggesting that the somatic hypermutation machinery introduces mutations normally in the AChR-MG thymic B cells.

\section{Thymic B cells of AChR-MG patients display normal CDR3 length and amino acid composition}

Because the antibody CDR3 region significantly contributes to the antigen-binding specificity of the antibody, many studies have tried to reveal remarkable characteristics in CDR3 regions of auto-antibodies. $B$ cells reactive to self antigens were found to have longer CDR3 regions (Keenan et al., 2008; Wardemann et al., 2003). In our study, we did not observe any differences in average CDR3 length between control-young, controladult, $\mathrm{AChR}-\mathrm{MG}_{\mathrm{CD} 22+}$ or $\mathrm{AChR}-\mathrm{MG}_{\mathrm{CD} 22+\operatorname{lgG}}$ sequences (Table 4). In addition, no differences in VJ distance were observed between the 4 different groups. The similarity in CDR3 length between control-young and control-adult corresponds with literature in which they describe shorter CDR3 lengths in pre-term neonates compared to term-neonates 
and adults, but not between term-neonates and adults itself (Souto-Carneiro et al., 2005). When the CDR3 amino acid (AA) length was subdivided into 4 different categories $(<9 ; 10$ $14 ; 15-19 ;>20)$, we found significantly more AChR-MG sequences in the 15-19 category, at the expense of the 10-14 category, compared to control sequences $(p<0.05)$ (data not shown). Despite only small differences between control and AChR-MG sequences were found, the CDR3 length displayed considerable variation in thymic B cells of both controls and AChR-MG patients, ranging from 6 to 27 amino acids. These findings again point to a high degree of heterogeneity in thymic $B$ cells of both groups.

We also analyzed the CDR3 amino acid composition because it directly affects the charge, hydrophobicity, size and shape of the antigen binding site. Since the accumulation of basic AA residues in the CDR3 can contribute to the generation of auto-antibodies (Dorner and Lipsky, 2005; Keenan et al., 2008), we measured the occurrence of arginines and/or lysines in the CDR3 regions. No differences in basic AA usage were found between AChR-MG and control sequences (data not shown), indicating that CDR3 regions of thymic $B$ cells from AChR-MG patients do not differ in their hydrophobicity compared to those of controls. In addition, the ratio between the number of negatively, neutrally and positively charged CDR3 regions did not differ between control-young, control-adult, AChR-MG ${ }_{\mathrm{CD} 22+}$ or $\mathrm{AChR}-\mathrm{MG}_{\mathrm{CD} 22+\mathrm{IgG}+}$ sequences (Table 4).

\section{More clonally expanded B cell clones are present in the AChR-MG thymus}

Sequences which derived from a common ancestor that contain distinguished mutations are termed 'clonally related' and are a marker of an antigen-driven humoral immune response. To investigate whether $B$ cells are clonally expanded in the healthy or autoimmune thymus, the $\operatorname{IgV}_{H}$ CDR3 $A A$ sequences were compared in and between controls and AChR-MG patients by constructing phylogenetic trees using bosque software (Ramirez-Flandes and Ulloa, 2008). A total of 11 clonal expansions were retrieved, including 9 from AChR-MG patients and 2 from control-adults (Table 5). In all MG patients, except for patient P28, clonally expanded B cell clones were found. None of the clonally expanded clones had members from both AChR-MG and control sequences, but one clone had members from both AChR-MG patients P82 and P90. Then, all clones identified were small with no more than five members isolated and no dominant clone was found in any of the thymuses, as previously reported for the AChR-MG thymus (Sims et al., 2001). We found that significantly more sequences of the $A C h R-M G_{C D 22+}$ group were a member of one of the clonally expanded $B$ cell clones compared to those of the control-adult group $(p<0.05)$ (data not shown). However, in both the AChR-MG and control thymus, the majority of the isolated sequences were not members of any of the 
11 expanded clones identified, emphasizing the uniqueness of most B cells. All identified clonally expanded $B$ cell populations showed expression of $V_{H} 3$ or $V_{H} 4$ family genes. The majority of expanded $B$ cell clones also contained highly mutated members, indicating high deviation from the germline sequence. In contrast, the members of clone number 8 only slightly deviated from the germline sequence and members of clone 3 were identical to their germline sequence. High mutation frequencies that differ between members of the same clonal population are indications for intraclonal diversification and affinity maturation. Then, overall similarity measurement using Bosque software showed significantly less homology between thymic B cells of AChR-MG patients compared to those of controls (data not shown), indicating that AChR-MG thymic B cells probably underwent more diversification towards certain antigens. Altogether, the existence of clonally related sequences in the thymus of both controls and AChR-MG patients indicates that the production of these antibodies is probably driven by self-antigen. Since only a fraction of the thymus has been used in this study to isolate and immortalize $B$ cells, there are probably many more clones present than we have detected and the true heterogeneity of the thymic $B$ cell population might therefore be underestimated.

Table V. Overview of clonally expanded B cell populations

\begin{tabular}{|c|c|c|c|c|c|c|c|}
\hline $\begin{array}{l}\text { Clone } \\
\text { number }\end{array}$ & Frequency & Patients & CDR3 AA sequence & VH gene & DH gene & $\begin{array}{l}\mathrm{JH} \\
\text { gene }\end{array}$ & Isotype \\
\hline 1 & 4 & $\mathrm{P} 21$ & ARKIYYGSGSPRHMDV & V3-11*03 & D3-10*01 & $\mathrm{J} 4 * 03$ & $\lg M$ \\
\hline 2 & 3 & P21 & ATYYGHG & V3-11*03 & $\mathrm{D} 4-17 * 01$ & $\mathrm{~J} 4 * 02$ & $\lg G+\lg M$ \\
\hline 3 & 2 & P42 & ARGQGVVTLGY & V4-59*01 & $\mathrm{D} 2-21 * 02$ & $\mathrm{~J} 4 * 02$ & $\lg M$ \\
\hline 4 & 2 & P42 & ARDKYDFWSGYLLHPEGYFDY & V3-30-3*02 & $\mathrm{D} 3-3 * 01$ & $\mathrm{~J} 4 * 03$ & $\lg G$ \\
\hline 5 & 5 & $\begin{array}{l}P 82(4 x)+ \\
P 90(1 x)\end{array}$ & ARDGGWKGGVWLFDY & V3-33*01 & DIR1*01R & $\mathrm{J} 4 * 02$ & $\lg G$ \\
\hline 6 & 2 & P82 & ARGLRLKLGSNLWSAEYNAFDI & V4-04*02 & D3-3*01 & $\mathrm{J} 4 * 02$ & $\lg G$ \\
\hline 7 & 2 & P90 & ARVHGPELLEVPY & V3-48*01 & $\mathrm{D} 3-10 * 02 \mathrm{R}$ & $\mathrm{J} 4 * 02$ & $\lg G$ \\
\hline 8 & 2 & $\mathrm{P} 90$ & ARVRSLWFREFPLNWFDP & V3-11*03 & D3-10*01 & $\mathrm{J} 5 * 02$ & $\lg G$ \\
\hline 9 & 2 & P90 & ARDRRVTTLTHYYYYGMDV & V4-31*06 & $\mathrm{D} 4-17^{*} 01$ & $\mathrm{~J} 6 * 02$ & $\lg G$ \\
\hline 10 & 2 & C15y & AKTFDY & V4-39*06 & NA & $\mathrm{J} 4 * 02$ & $\lg M$ \\
\hline 11 & 2 & C14y & AREDYGDYFDY & V3-74*01 & D4-17*01 & $\mathrm{J} 4 * 02$ & IgM \\
\hline
\end{tabular}

$\mathrm{V}, \mathrm{D}$ and $\mathrm{J}$ genes that are expressed by the Ig heavy chain are shown for each clonal $\mathrm{B}$ cell population. AA: amino acid; NA: not available

\section{Ig $V_{H}$ sequence analysis of antibodies with anti-striated muscle or anti-AChR reactivity}

The $\operatorname{lgV}_{H}$ CDR3 AA sequences of striational antibodies (Table 6) were all unique, except for one, which suggests that at least some of them may recognize different targets of the striated muscle tissue. Interestingly, two out of three members of clonally expanded B cell clone number 2 showed reactivity against striated muscle tissue, indicating that 
autoantibodies with the same sequence do not necessarily bind the same antigen or display different antigen affinity. The $\operatorname{IgV}_{\mathrm{H}}$ gene family usage in the $\mathrm{B}$ cells producing striational antibodies did not differ compared to the germline complexity or compared to that used in $A C h R-M G_{C D 22+} B$ cells (data not shown). In addition, the mutation frequences of $\mathrm{IgV}_{\mathrm{H}}$ sequences of striational antibodies displayed a rather wide range, from unmutated to more than $8 \%$ mutated, showing that also the mutation frequency not necessarily correlates with antigenic affinity. The fact that the light chain is also important for establishing the autoantibody specificity might explain differences in binding specificity between different striational antibodies.

Finally, we constructed a phylogenetic tree combining all $\operatorname{lgV}_{\mathrm{H}}$ full-length $A A$ sequences of control and AChR-MG thymic B cells. The anti-AChR antibodies P90-65 and P90-131 that we isolated from patient P90 (Vrolix et al., Manuscript in preparation) and previously characterized AChR-specific antibodies also isolated from the thymus (Farrar et al., 1997; Fostieri et al., 2005; Graus et al., 1997; Matthews et al., 2002) were included in the phylogenetic tree (Fig. 5A). Although we and others found clonally expanded B cells clones in the AChR-MG thymus (Sims et al., 2001), P90-131 was no member of any of the clones that we isolated. The $\operatorname{lgV}_{H}$ sequence of P90-131 was even fully unique and none of the AChR-MG or control sequences showed exactly the same VDJ gene rearrangement. It can be seen that all sequences of both control and AChR-MG thymus were extensively mixed throughout the phylogenetic tree, instead of being clustered per person or per disease condition. Although the sequences of many anti-AChR antibodies were clustered together, some of them were widely spread throughout the tree, indicating that they might display higher similarities to other non anti-AChR antibodies than to some antiAChR antibodies. It is important to notice that most of the sequences of anti-AChR antibodies showed high levels of diversification compared to their corresponding cluster of sequences. This suggests that these sequences underwent antigen selection and that they specifically evolved towards the AChR antigen. Indeed, when analyzing the mutation frequency of AChR-specific antibodies, it ranged from around 6 to $43 \%$ and the average was found to be significantly higher than that of our non-AChR $\operatorname{IgG}^{+}$sequences derived from the AChR-MG thymus ( $p<0.001$ ) (Fig. 5B). We also observed significantly higher mutation frequencies in both RGYW and WRCY motifs of the AChR-specific antibodies ( $p<0.001$ for both analyses, data not shown). These high levels of mutations in anti-AChR specific sequences suggest that AChR-MG thymic B cells which show mutation frequencies in their $\operatorname{lgV}_{H}$ sequences higher than the average plus three times the standard deviation of the mutation frequency of AChR-MG-IgG sequences might be indicative for the production of disease-specific pathogenic antibodies. 
Table VI. IgV $\mathrm{H}_{\mathrm{H}}$ gene sequence analysis of striational antibodies

\begin{tabular}{|c|c|c|c|c|c|c|c|}
\hline & Clone & Isotype & CDR3 (AA) & V gene & D gene & J gene & $\begin{array}{l}\text { Mutation } \\
\text { frequency }\end{array}$ \\
\hline 1 & P21-G3(8) & $\lg G$ & ATYYGHG & V3-11*03 & D4-17*01 & $\mathrm{J} 4 * 02$ & 6.79 \\
\hline 2 & P21-D8(9) & $\lg M$ & ATYYGHG & V3-11*03 & D4-17*01 & $\mathrm{J} 4 * 02$ & 7.24 \\
\hline 3 & P21-D7(4) & $\lg M$ & ARKIYYGSGSPRHMDV & V3-11*03 & D3-10*01 & $\mathrm{J} 4 * 03$ & 6.85 \\
\hline 4 & P21-E7(7) & $\lg M$ & ARLVSSGWPQFGTAYFDH & V5-51*01 & D6-19*01 & $\mathrm{J} 4 * 02$ & 4.52 \\
\hline 5 & P21-G7(1) & $\lg M$ & ARDRVSFRGYSYGYYYYGMDV & V3-07*01 & D5-5*01 & $\mathrm{J} 6 * 02$ & 0.91 \\
\hline 6 & P21-B11(8) & $\lg M$ & AHRPGYYYDSSGYYFDLGSHFDY & $\mathrm{V} 2-05 * 01$ & D3-22*01 & $\mathrm{J} 4 * 02$ & 1.95 \\
\hline 7 & P42-5 & $\lg M$ & ARDGRYDYVWGSYRLFDL & V1-69*01 & D3-16*02 & $\mathrm{J} 2 * 01$ & 0.45 \\
\hline 8 & P42-6 & $\lg M$ & AREKYSGSYYRLFDY & V3-33*01 & $\mathrm{D} 1-26 * 01$ & $\mathrm{~J} 4 * 02$ & 3.15 \\
\hline 9 & P42-8 & $\lg M$ & ARGGRGLATSKTGYYYYYYGMDV & V3-48*02 & D5- $12 * 01$ & $\mathrm{~J} 6 * 02$ & 0.90 \\
\hline 10 & P42-52 & $\lg M$ & ARALVGATGGDY & V3-21*01 & $\mathrm{D} 1-26 * 01$ & $\mathrm{~J} 4 * 02$ & 1.80 \\
\hline 11 & P42-159 & $\lg G$ & VADPFL & V3-30*03 & DIR2*01R & $\mathrm{J} 4 * 02$ & 8.11 \\
\hline 12 & P42-163 & $\lg G$ & ARDKYDFWSGYLLHPEGYFDY & V3-30-3*02 & D3-3*01 & $\mathrm{J} 4 * 02$ & 5.96 \\
\hline 13 & P28-IVE6 & $\lg M$ & TTEEDIVVVVAGFYYGMDV & V3-15*01 & $\mathrm{D} 2-15^{*} 01$ & $\mathrm{~J} 6 * 02$ & 2.63 \\
\hline 14 & P90-57 & $\lg G$ & ARNFPYSSGWFDS & V4-04*02 & D6-19*01 & $\mathrm{J} 5 * 02$ & 4.44 \\
\hline 15 & C4-7 & $\lg M$ & AKIHRKCSSTSCYFSHYYYYYDV & V3-30*02 & $\mathrm{D} 2-2 * 01$ & $\mathrm{~J} 6 * 02$ & 0.00 \\
\hline 16 & C14-142 & $\lg M$ & AKDTSVVPASSDY & V3-23*01 & $\mathrm{D} 2-2 * 01$ & $\mathrm{~J} 4 * 02$ & 0.00 \\
\hline 17 & C14-84 & $\lg M$ & ARNSLAVAGKVPFDY & V5-51*01 & D6-19*01 & $\mathrm{J} 4 * 02$ & 1.80 \\
\hline 18 & C14-45 & $\lg M$ & AKTTLNYFDYYFYYCIH & V3-23*01 & D2/OR15-2 & $\mathrm{J} 6 * 03$ & 3.62 \\
\hline 19 & C14-39 & $\lg M$ & ARVLGRGVAFDY & $\mathrm{V} 1-02 * 02$ & D3-10*01 & $\mathrm{J} 4 * 02$ & 2.25 \\
\hline
\end{tabular}

$\mathrm{V}, \mathrm{D}$ and $\mathrm{J}$ genes that are expressed by the Ig heavy chain are shown for each striational antibody. AA: amino acids

\section{Discussion}

Since the discovery of thymic B cells (Isaacson et al., 1987), the thymus can not be considered as an exclusive $T$ cell organ anymore. The concentration, organization and activated state of $B$ cells in the thymus indicate that they serve an important function (Fukuba et al., 1994; Isaacson et al., 1987; Spencer et al., 1992; Zoller, 1990). However, their contribution to autoimmune diseases is still unclear. We have shown before that the $B$ cell immortalization technique is a useful tool to study the thymic B cell repertoire (Vrolix et al., Manuscript in preparation). Here, for the first time, we used this method to simultaneously study the antibody repertoire produced by thymic B cells of healthy individuals and AChR-MG patients. We found more and phenotypically different $B$ cells in the thymus of AChR-MG patients. In addition, a higher percentage of B cells of the AChRMG thymus displayed reactivity against striated muscle proteins compared to the control thymus. Finally, $\operatorname{lgV}_{\mathrm{H}}$ gene sequence analysis showed remarkable similarities between thymic B cells of controls and AChR-MG patients, but we found more clonally expanded B cells clones in the thymus of AChR-MG patients. 


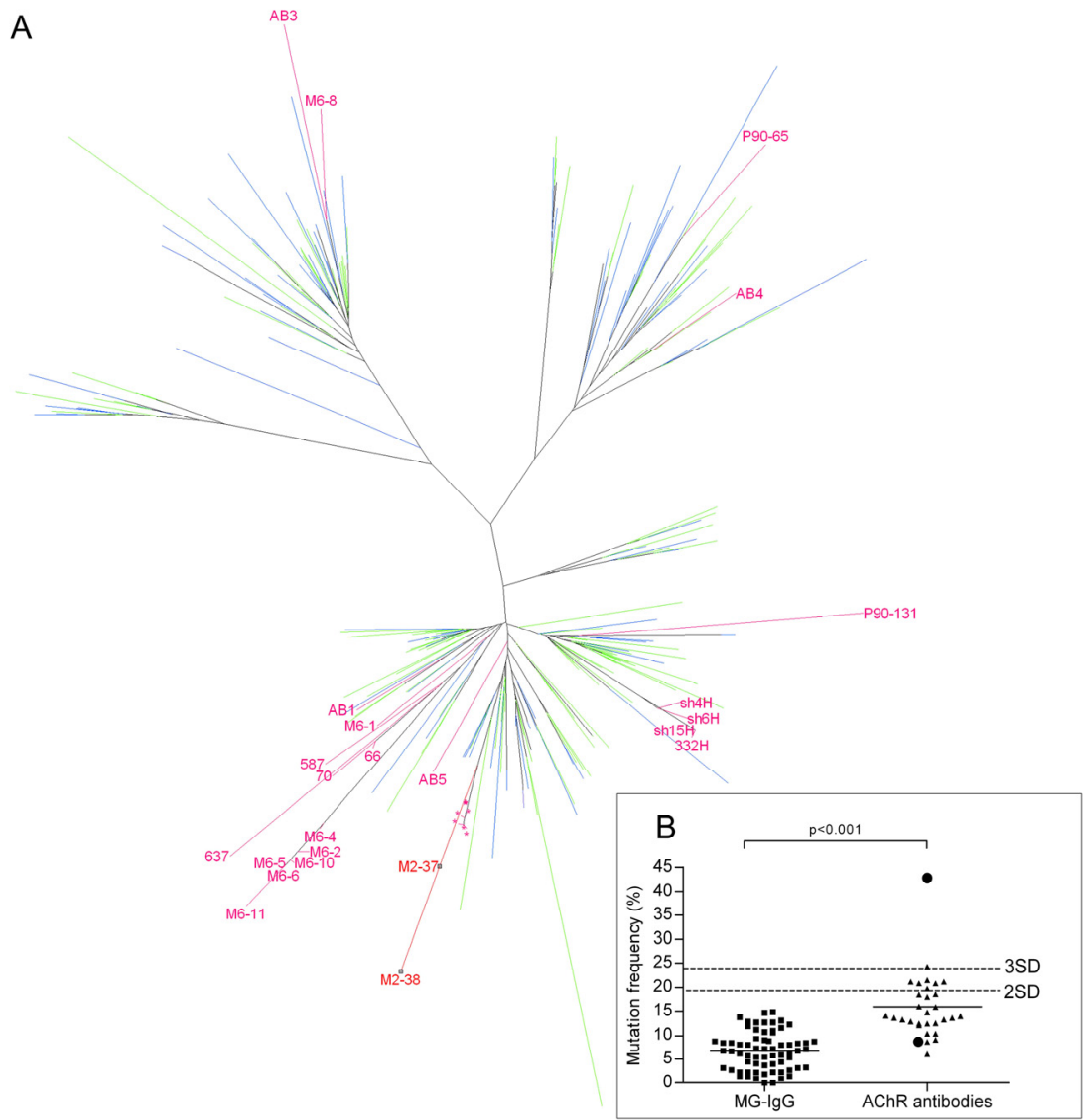

Figure 5. Anti-AChR antibody sequences versus other antibody sequences derived from thymic $B$ cells.

(A) Phylogenetic tree of $\operatorname{IgV}_{H} A A$ full length sequences. Sequences from control and AChR-MG thymus are shown in green and blue, respectively. Sequences from previously characterized anti-AChR antibodies are shown in red and are named as in the original publication (Farrar et al., 1997; Fostieri et al., 2005; Graus et al., 1997; Matthews et al., 2002; Vrolix et al., Manuscript in preparation). To improve the readability, anti-AChR antibodies named M2-53, M2-35, M2-8, M2-10, M2-13, M2-30 and M2-28 are indicated by an asterisk. (B) Mutation frequency in $\mathrm{IgV}_{\mathrm{H}}$ gene rearrangements of anti-AChR antibodies. Each rearrangement was compared to the closest matching germline $V_{H}$ gene to identify somatic mutations. The percentage of mutations was determined for all IgG-producing immortalized B cell lines from the MG thymus (MG-IgG) and for previously characterized anti-AChR antibodies. Anti-AChR antibodies P90-131 and P90-65 are indicated by a circle. Horizontal full lines represent the mean percentage of each group. Dashed lines show cut-off value calculated as the mean of MGIgG mutations plus two and three times the standard deviation. Student's t-test was used for statistical analysis. 
Our result that the number of $B$ cells in the thymus increases with age and with AChR-MG confirms previously reported findings (Flores et al., 2001). The increased expression of B cell survival factors in the MG thymus (Thangarajh et al., 2006) or the specific expression of autoantigens such as AChR or ErbB (Kyewski and Taubert, 2008; Mesnard-Rouiller et al., 2004; Vrolix et al., 2010b) might contribute to a thymic microenvironment which encourages $B$ cell survival, but the question still remains whether the B cells in the AChR-MG thymus originate from an intrathymic differentiation of normal thymic B cells, or whether they derive from the periphery and are attracted to the favorable thymic microenvironment.

The expression of EBV receptor CD21 on thymic B cells has been reported by us and others, both in controls and AChR-MG patients (Fend et al., 1991; Leprince et al., 1990; Spencer et al., 1992), but it has never been shown before that the percentage of thymic $B$ cells which express CD21 is twofold higher in AChR-MG patients than in controls. A dysregulated EBV infection has been found in many AChR-MG thymuses (Cavalcante et al., 2010) and might have contributed to the differential expression of CD21 on thymic $B$ cells of AChR-MG patients.

Thymic B cells of AChR-MG patients have been shown to produce striational antibodies in vitro (Vrolix et al., Manuscript in preparation; Williams and Lennon, 1986). We now demonstrated for the first time that thymic B cells of healthy individuals also produce striational antibodies, of both the IgM and IgG subtype. This suggests that striational antibodies belong to the repertoire of naturally produced antibodies and probably contribute to immune homeostasis by clearing cellular debris. The fact that no pathological effects have yet been assigned to striational antibodies might confirm their role as natural autoantibodies. Indeed, thymic B cells have been reported to be responsible for the production of natural IgM and IgG antibodies (Cukrowska B., 2002). Interestingly, the percentage of $B$ cells that produced striational antibodies was significantly higher in the AChR-MG thymus than in control thymus. These antibodies might arise because of the generally dysregulated immune system in AChR-MG patients. The fact that greater numbers of autoreactive naïve $B$ cells have been found in the circulation of patients with autoimmune diseases (Yurasov and Nussenzweig, 2007) seems to be true for the thymus as well and might explain why a higher percentage of thymic $B$ cells produced striational antibodies in AChR-MG patients. Striational antibodies might also be produced as a by-product of the general immune activation, since the neuromuscular damage primarily caused by anti-AChR antibodies could lead to increased modifications of intracellular antigens that might subsequently be presented as novel antigens. 
This is the first study in which thymic B cells and their antibodies from controls and AChR-MG patients were simultaneously compared. Despite the differences in number, phenotype and anti-striated muscle specificity between thymic B cells from controls and AChR-MG patients, the $\operatorname{IgV}_{\mathrm{H}}$ gene repertoire which they expressed behaved very similar regarding the VDJ gene family usage, mutation types and frequency, and CDR3 size and composition. We thus conclude that thymic B cells of AChR-MG patients do not intrinsically differ in genetic characteristics. Nevertheless, we found that the thymic $B$ cell repertoire of both controls and AChR-MG patients is very heterogeneous, because their $\mathrm{IgV}_{\mathrm{H}}$ genes show high variability in mutation frequency, CDR3 length and charge, and $\mathrm{V}_{\mathrm{H}}$ family usage, which had been reported before (Dunn-Walters et al., 1995; Sims et al., 2001; Zuckerman et al., 2010). This heterogeneity implies a polyclonal response of thymic $B$ cells against many different antigens, of which the identity still needs to be determined.

In accordance with previous reports (Sims et al., 2001; Zuckerman et al., 2010), we also demonstrated that clonal proliferation of $B$ cells is taking place in the thymus of AChR-MG patients. For the first time, we showed the existence of clonally expanded B cell clones in the thymus of controls, although in a lesser extent than in the thymus of AChRMG patients. It is possible that some of the $B$ cell clonal expansions represent an irrelevant response towards a certain antigen. However, the presence of more clonally expanded $B$ cell populations in the AChR-MG thymus compared to the control thymus points towards their involvement in the pathophysiology of AChR-MG.

The extensive collection of $\mathrm{IgV}_{\mathrm{H}}$ sequences obtained from thymic $B$ cells of both controls and AChR-MG patients challenged us to compare these sequences with those of previously characterized anti-AChR antibodies, which had been isolated from the AChRMG thymus as well. IgV $_{H}$ sequences of anti-AChR antibodies displayed significantly higher mutation frequencies compared to those of non-AChR reactive $\mathrm{IgG}^{+}$antibodies from the AChR-MG thymus. Indeed, the phylogenetic tree also showed that sequences of antiAChR antibodies were more diversified from their germline gene compared to other sequences within the same phylogenetic cluster. These findings suggest that IgGproducing B cells which are isolated from the thymus of AChR-MG patients and which also display very high mutation frequencies in their $\operatorname{lgV}_{\mathrm{H}}$ genes might be responsible for the production of pathogenic anti-AChR antibodies. This result might benefit further searches for disease-specific autoantibodies in MG, and the same principles might be applicable for other autoimmune disease as well.

Thus, using our improved method of B cell immortalization, we identified important characteristics of the antibody repertoire produced by thymic B cells of healthy individuals and AChR-MG patients. The fact that the antibody sequences of thymic B cells 
from AChR-MG patients did not display genetic abnormalities that could create intrinsic $B$ cell abnormalities implies that the differences in number, phenotype, anti-muscle reactivity and increased presence of clonal expansions that we observed in thymic $B$ cells of AChR-MG patients are probably caused by inappropriate extrinsic B cell signals. The nature of these extrinsic signals, however, still needs to be determined.

\section{Acknowledgements}

We would like to thank Jonas Hummel and Joost Van den Broeck for valuable practical assistance, and Els Meulemans, Guido Roemen and colleagues for helping us with spectratyping and sequencing experiments. We thank Danielle Beckering for her help with the patient data.

\section{References}

Akirav, E.M., Xu, Y., Ruddle, N.H., 2011. Resident B cells regulate thymic expression of myelin oligodendrocyte glycoprotein. J Neuroimmunol.

Cavalcante, P., Serafini, B., Rosicarelli, B., Maggi, L., Barberis, M., Antozzi, C., Berrih-Aknin, S., Bernasconi, P., Aloisi, F., Mantegazza, R., 2010. Epstein-Barr virus persistence and reactivation in myasthenia gravis thymus. Ann Neurol 67, 726-738.

Conti-Fine, B.M., Milani, M., Kaminski, H.J., 2006. Myasthenia gravis: past, present, and future. J Clin Invest 116, 28432854.

Cukrowska B., S.J., Rehakova Z., Tlaskalova-Hogenova H., 2002. Thymic B lymphocytes - cells secreting natural antibodies in eraly ontogeny. Cellular molecular biology letters 7, 42.

Dorner, T., Lipsky, P.E., 2005. Molecular basis of immunoglobulin variable region gene usage in systemic autoimmunity. Clin Exp Med 4, 159-169.

Dunn-Walters, D.K., Howe, C.J., Isaacson, P.G., Spencer, J., 1995. Location and sequence of rearranged immunoglobulin genes in human thymus. Eur J Immunol 25, 513-519.

Farrar, J., Portolano, S., Willcox, N., Vincent, A., Jacobson, L., Newsom-Davis, J., Rapoport, B., McLachlan, S.M., 1997. Diverse Fab specific for acetylcholine receptor epitopes from a myasthenia gravis thymus combinatorial library. Int Immunol 9, 1311-1318.

Fend, F., Nachbaur, D., Oberwasserlechner, F., Kreczy, A., Huber, H., Muller-Hermelink, H.K., 1991. Phenotype and topography of human thymic B cells. An immunohistologic study. Virchows Arch B Cell Pathol Incl Mol Pathol 60, 381-388.

Flores, K.G., Li, J., Hale, L.P., 2001. B cells in epithelial and perivascular compartments of human adult thymus. Hum Pathol 32, 926-934.

Foreman, A.L., Van de Water, J., Gougeon, M.L., Gershwin, M.E., 2007. B cells in autoimmune diseases: insights from analyses of immunoglobulin variable (Ig V) gene usage. Autoimmun Rev 6, 387-401.

Fostieri, E., Tzartos, S.J., Berrih-Aknin, S., Beeson, D., Mamalaki, A., 2005. Isolation of potent human Fab fragments against a novel highly immunogenic region on human muscle acetylcholine receptor which protect the receptor from myasthenic autoantibodies. Eur J Immunol 35, 632-643.

Fraussen, J., Vrolix, K., Martinez-Martinez, P., Losen, M., Meulemans, E., De Baets, M.H., Stinissen, P., Somers, V., 2010. A novel method for making human monoclonal antibodies. J Autoimmun 35, 130-134.

Fukuba, Y., Inaba, M., Taketani, S., Hitoshi, Y., Adachi, Y., Tokunaga, R., Inaba, K., Takatsu, K., Ikehara, S., 1994. Functional analysis of thymic B cells. Immunobiology 190, 150-163. 
Graus, Y.F., de Baets, M.H., Parren, P.W., Berrih-Aknin, S., Wokke, J., van Breda Vriesman, P.J., Burton, D.R., 1997. Human anti-nicotinic acetylcholine receptor recombinant Fab fragments isolated from thymus-derived phage display libraries from myasthenia gravis patients reflect predominant specificities in serum and block the action of pathogenic serum antibodies. J Immunol 158, 1919-1929.

Gronseth, G.S., Barohn, R.J., 2000. Practice parameter: thymectomy for autoimmune myasthenia gravis (an evidencebased review): report of the Quality Standards Subcommittee of the American Academy of Neurology. Neurology 55, 7-15.

Guigou, V., Emilie, D., Berrih-Aknin, S., Fumoux, F., Fougereau, M., Schiff, C., 1991. Individual germinal centres of myasthenia gravis human thymuses contain polyclonal activated B cells that express all the $\mathrm{Vh}$ and $\mathrm{Vk}$ families. Clin Exp Immunol 83, 262-266.

Inaba, M., Inaba, K., Hosono, M., Kumamoto, T., Ishida, T., Muramatsu, S., Masuda, T., Ikehara, S., 1991. Distinct mechanisms of neonatal tolerance induced by dendritic cells and thymic B cells. J Exp Med 173, 549-559.

Isaacson, P.G., Norton, A.J., Addis, B.J., 1987. The human thymus contains a novel population of B lymphocytes. Lancet 2 , 1488-1491.

Keenan, R.A., De Riva, A., Corleis, B., Hepburn, L., Licence, S., Winkler, T.H., Martensson, I.L., 2008. Censoring of autoreactive B cell development by the pre-B cell receptor. Science 321, 696-699.

Kuks, J.B., Oosterhuis, H.J., Limburg, P.C., The, T.H., 1991. Anti-acetylcholine receptor antibodies decrease after thymectomy in patients with myasthenia gravis. Clinical correlations. J Autoimmun 4, 197-211.

Kyewski, B., Taubert, R., 2008. How promiscuity promotes tolerance: the case of myasthenia gravis. Ann N Y Acad Sci $1132,157-162$

Leite, M.I., Jones, M., Strobel, P., Marx, A., Gold, R., Niks, E., Verschuuren, J.J., Berrih-Aknin, S., Scaravilli, F., Canelhas, A., Morgan, B.P., Vincent, A., Willcox, N., 2007. Myasthenia gravis thymus: complement vulnerability of epithelial and myoid cells, complement attack on them, and correlations with autoantibody status. Am J Pathol 171, 893905.

Leprince, C., Cohen-Kaminsky, S., Berrih-Aknin, S., Vernet-Der Garabedian, B., Treton, D., Galanaud, P., Richard, Y., 1990. Thymic B cells from myasthenia gravis patients are activated B cells. Phenotypic and functional analysis. J Immunol 145, 2115-2122.

Levinson, A.I., Wheatley, L.M., 1996. The thymus and the pathogenesis of myasthenia gravis. Clin Immunol Immunopathol 78, 1-5.

Lindstrom, J.M., Seybold, M.E., Lennon, V.A., Whittingham, S., Duane, D.D., 1976. Antibody to acetylcholine receptor in myasthenia gravis. Prevalence, clinical correlates, and diagnostic value. Neurology 26, 1054-1059.

Matthews, I., Sims, G., Ledwidge, S., Stott, D., Beeson, D., Willcox, N., Vincent, A., 2002. Antibodies to acetylcholine receptor in parous women with myasthenia: evidence for immunization by fetal antigen. Lab Invest $82,1407-$ 1417.

Melms, A., Schalke, B.C., Kirchner, T., Muller-Hermelink, H.K., Albert, E., Wekerle, H., 1988. Thymus in myasthenia gravis. Isolation of T-lymphocyte lines specific for the nicotinic acetylcholine receptor from thymuses of myasthenic patients. J Clin Invest 81, 902-908.

Mesnard-Rouiller, L., Bismuth, J., Wakkach, A., Poea-Guyon, S., Berrih-Aknin, S., 2004. Thymic myoid cells express high levels of muscle genes. J Neuroimmunol 148, 97-105.

Mori, S., Inaba, M., Sugihara, A., Taketani, S., Doi, H., Fukuba, Y., Yamamoto, Y., Adachi, Y., Inaba, K., Fukuhara, S., Ikehara, S., 1997. Presence of B cell progenitors in the thymus. J Immunol 158, 4193-4199.

Ramirez-Flandes, S., Ulloa, O., 2008. Bosque: integrated phylogenetic analysis software. Bioinformatics 24, $2539-2541$.

Sims, G.P., Shiono, H., Willcox, N., Stott, D.I., 2001. Somatic hypermutation and selection of B cells in thymic germinal centers responding to acetylcholine receptor in myasthenia gravis. J Immunol 167, 1935-1944.

Souto-Carneiro, M.M., Longo, N.S., Russ, D.E., Sun, H.W., Lipsky, P.E., 2004. Characterization of the human Ig heavy chain antigen binding complementarity determining region 3 using a newly developed software algorithm, JOINSOLVER. J Immunol 172, 6790-6802.

Souto-Carneiro, M.M., Sims, G.P., Girschik, H., Lee, J., Lipsky, P.E., 2005. Developmental changes in the human heavy chain CDR3. J Immunol 175, 7425-7436.

Spencer, J., Choy, M., Hussell, T., Papadaki, L., Kington, J.P., Isaacson, P.G., 1992. Properties of human thymic B cells. Immunology 75, 596-600. 
Thangarajh, M., Masterman, T., Helgeland, L., Rot, U., Jonsson, M.V., Eide, G.E., Pirskanen, R., Hillert, J., Jonsson, R., 2006. The thymus is a source of B-cell-survival factors-APRIL and BAFF-in myasthenia gravis. J Neuroimmunol 178 , 161-166.

Vincent, A., Beeson, D., Lang, B., 2000. Molecular targets for autoimmune and genetic disorders of neuromuscular transmission. Eur J Biochem 267, 6717-6728.

von Boehmer, H., Kisielow, P., 1990. Self-nonself discrimination by T cells. Science 248, 1369-1373.

Vrolix, K., Fraussen, J., Losen, M., J., V.d.B., K., L., Molenaar, P.C., Stinissen, P., Tzartos, S., Somers, V., De Baets, M.H., Martinez-Martinez, P., Manuscript in preparation. Immortalization of thymic autoreactive $B$ cells and monoclonal antibody production from AChR-antibody positive myasthenia gravis patients.

Vrolix, K., Fraussen, J., Molenaar, P.C., Losen, M., Somers, V., Stinissen, P., De Baets, M.H., Martinez-Martinez, P., $2010 a$. The auto-antigen repertoire in myasthenia gravis. Autoimmunity $43,380-400$.

Vrolix, K., Niks, E.H., Le Panse, R., van Ostaijen-Ten Dam, M.M., Muris, A.H., Jol-van der Zijde, C.M., van Tol, M.J., Losen, M., Molenaar, P.C., van Zoelen, E.J., Berrih-Aknin, S., De Baets, M.H., Verschuuren, J.J., Martinez-Martinez, P., 2010b. Reduced thymic expression of ErbB receptors without auto-antibodies against synaptic ErbB in myasthenia gravis. J Neuroimmunol 232, 158-165.

Wakkach, A., Guyon, T., Bruand, C., Tzartos, S., Cohen-Kaminsky, S., Berrih-Aknin, S., 1996. Expression of acetylcholine receptor genes in human thymic epithelial cells: implications for myasthenia gravis. J Immunol 157, 3752-3760.

Wardemann, H., Yurasov, S., Schaefer, A., Young, J.W., Meffre, E., Nussenzweig, M.C., 2003. Predominant autoantibody production by early human B cell precursors. Science 301, 1374-1377.

Wekerle, H., Ketelsen, U.P., Zurn, A.D., Fulpius, B.W., 1978. Intrathymic pathogenesis of myasthenia gravis: transient expression of acetylcholine receptors on thymus-derived myogenic cells. Eur J Immunol 8, 579-582.

Williams, C.L., Lennon, V.A., 1986. Thymic B lymphocyte clones from patients with myasthenia gravis secrete monoclonal striational autoantibodies reacting with myosin, alpha actinin, or actin. J Exp Med 164, 1043-1059.

Yoshikawa, H., Lennon, V.A., 1997. Acetylcholine receptor autoantibody secretion by thymocytes: relationship to myasthenia gravis. Neurology 49, 562-567.

Yurasov, S., Nussenzweig, M.C., 2007. Regulation of autoreactive antibodies. Curr Opin Rheumatol 19, 421-426.

Zoller, M., 1990. Intrathymic presentation of nominal antigen by B cells. Int Immunol 2, 427-434.

Zuckerman, N.S., Howard, W.A., Bismuth, J., Gibson, K., Edelman, H., Berrih-Aknin, S., Dunn-Walters, D., Mehr, R., 2010. Ectopic GC in the thymus of myasthenia gravis patients show characteristics of normal GC. Eur J Immunol 40, 1150-1161. 


\section{Chapter}

Reduced thymic expression of ErbB receptors

without auto-antibodies against synaptic ErbB in

myasthenia gravis

Vrolix K*, Niks EH*, Le Panse R*, van Ostaijen-ten Dam MM, Muris AH, Jol-van der Zijde CM, van Tol MJD, Losen M, Molenaar PC, van Zoelen EJJ, Berrih-Aknin S, De Baets MH, Verschuuren JJGM, and Martínez-Martínez P

*These authors contributed equally to the work.

Published in: Journal of Neuroimmunology 2010; 232 (1-2): 158-65. 


\section{Abstract}

In myasthenia gravis (MG), the neuromuscular transmission is impaired mainly by autoantibodies against the acetylcholine receptor (AChR) or MuSK. In about 5\% of the MG patients, however, the auto-antigen is still unknown. We investigated whether these idiopathic MG patients (iMG) have auto-antibodies against ErbB proteins, which influence the AChR density at the NMJ. Our results show reduced mRNA expression levels of ErbB4 in thymus tissue of iMG patients compared to AChR-MG and non-MG patients, but we could not detect anti-ErbB antibodies in sera of iMG patients. Therefore, our results do not support a role for ErbB receptors as auto-antigens in iMG patients. 


\section{Introduction}

Myasthenia gravis (MG) is an acquired auto-immune disease that affects the synaptic transmission between motor neurons and skeletal muscle cells (Conti-Fine et al., 2006; Drachman, 1994; Toyka et al., 1975; Vincent, 2002). In about 85\% of generalized MG patients, auto-antibodies are present against the acetylcholine receptor (AChR) (Lindstrom et al., 1976), which is located at the postsynaptic membrane of the neuromuscular junction (NMJ) (Engel et al., 1977; Engel et al., 1976). In about 5\% of the generalized MG patients the muscle-specific kinase (MuSK) is the target of the autoantibodies while antibodies to AChR are absent (Hoch et al., 2001). The remaining $10 \%$ of generalized MG patients show symptoms that are similar to those presenting with antiAChR positive MG (Chan et al., 2007). These 'idiopathic MG' (iMG) patients improve after immunosuppressive treatment (Muppidi and Wolfe, 2009; Zhou et al., 2004), which strongly suggests that iMG also has an auto-immune origin. Approximately half of the iMG subgroup appears to have antibodies to the AChR as well, although probably only with low affinity (Drachman, 1994). In a study of Leite and colleagues anti-AChR antibodies could only be detected by assays where the AChRs were clustered on the cell surface instead of being in a solubilized form, as is the case in routine assays for anti-AChR antibodies (Leite et al., 2008). However, in about 5\% of MG patients the auto-immune target still remains unknown. In this paper, we tested the possibility that ErbB proteins can act as auto-antigens in iMG.

ErbB proteins are receptors for neuregulins and are involved in the local activation of synaptic gene expression, such as AChR (Jo et al., 1995; Rimer, 2003). The ErbB receptor family consists of four members: ErbB1 (also known as the epidermal growth factor receptor or HER1), ErbB2 (also known as HER2 in humans and Neu in rodents), ErbB3 (or HER3) and ErbB4 (or HER4). In skeletal muscle, ErbB3 is expressed mainly at the terminal Schwann cells, whereas ErbB2 and ErbB4 are located postsynaptically in the depth of the folds (Buonanno and Fischbach, 2001; Jo et al., 1995; Zhu et al., 1995). Mutant mice lacking neuregulin or ErbB genes die early in embryogenesis due to defects in cardiac and neural development (Lemke, 1996; Sanes and Lichtman, 1999) but hemizygous mice are viable (Lemke, 1996). Mice hemizygous for the neuregulin-1 gene have a reduced concentration of AChRs and show myasthenic symptoms (Sandrock et al., 1997; Trinidad et al., 2000), while mice hemizygous for the ErbB2 or ErbB3 gene show modest but significant postsynaptic defects, but no clear cardiac defects (Kummer et al., 2006). As transmembrane proteins, ErbB receptors are potentially accessible to antibodies and could act as auto-antigens in an antibody-mediated immune response. 
In AChR-MG, the original trigger for auto-antibody production remains unknown. However, it has been shown that the thymus, a lymphoid organ responsible for the maintenance of immunological self-tolerance, plays an important part (Aharonov et al., 1975). First, functional and morphological abnormalities of the thymus occur often in MG patients, and $65-75 \%$ of AChR-MG patients display thymic hyperplasia with numerous germinal centers in the medulla (Levinson and Wheatley, 1996). These intrathymic germinal centers (GC) may be sites of an intense B-cell proliferation against the AChR (Sims et al., 2001) as lymphocytes extracted from the thymus of MG patients have been shown to produce anti-AChR antibodies in vitro (Kamo et al., 1982; Vincent et al., 1978). Second, the hyperplastic thymus has been shown to contain anti-AChR autoreactive T cells (Melms et al., 1988), and third, the removal of the thymus seems to improve the clinical symptoms in MG patients (Gronseth and Barohn, 2000; Kuks et al., 1991). Finally, the AChR is expressed in the thymus by myoid cells (muscle-like cells expressing numerous muscle genes), and thymic epithelial cells (Leite et al., 2007; Wakkach et al., 1996; Wekerle et al., 1978) involved in promiscuous expression of tissue-specific autoantigens that is important to provide protection against auto-immune diseases. It has been demonstrated that a polymorphism in the promoter region of the CHRNA 1 gene, which encodes the $\alpha$-subunit of the AChR, influences transcription levels of this autoantigen in the thymus and is associated with early onset MG (Giraud et al., 2007). All in all, this points to the thymus as the origin of the defective self-tolerance to the AChR in MG.

In contrast to patients with AChR-MG, the morphology of the thymus of MuSK-MG patients is generally comparable to age-matched controls (Leite et al., 2005). However, the thymus of iMG patients contains lymph node-type infiltrates similar to those in AChRMG patients, but with fewer germinal centers (Lauriola et al., 2005; Leite et al., 2005). Some iMG patients improve after thymectomy (Evoli et al., 2003). These observations also suggest the involvement of the thymus in iMG. Since the auto-antigenic target involved in iMG patients is not yet known, disregulation of specific genes in the thymus of iMG patients, which play a role in neuromuscular transmission, could sensitize potential targets as auto-antigens. Therefore, we investigated the expression pattern of ErbB genes in the thymus of iMG patients and examined the presence of anti-ErbB antibodies in their serum. Our results show that the expression of the ErbB4 gene in the thymus of iMG patients is decreased relative to controls. However, we failed to detect antibodies against the ErbB proteins in blood samples of any of the iMG patients that were studied. 


\section{Patients, materials and methods}

\section{ErbB mRNA expression quantification in thymus and muscle tissue}

\section{Patient information (French cohort)}

Thymic tissue and sternocleidomastoid muscle samples were obtained from MG patients during thymectomy, while thymic samples from non-MG patients were obtained from baby or adult females undergoing cardiovascular surgery at the Marie Lannelongue Chirurgical Center (Le Plessis-Robinson, France). We selected biopsies from female Caucasian MG patients known to be treated only by anti-cholinesterase drugs (i.e. not by corticosteroids, immunosuppressors, etc) and not affected by any other disease (including thymoma). These studies were approved by the local Ethics Committee (CCPPRB, KremlinBicêtre, France: agreement (18/10/1999)). Clinical details of the patients are summarized in Table 1.

\section{Microarray experiments}

Total RNA was extracted from individual frozen thymic or muscle fragments using the FastPrep FP120 instrument (Qbiogen, Illkirch, France) followed by a TRIzol extraction (Invitrogen, Cergy-Pontoise, France) and a DNAse treatment before purification onto Qiagen columns (Courtaboeuf, France). RNA quality was assessed on an Agilent Bioanalyser (Massy, France).

The thymic transcriptome study has been fully described previously (Le Panse et al., 2006). To minimize inter-individual variation, pools of RNA were prepared from the following donor groups: 1 ) Non-MG adults; $n=4$; $15-19$ years old; 2 ) iMG patients (without or only a few GCs); $n=3 ; 16-22$ years old. These MG patients were seronegative for antiAChR and anti-MuSK antibodies; 3) AChR-MG patients with various degree of thymic hyperplasia associated with the presence of GCs; $n=9 ; 18-25$ years old. For this last donor group, we had 2 RNA pools of thymi: a pool of 5 patients' thymi with a high degree of thymic hyperplasia and a RNA pool of 4 patients' thymi with a low degree of thymic hyperplasia. Then, we compared RNA levels from these RNA pools of adult thymi with a thymic reference (RNA extracted from 10 thymi of babies aged 1 week to 1 year old).

For the muscle transcriptome study, we compared RNA levels of muscle biopsies from iMG patients and age-matched AChR-MG patients with a common RNA reference (HT-1008 Muscle, ORIGENE technologies Inc., Rockville, Maryland, USA; a pool of RNA from muscle biopsies from healthy adults but not especially age-matched). To minimize inter-individual variation, pools of RNA were prepared from the following donors: 1) iMG 
patients, of which one was also used for the thymus transcriptome study; $n=3 ; 16-25$ years old. These MG patients were seronegative for anti-AChR and anti-MuSK antibodies; and 2) AChR-MG patients; $n=3 ; 24-27$ years old.

Microarray experiments were carried out using the "Human 1" cDNA arrays from Agilent (G4100A - containing 12,814 unique clones) according to the manufacturer's instructions, using $20 \mu \mathrm{g}$ of total RNA. For each array, reference RNA was compared with pooled RNA from one of the donor groups, a procedure that was repeated 4 times (4 measures per donor group) for the muscle study and 5 times for the thymic study (5 measures per donor group). Labelled cDNA was finally hybridized overnight on the microarray which was subsequently scanned using the 428 Affimetrix scanner (MWG, Courtaboeuf, France). The images were analyzed with GenePix pro V4.0 software (Axon Instruments, Dipsi Industrie, Châtillon, France). To allow inter-array comparison, each condition was centered on the median calculated from the repetitions, and a Lowesstransformation was finally applied to each array, using the TIGR Microarray Data Analysis System (http://www.tigr.org/). For each gene, a ratio (study sample/reference) was calculated and the distribution per array was centered to zero.

\section{Anti-ErbB auto-antibody measurement}

\section{Patient information (Dutch cohort)}

Patients with generalized MG without anti-AChR antibodies were included from a nationwide study as described previously (Niks et al., 2007). The diagnosis of generalized MG was based on acquired and clinically confirmed fluctuating weakness of muscles not restricted to the external eye muscles, the $\mathrm{m}$. levator palpebrae or the $\mathrm{m}$. orbicularis oculi. Absence of antibodies to the AChR in standard radioimmunoassays (RIA) was required more than once during periods of clinical weakness. The diagnosis was considered to be supported by a clinical response to intravenous acetylcholinesterase inhibitors or by electromyography if a decrement of the compound muscle action potential of $>10 \%$ was found during repetitive nerve stimulation or if single-fiber electromyography had shown an increased jitter or blocking.

All patients were re-examined by a single investigator (EHN) for standardized history taking and physical examination. The clinical condition during the first two weeks and at maximum disease severity was classified according to the MGFA Clinical Classification (Jaretzki et al., 2000). Serum from all patients was retested for antibodies to the AChR, MuSK and voltage-gated calcium channels in standard RIA (RSR Ltd, UK). DNA of iMG patients was tested for the rapsyn N88K mutation known to cause a late-onset congenital myasthenic syndrome (Burke et al., 2003). 
Of the 62 patients with iMG originally described in our epidemiological study (Niks et al., 2007), seven were lost to follow-up, while no informed consent was obtained from six, one patient had died and one 16-year-old girl had become AChR antibody positive three years after the onset of the symptoms. The remaining 47 patients were clinically reexamined. Subsequently, five patients were excluded because the symptoms were incompatible with generalized MG $(n=2)$, or because of the presence of a N88K rapsyn mutation $(n=1)$, or comorbidity in the form of severe Cushing's disease before the onset of MG symptoms $(n=1)$ or finally because one patient appeared to have presented fluctuating weakness ever since birth (classified as congenital myasthenic syndrome, $n=1$ ). Clinical characteristics of 42 patients with generalized iMG are summarized in Table 1. Muscle weakness was mild or moderate, and more of the limb-girdle type (MGFA class Ila or IIla). However, a few patients suffered from oculobulbar weakness, even requiring intubation in two cases (MGFA class V). The diagnosis was supported by repetitive nerve stimulation in 14 patients, by single fibre electromyography in 17 patients and by IV acetylcholinesterase inhibitor in eight patients. In one patient, diagnostic procedures were incomplete. Only repetitive nerve stimulation was performed but negative. In the remaining two patients, results of repetitive nerve stimulation, single fibre electromyography and IV acetylcholinesterase inhibitor were all negative. In all three patients however, clinical symptoms had responded to immunosuppressive therapy.

\section{Fluorescence-activated cell sorting (FACS)}

Sera from 42 iMG patients were screened for anti-ErbB-IgG using FACS. For this purpose murine 32D hematopoietic cells transfected with distinct combinations of human ErbB receptors were used. In the present study we used 32D13 cells (expressing both ErbB1 and ErbB3), 32D23 cells (expressing both ErbB2 and ErbB3) and 32D24 cells (expressing both ErbB2 and ErbB4). Transfected 32D cells were cultured in RPMI 1640/glutamax-I, containing penicillin $(100 \mathrm{U} / \mathrm{ml})$, streptomycin $(100 \mu \mathrm{g} / \mathrm{ml}), 10 \%$ fetal calf serum (FCS), 50 $\mu \mathrm{M} \beta$-mercaptoethanol, recombinant mouse IL-3 $(0.5 \mathrm{ng} / \mathrm{ml}$, R\&D systems, Minneapolis, MN, USA), geneticin $(\mathrm{G} 418,600 \mu \mathrm{g} / \mathrm{ml}$ ) and hygromycin B (for 32D13 and 32D23 cells, 400 $\mu \mathrm{g} / \mathrm{ml}$ ). The cells were cultured in a $37^{\circ} \mathrm{C}$ humidified atmosphere containing $95 \%$ air and $5 \% \mathrm{CO}_{2}$. High density 32D cells were harvested and resuspended in washing buffer (PBS containing $\left.1 \% \mathrm{BSA} / 1 \% \mathrm{FCS} / 0.2 \% \mathrm{NaN}_{3}\right)$. Subsequently cells $\left(0.15 \times 10^{6}\right)$ were incubated with sera diluted to a final concentration of 1:10, 1:20 and 1:40 in washing buffer for 1 hour while gently shaking. Cells were then washed five times with washing buffer and incubated for 30 min with rabbit anti-human-IgG-FITC conjugate (1:20, Dako, Glostrup, Denmark). As a negative control, normal human serum (NHS; healthy volunteers) was 
analyzed according to the same protocol. The expression of ErbB2 was checked with a mouse monoclonal anti-c-ErbB2 (clone L26, Immunologic, Duiven, The Netherlands) and goat anti-mouse Ig-APC conjugate (BD Pharmingen, San Jose, CA, USA). Cell lines 32D23 and 32D24 were positive for ErbB2 staining in contrast to 32D13 which was negative. FACS analysis was performed using a BD Biosciences FacsCalibur flowcytometer and the mean fluorescence intensity (MFI) was calculated with CellQuestPro software (BD Biosciences, San Jose, CA, USA). The MFI of each sample was normalized by dividing the obtained fluorescence values by the mean of the corresponding NHS group. The mean value of NHS plus two and three times the standard deviation was used as cut off value.

Table I. Characteristics of iMG patients

\begin{tabular}{|c|c|c|}
\hline & $\begin{array}{l}\text { Dutch patients } \\
(n=42)\end{array}$ & $\begin{array}{l}\text { French patients } \\
(n=5)\end{array}$ \\
\hline Women - $n(\%)$ & $28(67)$ & $5(100)$ \\
\hline Age at onset - median (range) in yrs & $38.1(5.9-66.8)$ & $19.75(16-22)$ \\
\hline Age at onset below 16 yrs - $n(\%)$ & $5(12)$ & \\
\hline Follow-up - median (range) in yrs & $10.4(0.6-45.5)$ & \\
\hline Caucasian - $n(\%)$ & $40(95)$ & $5(100)$ \\
\hline \multicolumn{3}{|l|}{ MGFA at onset } \\
\hline$-1-n$ & 19 & \\
\hline$-I I(a$ vs b) $-n$ & 23 (14 vs 6$)$ & \\
\hline \multicolumn{3}{|l|}{ MGFA at maximum or before thymectomy for French patients } \\
\hline- II (a vs b) - $n$ & 20 (11 vs 2 ) & 2 (1 vs 1$)$ \\
\hline- III (a vs b) - $n$ & 15 (9 vs 4 ) & 2 (0 vs 2 ) \\
\hline$-\operatorname{IV}(\mathrm{a}$ vs $\mathrm{b})-n$ & 3 (0 vs 2$)$ & 1 (0 vs 1 ) \\
\hline$-\mathrm{V}-n$ & 2 & 0 \\
\hline Interval onset to maximum - median (range) in yrs & $2.1(0-40.5)$ & \\
\hline \multicolumn{3}{|l|}{ Diagnosis supported by } \\
\hline - A. Electromyography - $n(\%)$ & $31(74)$ & $4(80)$ \\
\hline - B. Response to IV AChE inhibitors - $n(\%)$ & $8(19)$ & $5(100)$ \\
\hline - Neither A nor B - $n(\%)$ & $3(7)$ & 0 \\
\hline \multicolumn{3}{|l|}{ Therapy } \\
\hline - Oral AChE inhibitors - $n(\%)$ & $41(98)$ & $5(100)$ \\
\hline - Immunomodulative therapy - $n(\%)$ & $26(62)$ & 0 \\
\hline - Oral immunosuppression - $n(\%)$ & $23(55)$ & 0 \\
\hline - Thymectomy (with follicular hyperplasia) - $n$ & $11(3)$ & $5(100)$ \\
\hline Interval onset - start of immunomodulation - median (range) in yrs & $2.4(0-40.5)$ & \\
\hline
\end{tabular}




\section{Dot blotting}

Sera from 42 iMG patients were also screened for anti-ErbB-IgG using dot blotting. For this, we used human embryonic kidney (HEK) 293 cells, transiently transfected with expression vectors for human ErbB2 and ErbB4 genes using the Profection mammalian calcium phosphate transfection system (Promega Corporation, USA). These vectors were a kind gift of Dr. L. Schaeffer from the 'Laboratoire de biologie moléculaire et cellulaire' in Lyon, France. Transfected cells were maintained in Dulbecco's modified Eagle's medium (DMEM) with glucose and sodium pyruvate (Gibco, Invitrogen Corporation, Breda, The Netherlands) supplemented with $10 \%$ FCS (Bodinco, The Netherlands), $1 \%$ penicillin/streptomycin (Gibco) and 1\% L-glutamine (Gibco). The cells were cultured in a $37^{\circ} \mathrm{C}$ humidified atmosphere containing $95 \%$ air and $5 \% \mathrm{CO}_{2}$. After 72 hours, membrane proteins were isolated from the cells with a $0.6 \%$ cholate extraction buffer, containing $0.01 \mathrm{M} \mathrm{NaN}_{3}$ (Acros Organics, Geel, Belgium), 0.01 M EDTA (Sigma-Aldrich, St-Louis, USA), $0.01 \mathrm{M}$ iodoacetamide (Sigma), $0.1 \mathrm{mM}$ phenylmethylsulphonyl fluoride (Sigma) and 0.6\% cholate (Sigma) in PBS. The protein concentration was measured using the Bio-Rad system (Bio-Rad, California, USA). To verify the expression of ErbB2 and ErbB4 in transfected HEK cells, Western blotting was performed as described before (Mencarelli et al., 2009) using rabbit anti-ErbB2 antibody (C-18) (sc-284, Santa Cruz Biotechnology Inc., USA) or rabbit anti-ErbB4 antibody (C-18) (sc-283, Santa Cruz).

To detect anti-ErbB antibodies in sera of iMG patients, $5 \mu$ l of ErbB transfected HEK 293 cell extract $(0.4 \mathrm{mg} / \mathrm{ml}$ protein concentration) and non-transfected cell extract $(0.4$ $\mathrm{mg} / \mathrm{ml}$ ) were applied in three dots on a Protran nitrocellulose membrane (Schleicher and Schuell, Dassel, Germany). Following blocking in Odyssey blocking buffer (OBB; LiCor Westburg, Leusden, The Netherlands) diluted in PBS (1:1) (OBB/PBS), membrane strips were separately incubated with rabbit anti-ErbB2-antibody or anti-ErbB4 antibody (positive controls), diluted $1: 1000$ or $1: 1500$ respectively in OBB/PBS containing $0.5 \%$ goat serum (GS) (i.e. OBB/PBS/GS), with OBB/PBS/GS (negative control), with patient serum diluted 1:1000 in OBB/PBS/GS, or with NHS diluted 1:1000 in OBB/PBS/GS. Then, strips were washed three times with PBS 0.1\% Tween (Merck), and incubated with IRDye 800 goat anti-rabbit IgG (Rockland Immunochemicals), diluted 1:3700 in OBB/PBS/GS, or with IRDye 800 goat anti-human IgG (Rockland Immunochemicals), diluted 1:10000. Following the washing steps, strips were scanned with the Odyssey scanner (LiCor Westburg) at 800 $\mathrm{nm}$. Finally, ImageJ software (http://rsb.info.nih.gov/ij/) was used to quantify the integrated intensities of the dots. The mean integrated intensity of the background was subtracted. To correct for the non-specific binding of antibodies to other proteins than 
ErbB2 or ErbB4, the ratio was calculated between mean intensities of dots of transfected cell extract and dots of non-transfected cell extract. These ratios were normalized by dividing them by the mean of the NHS ratios. The mean of NHS plus two and three times standard deviation was used as cut off value.

\section{Statistical analysis}

SPSS Software 17.0 was used to perform statistical analyses. Comparison between nonnormally distributed values was performed using the non-parametric Mann-Whitney test. A two-sided probability value $<0.05$ was considered statistically significant.

\section{Results}

\section{Reduced ErbB4 expression in the thymus of iMG patients}

Since the thymus appears clearly involved in the auto-immune responses of AChR-MG patients, we investigated whether the ErbB-receptor genes were differentially expressed in the thymus of iMG patients (Table 1, French cohort), using gene expression microarray experiments previously described (Le Panse et al., 2006). Microarray data were analyzed to compare the expression levels of ErbB2, ErbB3 and ErbB4 in thymus biopsies of iMG, AChR-MG patients and age-matched non-MG patients (Figure 1). Although there was evidence of expression of ErbB2, ErbB3 and ErbB4 receptors in all pooled thymus RNA samples tested, no significant difference was observed between IMG and both non-MG and AChR-MG patients with respect to average thymic expression of ErbB2 (Figure 1A) and ErbB3 (Figure 1B). However, ErbB4 expression was significantly reduced in thymi of iMG compared to both non-MG $(p<0.0001)$ and AChR-MG patient thymi $(p=0.0175)$ (Figure 1C). Specifically, the iMG thymi had a significantly reduced expression of ErbB4 compared to AChR-MG thymi with a high degree of hyperplasia ( $p<0.0001$, not shown). The ErbB4 expression of iMG and AChR-MG thymi with low degree hyperplasia was not significantly different.

\section{No auto-antibodies against ErbB proteins in iMG patients}

To identify anti-ErbB antibodies in iMG patients, FACS and dot blotting analysis were used. In both methods, sera from 42 iMG patients (Table 1, Dutch cohort) were screened for anti-ErbB-IgG antibody binding to specific ErbB transfected cell lines. The results of the anti-ErbB antibody measurement by FACS are summarized in Figure 2. The median MFI of iMG patients was not significantly higher than that of healthy controls, for none of the 
three cell lines tested. In addition, no individual value of an iMG patient or a healthy control exceeded the cut off value, calculated as the mean plus three times SD of the corresponding NHS group (data not shown). These results show that there are no detectable levels of antibodies against ErbB1, ErbB2, ErbB3 and ErbB4 in this cohort of iMG patients.
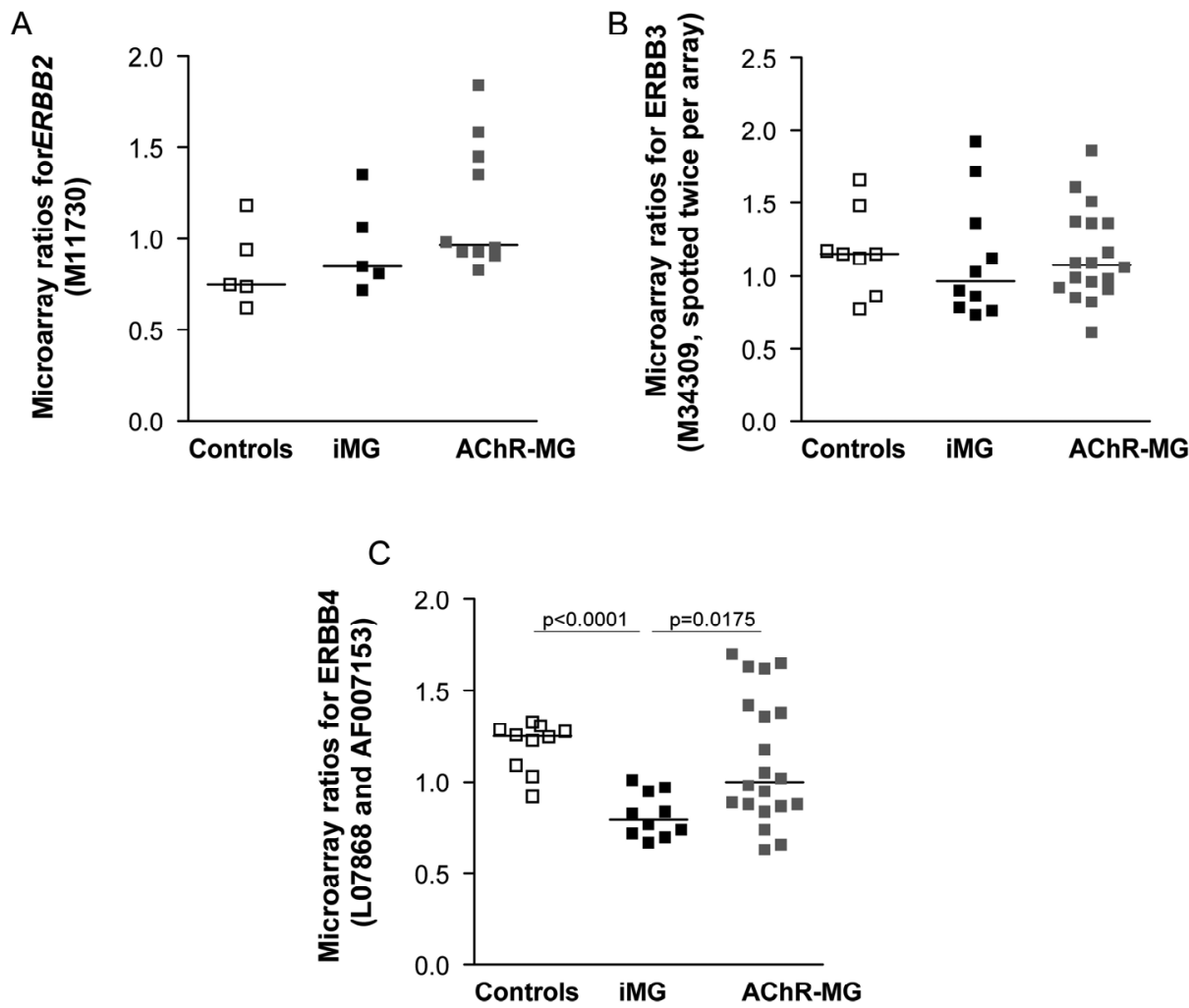

Figure 1. Thymic RNA levels for ErbB2, ErbB3 and ErbB4 expression from microarray data. Ratio of ErbB gene expression level between non-MG patients (controls), iMG or AChR-MG patients and the thymic reference. Each dot corresponds to the ratio of Erb gene expression in one array (one GenBank). For ErbB2 (A), one GenBank (M11730) was spotted per array. For ErbB3 (B), one GenBank (M34309) was spotted twice per array (however, for control and AChR-MG groups, 2 dots were not included in the analyses as they were not validated by quality control tests made by the manufacturer for the given batch of arrays). For ErbB4 (C), two GenBanks were spotted on the arrays (L07868 and AF007153). The data from the AChR-MG group represent patients with a low and with a high degree of thymic hyperplasia. The comparisons were repeated 5 times ( 5 arrays) for non-MG patients or IMG, and 10 times ( 5 arrays with the pool of AChR-MG patients with low degree of thymic hyperplasia and 5 arrays with the pool of AChR-MG patients with high degree of thymic hyperplasia) for AChR-MG patients. Horizontal lines represent the median value per group. The p-values were obtained by the Mann-Whitney test and shown when $<0.05$. 


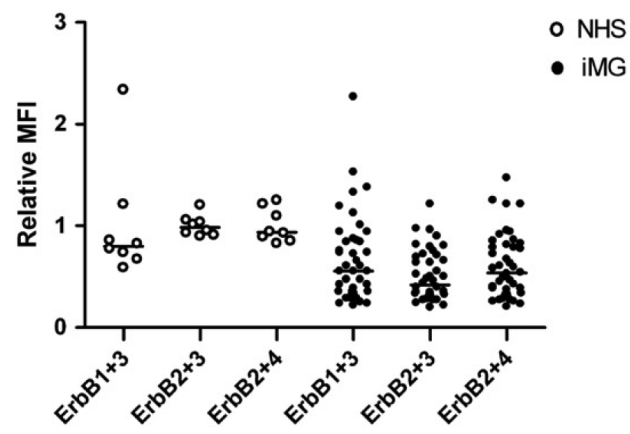

Figure 2. Detection of anti-ErbB2/3/4 antibodies by FACS. Sera from 42 iMG patients were screened for antiErbB-IgG by flow cytometry. 32D13 cells (expressing ErbB1+3); 32D23 cells (expressing ErbB2+3); and 32D24 cells (expressing ErbB2+B4) were incubated with serum from patients (solid circles) or normal human serum (NHS) (empty circles). Values are normalized with the mean MFI of the corresponding NHS group. Horizontal full lines represent the median MFI per group. The Mann-Whitney test did not show a significant increase in median MFI in iMG patients compared to NHS.

In addition to the FACS analysis, we used dot blotting of membrane extracts from transfected cells to measure anti-ErbB antibody titers in the same iMG patients. Results are shown in Figure 3. The high transfection efficiency of HEK cells with ErbB2 and ErbB4 cDNA was verified by Western blotting (Figure 3A). Low amounts of ErbB2 receptors were also endogenously present in non-transfected HEK cells, whereas ErbB4 receptors were undetectable in non-transfected HEK cells. Figure $3 \mathrm{~B}$ shows representative dot blots, where non-transfected and transfected HEK cell extracts were incubated with iMG patient serum (Figure 3B, row 1), normal human serum (Figure 3B, row 2), monoclonal anti-ErbB2 antibody (Figure 3B, row 3) and monoclonal anti-ErbB4 antibody (Figure 3B, row 4). To correct for unspecific antibody binding to endogenous HEK proteins, the mean integrated intensity of transfected cells were divided by the mean integrated intensity of nontransfected cells for each sample. The results are summarized in Figure 3C. The median fluorescence ratio in iMG patients was significantly lower than that of both positive controls (monoclonal anti-ErbB2 antibody $(p<0.001)$ and monoclonal anti-ErbB4 antibody $(p<0.001))$, but did not differ from the median ratio of healthy individuals. In addition to comparing median values of the ratio of the different groups, no individual ratio of an iMG patient or a healthy person exceeded the cut off value. To study the possibility that the negative results were due to low sensitivity of the techniques, we validated the sensitivity of the dot blotting protocol (Figure 3D). Anti-AChR antibodies were measured in AChR-MG patients, of whom the anti-AChR antibody titer had been determined by RIA before. Anti-AChR antibodies were detectable using the present dot blotting technique, although the dot blotting was less sensitive than the RIA (data not shown). 
A

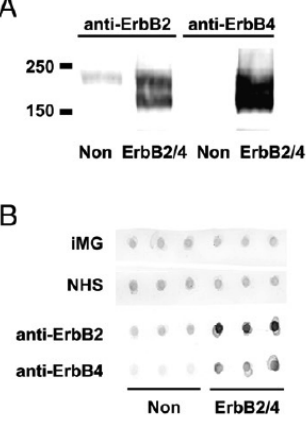

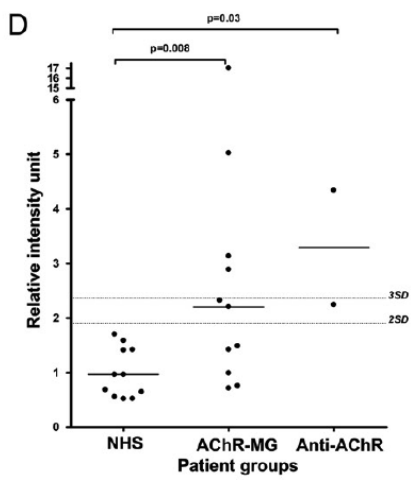

$p=0.001$

C

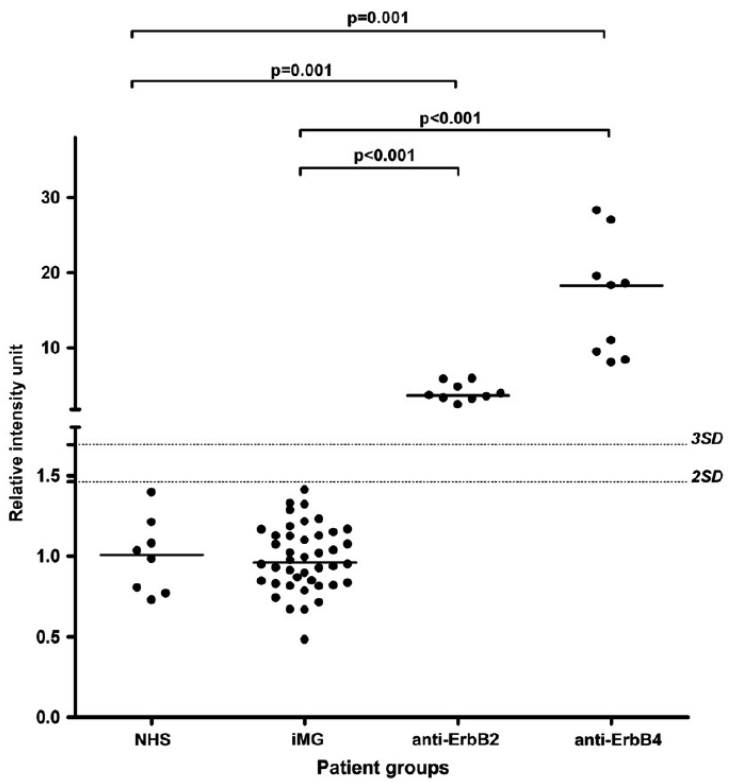

Figure 3. Detection of anti-ErbB2/4 antibodies by dot blotting analysis. Sera from 42 iMG patients were screened for anti-ErbB-IgG by dot blotting analysis. A) Expression of ErbB2 and ErbB4 in non-transfected (non) and transfected (ErbB2/ErbB4) HEK 293 cells, measured by Western blotting. B) Representative dot blots spotted with non-transfected and transfected HEK 293 cell extracts were incubated with iMG patient serum (iMG), normal human serum (NHS), anti-ErbB2 positive control antibody or anti-ErbB4 positive control antibody. C) Dot blot results of anti-ErbB antibody measurement in iMG patients. Each dot corresponds to the ratio between the mean intensity of triplicate measurements of transfected HEK cells and the mean intensity of the non-transfected HEK cells. Horizontal full lines represent the median value of the ratio per group, dashed lines show cut off value calculated as the mean of NHS plus two and three times the standard deviation. D) Dot blot results of anti-AChR antibody measurement in AChR-MG patients. Horizontal full lines represent the median ratio per group, dashed lines show cut off value calculated as the mean of NHS plus two and three times standard deviation. The $p$-values were obtained by the Mann-Whitney test and shown when $<0.05$. 
A

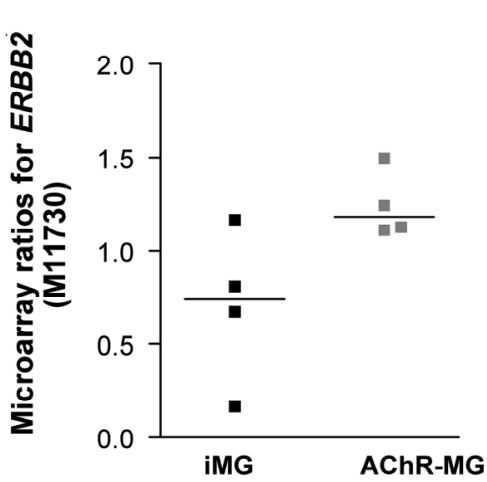

B

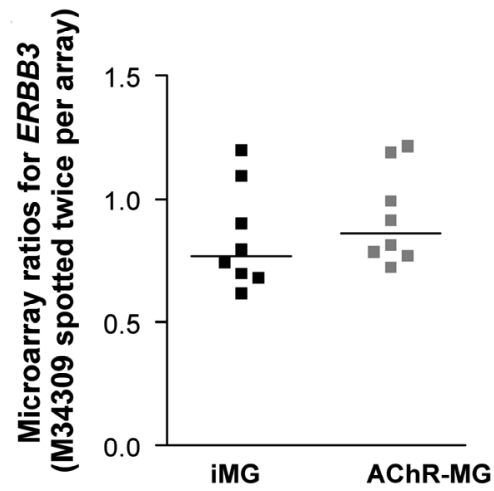

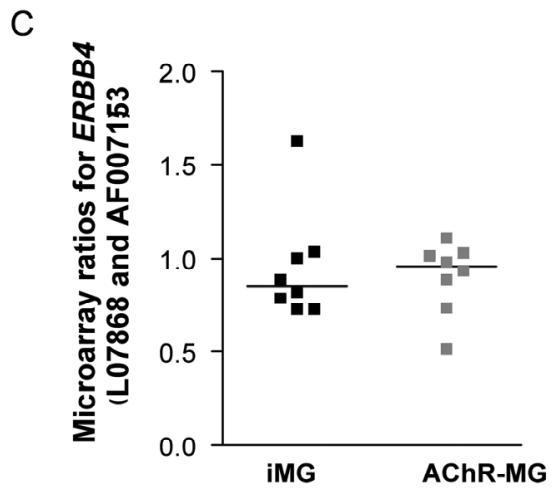

Figure 4. Muscle RNA levels for ErbB2, ErbB3 and ErbB4 expression from microarray data. Ratio aof ErbB gene expression level between muscle from MG patients (iMG or AChR-MG) and a muscle reference. For this study, 4 arrays were carried out for each comparison. Each dot corresponds to the ratio of ErbB gene expression in one array (one GenBank). For ErbB2 (A), one GenBank (M11730) was spotted per array. For ErbB3 (B), one GenBank (M34309) was spotted twice per array. For ErbB4 (C), two GenBanks were spotted on the arrays (L07868 and AF007153). Horizontal lines represent the median value per group. The Mann-Whitney test did not reveal significant differences between iMG and AChR-MG groups.

\section{No differential ErbB expression in muscle tissue of iMG patients}

It has been established that compensatory mechanisms exist that increase AChR gene expression in muscle tissue after antibody-induced AChR breakdown (Guyon et al., 1998), and therefore anti-ErbB antibodies, if present, might also induce changes in the muscle expression of ErbB genes. Therefore, we performed gene expression microarray experiments to compare the mRNA levels of the ErbB2, ErbB3 and ErbB4 genes in muscle biopsies from iMG and AChR-MG patients (Figure 4). No significant difference was 
observed with respect to the expression of ErbB2 (Figure 4A), ErbB3 (Figure 4B) and ErbB4 (Figure $4 \mathrm{C}$ ) compared to the muscle reference, neither among iMG nor the AChR-MG patients.

\section{Discussion}

Various studies have identified ErbB receptors, which are present at the NMJ, as potential candidates for the auto-immune target in iMG patients, particularly since myasthenic symptoms have been described in ErbB mutant mice (Kummer et al., 2006; Lemke, 1996; Sandrock et al., 1997; Sanes and Lichtman, 1999; Trinidad et al., 2000). Because the thymus is known to play a role in AChR-MG, we investigated ErbB isoform expression in the thymus of iMG patients and searched for anti-ErbB auto-antibodies in their serum. We found indications for an altered ErbB4 expression in the thymus, which could act as a risk factor in breaking tolerance to this protein. However, the antibody tests for ErbB in the sera of the 42 iMG patients were all negative. This strongly suggests that ErbB does not have a role as autoantigen in MG.

The relevance of this study depends, among other things, on the careful selection of iMG patients. While utmost care was exercised to select patients using routine assays for detecting anti-AChR and anti-MuSK antibodies, it should be borne in mind that recently new techniques have been reported for detecting low-affinity antibodies to AChR and MuSK. Leite and colleagues using human embryonic kidney cells transfected with AChR molecules clustered with co-transfected rapsyn, defined a further $66 \%$ of iMG patients as having low-affinity antibodies to the AChR (Leite et al., 2008). A similar approach has been developed to detect low-affinity anti-MuSK antibodies (Leite et al., 2010). Since many patients in our cohort had relatively early onset MG, it seems likely that some of these patients may have had low-affinity antibodies to AChR or MuSK. However, since these assays are not yet available for routine diagnosis and not yet fully validated in terms of pathogenicity of these low-affinity autoantibodies we considered ErbB as a potential autoantigen for the whole of our iMG cohort.

Our present negative finding could be explained, firstly, if the sensitivity of our assays for anti-ErbB would have been too low. However, we successfully used an analogue FACS analysis to demonstrate the presence of anti-MuSK antibodies, which confirms the sensitivity of the technique (data not shown). The dot blot assay was not able to detect anti-AChR antibodies in all the AChR-MG patients, and thus might be too insensitive for detection of low anti-ErbB antibody titers. A second possibility is that the auto-antibodies would only be able to bind to ErbB proteins when clustered together in 
the NMJ, as shown earlier for a subset of anti-AChR antibodies (Leite et al., 2008). A third, more remote, possibility is that patients with a low titer of putative antibodies might bind to the ErbB antigens with very high affinity, thereby leaving the blood serum depleted of free antibody.

If, on the contrary, anti-ErbB antibody would have been present in patients it is questionable that they would actually have caused MG-like symptoms. ErbB2 gene amplification and protein overexpression are known to be critical for the development of malignancies such as breast cancer. For more than ten years, such patients are frequently treated with trastuzumab (Herceptin), a humanized IgG1 monoclonal antibody directed against ErbB2 (Baselga et al., 1999; Cobleigh et al., 1999; Ross et al., 2009). Distinct side effects can occur during treatment with trastuzumab but, as far as we know, myasthenic muscle weakness in patients undergoing this therapy has not been reported, arguing against a possible myasthenic effect of anti-ErbB2 antibodies. No reports specifically analyzed these patients for myasthenic syndromes, leaving the possibility that milder forms of the disease might have been missed in these patients.

Thymic epithelial cells play a key role in self-tolerance education of thymocytes by expressing tissue-specific antigens. The promiscuous expression level of these antigens in the thymus seems to be critical for the generation of self-tolerance. Several studies have documented an inverse correlation between the amount of thymic self-antigen expression and susceptibility to organ-specific auto-immunity. Salmon et al. used transgenic mice with a $\beta$-galactosidase gene under the control of AChR- $\alpha$ gene promoter to show that a low thymic expression level of the transgene does not allow full tolerance, leading to the development of an auto-immune response against $\beta$-galactosidase when that enzyme is injected into the mice (Salmon et al., 1998). Similarly, in human insulindependent diabetes mellitus the susceptibility to diabetes is higher in patients with low expression of insulin in the thymus (Pugliese et al., 1997). In AChR-MG, decreased expression of the CHRNA1 gene has been associated with early onset of the disease (Giraud et al., 2007). Consequently, the low level of thymic ErbB4 expression in our iMG patients might prevent self-tolerance towards ErbB4, thus possibly provoking an autoimmune response. In other words, the finding of the decreased expression of ErbB4 in the thymus hypothetically could predict the occurrence of auto-antibodies against ErbB proteins. However, no anti-ErbB antibodies were detected in the serum of iMG patients. Although it has been shown that the buffering capacity of central tolerance is limited towards quantitative alterations in antigen availability (Giraud et al., 2007; Pugliese et al., 1997; Salmon et al., 1998), it seems that either the required threshold for anti-ErbB autoimmunity has not been reached yet, or that the robust nature of immunological tolerance 
is able to buffer low or medium levels of reactive T-cell clones in the peripheral circulation (Liston et al., 2005).

We conclude that further research is needed to identify the unknown autoantigen(s) in the iMG group, whether it be low-affinity antibodies against AChR, MuSK or otherwise. Interestingly, the thymic transcriptome of iMG patients is characterized by a down-regulation of several genes involved in synaptic transmission, including neurotransmitter receptors (Cizeron-Clairac et al., 2008; Le Panse et al., 2006). These genes could potentially correspond to auto-immune targets and would be worthwhile to focus on for seeking the auto-antigen responsible for iMG.

\section{Acknowledgements}

The authors thank Ingrid Hegeman for their technical support, Géraldine Cizeron-Clairac for her involvement in microarrays and Catelijne Stortelers for carrying out Western blot analyses for detecting the presence of anti-ErbB antibodies. We thank Philippe Dartevelle and Alain Serraf for the thymic samples, and Vincent de Montpreville for histological analyses on the French cohort of patients. This work was supported by a grant from the European Myastaid Project (LSHM-CT-2006-037833) and the Association Française contre les Myopathies (AFM).

\section{References}

Aharonov, A., Tarrab-Hazdai, R., Abramsky, O., Fuchs, S., 1975. Immunological relationship between acetylcholine receptor and thymus: a possible significance in myasthenia gravis. Proc Natl Acad Sci U S A 72, 1456-1459.

Baselga, J., Tripathy, D., Mendelsohn, J., Baughman, S., Benz, C.C., Dantis, L., Sklarin, N.T., Seidman, A.D., Hudis, C.A., Moore, J., Rosen, P.P., Twaddell, T., Henderson, I.C., Norton, L., 1999. Phase II study of weekly intravenous trastuzumab (Herceptin) in patients with HER2/neu-overexpressing metastatic breast cancer. Semin Oncol 26, 78-83.

Buonanno, A., Fischbach, G.D., 2001. Neuregulin and ErbB receptor signaling pathways in the nervous system. Curr Opin Neurobiol 11, 287-296.

Burke, G., Cossins, J., Maxwell, S., Owens, G., Vincent, A., Robb, S., Nicolle, M., Hilton-Jones, D., Newsom-Davis, J., Palace, J., Beeson, D., 2003. Rapsyn mutations in hereditary myasthenia: distinct early- and late-onset phenotypes. Neurology 61, 826-828.

Chan, K.H., Lachance, D.H., Harper, C.M., Lennon, V.A., 2007. Frequency of seronegativity in adult-acquired generalized myasthenia gravis. Muscle Nerve 36, 651-658.

Cizeron-Clairac, G., Le Panse, R., Frenkian-Cuvelier, M., Meraouna, A., Truffault, F., Bismuth, J., Mussot, S., Kerlero de Rosbo, N., Berrih-Aknin, S., 2008. Thymus and Myasthenia Gravis: what can we learn from DNA microarrays? J Neuroimmunol 201-202, 57-63.

Cobleigh, M.A., Vogel, C.L., Tripathy, D., Robert, N.J., Scholl, S., Fehrenbacher, L., Wolter, J.M., Paton, V., Shak, S., Lieberman, G., Slamon, D.J., 1999. Multinational study of the efficacy and safety of humanized anti-HER2 
monoclonal antibody in women who have HER2-overexpressing metastatic breast cancer that has progressed after chemotherapy for metastatic disease. J Clin Oncol 17, 2639-2648.

Conti-Fine, B.M., Milani, M., Kaminski, H.J., 2006. Myasthenia gravis: past, present, and future. J Clin Invest 116, $2843-$ 2854.

Drachman, D.B., 1994. Myasthenia gravis. N Engl J Med 330, 1797-1810.

Engel, A.G., Lindstrom, J.M., Lambert, E.H., Lennon, V.A., 1977. Ultrastructural localization of the acetylcholine receptor in myasthenia gravis and in its experimental autoimmune model. Neurology 27, 307-315.

Engel, A.G., Tsujihata, M., Lindstrom, J.M., Lennon, V.A., 1976. The motor end plate in myasthenia gravis and in experimental autoimmune myasthenia gravis. A quantitative ultrastructural study. Ann N Y Acad Sci 274, 60-79.

Evoli, A., Tonali, P.A., Padua, L., Monaco, M.L., Scuderi, F., Batocchi, A.P., Marino, M., Bartoccioni, E., 2003. Clinical correlates with anti-MuSK antibodies in generalized seronegative myasthenia gravis. Brain 126, 2304-2311.

Giraud, M., Taubert, R., Vandiedonck, C., Ke, X., Levi-Strauss, M., Pagani, F., Baralle, F.E., Eymard, B., Tranchant, C., Gajdos, P., Vincent, A., Willcox, N., Beeson, D., Kyewski, B., Garchon, H.J., 2007. An IRF8-binding promoter variant and AIRE control CHRNA1 promiscuous expression in thymus. Nature 448, 934-937.

Gronseth, G.S., Barohn, R.J., 2000. Practice parameter: thymectomy for autoimmune myasthenia gravis (an evidencebased review): report of the Quality Standards Subcommittee of the American Academy of Neurology. Neurology 55, 7-15.

Guyon, T., Wakkach, A., Poea, S., Mouly, V., Klingel-Schmitt, I., Levasseur, P., Beeson, D., Asher, O., Tzartos, S., BerrihAknin, S., 1998. Regulation of acetylcholine receptor gene expression in human myasthenia gravis muscles. Evidences for a compensatory mechanism triggered by receptor loss. J Clin Invest 102, 249-263.

Hoch, W., McConville, J., Helms, S., Newsom-Davis, J., Melms, A., Vincent, A., 2001. Auto-antibodies to the receptor tyrosine kinase MuSK in patients with myasthenia gravis without acetylcholine receptor antibodies. Nat Med 7, 365-368.

Jaretzki, A., 3rd, Barohn, R.J., Ernstoff, R.M., Kaminski, H.J., Keesey, J.C., Penn, A.S., Sanders, D.B., 2000. Myasthenia gravis: recommendations for clinical research standards. Task Force of the Medical Scientific Advisory Board of the Myasthenia Gravis Foundation of America. Ann Thorac Surg 70, 327-334.

Jo, S.A., Zhu, X., Marchionni, M.A., Burden, S.J., 1995. Neuregulins are concentrated at nerve-muscle synapses and activate ACh-receptor gene expression. Nature 373, 158-161.

Kamo, I., Furukawa, S., Tada, A., Mano, Y., Iwasaki, Y., Furuse, T., Ito, N., Hayashi, K., Satoyoshi, E., 1982. Monoclonal antibody to acetylcholine receptor: cell line established from thymus of patient with Myasthenia gravis. Science 215, 995-997.

Kuks, J.B., Oosterhuis, H.J., Limburg, P.C., The, T.H., 1991. Anti-acetylcholine receptor antibodies decrease after thymectomy in patients with myasthenia gravis. Clinical correlations. J Autoimmun 4, 197-211.

Kummer, T.T., Misgeld, T., Sanes, J.R., 2006. Assembly of the postsynaptic membrane at the neuromuscular junction: paradigm lost. Curr Opin Neurobiol 16, 74-82.

Lauriola, L., Ranelletti, F., Maggiano, N., Guerriero, M., Punzi, C., Marsili, F., Bartoccioni, E., Evoli, A., 2005. Thymus changes in anti-MuSK-positive and -negative myasthenia gravis. Neurology 64, 536-538.

Le Panse, R., Cizeron-Clairac, G., Bismuth, J., Berrih-Aknin, S., 2006. Microarrays reveal distinct gene signatures in the thymus of seropositive and seronegative myasthenia gravis patients and the role of CC chemokine ligand 21 in thymic hyperplasia. J Immunol 177, 7868-7879.

Leite, M.I., Jacob, S., Viegas, S., Cossins, J., Clover, L., Morgan, B.P., Beeson, D., Willcox, N., Vincent, A., 2008. IgG1 antibodies to acetylcholine receptors in 'seronegative' myasthenia gravis. Brain 131, 1940-1952.

Leite, M.I., Jones, M., Strobel, P., Marx, A., Gold, R., Niks, E., Verschuuren, J.J., Berrih-Aknin, S., Scaravilli, F., Canelhas, A., Morgan, B.P., Vincent, A., Willcox, N., 2007. Myasthenia gravis thymus: complement vulnerability of epithelial and myoid cells, complement attack on them, and correlations with autoantibody status. Am J Pathol 171, 893905.

Leite, M.I., Strobel, P., Jones, M., Micklem, K., Moritz, R., Gold, R., Niks, E.H., Berrih-Aknin, S., Scaravilli, F., Canelhas, A., Marx, A., Newsom-Davis, J., Willcox, N., Vincent, A., 2005. Fewer thymic changes in MuSK antibody-positive than in MuSK antibody-negative MG. Ann Neurol 57, 444-448.

Lemke, G., 1996. Neuregulins in development. Mol Cell Neurosci 7, 247-262. 
Levinson, A.I., Wheatley, L.M., 1996. The thymus and the pathogenesis of myasthenia gravis. Clin Immunol Immunopathol 78, 1-5.

Lindstrom, J.M., Seybold, M.E., Lennon, V.A., Whittingham, S., Duane, D.D., 1976. Antibody to acetylcholine receptor in myasthenia gravis. Prevalence, clinical correlates, and diagnostic value. Neurology 26, 1054-1059.

Liston, A., Lesage, S., Gray, D.H., Boyd, R.L., Goodnow, C.C., 2005. Genetic lesions in T-cell tolerance and thresholds for autoimmunity. Immunol Rev 204, 87-101.

Melms, A., Schalke, B.C., Kirchner, T., Muller-Hermelink, H.K., Albert, E., Wekerle, H., 1988. Thymus in myasthenia gravis. Isolation of T-lymphocyte lines specific for the nicotinic acetylcholine receptor from thymuses of myasthenic patients. J Clin Invest 81, 902-908.

Mencarelli, C., Hammels, C., Van Den Broeck, J., Losen, M., Steinbusch, H., Revert, F., Saus, J., Hopkins, D.A., De Baets, M.H., Steinbusch, H.W., Martinez-Martinez, P., 2009. The expression of the Goodpasture antigen-binding protein (ceramide transporter) in adult rat brain. J Chem Neuroanat.

Muppidi, S., Wolfe, G.I., 2009. Muscle-specific receptor tyrosine kinase antibody-positive and seronegative myasthenia gravis. Front Neurol Neurosci 26, 109-119.

Niks, E.H., Kuks, J.B., Verschuuren, J.J., 2007. Epidemiology of myasthenia gravis with anti-muscle specific kinase antibodies in The Netherlands. J Neurol Neurosurg Psychiatry 78, 417-418.

Pugliese, A., Zeller, M., Fernandez, A., Jr., Zalcberg, L.J., Bartlett, R.J., Ricordi, C., Pietropaolo, M., Eisenbarth, G.S., Bennett, S.T., Patel, D.D., 1997. The insulin gene is transcribed in the human thymus and transcription levels correlated with allelic variation at the INS VNTR-IDDM2 susceptibility locus for type 1 diabetes. Nat Genet 15, 293-297.

Rimer, M., 2003. Neuregulins: primary or secondary signals for the control of synapse-specific gene expression. J Neurocytol 32, 665-675.

Ross, J.S., Slodkowska, E.A., Symmans, W.F., Pusztai, L., Ravdin, P.M., Hortobagyi, G.N., 2009. The HER-2 receptor and breast cancer: ten years of targeted anti-HER-2 therapy and personalized medicine. Oncologist 14, 320-368.

Salmon, A.M., Bruand, C., Cardona, A., Changeux, J.P., Berrih-Aknin, S., 1998. An acetylcholine receptor alpha subunit promoter confers intrathymic expression in transgenic mice. Implications for tolerance of a transgenic selfantigen and for autoreactivity in myasthenia gravis. J Clin Invest 101, 2340-2350.

Sandrock, A.W., Jr., Dryer, S.E., Rosen, K.M., Gozani, S.N., Kramer, R., Theill, L.E., Fischbach, G.D., 1997. Maintenance of acetylcholine receptor number by neuregulins at the neuromuscular junction in vivo. Science 276, 599-603.

Sanes, J.R., Lichtman, J.W., 1999. Development of the vertebrate neuromuscular junction. Annu Rev Neurosci 22, 389442.

Sims, G.P., Shiono, H., Willcox, N., Stott, D.I., 2001. Somatic hypermutation and selection of B cells in thymic germinal centers responding to acetylcholine receptor in myasthenia gravis. J Immunol 167, 1935-1944.

Toyka, K.V., Brachman, D.B., Pestronk, A., Kao, I., 1975. Myasthenia gravis: passive transfer from man to mouse. Science 190, 397-399.

Trinidad, J.C., Fischbach, G.D., Cohen, J.B., 2000. The Agrin/MuSK signaling pathway is spatially segregated from the neuregulin/ErbB receptor signaling pathway at the neuromuscular junction. J Neurosci 20, 8762-8770.

Vincent, A., 2002. Unravelling the pathogenesis of myasthenia gravis. Nat Rev Immunol 2, 797-804.

Vincent, A., Scadding, G.K., Thomas, H.C., Newsom-Davis, J., 1978. In-vitro synthesis of anti-acetylcholine-receptor antibody by thymic lymphocytes in myasthenia gravis. Lancet 1, 305-307.

Wakkach, A., Guyon, T., Bruand, C., Tzartos, S., Cohen-Kaminsky, S., Berrih-Aknin, S., 1996. Expression of acetylcholine receptor genes in human thymic epithelial cells: implications for myasthenia gravis. J Immunol 157, 3752-3760.

Wekerle, H., Ketelsen, U.P., Zurn, A.D., Fulpius, B.W., 1978. Intrathymic pathogenesis of myasthenia gravis: transient expression of acetylcholine receptors on thymus-derived myogenic cells. Eur J Immunol 8, 579-582.

Zhou, L., McConville, J., Chaudhry, V., Adams, R.N., Skolasky, R.L., Vincent, A., Drachman, D.B., 2004. Clinical comparison of muscle-specific tyrosine kinase (MuSK) antibody-positive and -negative myasthenic patients. Muscle Nerve 30, 55-60.

Zhu, X., Lai, C., Thomas, S., Burden, S.J., 1995. Neuregulin receptors, erbB3 and erbB4, are localized at neuromuscular synapses. EMBO J 14, 5842-5848. 


\section{Chapter 7}

Proteasome inhibition with bortezomib depletes plasma cells and autoantibodies in experimental autoimmune myasthenia gravis

Gomez AM, Vrolix K, Martínez-Martínez P, Molenaar PC, Phernambucq M, van der Esch E, Duimel H, Verheyen F, Voll RE, Manz RA, De Baets MH and Losen M

Published in: Journal of Immunology 2011, 186 (4): 2503-13. 


\section{Abstract}

Bortezomib, an inhibitor of proteasomes, has been reported to reduce autoantibody titers and to improve clinical condition in mice suffering from lupus-like disease. Bortezomib depletes both short and long-lived plasma cells; the latter normally survive the standard immunosuppressant treatments targeting $T$ and $B$ cells. These findings encouraged us to test whether bortezomib is effective for alleviating the symptoms in the EAMG (experimental autoimmune myasthenia gravis) model for myasthenia gravis, a disease that is characterized by autoantibodies against the acetylcholine receptor (AChR) of skeletal muscle.

Lewis rats were immunized with saline (Control, $n=36$ ) or Torpedo AChR (EAMG, $\mathrm{n}=54$ ) in complete Freund's adjuvant in the first week of an experimental period of eight weeks. After immunization, rats received twice a week subcutaneous injections of bortezomib ( $0.2 \mathrm{mg} / \mathrm{kg}$ in saline) or saline injections.

Bortezomib induced apoptosis in bone marrow cells and reduced the amount of plasma cells in the bone marrow by up to $81 \%$. In the EAMG animals, bortezomib efficiently reduced the rise of anti-AChR autoantibody titers, prevented ultrastructural damage of the postsynaptic membrane, improved neuromuscular transmission and decreased myasthenic symptoms. This study thus underscores the potential of the therapeutic use of proteasome inhibitors to target plasma cells in antibody-mediated autoimmune diseases. 


\section{Introduction}

The resistance of long-lived plasma cells against immunosuppressive medication poses a serious problem for the treatment of antibody-mediated autoimmune diseases. Currently used immunosuppressive drugs, including corticosteroids, mitomycin C, cyclosporine $A$, azathioprine and cyclosphosphamide, affect mainly activated and dividing $B$ and/or $T$ cells (Sanders and Evoli, 2010). Plasma cells are the terminally differentiated, non-dividing effector cells of the B-cell lineage that have lost many surface markers. In their survival niches in the spleen and in particular in the bone marrow (Shapiro-Shelef and Calame, 2005), resident long-lived plasma cells are resistant to most therapies including immunosuppressive drugs and anti-CD20 antibodies that are aimed to inhibit the activation and/or proliferation of lymphocytes or to deplete certain lymphocyte subpopulations (DiLillo et al., 2008; Miller and Cole, 1967). Thus, resistance to available therapies might be due to persistent long-lived plasma cells that continue to produce autoantibodies notwithstanding immunosuppressive treatment (Arce et al., 2002).

However, because of their high rate of immunoglobulin production, both short and long-lived plasma cells are particularly sensitive to inhibition of the proteasome (Meister et al., 2007; Neubert et al., 2008). Indeed, proteasome inhibition causes accumulation of nondegraded, misfolded proteins within the ER of plasma cells and, subsequently, to activation of the 'terminal unfolded protein response' (UPR), ultimately leading to apoptosis (Obeng et al., 2006). The proteasome inhibitor bortezomib, also known under the trade name Velcade, is a boronic acid dipeptide (phenylalanine-leucine)-derivative which binds reversibly to the $26 \mathrm{~S}$ proteasome (Groll et al., 2006). After injection, bortezomib is distributed widely and quickly to the blood and most tissues (Hemeryck et al., 2007). Currently, bortezomib is approved for the treatment of multiple myeloma and mantle cell lymphoma. In addition to the treatment of B cell malignancies, proteasome inhibition could be a useful therapeutic strategy for antibody mediated autoimmunity such as lupus (Neubert et al., 2008).

In the present study we tested the effect of proteasome inhibition in a model for myasthenia gravis (MG), a well-characterized disease that is found to be critically dependent on the level of autoantibodies against the AChRs of muscle. In $85 \%$ of MG patients the disease is caused by autoantibodies against the muscle acetylcholine receptor (AChR) (Vrolix et al., 2010a). The remaining patients have autoantibodies against the muscle specific kinase (MUSK) (Hoch et al., 2001) (approximately 5\% of all MG patients) or no detectable autoantibodies (idiopathic MG, accounting for approximately $10 \%$ of all patients (Vrolix et al., 2010b). Both AChR and MuSK proteins are located in the 
postsynaptic membrane of the neuromuscular junction (NMJ) which is specialized to respond to the neurotransmitter acetylcholine (ACh) released from the overlying nerve ending. These proteins are thus essential for muscle contraction and MG is potentially fatal, since autoantibodies can cause respiratory failure by impairing neuromuscular transmission. In such an event of acute myasthenic crisis, the first choice of treatment is plasma exchange, mechanical ventilation (Gajdos et al., 2002) and intravenous treatment with high doses of IgG (IVIg) (Gajdos et al., 2008). Plasma exchange typically leads to significant improvement or remission within a few days in most patients, including those with the idiopathic MG, but the effect is, of course, not long lasting. Immunosuppressive drugs such as prednisone and azathioprine are generally used for long term therapy (Palace et al., 1998; Sanders and Evoli, 2010; Skeie et al., Trivedi and Wolfe, 2010). Since these depend mostly on preventing the activation, proliferation and differentiation of developing B and T cells, the autoantibody titers only drop over a period of months. Using an established immunotherapy protocol with prednisone and azathioprine, it may take as much as 18 months before patients improve (Palace et al., 1998). For the intermediate time interval, during which plasma cells continue to produce autoantibodies, proteasome inhibition might be a useful therapy. Moreover, since some MG patients do not respond well to any currently available treatment in terms of poor reduction of autoantibodies or the occurrence of side effects, proteasome inhibition might provide a therapeutic alternative.

In the experimental autoimmune myasthenia gravis model (EAMG) the disease is induced by immunizing rats with the $A C h R$ from the electric organ of the electric ray Torpedo californica (De Baets et al., 2003; Lindstrom, 1980). A small proportion of antibodies against the Torpedo AChR (tAChR) cross-reacts with the AChR of the muscle (Martinez-Martinez et al., 2007). Like in human MG with anti-AChR autoantibodies (AChR$M G)$, the disease symptoms in EAMG are caused by antibody-mediated destruction of the neuromuscular junction (Gomez et al., 2010; Losen et al., 2008).

Here we studied the effect of bortezomib in EAMG rats using two different treatment regimes: The first treatment consisted of bortezomib injections for 8 weeks, starting directly after immunization (herein referred to $8 \mathrm{w}-\mathrm{Bz}$ ). For the second treatment regime rats were injected with bortezomib starting only 4 weeks after immunization, when autoantibody titers were already detectable, until 8 weeks after immunization ( 4 w$\mathrm{Bz})$. Using this setup we investigated the potential therapeutic effect of bortezomib after onset of the disease. The results show that both treatment regimes reduce (auto-) antibody levels by depleting bone marrow plasma cells, but only the 8-week bortezomib- 
treatment led to a significant improvement of the clinical condition of the EAMG rats and to a reduction of postsynaptic damage.

\section{Methods}

\section{Animals}

Inbred female Lewis rats $(n=90)$ were obtained from the Department of Experimental Animal Services, Maastricht University (The Netherlands). Permission to perform this experiment was granted by the Committee on Animal Welfare, according to Dutch governmental rules. At 6 week of age, animals were weighed and divided in 6 experimental groups (Table 1) with an equal average weight.

\section{Induction of EAMG}

EAMG was induced in 7-week-old rats $(n=54)$ by active immunization with AChR purified from the electric organ of Torpedo californica (tAChR) in complete Freund's adjuvant (CFA). In brief, $20 \mu \mathrm{g}$ of tAChR (Lindstrom, 1980) were dissolved in $100 \mu \mathrm{L}$ of phosphatebuffered saline (PBS) and emulsified with an equal volume of CFA with $0.1 \%$ of Mycobacterium tuberculosis H37 (Difco Laboratories, Detroit, USA). Animals were initially anesthetized in a cylindrical tube through which $5 \%$ isofluorane in air was supplied. Subsequently, $3 \%$ isoflurane was supplied by a cap over the head and $200 \mu \mathrm{L} \mathrm{CFA/tAChR}$ emulsion were injected subcutaneously at the base of the tail at three different spots, as described by Lennon and colleagues (Lennon et al., 1975). Control animals $(n=36)$ were injected with an equal volume of emulsified PBS and CFA. Rats were sacrificed 8 weeks after immunization or earlier, if they had reached the humane endpoints as described below under 'clinical scoring'. They were sacrificed by inhalation of $\mathrm{CO}_{2}$ in air and subsequent cervical dislocation.

\section{Experimental design and administration of drugs}

Bortezomib was purchased as a lyophilized powder (Velcade, Janssen-Cilag B.V., Beerse, Belgium) and dissolved in sterile saline solution at a final concentration of $0.1 \mathrm{mg} / \mathrm{mL}$. Two weekly doses of $0.2 \mathrm{mg} / \mathrm{kg}$ bortezomib solution were administered subcutaneously, which is considered the highest to use without having increased mortality rates or severe side effects in rats (Cavaletti et al., 2007; Hemeryck et al., 2007; Sinn et al., 2007). Control and EAMG groups were subdivided in 3 treatment regimes each (Table 1). 'Saline' groups received two weekly subcutaneous injections of $0.9 \% \mathrm{NaCl}$ solution $(2 \mathrm{~mL} / \mathrm{kg})$ at the neck 
for 8 weeks. ' $4 w-B z$ ' groups received two weekly saline injections for the first 4 weeks after immunization (by which time autoantibody levels were highly elevated in the plasma) and subsequently two weekly injections of bortezomib for another 4 weeks. ' 8 w$B z^{\prime}$ groups received two weekly injections of bortezomib for 8 weeks, starting directly after immunization.

For practical reasons the experiment was conducted three times in sets of 30 animals each, including an equal number of all the aforementioned groups. The animals' tissues were analyzed using electron microscopy (EM), electromyography (EMG), immunofluorescence (IF) and fluorescence activated cell sorting (FACS) and the number of animals used for each method is indicated in Table 1.

Table I. Treatment groups

\begin{tabular}{|c|c|c|c|}
\hline & $\begin{array}{l}\text { 'Saline' groups } \\
\text { (no bortezomib) }\end{array}$ & $\begin{array}{l}\text { ' } 4 \mathrm{w}-\mathrm{Bz} \text { ' groups } \\
\text { (bortezomib started } 4 \\
\text { weeks after immunization) }\end{array}$ & $\begin{array}{l}\text { '8w-Bz' groups } \\
\text { (bortezomib started } \\
\text { directly after } \\
\text { immunization) }\end{array}$ \\
\hline $\begin{array}{l}\text { Control (immunized } \\
\text { with CFA) }\end{array}$ & $\begin{array}{l}n=12 \\
\text { (IF and FACS: } n=5 ; E M \text { and } \\
\text { EMG } n=7 \text { ) }\end{array}$ & $\begin{array}{l}n=12 \\
\text { (IF and FACS: } n=5 ; E M \text { and } \\
\text { EMG } n=7 \text { ) }\end{array}$ & $\begin{array}{l}\mathrm{n}=12 \\
\text { (IF and FACS: } \mathrm{n}=5 ; \mathrm{EM} \\
\text { and EMG } \mathrm{n}=7 \text { ) }\end{array}$ \\
\hline $\begin{array}{l}\text { EAMG (immunized } \\
\text { with AChR in CFA) }\end{array}$ & $\begin{array}{l}n=18 \\
\text { (IF and FACS: } n=8 ; E M \text { and } \\
\text { EMG } n=10 \text { ) }\end{array}$ & $\begin{array}{l}n=18 \\
\text { (IF and FACS: } n=8 ; E M \text { and } \\
\text { EMG } n=10 \text { ) }\end{array}$ & $\begin{array}{l}\mathrm{n}=18 \\
\text { (IF and FACS: } \mathrm{n}=8 ; \mathrm{EM} \\
\text { and EMG } \mathrm{n}=10 \text { ) }\end{array}$ \\
\hline
\end{tabular}

CFA: Complete Freuds' adjuvant; IF: immunofluorescence; FACS: fluorescence activated cell sorting;

EM: electron microscopy

\section{Weight and clinical scoring}

The animals' weight was measured on a weekly basis as a general indicator of health and for dose calculations. The severity of clinical signs of EAMG was scored weekly by measuring muscular weakness by two blinded investigators (A.M.G. and M.P.). The animals' muscle strength and fatigability was assessed by their ability to grasp and lift repeatedly a $300 \mathrm{~g}$ metal rack from the table, while suspended manually by the base of the tail for 30 s (Hoedemaekers et al., 1997a; Hoedemaekers et al., 1997b; Verschuuren et al., 1990). Clinical scoring was based on the presence of tremor, hunched posture, muscle strength and fatigability.

Disease severity was expressed as follows: 0 , no obvious abnormalities; $+[1]$, no abnormalities before testing, but reduced strength at the end; ++ [2], clinical signs 
present before testing, i.e. tremor, head down, hunched posture, weak grip, difficulty in breathing; +++ [3], severe clinical signs present before testing, no grip, moribund (Lennon et al., 1975). Animals that reached a clinical score of level 3, or lost more than $20 \%$ of their weight in the course of one week, were sacrificed within $24 \mathrm{~h}$.

\section{Tissue preparation}

For EM analysis, bone marrow was extracted from the femur bones by cutting off their upper and lower endings and flushing the shaft with $10 \mathrm{~mL}$ of sterile saline solution through the bone marrow cavity using a syringe with 25 gauge needle. For FACS analysis of bone marrow, PBS containing $2 \%$ fetal calf serum and $0.1 \% \mathrm{NaN}_{3}$ (FACS buffer) was used instead. Thymus and spleen tissue were entirely removed from the animals by dissection and the organ weight was measured. Single cell suspensions were prepared using the gentleMACS Tissue Dissociator (Miltenyi Biotec, Germany) according to the manufacturer's instructions. Cells of different tissues were resuspended in FACS buffer and run through a $70 \mu \mathrm{m}$ nylon cell strainer to remove large cell clumps. Numbers of viable cells were determined by counting trypan blue negative cells on hemocytometers. Cells were divided in microcentrifuge tubes $\left(10^{5}\right.$ cells $/ 100 \mu \mathrm{L} /$ tube $)$ and then stained for dead cells, T and B cells.

Heparinized blood samples were taken from the vena saphena weekly, starting on the week before immunization (week 0) until the last week of experiment (week 8). Peripheral blood mononuclear cells (PBMC's) were isolated by lysing red blood cells using FACS lysing buffer (Beckton Dickinson, BD). PBMC's from $80 \mu \mathrm{L}$ blood were divided in microcentrifuge tubes in a ratio of $20 / 20 / 40 \mu \mathrm{L}$ to stain for dead cells, T cells and B cells respectively.

\section{Proteasome activity assay}

The proteolytic activity of the proteasome was evaluated in whole blood (Lightcap et al., 2000 ) by means of a 20 S proteasome activity kit (Millipore, APT 280), as described by the manufacturer. Taking into account the pharmacokinetic and pharmacodynamic profiles of subcutaneous bortezomib administration (Moreau et al., 2008), blood samples were obtained between 3 and 6 hours after administration of bortezomib or saline. In brief, 80 $\mu \mathrm{g}$ of whole blood protein extract were incubated in the provided buffer with $3.8 \mu \mathrm{g}$ of a fluorophore-linked peptide substrate (LLVY-AMC) for $120 \mathrm{~min}$ at 37 으. Proteasome activity was measured by quantification of relative fluorescent units (RFU) from the release of the fluorescent cleaved product AMC (7-amino-4-methylcoumarin) using a $380 / 460 \mathrm{~nm}$ filter set in a fluorometer (Victor X3 Multilabel Reader, Perkin-Elmer). A 
solution of the $20 \mathrm{~S}$ proteasome subunit and the proteasome inhibitor lactacystin were used as controls for the assay.

\section{Autoantibody titers}

Antibody titers against rat AChR were measured in plasma samples with an immunoprecipitation radioimmunoassay. In brief, $2.5 \mu \mathrm{L}$ of plasma were incubated at 4 으 overnight with $100 \mu \mathrm{L}$ of rat muscle cell-membrane extract (containing approximately 5 $\mathrm{nmol} / \mathrm{L} \mathrm{AChR}$; isolated from denervated rat muscles). The AChR was labeled with an excess of ${ }^{125} \mathrm{I}$ - $\alpha$-bungarotoxin ( ${ }^{125} \mathrm{I}-\alpha$-BT, NEX126, $5 \mathrm{TBq} / \mathrm{mmol}$, PerkinElmer). The immunecomplexes were precipitated by addition of $150 \mu \mathrm{L}$ of goat anti-rat IgG serum and incubation for 4 hours at $4 \stackrel{\circ}{ }$ C. Pellets were washed three times in PBS with $0.5 \%$ Triton X100 and centrifuged at $25000 \mathrm{~g}$ for 5 minutes. Radioactivity was measured on an automatic $\gamma$-counter (2470 WIZARD2, PerkinElmer). Auto-antibody titers were expressed as nmoles of $\alpha$-bungarotoxin binding sites/L.

\section{Total IgG ELISA}

A sandwich ELISA was used to measure total IgG content in plasma samples. Briefly, ELISA plates (Microlon 655092, Greiner, Germany) were coated with $50 \mu \mathrm{L}$ of catching antibody (goat Ig anti-rat IgG, ab6252, Abcam, UK), diluted 1:200 in coating buffer (50 mM sodium carbonate, $\mathrm{pH}$ 9.6), for one hour at $37{ }^{\circ} \mathrm{C}$. Plates were washed with PBS containing $0.05 \%$ Tween-20 and blocked for 30 minutes with $100 \mu \mathrm{L}$ of $4 \%$ non-fat dry milk in PBS (BlottingGrade Blocker, cat 1706404, Bio-Rad). Afterwards, $50 \mu \mathrm{L}$ of plasma samples, diluted $1: 20000$ in incubation buffer (PBS $+1 \%$ BSA $+0.02 \%$ Tween-20), were incubated for 1 hour at $37^{\circ} \mathrm{C}$. A standard curve was made using serially diluted samples of purified rat IgG (Cat. 18015, Sigma-Aldrich). After washing, $50 \mu \mathrm{L}$ of HRP-conjugated antibody (ab6257, Abcam, UK), diluted 1:5000 in incubation buffer, were added and plates were incubated for another hour at $37^{\circ} \mathrm{C}$. Following a washing step, $100 \mu \mathrm{L}$ of TMB substrate solution (s(HS)TMB, SDT Reagents, Germany) were used to develop HRP-labeled antibodies bound to the plates. The color reaction was allowed to develop for 10 minutes and stopped with $50 \mu \mathrm{L}$ of $2 \mathrm{M}$ sulphuric acid. The optical density was measured at $450 \mathrm{~nm}$ filter using a microplate reader (Victor X3 Multilabel Reader, Perkin Elmer). Results were expressed as $\mathrm{mg}$ of total IgG per $\mathrm{mL}$ of plasma. 


\section{Apoptosis assays}

Early-apoptotic and dead cells were identified by flow cytometric analysis according to surface binding of FITC-labeled Annexin $V$ to exposed membrane phosphatidylserine and propidium iodide (PI) staining (Annexin V-FITC Apoptosis Detection Kit; BD Biosciences Pharmigen, Breda, The Netherlands). The cells $\left(10^{5} / 100 \mu \mathrm{L}\right)$ were washed with Annexin Vbinding buffer and incubated with $5 \mu \mathrm{L}$ of Annexin $V$ and $5 \mu \mathrm{L}$ of PI for 15 minutes at room temperature. Without washing, cells were immediately measured. Annexin $\mathrm{V}^{+} / \mathrm{PI}^{-}$cells were regarded as early-apoptotic, while Annexin $\mathrm{V}^{+} / \mathrm{PI}^{+}$cells were considered dead cells.

\section{Extracellular staining for T cell markers}

The cells were washed once with FACS buffer by centrifugation at $250 \mathrm{~g}$ at 4 으 $\mathrm{C}$ and incubated for 30 minutes at $4 \stackrel{\circ}{\circ}$ with antibodies directed against CD3 (FITC-labeled), CD4 (PE-labeled) and CD8 (PerCP-labeled) (all from BD), diluted 1:50 in FACS buffer. The samples were washed twice and kept at $4^{\circ} \mathrm{C}$ in the dark until measurement within 2 hours.

\section{Intracellular staining for B cell markers}

Cells were washed once with FACS buffer by centrifugation at $250 \mathrm{~g}$ at 4 으 $\mathrm{C}$ and incubated with PE-conjugated antibody against CD45RA (BD), diluted 1:20 in FACS buffer. After one washing step, cells were fixed with $2 \%$ paraformaldehyde in FACS buffer for 10 minutes at 37 으. After two more washing steps, cells were permeabilized with cold $90 \%$ methanol for 30 minutes on ice. Cells were washed twice and incubated with FITC-conjugated antibody directed against intracellular immunoglobulin kappa (IgK) (BD), diluted 1:20 in FACS buffer. The samples were washed twice and kept at 4 으 $\mathrm{C}$ in the dark until measurement within 2 hours. Since no appropriate CD markers were available to specifically detect rat plasma cells, we approached to measure rat plasma cells by using high levels of intracellular Igk expression.

\section{FACS analysis}

All cytofluorometric analyses were performed on a FACSCalibur (BD) and analyzed using the Cellquest Software (BD). Forward and sideward light angle scatters were collected. Using these plots, samples were gated to exclude cell debris and cellular aggregates for further analysis. For each marker, the percentage of positive cells stained above background was measured for all gated cells. The cut-off was defined using unstained cells processed alongside the experimental samples. 


\section{Plasma cell quantification by electron microscopy}

Bone marrow cell suspensions were fixed by mixing with an equal volume of $5 \%$ glutaraldehyde in PBS and then centrifuged at $800 \mathrm{~g}$. Pellets were resuspended in PBS and embedded in $10 \%$ gelatin, then centrifuged again at $1000 \mathrm{~g}$ to form a compact pellet. Cell pellets were postfixed with $1 \%$ osmium tetroxide in $0.1 \mathrm{M}$ phosphate buffer, $\mathrm{pH} 7.4$, dehydrated through a graded ethanol series and embedded in epon 812 (Electron Microscopy Sciences, Fort Washington, Pa, USA). Ultra-thin sections from whole pellets were contrasted with uranyl acetate and lead citrate and viewed with a Philips CM 100 electron microscope. Plasma cell recognition was based on morphological features that are particular to this cell type, like the typical 'cart-wheel' chromatin configuration in the nucleus and the presence of extensive rough endoplasmic reticulum in the cytoplasm, indicative of an intense protein production. Quantification was performed at 6 different portions of the sample, to have a systematic representation of the cell gradient in the sample that resulted from the centrifugation. Results are expressed as percentage of plasma cells; a total of 800 bone marrow cells were counted per sample.

\section{Electromyography}

Animals were initially anesthetized as described above and subsequently intubated in the trachea. Anesthesia was maintained with $3 \%$ isofluorane in air. Compound muscle action potential (CMAP) decrement was measured in the tibialis anterior muscle using the EMG system Viking IV (Nicolet Biomedicals Inc., Madison, USA), at the end of the experimental period. For stimulation, two small monopolar needle electrodes were used. The cathode was inserted near the peroneal nerve at the level of the knee and the anode more proximal and lateral at a distance of 3-4 $\mathrm{mm}$. For recording, a third monopolar needle electrode was inserted subcutaneously over the tibialis anterior muscle. The reference electrode was inserted subcutaneously near the ankle. A ring electrode around the tail served as ground electrode. To detect a decremental response of the CMAP, series of 8 supramaximal stimuli were given at $3 \mathrm{~Hz}$ with $0.2 \mathrm{~ms}$ duration. The test was considered positive for decrement when both the amplitude and the area of the CMAP negative peak showed a decrease of at least $10 \%$ (Losen et al., 2005). To demonstrate reproducibility, at least 3 consecutive decrement recordings were made of all investigated muscles. During the measurements, skin temperature was kept between $35^{\circ} \mathrm{C}$ and $37^{\circ} \mathrm{C}$ by means of an infrared heating lamp. If initially no decrement was present in the tibialis anterior muscle, neuromuscular transmission was challenged by a continuous intravenous infusion of curare ((+)-tubocurarine, T2379, Sigma-Aldrich). A solution of $20 \mu \mathrm{g} / \mathrm{mL}$ of curare was injected into the vena saphena using the Terfusion syringe pump (model STC-521, 
Terumo, Japan) at a rate of $1 \mathrm{~mL} / \mathrm{h}(0.33 \mu \mathrm{g}$ curare/min). During curare infusion, CMAP measurements were repeated with intervals of one minute until a repeated decrement was observed. The resistance against curare was used as an indirect, albeit non-linear, measure for the safety factor of neuromuscular transmission and thus for the performance of neuromuscular transmission (Janssen et al., 2008; Martinez-Martinez et al., 2009).

\section{Electron microscopy of muscle tissue}

Electron micrographs were taken from endplates of the tibialis anterior muscles. Anesthetized rats were transcardially perfused as previously described (Losen et al., 2005; Martinez-Martinez et al., 2007). Ultra-thin sections were viewed with Philips CM 100 electron microscope. At least five endplate regions were photographed from each muscle. Quantitative morphometry of the folding index (length of postsynaptic membrane / length of presynaptic membrane) was performed as previously described (Engel and Santa, 1971; Martinez-Martinez et al., 2009). For the analysis, the following number of animals was used per group: Control saline $(n=3)$; EAMG saline $(n=4)$; EAMG $4 w-B z(n=4)$; EAMG $8 w-B z(n=4)$. Between 5 and 25 endplate regions were analyzed per animal.

\section{Statistics}

GraphPad Prism 4 was used to perform statistical analyses. Comparison between normally distributed values was performed using 1- or 2-way ANOVA, wherever appropriate. Bonferroni post-hoc tests were used to compare groups to each other. $A$ two-sided probability value of 0.05 or lower was considered significant. Values are expressed as means \pm standard error of the mean (SEM) unless stated otherwise. Clinical scores were analyzed by the Chi square test for trend and survival was analyzed using the logrank test. 


\section{Results}

\section{Bortezomib reduces plasma cells in bone marrow}

To investigate if proteasome inhibition affects plasma cells in vivo, rats were injected with bortezomib or saline. Subcutaneous injections of bortezomib significantly reduced the proteasome activity in rat whole blood (Figure 1). The effect of bortezomib on plasma cells from the bone marrow was analyzed by electron microscopy and by FACS. In the bone marrow of bortezomib-treated rats, plasma cells with altered morphology were frequently observed (Figure 2), which was characterized by a vesicular appearance of the rough endoplasmic reticulum cisternae or pronounced dilatation of the rough endoplasmic reticulum. The percentage of plasma cells in bone marrow was markedly reduced in bortezomib-treated groups (Figure $3 \mathrm{~A}$ ). Animals that received bortezomib only between 4 and 8 weeks after immunization showed a significant decrease in their percentage of bone marrow plasma cells (57\% reduction in the $4 \mathrm{w}-\mathrm{Bz}$ Control group $[p<0.05]$ and $82 \%$ reduction in the $4 w-B z$ EAMG group $[p<0.01]$ compared to the corresponding saline-treated groups). Rats in the $8 \mathrm{w}-\mathrm{Bz}$ EAMG group also showed a strong and significant depletion of bone marrow plasma cells $(p<0.05 ; 70 \%$ reduction compared to the saline-treated EAMG group). Very similar results were obtained by FACS analysis using intracellular staining of the Igk light chain in bone marrow cells (Figure 3B).

\section{Bortezomib affects the lymphoid organs}

We investigated the overall effect of bortezomib treatment on the immune system by measuring the weight of thymus and spleen tissue and analyzing the proportions of $B$ cells and T cell subsets in the thymus, spleen, blood and bone marrow by FACS (Table 2).

Bortezomib treatment significantly reduced the mean thymus weight, both in the $4 w-B z(46 \%$ reduction; $p<0.01$ ) and $8 w-B z$ groups ( $50 \%$ reduction; $p<0.01$ ), compared with the saline group (data not shown). In contrast, the mean spleen weight significantly increased by bortezomib treatment in both $4 \mathrm{w}-\mathrm{Bz}(36 \%$ increase; $\mathrm{p}<0.05)$ and $8 \mathrm{w}-\mathrm{Bz}$ groups ( $32 \%$ increase; $p<0.05$ ) compared to the corresponding saline-treated groups (data not shown). No significant difference was observed between Control and EAMG animals.

To assess the effects of bortezomib treatment on the leukocyte viability we measured the proportion of early-apoptotic (annexin $\mathrm{V}^{+} / \mathrm{PI}^{-}$) and dead cells (annexin $\mathrm{V}^{+} / \mathrm{PI}^{+}$). In the spleen, thymus and bone marrow, a trend towards a higher proportion of earlyapoptotic and dead cells after bortezomib administration could be observed, but the differences did not reach statistical significance. However, the lymphocyte subpopulation 
in the bone marrow contained a significantly increased number of apoptotic or dead cells after bortezomib-treatment (data not shown). In the peripheral blood, unexpectedly, bortezomib treatment significantly decreased the proportion of dead cells in PBMCs in the $4 \mathrm{w}-\mathrm{Bz}$ group and $8 \mathrm{w}-\mathrm{Bz}$ groups compared to the saline groups. The proportion of early apoptotic cells in PBMC's was significantly lower in the $4 w$-Bz groups $(p<0.001)$ but not in the $8 w-B z$ groups.

In the spleen, the bone marrow and the blood, the proportion of $\mathrm{CD}_{4} 5 \mathrm{RA}^{+} / \mathrm{IgK}^{+} \mathrm{B}$ cells was significantly decreased after bortezomib treatment (Table 2 ), both in the $4 \mathrm{w}$-Bz and the $8 w-B z$ groups.

After treatment with bortezomib, the proportion of immature $\mathrm{CD} 4^{+} / \mathrm{CD}^{+}$positive cells in the thymus was decreased while the proportion of $\mathrm{CD}^{+} / \mathrm{CD}^{+} / \mathrm{CD} 8^{-}$T-helper cells and cytotoxic $\mathrm{CD}^{+} / \mathrm{CD}^{+} / \mathrm{CD} 4^{-} \mathrm{T}$ cells were increased. In the blood and the spleen, $\mathrm{CD}^{+} / \mathrm{CD}^{+} / \mathrm{CD}^{-}$were significantly increased; the proportion of $\mathrm{CD}^{+} / \mathrm{CD}^{+} / \mathrm{CD}^{-}$was significantly decreased in the spleen and bone marrow of bortezomib treated rats. In general, the two bortezomib treatment regimes led to similar changes of the rat immune system, with the exception of the proportion of apoptotic cells, as aforementioned.
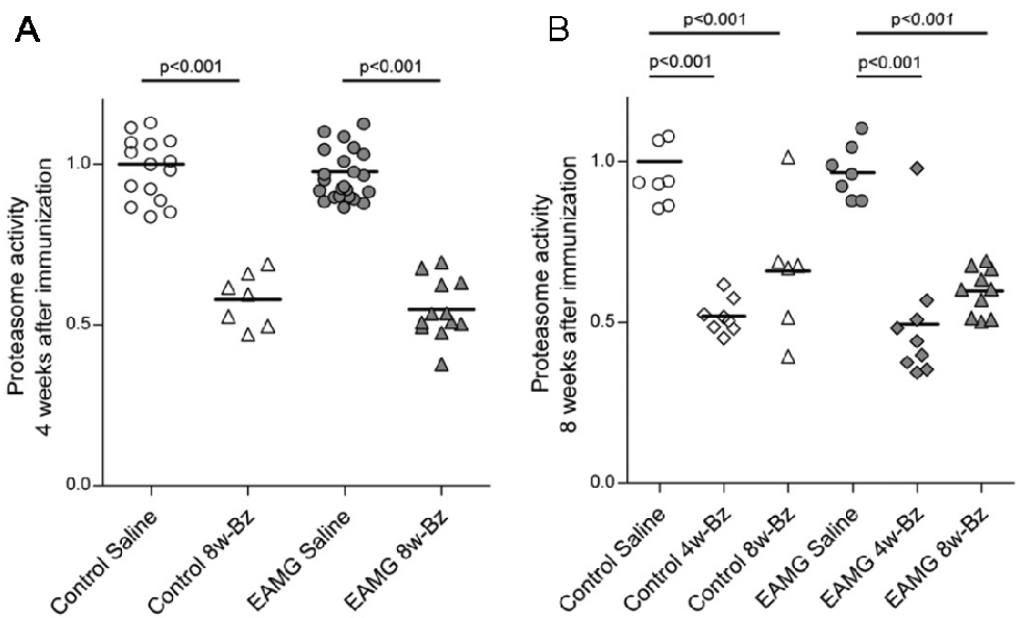

Figure 1. Proteasome activity in blood lysates. Samples were incubated with a labelled peptide substrate (LLVY$A M C$ ) and the amount of cleaved fluorophore AMC (7-amino-4-methylcoumarin) was measured in a fluorometer. (A) Proteasome activities at 4 weeks after immunization were normalized using the average relative fluorescence units (RFU) value of the Control-saline group at week 4. (B) Proteasome activities at 8 weeks after immunization were normalized using the average RFU value of the Control-saline group at week 8 . One-way ANOVA and Bonferoni post-hoc testing were used for statistical analyses. 


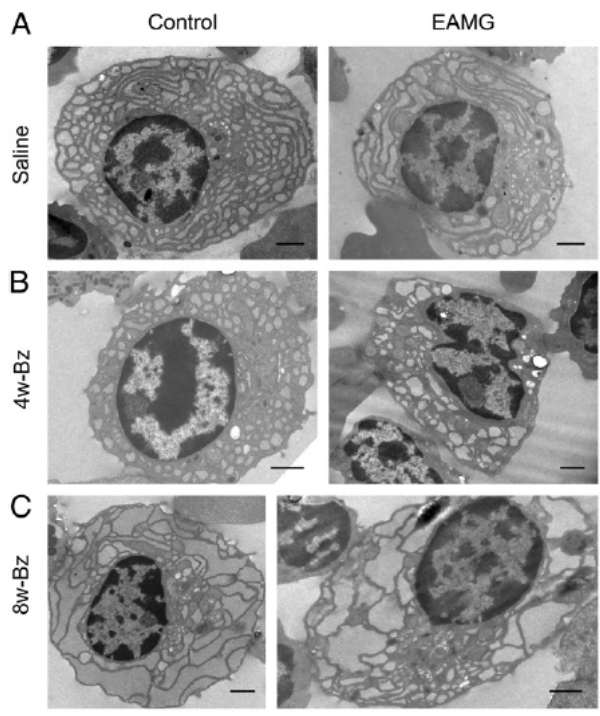

Figure 2. Electron micrographs of bone marrow plasma cells. After 4 weeks of bortezomib treatment, the rough endoplasmic reticulum cisternae have a vesicular appearance; after 8 weeks of treatment, pronounced dilatation of the rough endoplasmic reticulum is visible. Scale bars are $1 \mu \mathrm{m}$.
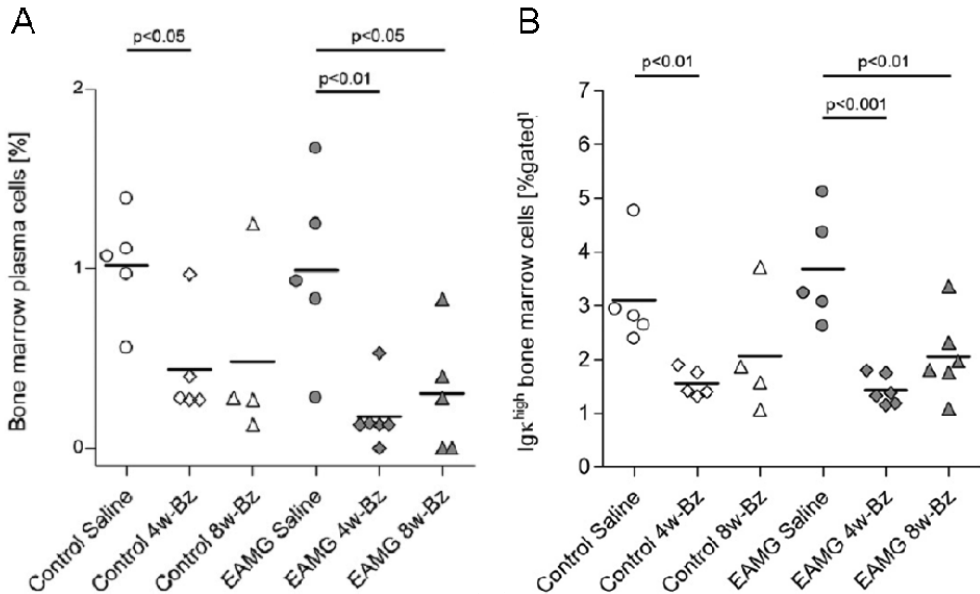

Figure 3. Analysis of plasma cells in the bone marrow 8 weeks after immunization. (A) Electron-microscopical analysis. Bortezomib treatment decreases the number of plasma cells in the bone marrow. (B) Flow cytometric analyses of IgK $^{\text {high }}$ cells. Data are shown as percentages of cells with respect to gated living bone marrow cells. The proportion of Igk ${ }^{\text {high }}$ cells was significantly lower in $4 w-B z$ and $8 w-B z$ groups compared to the corresponding saline-treated groups. Horizontal bars represent the mean percentage of each group. Two-way ANOVA and Bonferoni post-hoc testing were used for statistical analyses. 
Table II: FACS analysis of lymphoid organs

\begin{tabular}{|c|c|c|c|c|c|c|c|c|c|c|}
\hline & & Saline & & & $4 w-B z$ & & & $8 w-B z$ & & \\
\hline \multicolumn{11}{|l|}{ Dead cells } \\
\hline \multirow[t]{4}{*}{$\mathrm{Ann}^{+} \mathrm{PI}^{+}$} & Thymus & 11.25 & \pm & 1.43 & 13.63 & \pm & 1.17 & 14.19 & \pm & 1.94 \\
\hline & Spleen & 25.38 & \pm & 2.34 & 28.00 & \pm & 3.28 & 31.26 & \pm & 4.25 \\
\hline & Bone Marrow & 12.93 & \pm & 0.86 & 14.57 & \pm & 1.20 & 15.82 & \pm & 1.16 \\
\hline & PBMC & 5.72 & \pm & 0.66 & 2.84 & \pm & $0.17^{* * *}$ & 2.92 & \pm & $0.18 * * *$ \\
\hline \multicolumn{11}{|l|}{ Early apoptotic } \\
\hline \multirow[t]{4}{*}{ cells Ann ${ }^{+} \mathrm{PI}^{-}$} & Thymus & 8.23 & \pm & 0.96 & 12.11 & \pm & 0.63 & 10.22 & \pm & 1.60 \\
\hline & Spleen & 17.02 & \pm & 1.27 & 16.36 & \pm & 1.62 & 15.80 & \pm & 1.63 \\
\hline & Bone Marrow & 12.40 & \pm & 1.76 & 10.40 & \pm & 1.19 & 13.08 & \pm & 1.56 \\
\hline & PBMC & 2.25 & \pm & 0.18 & 1.23 & \pm & $0.12^{* * *}$ & 1.91 & \pm & 0.22 \\
\hline \multirow[t]{4}{*}{$\mathrm{CD} 5 \mathrm{RA}^{+} \operatorname{lgk}^{+}$} & Thymus & 0.48 & \pm & 0.05 & 0.89 & \pm & 0.12 & 0.63 & \pm & 0.10 \\
\hline & Spleen & 19.85 & \pm & 0.36 & 15.85 & \pm & $1.05^{*}$ & 16.13 & \pm & $1.24 *$ \\
\hline & Bone Marrow & 4.16 & \pm & 0.16 & 2.56 & \pm & $0.30 * *$ & 2.44 & \pm & $0.33 * * *$ \\
\hline & PBMC & 5.64 & \pm & 0.43 & 3.16 & \pm & $0.26 * * *$ & 2.57 & \pm & $0.18 * * *$ \\
\hline \multirow[t]{4}{*}{$\mathrm{CD}^{+} \mathrm{CD}^{+} \mathrm{CD}^{-}$} & Thymus & 7.72 & \pm & 0.39 & 10.53 & \pm & $0.65^{* *}$ & 9.62 & \pm & 0.61 \\
\hline & Spleen & 39.44 & \pm & 0.25 & 43.92 & \pm & $1.53^{*}$ & 44.72 & \pm & $0.71^{*}$ \\
\hline & Bone Marrow & 1.27 & \pm & 0.22 & 1.27 & \pm & 0.31 & 1.49 & \pm & 0.29 \\
\hline & PBMC & 56.52 & \pm & 0.68 & 63.21 & \pm & $0.63 * * *$ & 62.18 & \pm & $0.79 * * *$ \\
\hline \multirow[t]{4}{*}{$\mathrm{CD}^{+} \mathrm{CD}^{+} \mathrm{CD}^{-}$} & Thymus & 1.78 & \pm & 0.11 & 3.49 & \pm & $0.30 * * *$ & 2.80 & \pm & $0.31^{*}$ \\
\hline & Spleen & 12.89 & \pm & 0.26 & 9.82 & \pm & $0.39 * * *$ & 9.13 & \pm & $0.63^{* * *}$ \\
\hline & Bone Marrow & 1.67 & \pm & 0.30 & 0.82 & \pm & $0.08^{*}$ & 1.29 & \pm & 0.20 \\
\hline & PBMC & 19.48 & \pm & 0.40 & 20.91 & \pm & 0.47 & 20.85 & \pm & 0.43 \\
\hline \multirow[t]{4}{*}{$\mathrm{CD}^{+} \mathrm{CD}^{+}$} & Thymus & 83.57 & \pm & 1.24 & 77.41 & \pm & $1.87^{*}$ & 78.99 & \pm & 1.38 \\
\hline & Spleen & 1.33 & \pm & 0.06 & 1.27 & \pm & 0.07 & 1.46 & \pm & 0.07 \\
\hline & Bone Marrow & 1.60 & \pm & 0.39 & 1.03 & \pm & 0.11 & 0.99 & \pm & 0.12 \\
\hline & PBMC & 1.39 & \pm & 0.12 & 1.62 & \pm & 0.13 & 2.16 & \pm & $0.19 * *$ \\
\hline
\end{tabular}

Using flow cytometry, the effects of bortezomib treatment on apoptosis and on lymphocytes were measured in the thymus, spleen, bone marrow and peripheral blood. Results are shown as average percentages \pm SEM. One way ANOVA analysis and Bonferroni post-hoc testing, For analyzing the effect of Bortezomib treatment, the data of Control and EAMG groups were combined since no significant differences were observed between them in any of the parameters studied. Ann, Annexin V.

$* p<0.05, * * p<0.01$ and $* * * p<0.001$. 
A

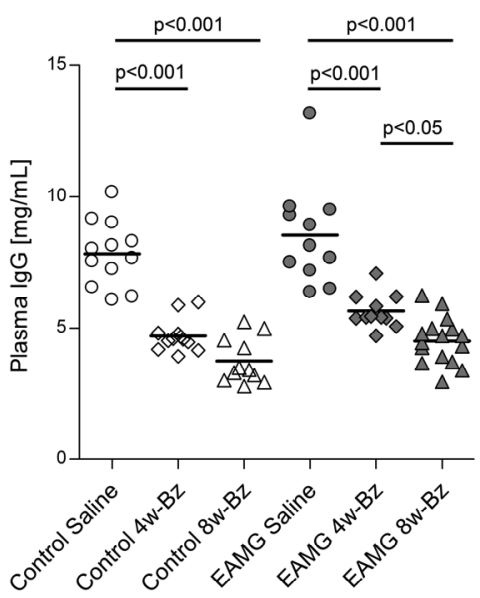

B

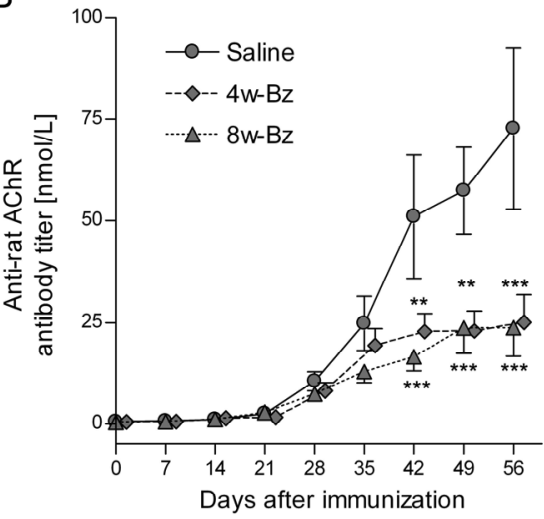

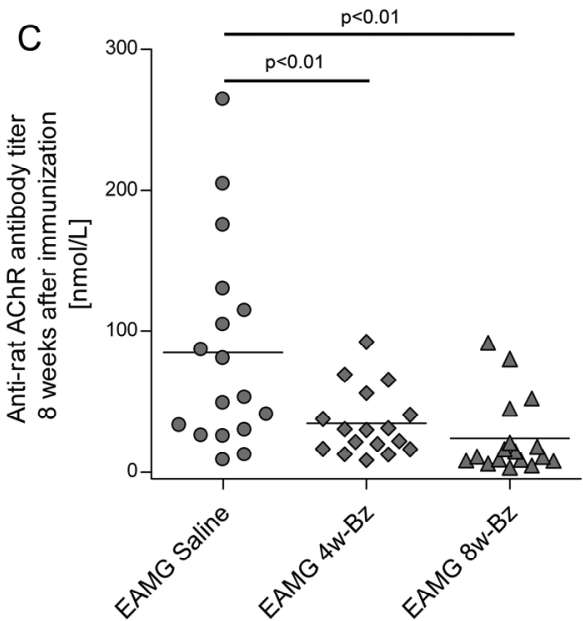

Figure 4. Total IgG and autoantibody titers in plasma. (A) Plasma IgG titers 8 weeks after immunization. Bortezomib significantly reduced plasma IgG levels. Two-way ANOVA and Bonferoni post-hoc testing were used for statistical analyses. (B) Average anti-rat AChR-titer; error bars correspond to the SEM. Stars indicate significant differences compared to the saline-treated groups $(* *<0.01 ; * * *<0.001)$. Autoantibody titers of the $4 \mathrm{w}-\mathrm{Bz}$ and the $8 \mathrm{w}-\mathrm{Bz}$ groups were not significantly different from each other at any time point. (C) Anti-rat AChR titers 8 weeks after immunization with Torpedo AChR. One-way ANOVA and Bonferoni post-hoc testing were used for statistical analyses. 


\section{Total IgG concentration is decreased by bortezomib}

The effect of bortezomib on total IgG content in plasma samples was measured by ELISA (Figure 4A). In comparison to the saline-treated group, total IgG at week 8 was significantly reduced in both the $4 \mathrm{w}-\mathrm{Bz}$ and the $8 \mathrm{w}-\mathrm{Bz}$ group $(\mathrm{p}<0.001)$. Importantly, this immunosuppressive effect of bortezomib was observed in both Control and EAMG animals, although IgG reduction was more pronounced in $8 \mathrm{w}$-Bz EAMG animals than in the $4 w-B z$ EAMG rats $(p<0.05)$. A slightly but significantly higher concentration of IgG was observed in all EAMG groups in comparison to the corresponding Control groups. Compared to the saline-treated groups, a highly significant reduction in IgG concentrations $(p<0.001)$ was already achieved after 4 weeks of bortezomib treatment in the $8 \mathrm{w}$-Bz group (data not shown).

\section{Bortezomib reduces auto-antibody titers in EAMG}

The plasma concentration of autoantibodies to the rat AChR was measured by radioimmunoassay. Autoantibodies were detectable 4 weeks after immunization in all EAMG animals and reached very high levels after 8 weeks (Figure 4B). The variability of autoantibody levels between animals is typical for the EAMG model, but it should be borne in mind that already a titer of $1 \mathrm{nM}$ of autoantibodies is sufficient to cause substantial damage to the NMJ (Janssen et al., 2008). As expected, no anti-AChR antibody titers could be detected in sham/CFA immunized animals (Control group; data not shown). On the other hand, animals that received bortezomib injections from the moment of immunization showed a significantly lower production of autoantibodies ( $p<0.01$; corresponding to a $72 \%$ reduction of average autoantibody titer) compared to the saline treated EAMG group 8 weeks after immunization (Figure $4 \mathrm{C}$ ). Interestingly, rats that received bortezomib 4 weeks after immunization had an autoantibody production profile similar to that observed in the $8 \mathrm{w}$-Bz group. After injection of bortezomib the production of anti-AChR antibodies was significantly reduced compared to saline-treated animals (corresponding to a $60 \%$ reduction; $\mathrm{p}<0.01$ ). This demonstrated that bortezomib effectively diminished antibody production not only when administrated at the moment of immunization but also once the immune response was already ongoing.

\section{Bortezomib ameliorates clinical conditions in EAMG}

To assess the effect of bortezomib on the overall condition of experimental animals we weighed them and scored their clinical status on a weekly basis. During the first 5 weeks of treatment, Control animals that had received bortezomib from the moment of 
immunization ( $8 \mathrm{w}-\mathrm{Bz}$ group) showed a slower increase in their total body weight compared to saline-treated Control animals (Figure $5 A$ and $B ; p<0.001$ ). After 5 weeks, the growth of these animals normalized again. A similar reduction of growth was observed 4 weeks later in the $4 \mathrm{w}-\mathrm{Bz}$ Control group. At the end of the experiment there were no significant differences between the average weights of the $4 \mathrm{w}-\mathrm{Bz}$ and the $8 \mathrm{w}-\mathrm{Bz}$ Control groups. As expected, Control animals did not present muscle weakness or any other clinical sign of EAMG.

A

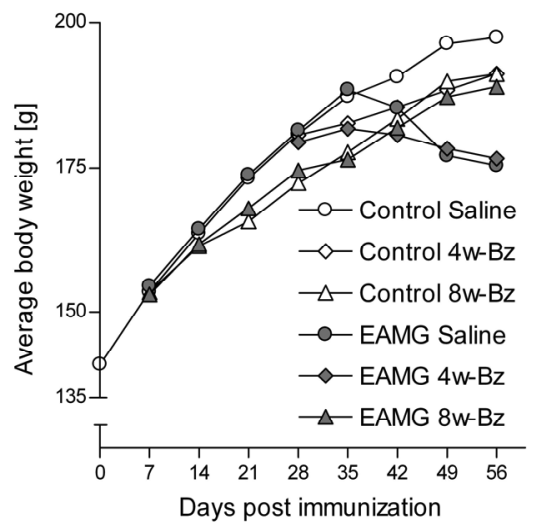

B

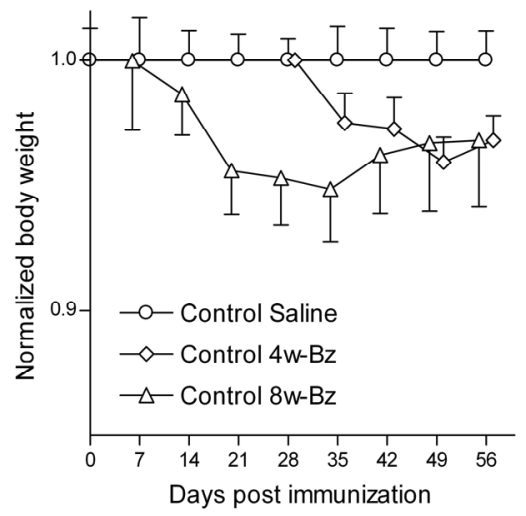

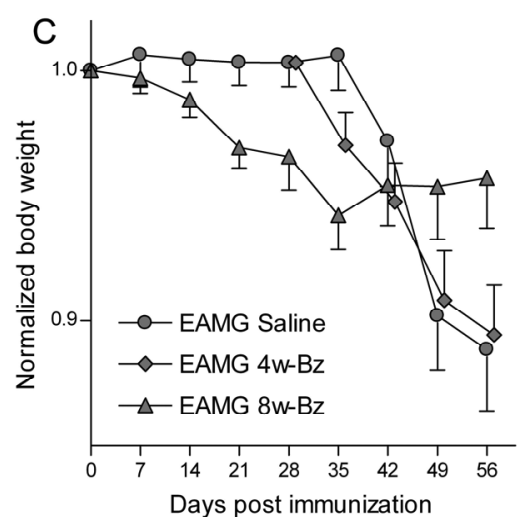

Figure 5. Average rat weights. (A) Body weights of bortezomib-treated animals increased slower compared to saline-treated animals. Weight loss occurred frequently in EAMG animals. (B, C) Normalized weights were calculated using the average weight of the saline-treated Control-group. Error bars correspond to the SEM. 
Animals immunized with Torpedo AChR developed clinical symptoms of EAMG starting 5 weeks after immunization, when antibody titers reached considerable levels. Frequently, weight loss preceded the observation of other myasthenic symptoms in EAMG animals, indicating weakness of bulbar muscles and difficulties in chewing and swallowing. The disease in some of these animals progressed rapidly to score 3 within two days and they had to be sacrificed (Figure 6A). By the end of the experiment $50 \%$ of animals (9/18) treated with saline solution reached a clinical score of 3 or lost more than $20 \%$ body weight and had to be sacrificed for ethical reasons. This percentage was reduced to $33 \%(6 / 18)$ in the $4 \mathrm{w}-\mathrm{Bz}$ group and to $11 \%(2 / 18)$ in the $8 \mathrm{w}$-Bz group (Figure $6 B)$. The survival rate of the $8 w-B z$ EAMG group was significantly higher compared to the saline-treated EAMG group (Figure 6A, $p<0.01$ ).

From the AChR-immunized animals, 78\% developed muscle weakness in the salinetreated EAMG group, $72 \%$ in the $4 \mathrm{w}-\mathrm{Bz}$ EAMG group and $39 \%$ in the $8 \mathrm{w}-\mathrm{Bz}$ EAMG group. The clinical score of the $8 \mathrm{w}$-Bz EAMG group was significantly lower compared to the $4 \mathrm{w}$ $B z$ group $(p<0.05)$ and the saline-treated EAMG group $(p<0.01$; Figure $6 B)$. Despite the reduced amount of autoantibodies, the muscle weakness and the survival rate of the $4 \mathrm{w}$ Bz EAMG group was not significantly different from the saline-treated EAMG group. The onset of weight loss in the 4w-Bz EAMG group even occurred somewhat earlier compared to the saline treated EAMG group (Figure $5 \mathrm{C}$ ); indicating that weight loss was partly caused by the (side) effects of bortezomib.

We evaluated the safety factor of neuromuscular transmission, which is a function of the postsynaptic density of AChRs, by performing electromyography studies in the presence of the AChR-blocking agent (+)-tubocurarine (curare). The amount of curare needed to induce a decrement in CMAP is related to the safety factor of neuromuscular transmission. Bortezomib had slight effects on the curare sensitivity of the NMJ in Control animals in the $4 \mathrm{w}-\mathrm{Bz}$ group (Figure $6 \mathrm{C}$ ). The neuromuscular transmission was significantly impaired in all EAMG groups compared to the corresponding Control groups. In the $8 \mathrm{w}-\mathrm{Bz}$ EAMG group, neuromuscular transmission was significantly improved compared to the saline-treated and the $4 w-B z$ EAMG groups $(p<0.05)$. 
A

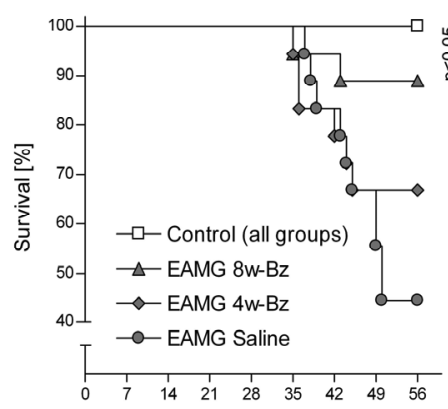

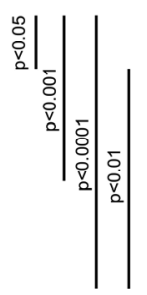

$\mathrm{B}^{[100 \%]} 18$

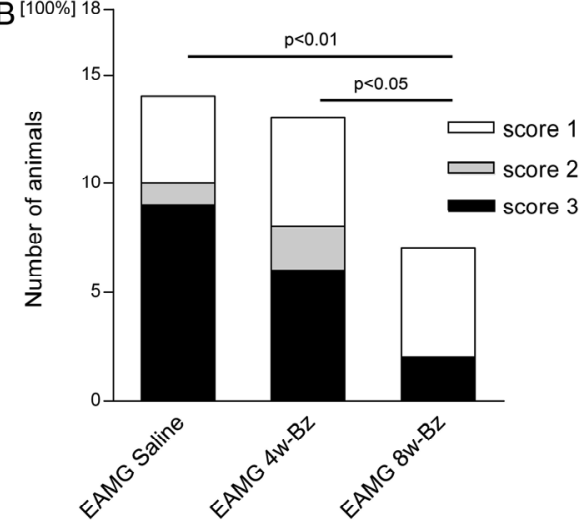

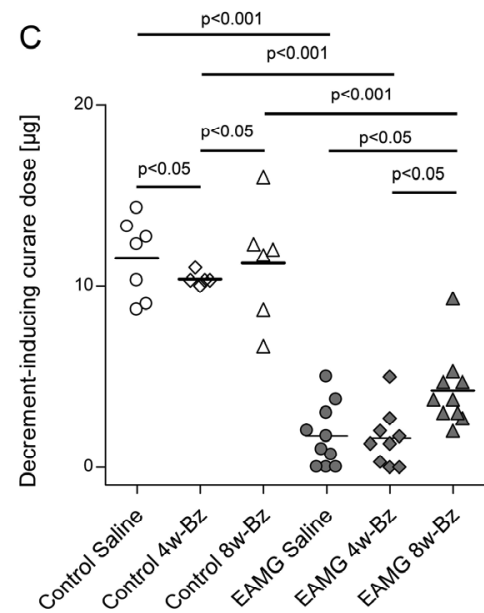

Figure 6. MG symptoms and muscle function. (A) Survival. (B) Clinical scores of muscle weakness. Each group contained 18 animals (indicated with ' $100 \%$ '). (C) EMG after curare infusion. The curare dose that induces at least $10 \%$ decrement of the CMAP was used as a measure of the neuromuscular safety factor. 
A

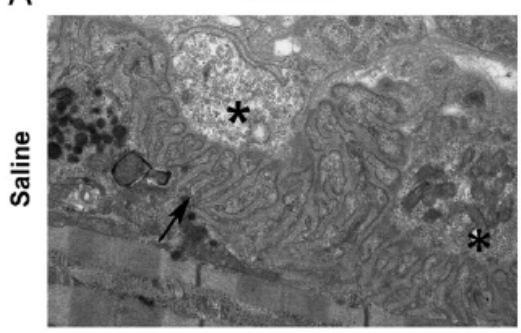

B
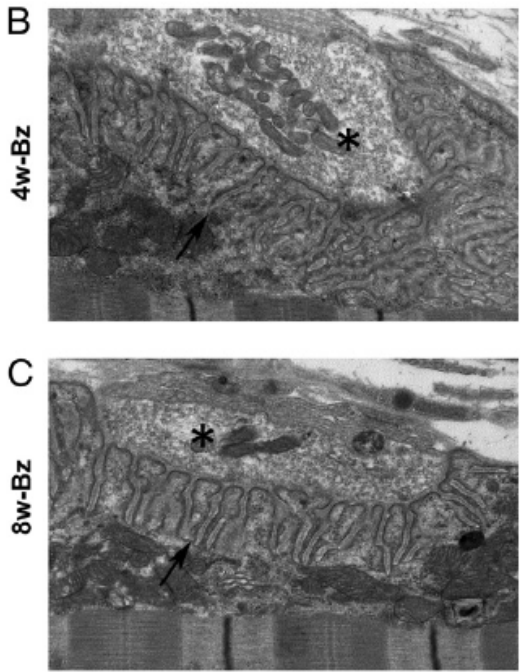

$2 \mu \mathrm{m}$
D

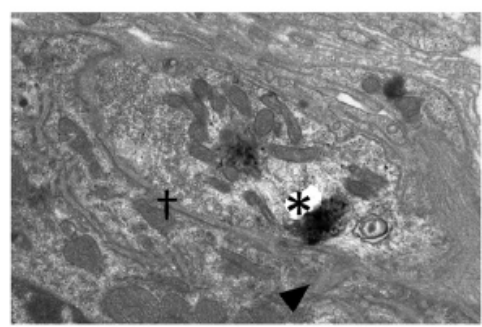

E

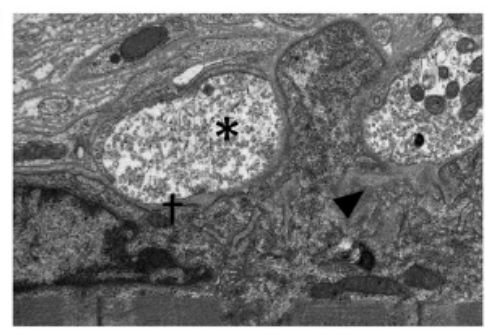

F

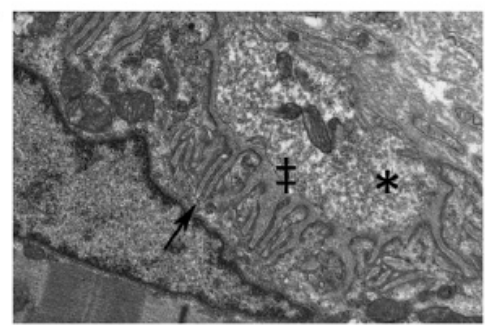

G

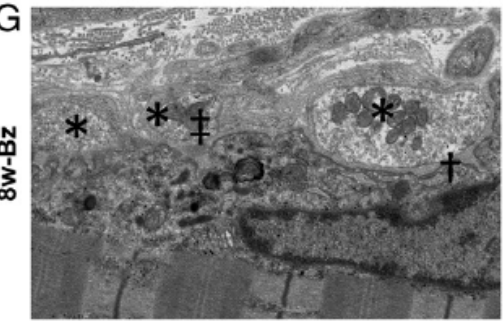

Figure 7. Electron micrographs of synaptic boutons of the NMJ. Nerve terminals are indicated by asterisks. In Control animals (A-C), the postsynaptic membrane contains secondary clefts (postsynaptic folds), which are indicated by arrows. In EAMG animals (D-G) pathologic changes of the postsynaptic membrane are indicated: degenerating folds (arrowhead), simplified and without folds (dagger); widening of the primary and secondary synaptic clefts (double dagger). The postsynaptic damage of an animal with an anti-AChR titer of 3 $\mathrm{nM}(\mathrm{F})$ was mild compared to an animal with a titer of $20 \mathrm{nM}(\mathrm{G})$. 


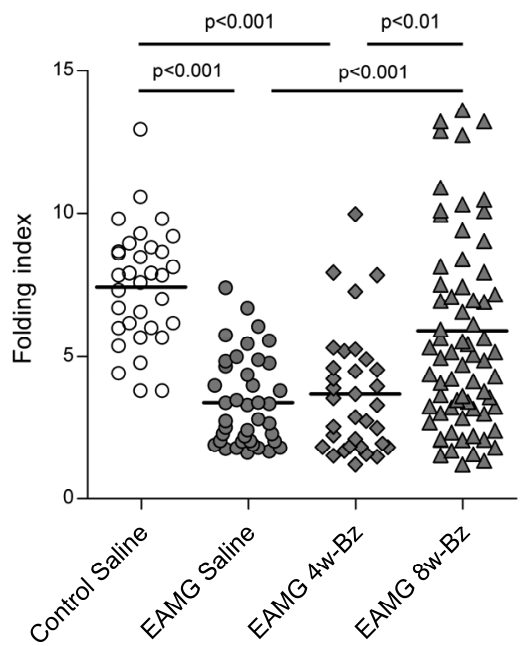

Figure 8. Analysis of folding index (length of postsynaptic membrane / length of presynaptic membrane) by quantitative morphometry of electron micrographs. Each point represents one endplate region with one or two synaptic boutons as shown in Fig. 7. Due to loss of postsynaptic folds, the folding index is significantly reduced in EAMG saline animals compared to Control saline animals. In the EAMG 8w-Bz, the reduction of postsynaptic folding was prevented by bortezomib. One-way ANOVA and Bonferoni post-hoc testing were used for statistical analyses.

Ultrastructural analysis of the NMJ revealed damage of the postsynaptic membrane morphology, with degenerating or absent secondary clefts in EAMG animals (Figure 7). The damage in endplates of animals with low titers in the $8 \mathrm{w}$-Bz group (Figure 7F) was less severe compared to animals with higher titers (Figure $7 \mathrm{D}, \mathrm{E}, \mathrm{G}$ ). Quantitative morphometric analysis of the synapse ultrastructure was performed to measure the loss of postsynaptic folds (Figure 8). The folding index was significantly reduced in the salinetreated EAMG animals compared to the saline-treated Control animals (a reduction of $55 \%, \mathrm{p}<0.001$ ). In the $8 \mathrm{w}-\mathrm{Bz}$ EAMG animals only a $20 \%$ reduction of the folding index compared to saline-treated control animals was observed and a considerable proportion of the endplates had a relatively high folding index. Compared to the saline-treated EAMG group, the folding index in the $8 \mathrm{w}-\mathrm{Bz}$ group was significantly higher $(\mathrm{p}<0.001)$. However, this treatment effect was not observed in the $4 w-B z$ group. In conclusion, bortezomib could not improve synaptic ultrastructure if treatment was started 4 weeks after immunization, but it efficiently prevented damage of the postsynaptic membrane when administrated for 8 weeks starting directly after immunization. 


\section{Discussion}

In this study we analyzed the effect of proteasome inhibition on the autoimmune response in the EAMG model for MG. Bortezomib reduced the amount of plasma cells, leading to a significant reduction of total serum IgG and autoantibody levels and caused an amelioration of myasthenic symptoms compared to a saline-treated EAMG group. Both the 4 and 8 week bortezomib treatment regimes ( $4 w-B z$ and $8 w-B z$ ) were generally well tolerated, but some side effects were noticed which are discussed below. There were no significant differences in autoantibody production between the $4 \mathrm{w}-\mathrm{Bz}$ and the $8 \mathrm{w}-\mathrm{Bz}$ group. Since bortezomib in the $4 \mathrm{w}-\mathrm{Bz}$ group was only administered starting 4 weeks after immunization with autoantigen, this suggests that mainly the late (effector) phase of the auto-immune response is affected by proteasome inhibition.

In the EAMG model, the production of antibodies against the muscle AChR is induced by immunization with tAChR from the electric ray. EAMG in Lewis rats is characterized by chronic muscle weakness starting 5 weeks after immunization. A transient acute phase of muscle weakness starting one week after immunization is seen in EAMG models using CFA with Bordetella pertussis and M. tuberculosis (Lindstrom, 1980). In the immunization protocol used here with CFA containing only $M$. tuberculosis the acute phase of muscle weakness does not occur (Lindstrom, 1980). Therefore we could investigate both a therapeutic as well as a preventive treatment regime. Bortezomib efficiently reduced the production of autoantibodies and also ameliorated MG symptoms in the $8 \mathrm{w}-\mathrm{Bz}$ group. The average levels of anti-AChR autoantibodies in this study were high (comparable to a previous study using the same protocol with $20 \mu \mathrm{g}$ tAChR (Manz et al., 2005; Slifka and Ahmed, 1998) and much higher than another study using $10 \mu \mathrm{g}$ tAChR (Janssen et al., 2008)), ranging between 3 and $80 \mathrm{nM}$ even in the $8 \mathrm{w}$-Bz groups. Since 1 $\mathrm{nM}$ of serum anti-muscle $\mathrm{AChR}$-antibodies can already reduce the amount of total muscle AChR by $50 \%$ in rats (Janssen et al., 2008), the limited improvement of muscle strength in this study is understandable. It is therefore conceivable that, if we could have used EAMG animals with a lower titer, the effects of $\mathrm{Bz}$ would have been more pronounced. Nevertheless, the resistance against curare, and thus the amount of functional AChR at the NMJ and the folding index of the postsynaptic membrane were significantly increased by bortezomib in the $8 \mathrm{w}-\mathrm{Bz}$ treatment group resulting in higher survival rates. In human MG patients, an autoantibody titer reduction of $50 \%$ after plasma exchange is generally sufficient to achieve clinical remission (Hawkey et al., 1981; Olarte et al., 1981), and therefore in this respect the bortezomib-induced reduction of autoantibody production by more than $65 \%$ within 4 weeks is therapeutically promising. 
However, despite the reduced autoantibody levels, the $4 \mathrm{w}-\mathrm{Bz}$ treatment did not result in a significant improvement of health in EAMG animals, in contrast to the $8 \mathrm{w}-\mathrm{BZ}$ treatment where bortezomib caused amelioration in the condition of the animals. Two side effects of bortezomib might have influenced this result. Firstly, bortezomib negatively affected body weight during the first 4 weeks of administration in Control animals and presumably also in EAMG animals. In the 4w-Bz EAMG group, this coincided with the weight-loss as a result of muscle weakness and the resulting problems with eating and drinking. Since a $20 \%$ weight loss was chosen as a criterion to sacrifice animals for ethical reasons, the bortezomib treatment could have reduced survival time to some extent. Secondly, we observed a mild impairment of neuromuscular transmission in the $4 \mathrm{w}-\mathrm{Bz}$ Control group (but not in the $8 \mathrm{w}-\mathrm{Bz}$ Control group) in comparison to the salinetreated Control group. This effect possibly indicates transient nerve damage similar to the bortezomib-induced polyneuropathy (Bruna et al., ; Cavaletti et al., 2007). Arguably, the weight loss in control animals was caused by an effect of proteasome inhibition on the gastrointestinal tract, which has been seen in patients (Kane et al., 2003). However, our study was not designed for investigating the side effects of bortezomib and therefore we cannot conclusively attribute the effect on weight to any particular side effect. In the $8 \mathrm{w}$ $\mathrm{Bz}$ Control group, weight gain, neuromuscular transmission and apoptosis were normalized 8 weeks after immunization, suggesting that by that time compensatory mechanisms limited these adverse effects of bortezomib.

Despite comparable autoantibody titers, the ultrastructural postsynaptic damage of the $4 \mathrm{w}-\mathrm{Bz}$ EAMG group was significantly higher compared to the 8w-Bz EAMG group. Since the repair of the postsynaptic membrane takes at least 10 days (Engel et al., 1979) it seems possible that the observed loss of postsynaptic folding in the $4 \mathrm{w}-\mathrm{Bz}$ group is the result of earlier damage, in particular in the time period between 4 and 7 weeks after immunization, when titers were higher compared to the 8w-Bz EAMG group.

Apart from the intended killing of plasma cells, bortezomib affected the immune system in a more general fashion. In particular the thymus was affected by bortezomib; an effect that might not be harmful, since thymectomy is a frequently used treatment in MG, albeit with unproven efficacy so far. In this respect it is relevant that in human thymocyte cultures from thymectomized MG patients we observed that bortezomib induced cell death and reduction of autoantibody production (unpublished observations: A. Gomez, K. Vrolix, M. Losen). Similar to a previous study in mice (Maseda et al., 2008) we found in our rat model that bortezomib mainly affects immature thymocytes. In the spleen, bone marrow and the blood of rats, the proportion of $\mathrm{CD}_{4} 5 \mathrm{RA}^{+} / \operatorname{lgk}^{+}$positive $\mathrm{B}$ cells was significantly decreased, while the proportion of CD3 positive T cells of total 
lymphocytes was increased. There was a trend for increased proportion of dead and apoptotic cells in the thymus, bone marrow and spleen of bortezomib-treated animals. In contrast, bortezomib induced a significant reduction of apoptotic cells in the blood. Since the PBMCs only represent a minor proportion of leukocytes, this effect could be attributed to migration of cells into other lymphoid organs, for example the spleen which was significantly enlarged in bortezomib-treated rats.

In the past the EAMG model has been instrumental for testing the efficacy of new therapies that are now used for the treatment of MG (reviewed by Souroujon et al., 2010), for example cyclophosphamide (Pestronk et al., 1983), pixantrone (Ubiali et al., 2008), linomide (Karussis et al., 1994), azathioprine and hydrocortisone (Abramsky et al., 1976). Also MMF efficiently reduces autoantibodies in a rat model of EAMG (Janssen et al., 2008). This study now indicates that bortezomib might be useful to complement these drugs for the treatment of MG since it can additionally target plasma cells that produce autoantibodies. Because of the observed plasma cell reduction in rats it is reasonable to presume that a course of bortezomib treatment might well eliminate short- and longlived plasma cells also in man and therefore induce a long-lasting treatment response in antibody-mediated autoimmune diseases.

\section{Acknowledgements}

We would like to thank Joost Van den Broeck, Caroline Hammels, Jo Stevens and Jonas Hummel for valuable help and Pauline Wouters, Richard Frijnts and Rik Tinnemans for their excellent technical assistance for performing the animal experiments.

\section{References}

Abramsky, O., Tarrab-Hazdai, R., Aharonov, A., Fuchs, S., 1976. Immunosuppression of experimental autoimmune myasthenia gravis by hydrocortisone and azathioprine. J Immunol 117, 225-228.

Arce, S., Cassese, G., Hauser, A., Dorner, T., Odendahl, M., Manz, R., Radbruch, A., Hiepe, F., 2002. The role of long-lived plasma cells in autoimmunity. Immunobiology 206, 558-562.

Bruna, J., Udina, E., Ale, A., Vilches, J.J., Vynckier, A., Monbaliu, J., Silverman, L., Navarro, X., Neurophysiological, histological and immunohistochemical characterization of bortezomib-induced neuropathy in mice. Exp Neurol 223, 599-608.

Cavaletti, G., Gilardini, A., Canta, A., Rigamonti, L., Rodriguez-Menendez, V., Ceresa, C., Marmiroli, P., Bossi, M., Oggioni, N., D'Incalci, M., De Coster, R., 2007. Bortezomib-induced peripheral neurotoxicity: a neurophysiological and pathological study in the rat. Exp Neurol 204, 317-325.

De Baets, M., Stassen, M., Losen, M., Zhang, X., Machiels, B., 2003. Immunoregulation in experimental autoimmune myasthenia gravis--about T cells, antibodies, and endplates. Ann N Y Acad Sci 998, 308-317. 
DiLillo, D.J., Hamaguchi, Y., Ueda, Y., Yang, K., Uchida, J., Haas, K.M., Kelsoe, G., Tedder, T.F., 2008. Maintenance of longlived plasma cells and serological memory despite mature and memory B cell depletion during CD20 immunotherapy in mice. J Immunol 180, 361-371.

Engel, A.G., Sakakibara, H., Sahashi, K., Lindstrom, J.M., Lambert, E.H., Lennon, V.A., 1979. Passively transferred experimental autoimmune myasthenia gravis. Sequential and quantitative study of the motor end-plate fine structure and ultrastructural localization of immune complexes (IgG and C3), and of the acetylcholine receptor. Neurology 29, 179-188.

Engel, A.G., Santa, T., 1971. Histometric analysis of the ultrastructure of the neuromuscular junction in myasthenia gravis and in the myasthenic syndrome. Ann N Y Acad Sci 183, 46-63.

Gajdos, P., Chevret, S., Toyka, K., 2002. Plasma exchange for myasthenia gravis. Cochrane Database Syst Rev, CD002275.

Gajdos, P., Chevret, S., Toyka, K., 2008. Intravenous immunoglobulin for myasthenia gravis. Cochrane Database Syst Rev, CD002277.

Gomez, A.M., Van Den Broeck, J., Vrolix, K., Janssen, S.P., Lemmens, M.A., Van Der Esch, E., Duimel, H., Frederik, P., Molenaar, P.C., Martinez-Martinez, P., De Baets, M.H., Losen, M., 2010. Antibody effector mechanisms in myasthenia gravis-Pathogenesis at the neuromuscular junction. Autoimmunity 43, 353-370.

Groll, M., Berkers, C.R., Ploegh, H.L., Ovaa, H., 2006. Crystal structure of the boronic acid-based proteasome inhibitor bortezomib in complex with the yeast 20 S proteasome. Structure 14, 451-456.

Hawkey, C.J., Newsom-Davis, J., Vincent, A., 1981. Plasma exchange and immunosuppressive drug treatment in myasthenia gravis: no evidence for synergy. J Neurol Neurosurg Psychiatry 44, 469-475.

Hemeryck, A., Geerts, R., Monbaliu, J., Hassler, S., Verhaeghe, T., Diels, L., Verluyten, W., van Beijsterveldt, L., Mamidi, R.N., Janssen, C., De Coster, R., 2007. Tissue distribution and depletion kinetics of bortezomib and bortezomibrelated radioactivity in male rats after single and repeated intravenous injection of $14 \mathrm{C}$-bortezomib. Cancer Chemother Pharmacol 60, 777-787.

Hoch, W., McConville, J., Helms, S., Newsom-Davis, J., Melms, A., Vincent, A., 2001. Auto-antibodies to the receptor tyrosine kinase MuSK in patients with myasthenia gravis without acetylcholine receptor antibodies. Nat Med 7, 365-368.

Hoedemaekers, A., Graus, Y., van Breda Vriesman, P., de Baets, M., 1997a. Age- and sex-related resistance to chronic experimental autoimmune myasthenia gravis (EAMG) in Brown Norway rats. Clin Exp Immunol 107, 189-197.

Hoedemaekers, A.C., Verschuuren, J.J., Spaans, F., Graus, Y.F., Riemersma, S., van Breda Vriesman, P.J., De Baets, M.H., 1997b. Age-related susceptibility to experimental autoimmune myasthenia gravis: immunological and electrophysiological aspects. Muscle Nerve 20, 1091-1101.

Janssen, S.P., Phernambucq, M., Martinez-Martinez, P., De Baets, M.H., Losen, M., 2008. Immunosuppression of experimental autoimmune myasthenia gravis by mycophenolate mofetil. J Neuroimmunol 201-202, 111-120.

Kane, R.C., Bross, P.F., Farrell, A.T., Pazdur, R., 2003. Velcade: U.S. FDA approval for the treatment of multiple myeloma progressing on prior therapy. Oncologist 8, 508-513.

Karussis, D.M., Lehmann, D., Brenner, T., Wirguin, I., Mizrachi-Koll, R., Sicsic, C., Abramsky, O., 1994. Immunomodulation of experimental autoimmune myasthenia gravis with linomide. J Neuroimmunol 55, 187-193.

Lennon, V.A., Lindstrom, J.M., Seybold, M.E., 1975. Experimental autoimmune myasthenia: A model of myasthenia gravis in rats and guinea pigs. J Exp Med 141, 1365-1375.

Lightcap, E.S., McCormack, T.A., Pien, C.S., Chau, V., Adams, J., Elliott, P.J., 2000. Proteasome inhibition measurements: clinical application. Clin Chem 46, 673-683.

Lindstrom, J., 1980. Experimental autoimmune myasthenia gravis. J Neurol Neurosurg Psychiatry 43, 568-576.

Losen, M., Martinez-Martinez, P., Phernambucq, M., Schuurman, J., Parren, P.W., De Baets, M.H., 2008. Treatment of myasthenia gravis by preventing acetylcholine receptor modulation. Ann N Y Acad Sci 1132, 174-179.

Losen, M., Stassen, M.H., Martinez-Martinez, P., Machiels, B.M., Duimel, H., Frederik, P., Veldman, H., Wokke, J.H., Spaans, F., Vincent, A., De Baets, M.H., 2005. Increased expression of rapsyn in muscles prevents acetylcholine receptor loss in experimental autoimmune myasthenia gravis. Brain 128, 2327-2337.

Manz, R.A., Hauser, A.E., Hiepe, F., Radbruch, A., 2005. Maintenance of serum antibody levels. Annu Rev Immunol 23, 367-386. 
Martinez-Martinez, P., Losen, M., Duimel, H., Frederik, P., Spaans, F., Molenaar, P., Vincent, A., De Baets, M.H., 2007. Overexpression of rapsyn in rat muscle increases acetylcholine receptor levels in chronic experimental autoimmune myasthenia gravis. Am J Pathol 170, 644-657.

Martinez-Martinez, P., Phernambucq, M., Steinbusch, L., Schaeffer, L., Berrih-Aknin, S., Duimel, H., Frederik, P., Molenaar, P., De Baets, M.H., Losen, M., 2009. Silencing rapsyn in vivo decreases acetylcholine receptors and augments sodium channels and secondary postsynaptic membrane folding. Neurobiol Dis 35, 14-23.

Maseda, D., Meister, S., Neubert, K., Herrmann, M., Voll, R.E., 2008. Proteasome inhibition drastically but reversibly impairs murine lymphocyte development. Cell Death Differ 15, 600-612.

Meister, S., Schubert, U., Neubert, K., Herrmann, K., Burger, R., Gramatzki, M., Hahn, S., Schreiber, S., Wilhelm, S., Herrmann, M., Jack, H.M., Voll, R.E., 2007. Extensive immunoglobulin production sensitizes myeloma cells for proteasome inhibition. Cancer Res 67, 1783-1792.

Miller, J.J., 3rd, Cole, L.J., 1967. Resistance of long-lived lymphocytes and plasma cells in rat lymph nodes to treatment with prednisone, cyclophosphamide, 6-mercaptopurine, and actinomycin D. J Exp Med 126, 109-125.

Moreau, P., Coiteux, V., Hulin, C., Leleu, X., van de Velde, H., Acharya, M., Harousseau, J.L., 2008. Prospective comparison of subcutaneous versus intravenous administration of bortezomib in patients with multiple myeloma. Haematologica 93, 1908-1911.

Neubert, K., Meister, S., Moser, K., Weisel, F., Maseda, D., Amann, K., Wiethe, C., Winkler, T.H., Kalden, J.R., Manz, R.A., Voll, R.E., 2008. The proteasome inhibitor bortezomib depletes plasma cells and protects mice with lupus-like disease from nephritis. Nat Med 14, 748-755.

Obeng, E.A., Carlson, L.M., Gutman, D.M., Harrington, W.J., Jr., Lee, K.P., Boise, L.H., 2006. Proteasome inhibitors induce a terminal unfolded protein response in multiple myeloma cells. Blood 107, 4907-4916.

Olarte, M.R., Schoenfeldt, R.S., Penn, A.S., Lovelace, R.E., Rowland, L.P., 1981. Effect of plasmapheresis in myasthenia gravis 1978-1980. Ann N Y Acad Sci 377, 725-728.

Palace, J., Newsom-Davis, J., Lecky, B., 1998. A randomized double-blind trial of prednisolone alone or with azathioprine in myasthenia gravis. Myasthenia Gravis Study Group. Neurology 50, 1778-1783.

Pestronk, A., Drachman, D.B., Teoh, R., Adams, R.N., 1983. Combined short-term immunotherapy for experimental autoimmune myasthenia gravis. Ann Neurol 14, 235-241.

Sanders, D.B., Evoli, A., 2010. Immunosuppressive therapies in myasthenia gravis. Autoimmunity 43, 428-435.

Shapiro-Shelef, M., Calame, K., 2005. Regulation of plasma-cell development. Nat Rev Immunol 5, 230-242.

Sinn, D.I., Lee, S.T., Chu, K., Jung, K.H., Kim, E.H., Kim, J.M., Park, D.K., Song, E.C., Kim, B.S., Yoon, S.S., Kim, M., Roh, J.K., 2007. Proteasomal inhibition in intracerebral hemorrhage: neuroprotective and anti-inflammatory effects of bortezomib. Neurosci Res 58, 12-18.

Skeie, G.O., Apostolski, S., Evoli, A., Gilhus, N.E., Illa, I., Harms, L., Hilton-Jones, D., Melms, A., Verschuuren, J., Horge, H.W., Guidelines for treatment of autoimmune neuromuscular transmission disorders. Eur J Neurol.

Slifka, M.K., Ahmed, R., 1998. Long-lived plasma cells: a mechanism for maintaining persistent antibody production. Curr Opin Immunol 10, 252-258.

Souroujon, M.C., Brenner, T., Fuchs, S., 2010. Development of novel therapies for MG: Studies in animal models. Autoimmunity $43,446-460$.

Trivedi, J.R., Wolfe, G.I., 2010. Myasthenia gravis therapy and thymectomy. In: Christadoss, P. (Ed.), Myasthenia gravis disease mechanisms and immune intervention, Linus Publications, Deer Park, NY, pp. 55-79.

Ubiali, F., Nava, S., Nessi, V., Longhi, R., Pezzoni, G., Capobianco, R., Mantegazza, R., Antozzi, C., Baggi, F., 2008. Pixantrone (BBR2778) reduces the severity of experimental autoimmune myasthenia gravis in Lewis rats. J Immunol 180, 2696-2703.

Verschuuren, J.J., Spaans, F., De Baets, M.H., 1990. Single-fiber electromyography in experimental autoimmune myasthenia gravis. Muscle Nerve 13, 485-492.

Vrolix, K., Fraussen, J., Molenaar, P.C., Losen, M., Somers, V., Stinissen, P., De Baets, M.H., Martinez-Martinez, P., $2010 a$. The auto-antigen repertoire in myasthenia gravis. Autoimmunity $43,380-400$.

Vrolix, K., Niks, E.H., Le Panse, R., van Ostaijen-ten Dam, M.M., Muris, A.-H., Jol-van der Zijde, C.M., van Tol, M.J., Losen, M., Molenaar, P.C., van Zoelen, E.J.J., Berrih-Aknin, S., De Baets, M.H., Verschuuren, J.J., Martínez-Martínez, P., 2010b. Reduced thymic expression of ErbB receptors without auto-antibodies against synaptic ErbB in myasthenia gravis. J Neuroimmunol In press. 


\section{Summary and}

\section{general discussion}


In this thesis we focused on B cells and autoantibodies in MG patients to obtain better insights into their precise role in the disease pathology. We first developed a method to efficiently produce human monoclonal antibodies and then applied this method to investigate the antibody repertoire produced by thymic B cells of MG patients. Moreover, we searched for the yet unknown pathogenic autoantibodies in iMG patients, and finally, we tested a new treatment possibility for MG to target plasma cells.

Chapter 1 reviews the autoantibodies that have been reported in MG patients thus far. Even though MG is a prototypic organ-specific autoimmune disorder, multiple antigens are targeted by autoantibodies. Anti-AChR and anti-MuSK antibodies are considered the main autoantibodies in AChR-MG and MuSK-MG patients, respectively. Both autoantibodies exert pathogenic effects by disturbing the neuromuscular transmission and cause skeletal muscle weakness. Besides these well characterized autoantibodies, various autoantibodies associated with thymic abnormalities have been reported in MG patients, as well as many non-MG-specific autoantibodies. A general dysfunction of the immune system might explain the increased co-occurrence of different autoimmune diseases and the simultaneous presence of distinct autoantibodies in MG patients. These autoantibodies do not necessarily exert pathological effects in MG patients, but their exact role remains poorly understood. This review underscores that in autoimmune patients antibodies against a whole array of antigens are present, rather than against a single pathophysiological target.

In Chapter 2, the effector functions of anti-AChR and anti-MuSK antibodies in MG patients are explained in more detail. In AChR-MG patients, pro-inflammatory antibodies of the IgG1 and IgG3 subclass modulate the AChR, cause complement activation and decrease the levels of $A C h R$ and $A C h R$-associated proteins and reduce postsynaptic folding at the NMJ. In patients with anti-MuSK antibodies, there is a less pronounced loss of AChR density and no evidence for a loss of junctional folds. Anti-MuSK antibodies are predominantly of the IgG4 subclass, which functionally differs from other IgG subclasses in its anti-inflammatory activity. Moreover, IgG4 undergoes a post-translational modification termed Fab arm exchange that prevents cross-linking of antigens. These findings suggest that MuSK-MG probably differs in its etiological and pathological mechanisms from AChR-MG. Understanding the effector functions of autoantibodies on NMJ structure and function might lead to the development of antigen-specific therapies.

Chapter 3 describes an improved B cell immortalization method to produce human monoclonal antibodies. Compared to other antibody-production techniques, the major advantage of $B$ cell immortalization is the generation of fully human antibodies from the human $B$ cell repertoire that truly reflect both the specificity and diversity of the human 
immune response, without the need for specific immunization. Since the existing B cell immortalization methods resulted in low reproducibility in our hands, we aimed at developing a novel B cell immortalization procedure with high efficiency and reproducibility when seeding low $B$ cell numbers per well, and that could be easily adopted for the production of antibodies from patients with autoimmune diseases. We developed a reproducible $B$ cell immortalization method with an efficiency of up to $83 \%$ for fast IgG production from $\mathrm{CD} 22^{+} \mathrm{IgG}{ }^{+}$peripheral blood B cells, by simultaneous $\mathrm{B}$ cell stimulation using CpG2006 and B cell infection by EBV followed by an additional stimulus of CpG2006 and II-2. In addition, the clonality analysis showed monoclonality in almost $90 \%$ of the immortalized B cell lines, eliminating the need for further subcloning. We concluded that this B cell immortalization method can be applied to characterize the antibodies from patients with an autoimmune disease.

In Chapter 4, we used our B cell immortalization method to immortalize thymic B cells from AChR-MG patients. Autoreactive B cells have been found in the human thymus, but their contribution to autoimmune diseases is unknown. To study the $B$ cell repertoire in the autoimmune thymus, we focused on AChR-MG, because thymic B cells have been implicated in its pathophysiology. We successfully immortalized thymic B cells with reactivity against striated muscle proteins. In addition, we isolated a full-size monoclonal antibody (P90-131) directed against the gamma subunit of the fetal AChR. P90-131 is the first anti-gamma AChR antibody to be described to exert pathogenic effects when gamma-subunit containing AChRs are present by inducing AChR internalization in vitro. The fact that the fetal AChR has been described as a specific marker of human rhabdomyosarcoma (RMS) indicates that P90-131 could potentially be used as a cytotoxic treatment for these RMS patients. Most importantly, the isolation of representative striational and anti-AChR antibodies from the thymus of AChR-MG patients led to the conclusion that our EBV immortalization technique is suitable to study the $B$ cell repertoire in the autoimmune thymus.

Chapter 5 describes an in-depth characterization of the antibody repertoire produced by thymic B cells. Although thymic B cells play an important role in the pathology of $A C h R-M G$, the antibody repertoire produced by thymic $B$ cells of $A C h R-M G$ patients has never been directly compared to that of healthy individuals. We used the $B$ cell immortalization method to investigate our hypothesis that the thymic B cell and antibody repertoire of AChR-MG patients displays important intrinsic differences compared to that of controls. The results showed more and phenotypically different $B$ cells in the thymus of AChR-MG patients. In addition, more B cells of the AChR-MG thymus displayed reactivity against striated muscle proteins compared to those of the 
control thymus. Despite these differences, sequence analysis of the $\operatorname{lgV}_{\mathrm{H}}$ gene showed remarkable similarities, concerning $\mathrm{VH}$ family gene distribution, mutation frequency and CDR3 composition, between thymic B cells of controls and AChR-MG patients. However, we found more clonally expanded B cells clones in the thymus of AChR-MG patients and noticed that specific anti-AChR antibodies displayed significantly higher mutation frequencies compared to non anti-AChR $\operatorname{lgG}{ }^{+}$antibodies.

Chapter 6 focuses on the autoantigen in idiopathic MG (iMG) patients. In approximately 5\% of MG patients, no antibodies against AChR, MuSK or Lrp4 are detected and the autoantigen remains unknown. Besides AChR, MuSK and Lrp4, ErbB proteins are also located at the postsynaptic membrane of the $\mathrm{NMJ}$ and they influence the AChR density. When antibodies target ErbB proteins, the AChR density might be disturbed, which could potentially lead to myasthenic symptoms. We investigated whether iMG patients have antibodies against ErbB proteins. We found indications for an altered ErbB expression in the thymus of iMG patients compared to non-MG patients, which could act as a risk factor in breaking tolerance to this protein. However, the antibody tests for ErbB in the sera of iMG patients were all negative. The results do not support a role for ErbB receptors as autoantigens in iMG patients.

In Chapter 7, we investigated the potential of a new therapeutic approach to treat MG patients. As in many B cell mediated autoimmune diseases, also in MG the long-lived plasma cells are responsible for the production of the pathogenic autoantibodies. However, long-lived plasma cells are resistant to most therapies, including immunosuppressive drugs and anti-CD20 antibodies that are aimed to inhibit the activation and proliferation of all or certain lymphocytes. Thus, the resistance of MG patients to available therapies might be due to the persistent long-lived plasma cells that continue to produce autoantibodies notwithstanding immunosuppressive treatment. Since the drug bortezomib has been reported to deplete long-lived plasma cells and autoantibody titers in mice suffering from lupus-like disease, we tested whether bortezomib is effective for alleviating the symptoms in the experimental autoimmune rat model for myasthenia gravis (EAMG). We found that bortezomib induced apoptosis in bone marrow cells and reduced the amount of plasma cells in the bone marrow by up to $80 \%$. In the EAMG animals, bortezomib efficiently reduced the rise of anti-AChR antibody titers, prevented ultrastructural damage of the postsynaptic membrane, improved neuromuscular transmission, and decreased myasthenic symptoms. This study thus emphasizes the potential therapeutic use of bortezomib to target plasma cells in MG and other antibody-mediated autoimmune diseases. 
The fact that B cells play a pathological role in MG is nowadays widely accepted. They produce anti-AChR or anti-MuSK antibodies, which in turn cause damage at the NMJ, leading to a disturbed neuromuscular transmission and muscle weakness. Moreover, therapies specifically targeting B cells led to clinical improvement in MG patients. However, much more research is needed to fully understand the pathological mechanisms in MG. In this thesis, we further investigated the role of thymic B cells and their autoantibodies in the pathology of MG by using B cell immortalizations. We have shown that our improved $B$ cell immortalization is a valuable technique to characterize the $B$ cell repertoire in the thymus of AChR-MG patients. Similar immortalization experiments can also be applied on different B cell subsets or on B cells isolated from different lymphoid tissues to analyze their relative contributions to the MG pathology. Since the thymus plays an important role in the induction and maintenance of immune tolerance, further characterization of the role of thymic B cells will enhance our knowledge on general pathological mechanisms involved in autoimmune diseases. Our B cell immortalization method also led to the development of full-size human monoclonal antibodies. The generation of such antibodies offers good opportunities to study their role in autoimmune diseases. In addition, full-size human monoclonal antibodies have the potential to be further analyzed and modified to be used as internal standards in diagnostic assays or for the design of therapeutic competitor antibodies. Interestingly, our $B$ cell immortalization method can also be applied on MuSK-MG, since the generation of anti-MuSK antibodies from MuSK-MG patients is essential to analyze the pathological effects of anti-MuSK antibodies on target tissue. Human anti-MuSK antibodies can also be used to create better animal models for MuSK-MG. Moreover, the immortalization of B cells from iMG patients can lead to the identification of novel disease relevant autoantigens, which has direct relevance for the diagnosis of the disease. Indeed, this B cell immortalization method has also led to the identification of auto-antigens in MS patients in the research group of Prof. Somers and Prof. Stinissen (J. Fraussen, Hasselt University, Diepenbeek, Belgium). Thus, our results indicate that better insights in the pathogenic role of B cells in MG can be obtained by using our B cell immortalization method. This technique is also applicable to other antibody-mediated autoimmune diseases and will ultimately lead to improved therapies for autoimmune patients.

In this thesis, we also searched for better therapies for MG by targeting long-lived plasma cells. The fact that bortezomib improved the clinical outcome of EAMG animals emphasizes the therapeutic value of proteasome inhibitors to target plasma cells in antibody-mediated autoimmune diseases. Bortezomib can induce a faster remission in antibody titer and, therefore, might be useful to complement classical 
immunosuppressive drugs for the treatment of MG. However, more research is needed to diminish the occurrence of peripheral neuropathy, which is the main side-effect seen in patients treated with bortezomib. The investigation of other proteasome inhibitors which do not induce these side effects could also make the treatment with proteasome inhibitors safer.

Much research, including that described in this thesis, has thus focused on B cells as producers of pathogenic autoantibodies in order to be able to explain the pathology of MG. However, B cells may also contribute to MG by exerting additional functions, such as antigen presentation, $\mathrm{T}$ cell activation, regulation of antigen expression in the thymus, cytokine production or the negative regulation of immune responses. Different subsets of $B$ cells may exert different effector functions and probably many B cell subsets and functions still need to be discovered. Therefore, future studies should also focus on other effector functions to complete our B cell picture and to determine whether all B cell subsets equally contribute to the MG pathology. Only when the roles of B cells as mediators of autoimmune diseases are fully understood, more precise and antigenspecific therapies targeting pathogenic B cell subsets can be developed, sparing nondisease related $\mathrm{B}$ cells.

MG itself only occurs rarely, but it is one of the best understood autoimmune diseases, mainly because the major autoantigens are well characterized, and it serves as a prototypic B-cell mediated autoimmune disease. Studying the pathological mechanisms of $B$ cells in MG has consequently contributed to a better understanding of autoimmunity in general. However, since B cells do not act alone but strongly interact with other immune cells, one can not draw conclusions about autoimmune pathologies only based on data obtained from B cells. It is important to realize that probably all aspects of the immune system play a certain role. In addition, not only immunological, but also genetic, hormonal and environmental components are certainly involved in autoimmunity. This emphasizes that knowledge obtained from different disciplines should be combined to completely understand autoimmunity and autoimmune diseases.

In general, it is accepted that autoimmune diseases are caused by a failure of the mechanisms that maintain immune self-tolerance. These mechanisms normally prevent autoimmunity by maintaining a proper discrimination of self from non-self antigens. Central tolerance mechanisms, mainly occurring in the bone marrow and the thymus, are responsible for the elimination of self-reactive immature lymphocytes. Mechanisms of peripheral tolerance, being assisted by the innate immune system, complement these central tolerance mechanisms for antigens that are not expressed centrally to the 
developing lymphocytes. In addition, lymphocytes can distinguish self from non-self antigens by a high and constant antigen concentration that provides signals to make lymphocytes tolerant. When autoreactive lymphocytes do escape some of the mechanisms that should have tolerized them, autoimmunity arises. Low levels of autoimmunity are needed for the normal physiology of the immune system, but when too many checkpoints are overcome, it will lead to autoimmune disease. Although the principle of self-tolerance in autoimmunity is well understood, the factors which cause a failure in self-tolerance mechanisms and thereby induce autoimmune diseases remain unknown. Probably, autoimmune diseases are not triggered by a hit and run event, but they may arise when cumulative events cross a crucial level or reach a breakthrough point. In this way, a 'multiple-hit hypothesis' model might be useful to study autoimmune diseases. Here, we applied the 'multiple-hit hypothesis' model to what is known for MG (Figure 1).

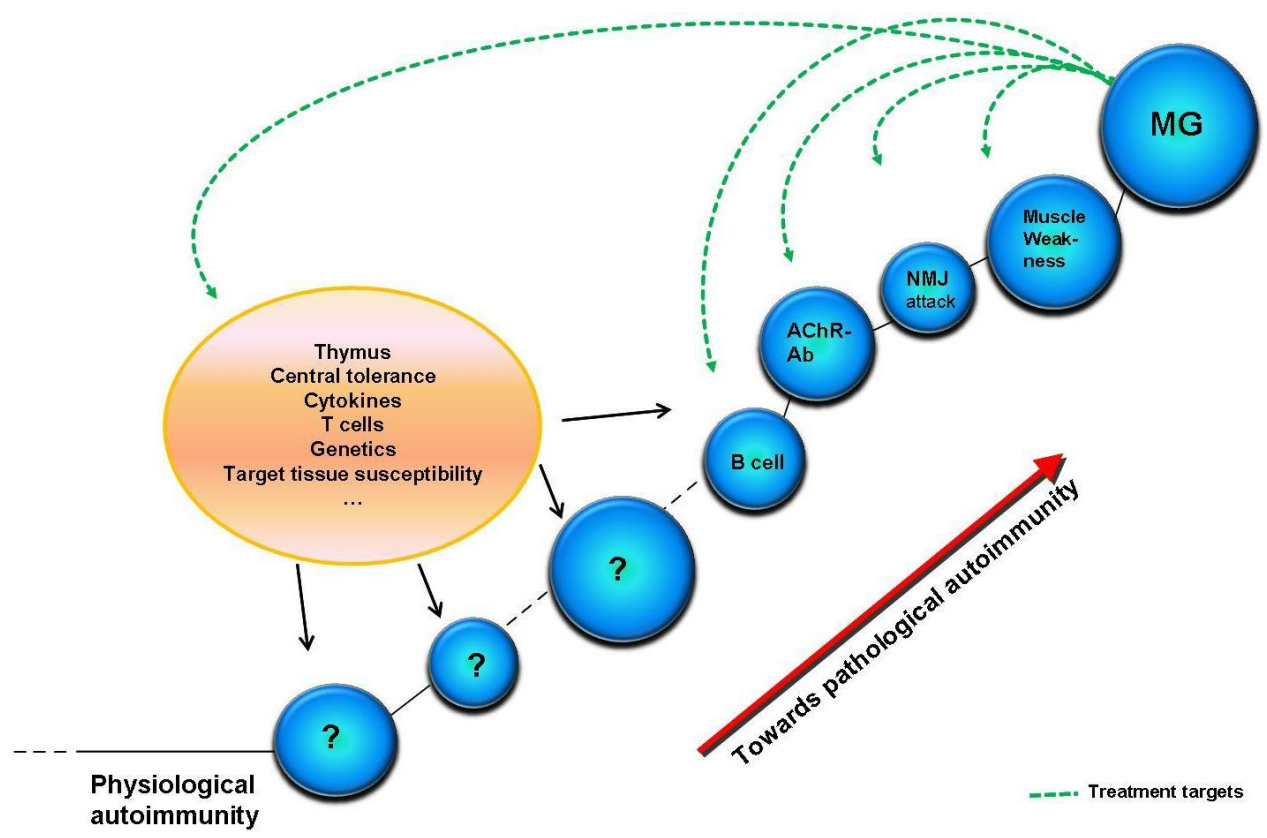

Figure 1. Multiple hit hypothesis for MG. 
Since all studies performed on MG patients are unavoidably performed after the onset of their disease, it is very hard to discriminate between causes and consequences of the autoimmune response. It is assumed that ultimately B cells produce pathogenic antibodies which attack the NMJ and induce muscle weakness. Several other factors have also been associated with MG pathology, including cytokine dysregulation, thymic abnormalities, T cell functioning, skeletal muscle vulnerability, promiscuous antigen expression in the thymus, genetic make-up and many more, but their exact position on the 'multiple-hit hypothesis chain' is not clear yet. It is also still unknown whether some factors actually contribute less to the MG pathology, or whether they are simply less well studied. In addition, it is not understood whether some factors contribute to the induction of MG in particular or whether they contribute to autoimmune pathology in general. Even though the final factors on the 'multiple-hit hypothesis chain' of MG are relatively well clarified, much more research is needed to identify the importance and location of every link in the chain.

Using this 'multiple-hit hypothesis' model to study autoimmune diseases in general, many questions can still be asked. Will we find a point where the chain of physiological autoimmunity passes into the chain of pathological autoimmunity and might it be possible to prevent this? Will there be one factor that can be seen as the triggering event for all autoimmune diseases or is it a matter of assembling sufficient randomly occurring autoimmune hits? How many checkpoints can be broken down before autoimmune diseases occur? Do the chains of different autoimmune diseases diverge from an original trigger onwards or do they diverge at a later stage, depending on which other autoimmune hits have occurred? Is there a gray zone in which autoimmune hits accumulate but not necessarily lead to the passage towards autoimmune disease? What is the contribution of target organs in particular to autoimmune susceptibility? Might there even be a factor of chance involved?

The key to answering these questions may lie within reach, but more basic research is definitely needed since it might lead us to a 'cure' for autoimmune diseases. Many fundamental mechanisms may link the pathology of different autoimmune diseases and exploration of these common features will benefit all of the autoimmune diseases. Only when these questions are answered, we will finally be able to turn the chronic autoimmune disease into a condition where patients can get full recovery without the life-long need of treatment. In the meanwhile, we must make do with what we have and try to make myasthenia no longer gravis... 


\section{Samenvatting en}

algemene discussie 
Het onderzoek dat in dit proefschrift beschreven wordt, richt zich op B-cellen en hun auto-antilichamen bij myasthenia gravis (MG) patiënten om zo hun precieze rol in het ziekteproces beter te begrijpen. Eerst hebben we een verbeterde B-cel immortalisatie methode ontwikkeld om op efficiënte wijze humane monoclonale antilichamen te produceren. Daarna hebben we deze methode gebruikt om het antilichaam repertoire dat geproduceerd wordt door B-cellen uit de thymus van MG patiënten uitgebreid te bestuderen. Vervolgens hebben we gezocht naar nieuwe pathogene auto-antilichamen bij idiopathische MG (iMG) patiënten. Tenslotte hebben we de mogelijkheid onderzocht om experimentele autoimmune MG (EAMG) te behandelen met een nieuw geneesmiddel dat plasmacellen doodt.

Hoofdstuk 1 geeft een samenvatting van alle auto-antilichamen die tot nu toe bij MG patiënten werden gevonden. Anti-AChR en anti-MuSK antilichamen worden beschouwd als de belangrijkste antilichamen in respectievelijk AChR-MG en MuSK-MG patiënten. Beide auto-antilichamen verstoren de neuromusculaire transmissie en veroorzaken daarmee spierzwakte in de skeletspieren. Naast deze auto-antilichamen kunnen ook auto-antilichamen gericht tegen andere extracellulaire epitopen aanwezig zijn in MG patiënten. Zo komen onder andere auto-antilichamen die geassocieerd zijn met afwijkingen aan de thymus vaak voor alsook auto-antilichamen die niet specifiek zijn voor MG. Een gegeneraliseerde afwijking aan het immuunsysteem zou kunnen verklaren waarom veel verschillende auto-antilichamen gelijktijdig aanwezig zijn bij MG patiënten of waarom meerdere auto-immuunziektes vaak samen optreden. Deze auto-antilichamen oefenen niet noodzakelijk een direct pathogeen effect uit, maar hun precieze rol in MG moet nog verder worden onderzocht. Deze literatuurstudie benadrukt dat autoantilichamen in patiënten met een auto-immune aandoening vaak niet gericht zijn tegen slechts één antigen, maar tegen een brede waaier aan antigenen.

Hoofdstuk 2 geeft een overzicht van de effectorfuncties van anti-AChR en anti-MuSK antilichamen. Bij AChR-MG patiënten zijn hoofdzakelijk pro-inflammatoire antilichamen van de IgG1 en IgG3 subklasse aanwezig. Deze antilichamen moduleren de AChR, veroorzaken complement activatie, verlagen de hoeveelheid $\mathrm{AChR}$ en daarmee geassocieerde eiwitten en verminderen het aantal postsynaptische plooien in de NMJ. Bij MuSK-MG patiënten is de vermindering in densiteit van de AChR en in het aantal postsynaptische plooien minder uitgesproken. Anti-MuSK antilichamen behoren voornamelijk tot de IgG4 subklasse, die omwille van zijn anti-inflammatoire activiteit functioneel verschilt van andere IgG subklasses. Bovendien ondergaan IgG4 antilichamen een posttranslationele verandering, Fab arm uitwisseling genaamd, waardoor geen crosslinking van antigenen kan optreden. Deze veranderingen wijzen erop dat MuSK-MG 
waarschijnlijk verschilt van AChR-MG wat betreft etiologische en pathologische mechanismen. Het is belangrijk dat de effectorfuncties van auto-antilichamen op de structuur en functie van de NMJ nog beter worden begrepen om zo antigen-specifieke therapieën te kunnen ontwikkelen.

Hoofdstuk 3 beschrijft hoe we een verbeterde B-cel immortalisatie methode ontwikkeld hebben om humane monoclonale antilichamen te produceren. In vergelijking met andere technieken waarmee antilichamen geproduceerd worden heeft B-cel immortalisatie als belangrijkste voordeel dat volledig humane antilichamen gekloneerd worden waarvan de specificiteit en diversiteit ook representatief zijn voor het humane antilichaamrepertoire, zonder dat hiervoor specifieke immunisatie nodig is. Aangezien de bestaande $\mathrm{B}$-cel immortalisatie technieken bij ons resulteerden in een lage reproduceerbaarheid, was er behoefte aan een nieuwe methode met hoge efficiëntie en reproduceerbaarheid om lage B-cel aantallen te immortaliseren. Deze methode zou dan gemakkelijk aangepast kunnen worden om antilichamen te produceren van patiënten met een auto-immuunziekte. We hebben een verbeterde procedure ontwikkeld om snel IgG antilichamen aan te maken uit $\mathrm{CD} 22^{+} \operatorname{IgG}{ }^{+}$B-cellen van het perifere bloed. Deze procedure bereikte een immortalisatie efficiëntie van $83 \%$. Hierbij werden B-cellen gedurende 2 weken gelijktijdig gestimuleerd met CpG2006 en geïnfecteerd met EBV, gevolgd door een nieuwe stimulatie met CpG2006 en IL-2 gedurende een week. Bovendien werd met deze methode een percentage monoklonale B-cellijnen van bijna $90 \%$ behaald, waardoor subkloneren niet langer noodzakelijk is. Bijgevolg kan deze B-cel immortalisatiemethode toegepast worden om antilichamen van patiënten te karakteriseren.

In hoofdstuk 4 hebben we de verbeterde B-cel immortalisatie methode toegepast op B cellen uit de thymus van MG patiënten. Autoreactive B-cellen werden reeds aangetoond in de humane thymus, maar hun bijdrage tot auto-immuunziektes is niet duidelijk. Om het B-cel repertoire in de auto-immune thymus te bestuderen, hebben we ons gericht op AChR-MG. In de thymus van MG patiënten is het aantal B-cellen fors toegenomen. We immortaliseerden thymus B-cellen, waarna hiervan ongeveer $25 \%$ antilichamen produceerden tegen eiwitten van gestreept spierweefsel (striationele eiwitten). Ook isoleerden we een monoklonaal antilichaam (P90-131) dat specifiek gericht is tegen het gamma-subunit van de foetale AChR. P90-131 is tevens het eerste antigamma AChR antilichaam dat ook pathogene effecten kan uitoefenen wanneer AChRs met gamma-subunits aanwezig zijn door in vitro de internalisatie van $A C h R$ te induceren. De foetale AChR is beschreven als een specifieke merker voor de kwaadaardige humane aandoening rhabdomyosarcoma (RMS), wat erop wijst dat P90-131 gebruikt zou kunnen 
worden als cytotoxische behandeling bij RMS patiënten. De isolatie van representatieve antilichamen, gericht tegen dwarsgestreepte spieren en tegen de $A C h R$, uit de thymus van AChR-MG patiënten geeft aan dat deze B cel immortalisatietechniek geschikt is om het B-cel- en antilichaamrepertoire van de auto-immune thymus in detail te bestuderen.

In hoofdstuk 5 wordt het antilichaamrepertoire dat door B-cellen uit de thymus geproduceerd wordt in detail bestudeerd. B-cellen uit de thymus spelen een belangrijke rol in het ziekteproces van AChR-MG. Het antilichaamrepertoire van deze B-cellen is echter nooit rechtstreeks vergeleken met het repertoire van B-cellen uit gezond thymusweefsel. We hebben de B-cel immortalisatiemethode gebruikt om te testen of het B-cel- en antilichaamrepertoire van de thymus van AChR-MG patiënten belangrijke verschillen vertoont ten opzichte van dat van gezonde personen. De resultaten toonden een hoger percentage en fenotypisch verschillende B-cellen in de thymus van AChR-MG patiënten. Ook produceerden een hoger aantal B-cellen uit de AChR-MG thymus antistoffen tegen dwarsgestreept spierweefsel in vergelijking met B-cellen uit de controle thymus. Ondanks deze verschillen werden er geen verschillen gevonden in gensequenties van de zware keten van het variabele deel van immunoglobulines $\left(\mathrm{IgV}_{\mathrm{H}}\right)$ tussen thymus $\mathrm{B}$ cellen van controle personen en AChR-MG patiënten. Hierbij werd onder andere gekeken naar de verdeling van $\lg _{\mathrm{H}}$ genfamilies, mutatiefrequentie en samenstelling van de CDR3. Wel vonden we een hoger aantal klonaal geëxpandeerde B-cellen in de thymus van AChRMG patiënten en zagen we dat anti-AChR antilichamen hogere mutatiefrequenties vertoonden in vergelijking met IgG antilichamen die niet tegen de AChR gericht waren. Deze resultaten tonen aan dat het B-cel- en antilichaamrepertoire uit de thymus verschilt tussen gezonde personen en AChR-MG patiënten, maar deze verschillen worden niet veroorzaakt door intrinsieke verschillen in de Ig gensequenties.

In hoofdstuk 6 wordt gezocht naar nieuwe auto-antigenen bij idiopatische MG patiënten (iMG). Bij ongeveer 5\% van de MG patiënten worden geen antilichamen tegen AChR, MuSK of Lrp4 gedetecteerd en blijft het auto-antigen onbekend. Naast AChR, MuSK en Lrp4 bevinden zich ook ErbB eiwitten op de postsynaptische membraan van de NMJ die de dichtheid van AChRs beïnvloeden. Wanneer antilichamen aan ErbB eiwitten zouden binden, zou dit de dichtheid van AChR moleculen kunnen verstoren en zo kunnen leiden tot stoornissen in de NMJ. In deze studie hebben we onderzocht of antilichamen tegen ErbB eiwitten aanwezig zijn bij iMG patiënten. Een veranderde expressie van ErbB werd waargenomen in de thymus van iMG patiënten ten opzichte van niet-MG patiënten. Deze veranderde expressie zou kunnen leiden tot een verstoorde immuuntolerantie tegen dit eiwit. Desondanks konden we geen ErbB antilichamen in iMG patiënten 
aantonen. Deze resultaten wijzen dus niet op een rol voor ErbB receptoren als autoantigen bij iMG patiënten.

In hoofdstuk $\mathbf{7}$ hebben we onderzoek verricht naar een nieuwe behandelingsstrategie voor MG. Zoals bij veel B-cel gemedieerde auto-immuunziektes zijn ook bij MG de lang-levende plasmacellen verantwoordelijk voor de belangrijkste productie van pathogene auto-antilichamen. Helaas zijn lang-levende plasmacellen resistent tegen veel therapieën, inclusief immuunsuppressiva en anti-CD20 antilichamen. De resistentie van sommige MG patiënten tegen bestaande therapieën kan dus te wijten zijn aan het feit dat lang-levende plasma cellen auto-antilichamen blijven produceren ondanks de immuunsuppressieve behandelingen. Recent is aangetoond dat de proteasoominhibitor bortezomib het aantal lang-levende plasmacellen evenals de antilichaam titers significant doet afnemen bij muizen die lijden aan lupus. Daarom hebben wij nu getest of bortezomib ook de klinische symptomen kan verbeteren bij het experimentele autoimmune ratten model voor MG (i.e. EAMG). De resultaten toonden dat behandeling met bortezomib apoptose induceerde in beenmergcellen en het aantal plasmacellen in het beenmerg deed afnemen met $80 \%$. Ook inhibeerde bortezomib in de EAMG ratten de anti-AChR antilichaam productie en zorgde het voor een preventie van ultrastructurele schade aan het postsynaptische membraan, een verbeterde neuromusculaire transmissie en voor afname van de klinische symptomen. Deze studie toont aan dat bortezomib de mogelijkheid biedt om plasmacellen te doden in MG en in andere antilichaam-gemedieerde auto-immuunziektes.

Het feit dat B cellen een pathologische rol spelen in MG wordt in de literatuur algemeen aanvaard. Ze produceren namelijk anti-AChR en anti-MuSK antilichamen die schade veroorzaken aan de NMJ, wat leidt tot een verstoorde neuromusculaire transmissie en spierzwakte. Bovendien leiden therapieën die gericht zijn tegen B cellen tot een klinische verbetering in MG patiënten. Toch is nog veel onderzoek nodig om de pathologische mechanismen in MG volledig te doorgronden. In deze thesis hebben we de rol van thymus B-cellen en hun auto-antilichamen in het ziekteproces van MG nader onderzocht door gebruik te maken van B-cel immortalisaties. We hebben aangetoond dat onze verbeterde B-cel immortalisatie zeer geschikt is om het B-cel repertoire uit de thymus van MG patiënten te karakteriseren. Gelijkaardige immortalisaties kunnen ook toegepast worden op verschillende soorten B-cellen of op B-cellen uit verschillende lymphoïde weefsels, om zo hun bijdrage aan de pathologie van MG te analyseren. Omdat de thymus een belangrijke rol speelt bij het induceren en onderhouden van immuuntolerantie zal een verdere karakterisatie van B-cellen uit de thymus leiden tot 
betere kennis over de algemene pathologische mechanismen die betrokken zijn bij autoimmuunziektes. Onze B-cel immortalisatiemethode heeft ook geleid tot de ontwikkeling van volledig humane monoklonale antilichamen. Het aanmaken van zulke antilichamen biedt goede mogelijkheden om hun rol in auto-immuunziektes beter te bestuderen. Bovendien kunnen volledig humaan monoklonale antilichamen verder geanalyseerd worden of aangepast worden voor gebruik als interne standaard bij diagnostische tests of voor het ontwerpen van therapeutische competitor antilichamen. Ook kan de B-cel immortalisatie methode toegepast worden bij MuSK-MG, aangezien de aanmaak van antiMuSK antilichamen van MuSK-MG patiënten essentieel is om de pathologische effecten van anti-MuSK antilichamen op het spierweefsel te kunnen bestuderen. Humane antiMuSK antilichamen kunnen eveneens gebruikt worden om betere diermodellen voor MuSK-MG te maken. Verder kan het immortaliseren van B cellen van iMG patiënten leiden tot de identificatie van nieuwe ziekte-gerelateerde auto-antigenen, wat relevant zou zijn voor de diagnose van de ziekte. Deze B-cel immortalisatiemethode heeft inderdaad al geleid tot de identificatie van auto-antigenen bij multiple sclerose (MS) patiënten in de onderzoeksgroep van Prof. Somers en Prof. Stinissen (J. Fraussen, Universiteit Hasselt, Diepenbeek, België). Daarmee tonen we dus aan dat betere inzichten kunnen verkregen worden in de pathogene rol van B-cellen bij MG door gebruik te maken van onze B-cel immortalisatie methode. Deze techniek is bovendien ook toepasbaar op andere antilichaam-gemedieerde auto-immuunziektes en zal uiteindelijk leiden tot betere therapieën voor auto-immuun patiënten.

In deze thesis hebben we ook onderzoek verricht naar betere therapieën voor MG met lang-levende plasmacellen als doelwit. Bortezomib verbeterde de klinische symptomen bij EAMG dieren, wat suggereert dat proteasoominhibitoren gericht tegen plasmacellen een nieuwe therapie kunnen vormen voor antilichaam-gemedieerde autoimmuunziektes. Bortezomib kan een snelle remissie in auto-antilichaam titer induceren en kan daarom gebruikt worden als aanvulling bij klassieke immuunsuppressive geneesmiddelen om MG te behandelen. Toch is nog meer onderzoek nodig om het voorkomen van perifere neuropathie, de belangrijkste nevenwerking van bortezomib, te verminderen. Onderzoek naar andere proteasoominhibitoren die deze nevenwerkingen niet veroorzaken zal er ook toe kunnen bijdragen dat de behandeling met proteasoominhibitoren veiliger wordt.

Veel onderzoek, inclusief datgeen beschreven in dit proefschrift, richt zich op Bcellen als zijnde producenten van pathogene auto-antilichamen om zo de pathologie van MG beter te kunnen verklaren. Toch kunnen B-cellen ook op een andere manier bijdragen 
aan MG pathologie, via antigeenpresentatie, $T$ cel activatie, regulatie van antigeenexpressie in de thymus, productie van cytokines of negatieve regulatie van immuunresponsen. Deze verschillende effectorfuncties worden waarschijnlijk uitgeoefend door verschillende subsets van B-cellen en ongetwijfeld zullen nog veel B-cel subsets en hun bijbehorende functies ontdekt worden. Daarom is het belangrijk dat verder onderzoek zich ook richt op andere effectorfuncties van B-cellen om zo het beeld van B-cellen te vervolledigen en om te kunnen bepalen of alle B-cel subsets elk een deel hebben aan de MG pathologie. Slechts wanneer alle functies van B-cellen als mediatoren van auto-immuunziektes volledig begrepen zijn, kunnen precieze en antigen-specifieke behandelingen ontwikkeld worden die zich enkel richten tegen pathogene subsets van Bcellen.

Ondanks dat MG weinig voorkomt, is het toch een van de best begrepen autoimmuunziektes, voornamelijk omdat de belangrijkste auto-antigenen goed gekarakteriseerd zijn. Daarom is MG een prototype ziekte voor B-cel gemedieerde autoimmuunziektes en levert het bestuderen van de pathologische mechanismen van B-cellen in MG zeker bij tot betere kennis van auto-immuniteit in het algemeen. Toch moet beklemtoond worden dat B-cellen niet alléén handelen maar altijd interacties ondergaan met andere immuuncellen. Hierdoor kunnen geen conclusies getrokken worden omtrent autoimmune pathologieën wanneer resultaten verkregen zijn van B-cel onderzoek alléén. Hoogstwaarschijnlijk spelen alle aspecten van het immuunsysteem een bepaalde rol. Daarnaast spelen ook genetische, hormonale en omgevingsfactoren een rol bij autoimmuniteit. Dit benadrukt dat kennis van verschillende disciplines gecombineerd moet worden om een volledig beeld te kunnen vormen over autoimmuniteit en autoimmuunziektes.

In het algemeen wordt aangenomen dat auto-immuunziektes veroorzaakt worden door falende mechanismen die immuun zelftolerantie zouden moeten onderhouden. Normaal voorkómen deze mechanismen autoimmuniteit door een correct onderscheid tussen zelf en niet-zelf in stand te houden. Centrale tolerantie mechanismen, die vooral in het beenmerg en de thymus plaatsvinden, zorgen voor de eliminatie van zelf-reactive immature lymphocyten. Perifere tolerantie mechanismen, in samenspraak met het aangeboren immuunsysteem, vervolledigen de centrale tolerantie mechanismen voor antigenen die centraal niet zijn blootgesteld aan ontwikkelende lymphocyten. Bovendien kunnen lymphocyten een onderscheid maken tussen zelf en niet-zelf door een hoge en constante antigenconcentratie die de lymphocyten tolerant maakt. Wanneer autoreactieve lymphocyten toch ontsnappen aan de mechanismen die hen tolerant zouden gemaakt moeten hebben, ontstaat autoimmuniteit. Lage hoeveelheden aan 
autoimmuniteit zijn wel noodzakelijk voor het normaal functioneren van het immuunsysteem, maar wanneer teveel controlepunten overgeslagen worden kan dit leiden tot auto-immuunziektes. Ondanks dat het principe van zelf-tolerantie bij autoimmuniteit duidelijk is, zijn de factoren die de tolerantiemechanismen verstoren en zo ziekte induceren niet gekend. Vermoedelijk ontstaan auto-immuunziektes niet door een 'hit and run' principe, maar door de opeenvolging van meerdere gebeurtenissen die een bepaald niveau of breekpunt overschrijden. Daarom kan een 'multiple-hit hypothese' model nuttig zijn om auto-immuunziektes beter te begrijpen. Hier passen we het multiple-hit hypothese model toe op wat tot nu toe gekend is over MG (Figuur 1).

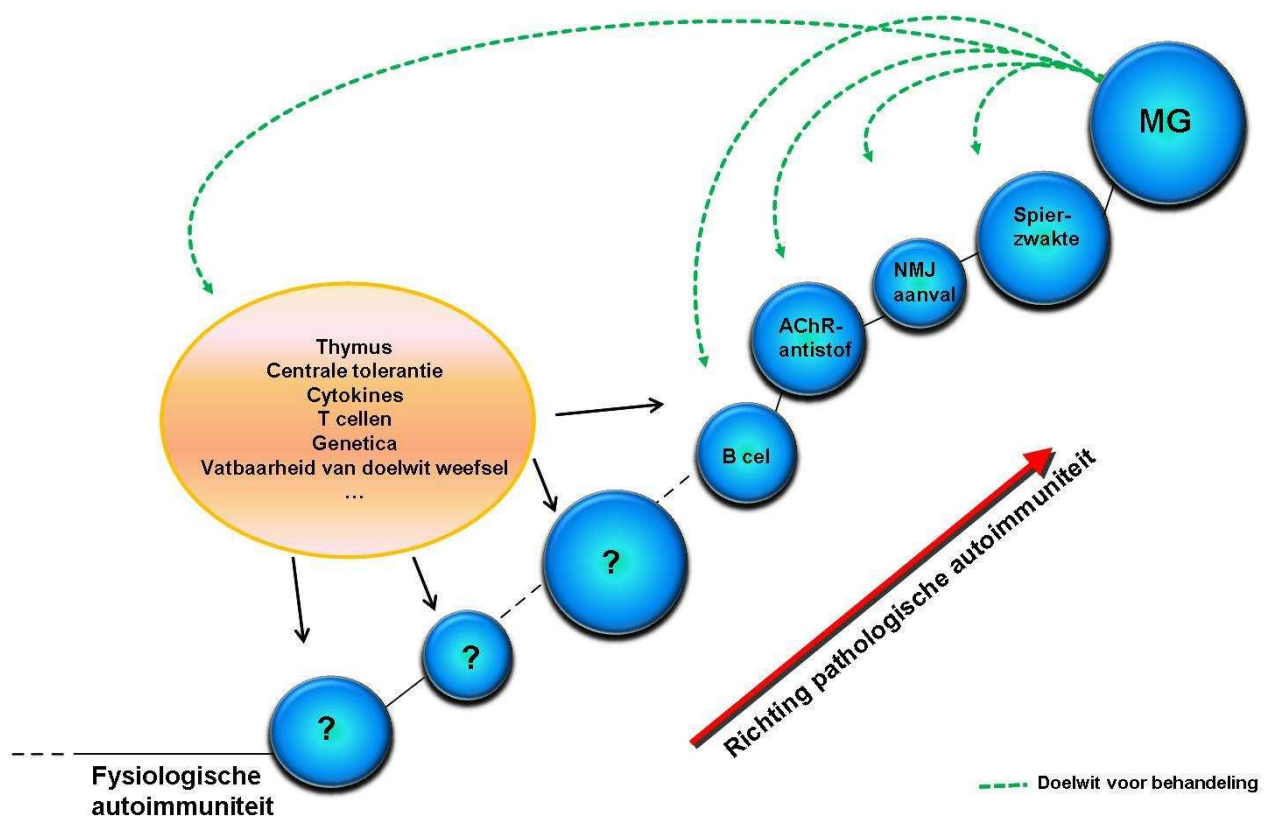

Figuur 1. Multiple hit hypothese toegepast op MG.

Aangezien alle studies met MG patiënten onvermijdelijk pas na de aanvang van het ziekteproces zijn uitgevoerd, is het moeilijk een onderscheid te maken tussen oorzaken en gevolgen van de autoimmune respons. Er wordt aangenomen dat uiteindelijk B-cellen pathogene antilichamen produceren die de NMJ aanvallen en spierzwakte veroorzaken. Vele andere factoren zijn ook in verband gebracht met de pathologie van MG, zoals ontregelde cytokineproductie, afwijkingen aan de thymus, $\mathrm{T}$ cel functies, vatbaarheid van het skeletspierweefsel zelf, antigenexpressie in de thymus en genetische opbouw. Hun 
exacte rol in MG en dus hun locatie op de 'multiple-hit hypothese' keten is echter nog niet duidelijk. Eveneens is niet bekend of bepaalde factoren effectief minder bijdragen tot de MG pathologie of dat ze gewoon minder goed bestudeerd zijn. Bovendien blijft het onduidelijk of sommige factoren specifiek bijdragen tot de inductie van MG of dat ze bijdragen tot de algemene pathologie van auto-immuunziektes. Ook al zijn de finale factoren van de multiple-hit hypothese keten van MG relatief goed gekend, toch is verder onderzoek noodzakelijk om het belang en de locatie van iedere link in de keten te kunnen identificeren.

Het gebruik van dit multiple hit hypothese model om autoimmuunziektes te bestuderen doet ook veel vragen ontstaan. Zullen we een punt vinden waar de keten van fysiologische autoimmuniteit overgaat naar de keten van pathologische autoimmuniteit en zal het mogelijk zijn om die overgang te voorkomen? Zal er één factor gevonden worden die beschouwd kan worden als de trigger voor alle auto-immuunziektes of is het eerder een kwestie van voldoende toevallige auto-immune hits te verzamelen? Hoeveel controlepunten moeten defect zijn voordat werkelijk een auto-immuunziekte optreedt? Divergeren de ketens van verschillende autoimmuunziektes vanaf het beginpunt of vanaf een later stadium, afhankelijk van welke andere autoimmune hits zich hebben opgestapeld? Is er een soort van grijze zone waarin autoimmune hits zich opstapelen maar niet noodzakelijk leiden tot de overgang naar ziekte? Wat is de bijdrage van de doelorganen zelf tot de vatbaarheid voor autoimmuniteit? En in welke mate kan kans een rol spelen?

De sleutel tot de antwoorden op deze vragen ligt misschien binnen handbereik, maar meer basisonderzoek blijft noodzakelijk om tot een betere behandeling van autoimmuunziektes te komen. De pathologieën van verschillende auto-immuunziektes zouden gelinkt kunnen worden door gemeenschappelijke fundamentele mechanismen en onderzoek hiernaar zal voordelig zijn voor alle auto-immuunziektes. Enkel wanneer deze vragen zijn beantwoord, zullen we in staat zijn om de chronische auto-immune aandoening te kunnen omkeren naar een volledig herstel zonder de noodzaak van levenslange behandelingen. Ondertussen moeten we roeien met de riemen die we hebben en ervoor zorgen dat myasthenia niet langer zo gravis is... 


\section{Curriculum vitae}




\section{Curriculum vitae}

Kathleen Vrolix werd geboren op 14 februari 1986 in Bree en groeide op in Overpelt (België). In 2003 voltooide ze haar middelbare opleiding Latijn-wetenschappen aan het 'Mater Dei Instituut' te Overpelt. In datzelfde jaar startte ze haar studie bio-medische wetenschappen aan de Universiteit Hasselt. Haar masterstage liep ze op de afdeling 'Psychiatrie en Neuropsychologie' aan de universiteit van Maastricht (UM) waarbij de acetylcholine receptor en hiermee geassocieerde eiwitten werden bestudeerd in spiercellijnen. In 2007 behaalde ze met grote onderscheiding haar masterdiploma in de afstudeerrichting 'Klinische Moleculaire Levenswetenschappen'. Later dat jaar startte ze als promovenda aan de 'translationale Universiteit Limburg' (tUL), een samenwerkingsproject van de 'School of Mental Health and Neuroscience' (MheNS) aan de UM en het Biomedisch onderzoeksinstituut van de Universiteit Hasselt, onder de supervisie van Prof. Dr. De Baets, Prof. Dr. Somers, Dr. Martínez-Martínez en Dr. Losen. Tijdens dit promotietraject onderzocht ze de rol van B cellen in de auto-immuunziekte myasthenia gravis. De resultaten van haar onderzoek staan beschreven in dit proefschrift.

Kathleen Vrolix was born on February $14^{\text {th }} 1986$ in Bree, and grew up in Overpelt (Belgium). In 2003 she graduated from secondary school at the 'Mater Dei Instituut' in Overpelt. Then she started her bachelor Biomedical Sciences at the University of Hasselt. She performed her master internship at the department of Psychiatry and Neuropsychology at the Maastricht University (UM). During this internship, she studied the acetylcholine receptor and its associated proteins in muscle cell lines. In 2007, she graduated with great honours as a master in Clinical Molecular Life Sciences. In the same year she started her PhD-project at the 'translational University of Limburg' (tUL), which is a collaboration between the School of Mental Health and Neuroscience (MheNS) at the UM and the Biomedical Research Institute at Hasselt University, under the supervision of Prof. Dr. De Baets, Prof. Dr. Somers, Dr. Martínez-Martínez and Dr. Losen. During this project, she investigated the role of $B$ cells in the autoimmune disease myasthenia gravis. The results of her work are described in this thesis. 


\section{Publications}

Fraussen J, Vrolix K, Martínez-Martínez P, De Baets MH, Stinissen P, Somers. B cell characterization and reactivity analysis in Multiple Sclerosis. Autoimmunity reviews; 2009: 8 (8): 654-8.

Vrolix K, Fraussen J, Losen M, Somers V, Stinissen P, De Baets M, Martínez-Martínez. The auto-antigen repertoire in myasthenia gravis. Autoimmunity 2010; 43 (5-6): 380-400.

Gomez A*, Van Den Broeck J*, Vrolix K*, Janssen SP, Lemmens MA, Van Der Esch E, Duimel H, Frederik P, Molenaar PC, Martínez-Martínez P, De Baets MH, Losen M. Antibody effector mechanisms in myasthenia gravis - Pathogenesis at the neuromuscular junction. Autoimmunity 2010; 43 (5-6): 353-370.

Vrolix K*, Niks EH*, Le Panse R*, van Ostaijen-Ten Dam MM, Muris AH, Jol-van der Zijde $\mathrm{CM}$, van Tol MJ, Losen M, Molenaar PC, van Zoelen EJ, Berrih-Aknin S, De Baets $\mathrm{MH}$, Verschuuren JJ, Martínez-Martínez P. Reduced thymic expression of ErbB receptors without auto-antibodies against synaptic ErbB in myasthenia gravis. J. Neuroimmunology 2010; 232 (1-2): 158-65.

Fraussen J, Vrolix K, Martínez-Martínez P, Losen M, Meulemans E, De Baets MH, Stinissen $\mathrm{P}$, Somers $\mathrm{V}$. A novel method for making human monoclonal antibodies. Journal of Autoimmunity, 2010, 35 (2), 130-4.

Gomez AM, Vrolix K, Martínez-Martínez P, Molenaar PC, Phernambucq M, van der Esch E, Duimel H, Verheyen F, Voll RE, Manz RA, De Baets MH, Losen M. Proteasome inhibition with bortezomib depletes plasma cells and autoantibodies in experimental autoimmune myasthenia gravis. J Immunol 2011; 186 (4): 2503-13.

Vrolix K, Fraussen J, Losen M, Van den Broeck J, Lazaridis K, Molenaar PC, Stinissen P, Tzartos S, Somers V, De Baets MH, Martínez-Martínez P. Immortalization of thymic autoreactive B cells and monoclonal antibody production from AChR-antibody positive myasthenia gravis patients. Submitted.

Fraussen J, Vrolix K, Martínez-Martínez P, Losen M, Hupperts R, Van Wijmeersch B, De Baets $\mathrm{MH}$, Stinissen $\mathrm{P}$, Somers V. Clonally expanded B cells in peripheral blood and cerebrospinal fluid of patients with multiple sclerosis and clinically isolated syndrome. Submitted. 
Vrolix K, Fraussen J, Losen M, Molenaar PC, Somers V, Le Panse R, Berrih-Aknin S, Stinissen P, De Baets MH, Martínez-Martínez P. Different B cell and antibody repertoire in thymus of myasthenia gravis patients compared to controls. In preparation.

Fraussen J, Vrolix K, Martínez-Martínez P, Losen M, Hupperts R, Van Wijmeersch B, De Baets $\mathrm{MH}$, Stinissen $\mathrm{P}$, Somers $\mathrm{V}$. Reactivity profile of memory $\mathrm{B}$ cells from peripheral blood and cerebrospinal fluid in multiple sclerosis and clinically isolated syndrome. In preparation.

\section{Book chapter}

Van den Broeck J, Gomez A, Vrolix K, Martínez-Martínez P, Molenaar PC, De Baets MH and Losen M. Effector functions of IgG isotypes in Myasthenia Gravis. In: Premkumar Christadoss, ed. Myasthenia Gravis: disease mechanisms and immune intervention. Linus publishing inc. 2009

\section{Oral presentations}

Vrolix K, Fraussen J, Somers V, Losen M, De Baets M, Martínez-Martínez P. Auto-antigen identification in myasthenia gravis. Myastaid meeting, May 2008, Paris, France.

Vrolix K, Fraussen J, Van den Broeck J, Meulemans E, Somers V, Losen M, De Baets M, Martínez-Martínez P. Characterization of the auto-antibody repertoire in myasthenia gravis by immortalizing thymic B cells. Joint Meeting Belgian Dutch Neuromuscular Study Club and German Reference Center for Neuromuscular Diseases of the DGNN, April 2010, Vaals, The Netherlands.

Vrolix K, Fraussen J, Van Den Broeck J, Meulemans E, Phernambucq M, Somers V, Losen M, De Baets M, Martínez-Martínez P. Monoclonal antibody production by immortalization of $B$ cells from the thymus of myasthenia gravis patients. International Congress on Autoimmunity, May 2010, Ljubljana, Slovenia.

Vrolix K, Fraussen J, Van Den Broeck J, Meulemans E, Phernambucq M, Somers V, Losen M, De Baets M, Martínez-Martínez P. Monoclonal antibody production by immortalization of $B$ cells from the thymus of myasthenia gravis patients. Aachen-Maastricht Neuromuscular Research Meeting, November 2010, Aachen, Germany. 


\section{Poster presentations}

Vrolix K, Martínez-Martínez P, Losen M, Dumont D, Somers V, Phernambucq M, Janssen S, Stinissen $\mathrm{P}$, De Baets $\mathrm{MH}$. Analysis of native AChR-associated proteins in muscle extracts.

- $11^{\text {th }}$ International Conference on Myasthenia Gravis and Related Disorders, 2007, Chicago, USA.

Vrolix K, Fraussen J, Meulemans E, Phernambucq M, Losen M, Somers V, MartínezMartínez $P$, De Baets $M$. Monoclonal antibody production by improved EBV immortalization of thymic B cells from a Myasthenia Gravis patient.

-B cell meeting ESF-EMBO symposium, 2008, St Feliu De Giuxols, Spain.

Vrolix K, Fraussen J, Meulemans E, Phernambucq M, Losen M, Somers V, De Baets M, Martínez-Martínez P. Monoclonal antibody production by immortalization of $B$ cells from the thymus of myasthenia gravis patients.

- $9^{\text {th }}$ International Congress of Neuroimmunology (ISNI), 2008, Texas, USA.

- Jaarcongres NVVI, 2008, Noordwijkerhout, The Netherlands.

$-2^{\text {nd }}$ European Congress of Immunology (ECI), 2009, Berlin, Germany

- International Conference on Myasthenia, 2009, Paris, France

Fraussen J, Vrolix K, Martinez-Martinez P, Hupperts R, Van Diepen A, Medaer R, Van Wijmeersch B, Meulemans E, De Baets MH, Stinissen P, Somers V. Antibody-producing monoclonal B cell lines from multiple sclerosis patients obtained by $B$ cell immortalization.

- Biomedica, 2009, Luik, Belgium

- Federation of Clinical Immunology Societies (FOCIS), 2009, San Fransisco, USA

- European congress on Immunology 2009, Berlin, Germany

Fraussen J, Vrolix K, Martinez-Martinez P, Losen M, Hupperts R, Van Diepen A, Medaer R, Van Wijmeersch B, De Baets $\mathrm{MH}$, Stinissen $\mathrm{P}$ and Somers V. Autoreactive monoclonal antibodies from multiple sclerosis patients obtained by a $\mathrm{B}$ cell immortalization method.

- 7th International Congress on Autoimmunity 2010, Ljubljana, Slovenia 
- European Committee for Treatment and Research in Multiple Sclerosis (ECTRIMS), 2010, Gothenburg, Sweden

Gomez A, Vrolix K, Martinez-Martinez P, Molenaar P, Phernambucq M, Van der Esch E, Duimel H, Verheyen F, Voll RE, Manz RA, De Baets MH, Losen M. Proteasome inhibition with Bortezomib depletes plasma cells and autoantibodies in experimental autoimmune myasthenia gravis.

- International Conference on Myasthenia, 2009, Paris, France

- 7th International Congress on Autoimmunity 2010, Ljubljana, Slovenia

Fraussen J, Vrolix K, Martinez-Martinez P, Losen M, Hupperts R, Van Wijmeersch B, De Baets $\mathrm{MH}$, Stinissen P, Somers V. Peripheral and intrathecal B cells from multiple sclerosis patients are clonally expanded and produce autoreactive antibodies.

- $10^{\text {th }}$ International Congress of Neuroimmunology, 2010, Sitges, Spain

- FWO/WOG symposium, 2010, Diepenbeek, Belgium

\section{Patent}

Martinez-Martinez P, Vrolix K, Molenaar P, De Baets MH, Losen M. Human monoclonal antibody against the gamma subunit of the acetylcholine receptor for use in the treatment of rhabdomyosarcoma (in progress). 
Dankwoord 
Ook al is het grootste deel van dit proefschrift klaar, het moeilijkste blijft toch om nu de juiste woorden te vinden om iedereen te bedanken die, op welke manier dan ook, hieraan heeft meegeholpen.

Allereerst zou ik mijn promoter Prof. Dr. Marc De Baets willen bedanken. Marc, je hebt me 4 jaar geleden de kans gegeven om dit promotietraject te starten. Ondanks je drukke agenda volgde je mijn resultaten op de voet, hield je me up-to-date door steeds de recentste literatuur door te geven en toonde je me het belang van het onderhouden van wetenschappelijke contacten. Bovendien heb ik veel bijgeleerd van je klinische kennis over myasthenie en over onderzoek in het algemeen. Ook tijdens de laatste loodjes kon ik steeds op je hulp en advies rekenen. Hartelijk bedankt!

Daarnaast wil ik uiteraard mijn co-promoteren Dr. Pilar Martinez-Martinez en Dr. Mario Losen van harte bedanken. Piluca, you've always supported me, from the beginning as a major student until now. You have taught me how to work independently and how to improve my criticism towards research data. Whenever I was less motivated, you emphasized the challenges of our project and tried to convince me about the importance of our research and findings. Thanks Piluca, l've learned a lot from you! Mario, op jou kon ik steeds rekenen voor een technische uitleg, gaande van bosque programmeercodes of word- en endnote futiliteiten tot antilichaam eigenschappen en concentratiecurves. Je kritische kijk op resultaten alsook je hulp bij het neerschrijven hiervan hebben me zeker goed geholpen. Thanks a lot to both of you! I wish you all the best in the future!

Daarna wordt het tijd om de collega's uit Diepenbeek te bedanken: Prof. Dr. Veerle Somers, mijn tweede promotor, Prof. Dr. Piet Stinissen en Dr. Judith Fraussen. Beste Piet, ik ben heel blij dat ik aan de hand van het tUL-project met jouw onderzoeksgroep heb kunnen samenwerken en deze samenwerking is dan ook zeker een meerwaarde geweest voor mijn Phd-onderzoek; bedankt! Veerle, je bekeek mijn resultaten altijd met veel enthousiasme en probeerde me er steeds van te overtuigen dat, ook al leken de resultaten in mijn ogen niet altijd veelbelovend, we goed bezig waren. Hartelijk bedankt hiervoor. En dan natuurlijk een dikke merci voor Dr. Fraussen :-)! Judith, wat begon met 'een keertje wat cellen kweken in Diepenbeek' is uitgegroeid tot een heuse leerschool waarbij je me alle kneepjes van het B-celkweek-vak leerde. Dankzij jou zijn we erin geslaagd om de B cel immortalisatie hier ook aan de praat te krijgen! Ik ben dan ook heel blij dat we hebben kunnen samenwerken, niet alleen voor het uitwisselen van kennis, protocols en stalen (hoe gemakkelijk, in Lanaken), maar ook omwille van het feit dat jij 
precies wist hoe het was om aan zulk project te werken. Bedankt voor je hulp en steun, de gezellige babbels en de nuttige tips, ik heb er heel veel aan gehad! Ik wens je dan ook veel succes met je verdere carriere!

Verder wil ik de leden van de beoordelingscommissie onder leiding van Prof. Dr. Harry Steinbusch bedanken voor het lezen en beoordelen van mijn proefschrift. Harry, ook bedankt voor je steun tijdens mijn promotietraject en voor de wijze raad die je me van tijd tot tijd meegaf.

Dan wil ik de andere collega's van de Neurim-group van harte bedanken voor de leuke tijd samen. Gerard and Jo, de nieuwere generatie, veel succes met jullie eigen onderzoek! Op tijd en stond een koffie en dat lukt jullie zeker;-)! Chiara and Alejandro, my dear roommates! We have had a wonderful time together! Chiara, I'Il never forget your hospitality during our trip to Tuscany (or was it Blankenberge?)! We have seen each other in a sad or angry mood, but much more often we had fun together, both at work and after work! Now you are the next one to finish the PhD thesis! I wish you all the best! Alejandro, my dear paranimph, I could always count on you! You always relativized my complains or worries, I am very thankful for that! I enjoyed working with you, from the serious Velcade experiments to the 'horrible' B cell meeting in Spain :-). But most importantly, I'll never forget the countless moments of fun we have had: suicide bunny (and other) jokes, celebrating carnaval, Gentse feesten, many dinners and especially our trips to Italy and Croatia. Thanks to you l'll forever divide Germany in pieces of $160 \mathrm{~km}$ (:). One day, I hope to visit you in Argentina! Good luck in the future! Thanks guys, it is nice to realize that your colleagues are your friends!

Ook nog een bedankje aan mijn voorganger Marko Phernambucq! Leuk met je samengewerkt te hebben, en ik ben blij dat je zo'n fijne baan gevonden hebt. Veel plezier in het Noorden! Dr. Peter Molenaar, beste Peter, bedankt dat je steeds bereid was om mijn manuscripten met een kritisch oog na te lezen en te verbeteren. Het heeft er zeker een extra waarde aan toegevoegd. Marjorie, nice that you came in our group! I wish you all the best with your carrier, and enjoy your new family!

Uiteraard ben ik ook veel dank verschuldigd aan alle studenten die me tijdens dit promotieonderzoek geholpen hebben. Philipp Becker, Joost Van den Broeck en Jonas Hummel, bedankt voor de vele uren celkweek die jullie me bespaard hebben. Vele handen maken licht(er) werk! Anne-Hilde, jij bedankt voor het eindeloos herhalen van de ErbB-dotblots! En ook buiten het werk hebben we veel plezier beleefd, van Italië tot Mestreechse carnaval tot Octopusfeestjes! Ik wens je het allerbeste toe met je nieuwe 
onderzoek, en laat me weten als het klaar is! Els, ook leuk dat jij ineens in onze groep kwam! Bedankt voor het vele bloedprikken en vooral voor de gezelligde babbels! En dan nog een dikke merci aan de allerbeste verpleegster van de groep, ons zonnetje in huis, Danielle! Zonder jou was er nooit zoveel bloed gevloeid $(;)$ en was de patiëntendatabase waarschijnlijk nog niet in orde! Al was het maar twee dagen per week $;$, toch echt bedankt dat je er voor me was!

Ook zou ik graag alle analisten willen bedanken die voor me klaar stonden als ik hun hulp nodig had. Nicole (nog zo'n zonnetje!), Marjanne, Hellen, Denise, Ralf, Marjan en Jorike: bedankt! Jorike, jij verdient nog een extra merci, niet alleen omdat je altijd alles onmiddellijk liet vallen als ik weer iets niet kon vinden of als ik iets wilde bestellen, maar vooral voor je luisterend oor en opbeurende raad als het even wat minder vlot ging. Ik ben blij dat je bij ons gewerkt hebt en hoop dat je nu heel hard geniet van je welverdiende pensioen!

Ik wil ook onze secretaresses Marie-Therese en Lisa bedanken voor hun hulp met administratieve zaken (en het organiseren van leuke kerstfeestjes!). Bedankt dat jullie de papier-rompslomp die bij een promotie hoort voor mij met plezier in orde brachten, ook al stond ik voor de $100^{\mathrm{e}}$ keer aan jullie deur!

Verder bedank ik ook alle andere onderzoeksgroepen waarmee ik de voorbije jaren heb mogen samenwerken. Aan de mensen van de pathologie-afdeling: Els, Guido, Jolanda, Sabine, Tina en Sara; dankzij jullie heb ik de vele fragmentanalyses en sequencing experimenten, nadat we eerst de primers 'even' moesten zoeken, tot een goed einde kunnen brengen. Bedankt hiervoor! Ook zou ik Prof. Dr. Bert Smeets en collega's willen bedanken voor het ter beschikking stellen van hun ML-2 labo, waardoor ik 'zorgenloos' mijn B cellen heb kunnen kweken. Ook bedankt aan Joziene Jaspers en Henk van Rie voor het uitvoeren van onze Facs-sort experimenten. Tenslotte ook bedankt aan Sandra en Martine voor hun hulp in het RNL-labo!

Verder wil ik iedereen van de afdeling Neuroscience bedanken; jullie maakten deel uit van de leuke sfeer in en rond het labo! Bedankt! Sven en Ronald, ik vond het fijn om met jullie de LDO te organiseren. Ik kijk al uit naar de echte whipe-out! Tim, nog een Belgisch Limburger hier, niemand kan zo zot doen als jij! Leuk dat je bent teruggekomen! Annerieke, Rinske, Marijke, Eveline, Sofie, Caroline, Eva B, Olga, Marisela, Evi, Liesbeth en Eva; leuk om zoveel fijne meisjes rond me te hebben gehad! Merci allemaal! I also would 
like to thank all other people from our department for the nice time together! May our paths often cross again!

En aan de liefste missies, mijn friendsies: ik ben heel blij dat jullie er zijn! Ann, mijn andere paranimf, ik vind het super dat jij vandaag naast me wil staan! Steeds weer vroeg je hoe het met mijn cellen ging, al had je geen idee wat ik er eigenlijk mee deed. Je vertegenwoordigt vandaag de andere missies, want ik mocht geen 6 paranimfen kiezen. Missies, jullie zijn de allerbeste! KK, al wou je ook graag paranimf zijn, jouw rol komt nog (:). MD, merci voor de mooie cover! LA en MC, ook jullie stonden altijd voor me klaar, merci! Al lijken onze wegen soms wat verder uit elkaar te lopen en is afspreken niet altijd even simpel, we blijven beste vriendinnetjes! Merci voor de steun die ik altijd van jullie kreeg! Merci missies, voor de on-tel-baar veel leuke momenten die we al gehad hebben en voor diegene die nog zullen volgen!

Britt en Sofie, jullie ken ik al vanop dag 1 van de opleiding biomedische wetenschappen en ik wil jullie bedanken voor de vele leuke momenten die we samen gehad hebben maar ook voor jullie luisterend oor als ik weer eens met een klaagzang kwam aanzetten $(;)$. En die 3 keer per jaar, dat blijft een gouden regel! Veel succes nog met jullie eigen promotieonderzoek en natuurlijk ook met jullie huisjes en mini's :-)!

Ook bedankt aan alle andere 'biomedische' vrienden, vooral ons journal-clubje; merci voor de vele gezellige momenten! Het allerbeste verder!

Ook wil ik mijn familie bedanken voor de warme omgeving vroeger en nu en voor de interesse die ze steeds getoond hebben in mijn onderzoek.

Mama en papa, bedankt dat jullie me altijd gesteund hebben in wat ik deed. Bedankt voor jullie onvoorwaardelijke liefde en hulp, ik kom graag bij jullie thuis! Jolien, je kan er dan wel niet bij zijn vandaag, ik weet dat je het goed doet daar in Afrika!

En liefste Jochen, wat een stomme western blot al niet veroorzaakt $;$. Je bent mijn allergrootste steun geweest en bent me steeds blijven aanmoedigen, waarvoor ik je niet genoeg kan bedanken. Een heel dikke merci! Heel veel succes nog met de laatste loodjes van je eigen thesis! 


\section{Co-authors}


Berrih-Aknin-S

De Baets MH

Duimel H

Fraussen J

Frederik P

Gomez A

Janssen S

Jol-van der Zijde CM

Lemmens $\mathrm{M}$

Le Panse $\mathrm{R}$

Losen M

Maessen JG

Manz RA

Martinez-Martinez $\mathrm{P}$

Meulemans E

Molenaar $\mathrm{P}$
Unite Mixté de Recherche, CNRS, Thérapies de maladies du muscle strié, Hopital Marie Lannelongue, Le Plessis-Robinson, France

Division of Neuroscience, School for Mental Health and Neuroscience, Faculty of Health, Medicine and Life Sciences, Maastricht University, The Netherlands

School of Life Sciences, Biomedical Research Institute and translationale Universiteit Limburg, Hasselt University, Belgium

Electron Microscopy Unit, Department of Molecular Cell Biology, Maastricht University, The Netherlands

School of Life Sciences, Biomedical Research Institute and translationale Universiteit Limburg, Hasselt University, Belgium Electron Microscopy Unit, Department of Molecular Cell Biology, Maastricht University, The Netherlands

Division of Neuroscience, School for Mental Health and Neuroscience, Faculty of Health, Medicine and Life Sciences, Maastricht University, The Netherlands

Division of Neuroscience, School for Mental Health and Neuroscience, Faculty of Health, Medicine and Life Sciences, Maastricht University, The Netherlands

Department of Pediatrics, Section of Immunology, Hematology, Oncology, Bone Marrow Transplantation and Auto-immunity, Leiden University Medical Center, The Netherlands Division of Neuroscience, School for Mental Health and Neuroscience, Faculty of Health, Medicine and Life Sciences, Maastricht University, The Netherlands

Unite Mixté de Recherche, CNRS, Thérapies de maladies du muscle strié, Hopital Marie Lannelongue, Le Plessis-Robinson, France

Division of Neuroscience, School for Mental Health and Neuroscience, Faculty of Health, Medicine and Life Sciences, Maastricht, University, The Netherlands

Department of Cardiothoracic Surgery, Maastricht University Medical Centre, The Netherlands

Institute for Systemic Inflammation Research, University of Lübeck, Lübeck, Germany

Division of Neuroscience, School for Mental Health and Neuroscience, Faculty of Health, Medicine and Life Sciences, Maastricht University, The Netherlands

Department of Pathology, Academic Hospital Maastricht, The Netherlands

Division of Neuroscience, School for Mental Health and Neuroscience, Faculty of Health, Medicine and Life Sciences, Maastricht University, The Netherlands 
Muris AH

Niks E

Phernambucq $\mathrm{M}$

Somers V

Stinissen P

Van den Broeck J

Van der Esch E

Van Garsse L

Van Ostaijen M

Van Tol MJ

Van Zoelen EJ

Verheyen $\mathrm{F}$

Verschuuren J

Voll RE
Division of Neuroscience, School for Mental Health and Neuroscience, Faculty of Health, Medicine and Life Sciences, Maastricht University, The Netherlands

Department of Neurology, Leiden University Medical Center, The Netherlands

Division of Neuroscience, School for Mental Health and Neuroscience, Faculty of Health, Medicine and Life Sciences, Maastricht University, The Netherlands

School of Life Sciences, Biomedical Research Institute and translationale Universiteit Limburg, Hasselt University, Belgium

School of Life Sciences, Biomedical Research Institute and translationale Universiteit Limburg, Hasselt University, Belgium

Division of Neuroscience, School for Mental Health and Neuroscience, Faculty of Health, Medicine and Life Sciences, Maastricht University, The Netherlands

Division of Neuroscience, School for Mental Health and Neuroscience, Faculty of Health, Medicine and Life Sciences, Maastricht University, The Netherlands

Department of Cardiothoracic Surgery, Maastricht University Medical Centre, The Netherlands

Department of Pediatrics, Section of Immunology, Hematology, Oncology, Bone Marrow Transplantation and Auto-immunity, Leiden University Medical Center, The Netherlands

Department of Pediatrics, Section of Immunology, Hematology, Oncology, Bone Marrow Transplantation and Auto-immunity, Leiden University Medical Center, The Netherlands Department of Cell Biology, Radbound University Nijmegen, The Netherlands

Electron Microscopy Unit, Department of Molecular Cell Biology, Maastricht University, The Netherlands

Department of Neurology, Leiden University Medical Center, The Netherlands

Department of Internal Medicine 3, Nikolaus Fiebiger-Center of Molecular Medicine, University Hospital Erlangen, Germany 
